\title{
A Blueprint for Recovery
}

\author{
By \\ Nazanin Sepehry-Rad \\ Ryerson University, 2016 \\ A thesis \\ presented to Ryerson University \\ in partial fulfillment of the \\ requirements for the degree of \\ Master of Architecture \\ in the Program of \\ The Department of Architectural Science
}

Toronto, Ontario, Canada, 2016

(c) Nazanin Sepehry-Rad, 2016 



\section{Author's declaration}

I hereby declare that I am the sole author of this theis. This is a true copy of the thesis, including any required final revisions.

I authorize Ryerson University to lend this thesis to other institutions or individuals for the purpose of scholarly research.

I further authorize Ryerson University to reproduce this thesis by photocopying or by other means, in total or in part, at the request of other institutions or individuals for the purpose of scholarly research.

I understand that my thesis may be made electronically available to the public. 


\section{A Blueprint for Recovery}

Nazanin Sepehry-Rad

Master of Architecture 2016

Ryerson University

\section{Abstract}

Built environments inevitably serve as grand mnemonic elements that contain and transmit layers of culture and history. Failing to acknowledge the significance of difficult memories in the identity and culture of cities induces the gradual erosion of history as well as preventing movement toward a better future. In order to preserve the latent value in the identity of the city, architectural strategies should be implemented by which forgotten memories and hidden traces could be recalled to conscious narration. Recalling a story from the past, intentionally or unconsciously forgotten as a form of amnesia, can help re-contextualize memory images that awaken within us a new avenue to the future. This thesis intends to refine the dynamics of remembrance, illuminating the power of architecture as a medium for providing frames of perception and horizons of understanding of past experiences. 


\section{Acknowledgment}

This thesis owes its existence to my supervisor, Marco Polo whose faith in me and in the unconventional theme of this thesis has allowed me to achieve what I had imagined to be impossible. I deeply appreciate your knowledge and passion for the topic I pursued. Thank you for your patience and guidance and criticism that played a major role in my ability to push the boundaries of this journey. You are an invaluable mentor and it was a great experience to learn from your insight and approach to a thesis.

Many thanks to June Komisar and Masha Etkind, members of my committee for their support and effective critique at various stages of this project.

Lastly, I would like to thank my family who have encouraged me to follow my dreams, even when they are not within reach. A special thanks to my friends and colleagues for all your valuable comments and encouragements. 
viii 
To all martyrs of my country 


\section{Table of Contents}

Abstract v

Acknowledgment vii

List of Illustrations xii

Prologue 1

01 Oblivion and Recall 5

1.1 The Politics of Remembrance 7

1.2 Collective Memory 8

1.3 Difficult Memories and Reconciliation 11

1.4 Palimpsests of Memory 13

02 Architecture as Mnemonic $\quad 17$

2.1 Carved Memories 19

2.2 Uncertain Topographies 22

2.3 Architectural Precedent 25

2.4 Echoes of War 43

2.5 The Sacred Journey $\quad 46$

03 In Search of the Hidden 51

3.1 Martyrdom in the Islamic Tradition 53

3.2 The Battle of Karbala 56

3.3 Martyrdom in the Modern Context 59

3.4 Martyrdom in Mystical Sufism 63

3.5 Echoes of Paradise 66 


\section{The Life and Death of Khorramshahr $\quad 71$}

4.1 Site Selection 73

4.2 The Life and Death of Khorramshahr 74

4.3 The Sacred Defense 75

4.4 Repressed Memories 77

4.5 Resurfacing Memories 78

4.6 Design Proposal 79

4.7 Passengers of Light 82

05 A Journey for Recovery $\quad 87$

5.1 Design Principles 89

5.2 Context 92

5.3 Architectural Expression 94

5.4 Programmatic Elements 98

5.5 Climatic Considerations 100

5.6 Spatial Sequence and Procession $\quad 102$

$\begin{array}{ll}5.7 & \text { Epilogue } \\ & 122\end{array}$

\section{Appendix}

125

Works Cited

136 


\section{List of Illustrations}

\section{O2 Architecture as Mnemonic}

Fig 2.1 View of the grounds of the Topography of Terror

(c) Stefan Müller; 2010

Fig 2.2 The emptiness of the site, Topography of Terror

(c) Stefan Müller; 2010

Fig 2.3 The exposed remains of the cellar rooms of a former SS mess hut

(c) Nihad Nino Pusija.Topography of Terror Foundation. 2010

Fig 2.4 View into the exhibition, Topography of Terror

(c) Britta Scherer.Topography of Terror Foundation. 2013

Fig 2.5 The re-designed information panel at the main at the main entrance, Topography of Terror

Fig 2.6 An aerial view of the v-shaped design, Vietnam Veterans Memorial

Fig 2.7 Connection and Separation, Vietnam Veterans Memorial

Fig 2.8 Reflective granite wall, Vietnam Veterans Memorial

Fig 2.9 Inscription of the names of the soldiers, Vietnam Veterans Memorial

(c) Win McNamee. 2005

Fig 2.10 Field of stelae, Memorial to the Murdered Jews

(c) Wolfgang Staudt. 2007

Fig 2.11 The undulating ground, Memorial to the Murdered Jews

Fig 2.12 Information panels as concrete blocks, Memorial to the Murdered Jews

Fig 2.13 Crid of rectangular concrete blocks seen in the ceiling, Memorial to the Murdered Jews

Fig 2.14 Zigzag form of the building, Jewish Museum Berlin

Fig 2.15 The voids, Jewish Museum

Fig 2.16 The old and the new with no apparent connection, Jewish Museum

Fig 2.17 Intersections between the routes, Jewish Museum

(c) THomas Bruns, Jüdisches Museum Berlin Press. 2007

Fig 2.18 The dark Holocaust Tower, Jewish Museum 
Fig 2.19 The Axis of Continuity, Jewish Museum

(c) Laurian Chinitoiu. 2015

Fig 2.20 Disorientation in the Garden of Exile, Jewish Museum

(c) Shawn Liu Studio. 2014

Fig 2.21 49 Columns with growing trees, Jewish Museum

(c) Shawn Liu Studio. 2014

Fig 2.22 Site Plan, National Museum of Afghanistan

(c) Matteo Cainer Architects

Fig 2.23 Bird's-eye View from the south, National Museum of Afghanistan

(c) Matteo Cainer Architects

Fig 2.24 Main entrance to the building, National Museum of Afghanistan

(c) Matteo Cainer Architects

Fig 2.25 Interior foyer, National Museum of Afghanistan

(c) Matteo Cainer Architects

Fig 2.26 Function diagram, National Museum of Afghanistan

Fig 2.27 Interior foyer, National Museum of Afghanistan

(c) Matteo Cainer Architects

(c) Matteo Cainer Architects

(c) Contemporary Architecture of Iran

Fig 2.30 The surrounding context, The Holy Defense Museum

(c) Contemporary Architecture of Iran

Fig 2.31 Main entrance, The Holy Defense Museum

(c) Tohid Khosravi, 2015

Fig 2.32 Site analysis, The Holy Defense Museum

(c) The Holy Defense Museum

Fig 2.33 The "Hall of Butterflies", The Holy Defense Museum

(c) Amir Daftari, 2016

Fig 2.34 Human sculptures, The Holy Defense Museum

Fig 2.35 The "Hall of Prelude", The Holy Defense Museum

Fig 2.36 Life-size recreation of Khorramshahr, The Holy Defense Museum

(c) The Holy Defense Museum

(c) Contemporary Architecture of Iran

(c) Marzieh Mousavi, 2013

Fig 2.39 Symbolization of Mosque in the "Hall of Defense", The Holy Defense Museum 
Fig 2.40 Battle of Cettysburg re-enactment

Confederate Civil War re-enactors march towards Union lines during Pickett's Charge on the last day of a Battle of Cettysburg re-enactment on June 30, 2013 in Cettysburg, Pennsylvania. (John Moore/Cetty Images)

Fig 2.41 Confederate Civil War re-enactors launch an evening attack, Cettysburg

Confederate Civil War re-enactors launch an evening attack during a threeday Battle of Cettysburg re-enactment on June 29, 2013 in Cettysburg, Pennsylvania. (John Moore/Cetty Images)

Fig 2.42 "Wounded" Civil War re-enactors, Cettysburg

"Wounded" Civil War re-enactors litter the battlefield at the end of Pickett's Charge on the last day of a Battle of Cettysburg re-enactment on June 30, 2013 in Cettysburg, Pennsylvania. (John Moore/Cetty Images)

Fig 2.43 Surrender to Union troops, Gettysburg

Confederate Civil War re-enactors from Hood's Texas Brigade (L), surrender to Union troops as part of a three-day Battle of Cettysburg re-enactment on June 29, 2013 in Cettysburg, Pennsylvania. (John Moore/Cetty Images)

Fig 2.45 Martyrs of Talayieh memorial

(c) Hossein Hadipour. 2015

Fig 2.44 A mullah delivering eulogy for the martyrs in Talayieh, Iran

Fig 2.46 Muslim pilgrims in Hajj, Mecca

(c) AP Photo/Mosa’ab Elshamy.2015

Fig 2.47 Pilgrimage Holy Island on the Northumbrian coast of England

(c) Northern Cross. 2010

Fig 2.48 Pilgrimage to Amarnath Cave, Himalaya mountains, Kashmir

(c) Tristan Savatier.2009

Fig 2.49 "Pilgrims not bikers" in The Run for the Wall

(c) Don Shrubshell.2009

Fig 2.50 Reception of the veterans along the route, The Run for the Wall

(c) Barbara Graham.2014

\section{O3 In Search of the Hidden}

Fig 3.1 Imam Hussain and his followers surrounded by the enemy on the Karbala plain

Whoishussain.org. Web. 17 Apr. 2016. <https://whoishussain.org/who-ishussain/the-full-story/>.

Fig 3.2 Imam Hussain at the Battle of Karbala

Al-Musavi, Abbas. Battle of Karbala. Painting. 1900. Brooklyn Museum, New York. brooklynmuseum.org.

Fig 3.3 Muharram mourning ceremony in Tehran, Qajar period

Sevruguin, Antoin. Tehran (Iran) Maydan-i Tupkhana. 1800s. Myron Bement Smith Collection, 1899-1962, Freer Gallery of Art and Arthur M. Sackler Gallery Archives. Smithsonian Institution, Washington D.C.

Fig 3.4 Ta'ziya Performance in Tehran in Qajar period

Sevruguin, Antoin. Ta'ziya Performance at the Takkiya Dawlat, Tehran (Iran). 1800s. Myron Bement Smith Collection, 1899-1962, Freer Gallery of Art and Arthur M. Sackler Gallery Archives. Smithsonian Institution, Washington D.C. 
Fig 3.5 Game-zani in Muharram mourning ceremonies, Qajar period

Chamezani, Muhharran, One of 274 Vintage Photographs. 1800s. Arts of the Islamic World, Brooklyn Museum, Purchase Cift of Leona Soudavar in Memory of Ahmad Soudavar, 1997.3.249.

Fig 3.6 The red headband addresses the martyred Imam Hussain

sajed.ir. Web. 5 Dec. 2015. <http://www.sajed.ir/pe/components/com joomgallery/img_originals/_9/Razmandegan-012.jpg>.

Fig 3.7 A dead soldier's body transforms into a tulip

Chalipa, Kazim. Certitude of Belief (Yaqin). 1981. Middle Eastern Posters Collection, The University of Chicago Library. Special Collections Research Center.

Fig 3.8 Visual association of martyrs of the Sacred Defense with Imam Hussain

Blindfolded Soldier Shot at Gunpoint. 1981. Middle Eastern Posters Collection, The University of Chicago Library. Special Collections Research Center.

Fig 3.9 Re-enactment of the Battle of Karbala as a Passion Play on the day of Ashura

Behboudi, Fatemeh. 2015. Mehr NewsAgency. Web. 17 Apr. 2016. <http:// www.mehrnews.com/photo/2951517/>.

Fig 3.10 Narration of the Battle of Karbala as a form of theater

Behboudi, Fatemeh. 2015. Mehr NewsAgency. Web. 17 Apr. 2016. <http:// www.mehrnews.com/photo/2951517/>.

Fig 3.11 The national emblem of Iran on the coffins of the Unknown martyrs of the Sacred Defense in a funeral ceremony in Tehran

Bazri, Abouzar. 2014. Mehr NewsAgency. Web. 17 Apr. 2016. <http://www. mehrnews.com/photo/2442445/s.

Fig 3.12 Mourning parade as a form of commemorating the Karbala event

Zareh, Mehdi. 2015. Mehr NewsAgency. Web. 17 Apr. 2016. <http://media. mehrnews.com/d/2015/10/25/4/1882966.jpg?ts=1458370831520>.

Fig 3.13 Imam Hussain mourning ceremony

Bakhshi, Mehdi. 2014. Mehr NewsAgency. Web. 17 Apr. 2016. <http:// khabarfarsi.com/ext/10947841>.

Fig 3.14 Folio from The Conference of the Birds Manuscript

Sava, Habiballah. "The Concourse of the Birds", Folio 11r from a Mantiq Al-tair. 1600. Metropolitan Museum of Art, New York. Metmuseum.org. Web. 12 Apr. 2016.

Fig 3.15 The execution of Mansur Hallaj

Dihlavi, Amir Khusraw. The Hanging of Mansur Al-Hallaj. 1600. The Walters Art Museum, Baltimore. Art.thewalters.org. Web. 12 Apr. 2016.

Fig 3.16 Mughal Ruler Babur Supervising the Creation of a Garden

Folio from a "Baburnama" Manuscript. C. 1590-1598. Opaque watercolour on paper with gold and coloured ruled borders. National Gallery of Canada.

Fig 3.17 Folio from Shahnameh Manuscript. c.1074

The Turanian King Afrasiyab Conferring with His Brother Garsivaz: Folio from Shahnameh Manuscript. C. 1074. Opaque watercolor, ink, silver and gold on paper. The Heilbrunn Timeline of Art History, The Metropolitan Museum of Art, State of New York.

Fig 3.18 Persian garden miniature, c.1450s

Folio from a Haft Awrang (Seven Thrones) by Jami. C.1400s. Opaque watercolor, ink and gold on paper. Freer Gallery of Art, Smithsonian Institution. Washington, D.C. 
Fig 3.19 Persian garden miniature, c.1450s

Folio from a Haft Awrang (Seven Thrones) by Jami. C.1400s. Opaque watercolor, ink and gold on paper. Freer Callery of Art, Smithsonian Institution. Washington, D.C.

Fig 3.20 Naranjestan-i Qavam, Shiraz

Shoraka, Ramin. 2014. Flickr. Web. 17 Apr. 2016.<https://www.flickr.com/ photos/rshoraka/15117858442>

Fig 3.21 Delgosha Garden, Shiraz

Web. 17 Apr. 2016. <http://shirazhematopath.sums.ac.ir/fa/page. php?rid $=27>$.

Fig 3.22 Shazeh Garden in the middle of the desert, Kerman

Shazdeh Garden. 2012. Mermarnet. Web. 17 Apr. 2016. <http://www. memarnet.com/fa/node/301s.

Fig 3.23 Spring in Shazdeh Garden, Kerman

Sadeghi, Hamid. 2013. Mehr NewsAgency. Web. 17 Apr. 2016.

Fig 3.24 Entrance to Shazdeh Garden, Kerman

Khajooyi, Laleh. 2015. Mehr NewsAgency. Web. 17 Apr. 2016.

Fig 3.25 Winter in Shazdeh Garden, Kerman

Sadeghi, Hamid. 2013. Mehr NewsAgency. Web. 17 Apr. 2016.

Fig 3.26 Autumn in Shazdeh Garden, Kerman

Fig 3.27 Chehel Sotoun Palace, Isfahan

Shoraka, Ramin. 2014. Flickr. Web. 17 Apr. 2016.<https://www.flickr.com/ photos/rshoraka/15117858442>

\section{O4 The Life and Death of Khorramshahr}

Fig 4.1 Khuzestan Province in Iran

Fig 4.2 Khorramshahr city

Google Map. 2015

Fig 4.3 Khorramshahr ruins

Kelari, Mahmud. 1980s. Fararu. Web. 17 Apr. 2016. <http://fararu.com/fa/ news/207653/>

Fig 4.4 Iranian soldiers in Khuzestan

wikimedia. sajed.ir, n.d. Web. 5 Dec. 2015. <http://cdn.warisboring.com/ images/8667.jpeg>.

Fig 4.5 A Group of Iranian soldiers defend the city of Khorramshahr tumblr. N.p., n.d. Web. 5 Dec. 2015. <http://40. media.tumblr.com/tumblr_ m8gh4tOz5d19fthwa01_500.jpg>.

Fig 4.6 Soldiers praying in the trenches

Badrfar, Mahmud. 1980s. Fararu. Web. 17 Apr. 2016. <http://fararu.com/fa/ news/207997/s.

Fig 4.7 Exhilarated children on the day of Liberation of Khorramshahr in 1982, the title on the newspaper reads, "Khorramshahr was liberated."

1982. MehrNews Agency. Web 17 Apr. 2016.< http://www.mehrnews.com/ photo/2759526/>

Fig 4.8 Khorramshahr Jame Mosque after bombing 
Fig 4.9 Divers preparation for the operation

N.p., 1987. Web. 4 Dec. 2015. <http://www.ion.ir/content/imgcache/40124/ image_460_270.jpg>.

Fig 4.10 Karbala 4 Operation map

wikimedia. N.p., n.d. Web. 5 Dec. 2015. <https://upload.wikimedia.org/ wikipedia/commons/thumb/a/a9/Operation_Karbala_4_map.svg/30opxoperation_Karbala_4_map.svg.png>.

Fig 4.12 Discovery of 175 bodies with their hands tied

khabariha.ir. N.p., 2015. Web. 5 Dec. 2015. <http://khabariha.ir/wp-content/ uploads/2015/06/

Fig 4.11 Funeral ceremony for the missing 175 martyrs in Tehran

(c) Amin Khosroshahi 2015

Fig 4.13 The initial proposed site - Sheikh's Palace before demolition

Schroeder, Charles R. "Memories of an American Boy." Photograph. iranian. com, N.d. Web. 4 Dec.2015. <http://www.commoncoordinates.com/ AbadanInThe50s/Abadan1958/183.jpg>.

Fig 4.14 The current site is located on the middle of the axial line of the Operation launching area

Google Map. 2016

Bing Mao. 2015

Fig 4.16 Half demolished buildings on site

N.p., 2014. Web. 5 Dec. 2015. <http://s5.picofile.com/file/8118879250/_37_. jpg>.

Fig 4.17 Memorials and symbolic markers built all over the west and south-west of Iran on sites of the Iran-Iraq War

rahianenoor.com. N.p., 2012. Web. 4 Dec. 2015.<http://www.rahianenoor com/images/docs/000000/no0000899-r-b-003.JPG>.

Fig 4.18 Veterans narrating the stories of the war

(c) Mahmoud Rahimi. 2015

Fig 4.19 Passageway to the riverfront

(c) Zeinab Parvin, 2015

Fig 4.20 Boats aground as part of the exhibition

(c) Zeinab Parvin, 2015

Fig 4.21 Walking on the old boats

Fig 4.22 The symbolic gateway to the Martyrs of Alghameh Memorial

jamnews.ir. N.p., 2014. Web. 4 Dec. 2015. <http://media.jamnews.ir/ $\operatorname{larg} 1 / 1393 / 12 / 27 / \mid M G 17533641 . j p g>$.

Fig 4.23 Arvand riverfront as a site of mourning and remembrance jamnews.ir. N.p., 2015. Web. 4 Dec. 2015. <http://media.jamnews.ir/ $\operatorname{larg} 1 / 1393 / 12 / 27 / \mid M G 17531915 . j p g>$.

\section{A Journey for Recovery}

Fig 5.1 The position of proposed site in Khorramshahr city

Fig 5.2 The existing condition of the site Bing Map. 2015 
Fig 5.3 Boats aground hidden in marshland

(c) Zeinab Parvin, 2015

Fig 5.4 The pedestrian route along the edge of marshland on the left

(c) Zeinab Parvin, 2015

Fig 5.5 Orientation of the building on site

By Author

Fig 5.7 Third axis facing toward Mecca (Qibla)

By Author

Fig 5.6 Three main components of the building

By Author

Fig 5.8 The final iteration of design

By Author

Fig 5.9 Site Plan

90

By Author

Fig 5.10 Bird's-eye view from northwest

By Author

Fig 5.11 Ground Floor Plan

Fig 5.12 First Floor Plan

Fig 5.13 Lower Level Plan

Fig 5.14 Inward looking building with terraces with overhang and wooden shutters

By Author

Fig 5.15 Arrival point-Transition from devastation to life By Author

Fig 5.16 Prolonged procession from arrival point to the building

By Author

Fig 5.18 Paradise at the center of the maze

By Author

Fig 5.17 Purposeful disorientation in the multicursal maze

By Author

Fig 5.19 Entry to the building

By Author

Fig 5.20 Lower Level Plan

By Author

Fig 5.22 Passenger bus as a symbolic icon in the collective memory of the war 1980s. Fararu. Web. 17 Apr. 2016. <http://fararu.com/fa/news/207485/>.

Fig 5.23 Dispatched soldiers escorted by their loved ones 1980s. Fararu. Web. 17 Apr. 2016. <http://fararu.com/fa/news/207485/>.

Fig 5.24 Dispatched soldiers escorted by their loved ones 
Fig 5.25 The Valley of Quest

By Author

Fig 5.26 The tower facing Mecca

By Author

Fig 5.27 The Valley of Love By Author

Fig 5.28 The Valley of Gnosis By Author

Fig 5.29 The Valley of Detachment By Author By Author

Fig 5.31 The Valley of Perplexity By Author By Author

Fig 5.33 Epilogue-Toward Heaven By Author

Fig 5.34 Visitors making their way back to the arrival point By Author

Fig 5.35 View to the Iran-Iraq border By Author 

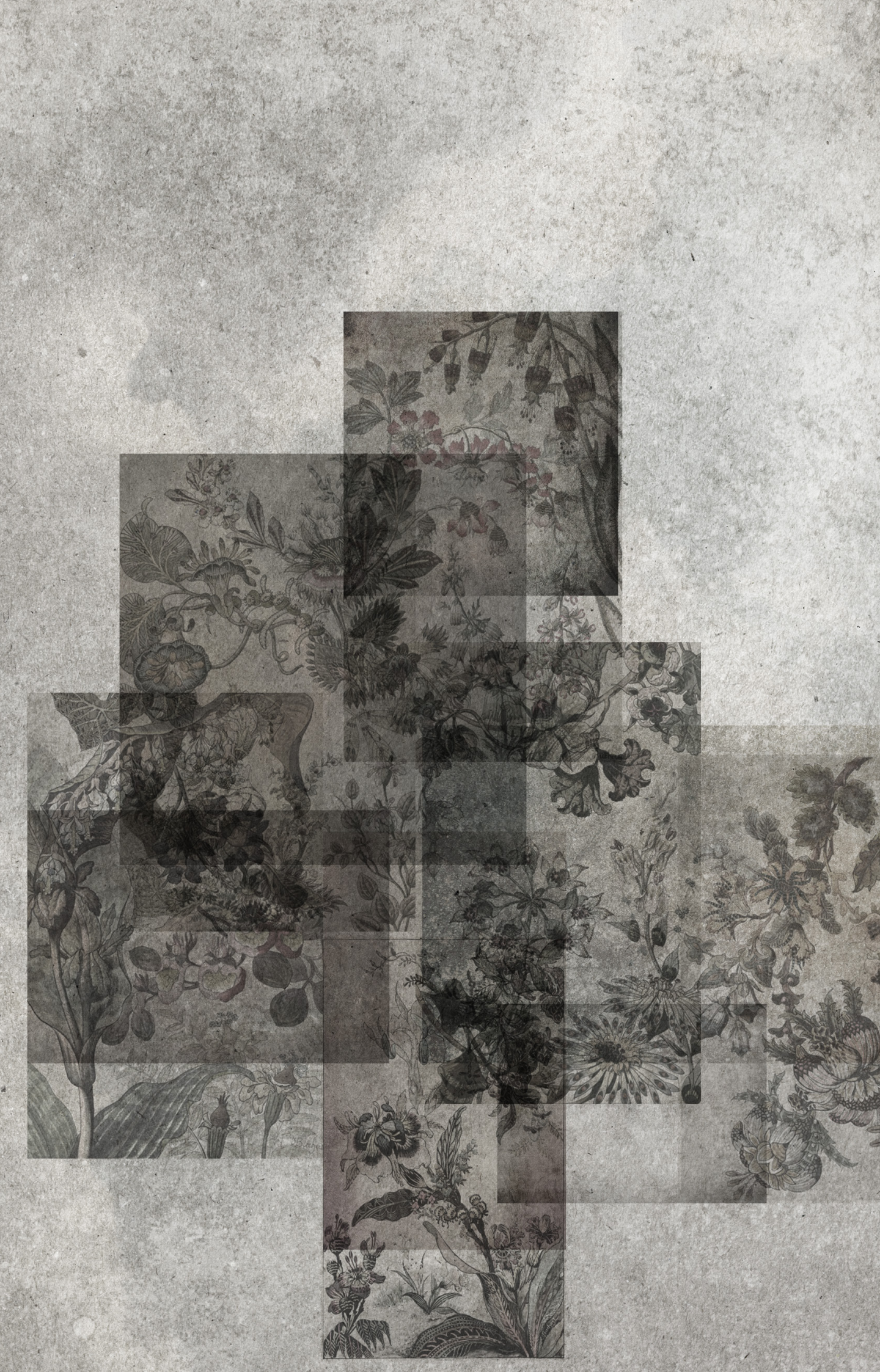
"So the garden became black by the morning like a pitch dark night in complete ruins."

Surah Al-Qalam, 20

-The Noble Quran 



\section{Prologue}

This thesis emerged out of a desire to explore the realms of collective memory and how personal and group narratives of loss and suffering can be articulated through architecture. The thesis started with several questions on the discourse of memory and remembrance:

What core motivations induce the process of memorialization? Why do we need to create permanent, physical markers of atrocity if it is ingrained in everyone's mind and soul? What is the role of identity in remembrance of the past?

What kind of artifice is the most effective response to negative histories of conflict and war? How can architecture narrate the difficult past in a hopeful manner? What architectural elements can contribute to remembering the past without glorifying it? How can symbolization and mythical allegories shape our interpretation of the past? How can memorials interact with new generations who have little or no first-hand experience of what they commemorate?

This thesis uses the city of Khorramshahr in Iran as a vehicle to examine issues of remembrance and reconciliation. Khorramshahr with its ancient history suffered great damage during the Iran-Iraq War of the 1980 s known as the Sacred Defense. Tens of thousands 
of Iranian troops were killed during the war and many more are still missing. In 2015, the bodies of 175 missing Iranian veterans were discovered in Iraq. They were allegedly buried alive with their hands tied. This discovery came as a shock to millions of Iranians who still have wounded hearts because of the 8-year war.

In light of all the suffering during the war, particularly the missing veterans who were martyred, the thesis design proposal seeks to articulate the memories of a tragic past through a sensory architectural experience. The selected site for the memorial museum is part of the national battlefield tour of the "Passengers of Light", located in Khorramshahr on the border between Iran and Iraq. This thesis seeks to develop a "Blueprint for Recovery", which obviously is not an absolute response that suits all conditions; rather it can be regarded as a departure point for articulating many other tragic memories of the past. 

Act

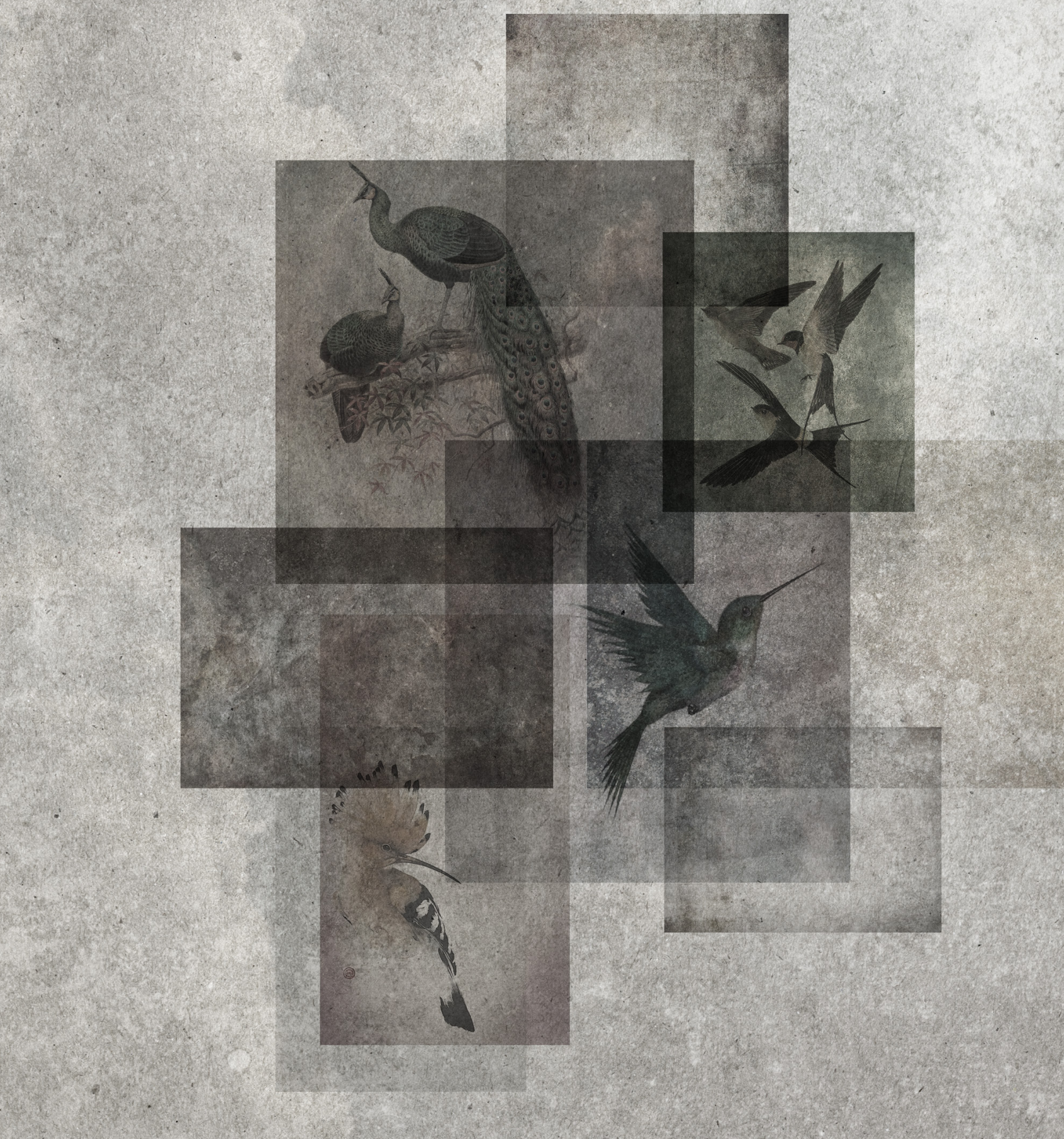




\section{PART ONE \\ OBLIVION AND RECALL}





\subsection{The Politics of Remembrance}

Today in the 21st century, memory and musealization are enlisted to provide protection against elimination and disappearance, "to counter our deep anxiety about the speed of change and the evershrinking horizons of time and space." There is a fear of memory loss that is essentially extending collecting to almost any kind of object and any kind of recorded memory.

Remembering entails the process of retrieval, unfolding "a past experience from the treasure chests of Mnemosyne." ${ }^{2}$ This complicated process requires the active, conscious transformation and adjustment of past experiences to fit current situations. Images and events recorded in our memory are not carved in stone, as we might believe, but rather they are subject to a selective, continuous reforming that is a reflection of our current experiences and thoughts. In every process of remembering, memories are constantly being reinterpreted and revised. The memory of place functions similarly. Earlier experiences of a place are frequently revisited, adjusted, edited, and changed. As Bastéa has stated, "Architecture might be

1 Andreas Huyssen, Present Pasts: Urban Palimpsests and the Politics of Memory, Cultural memory in the present (Stanford, Calif.: Stanford University Press, 2003), p.23

2 Eleni Bastéa, Memory and Architecture (Albuquerque: University of New Mexico Press, 2004), p.10 
experienced through the body but it is remembered in the mind and heart."3

Our common understanding of memory includes two related concepts: first, the notion of the term referring to a residue of past experiences that actively remain and are remembered in the mind; and second, the capacity for past recollection. Memory here is considered to be closely linked to the individual; it is our individual mind that activates a past event or experience, or forgets and erases. In a more modern sense of the term, it can be seen as a subjective matter. In order to make it less personal and more external to the self, memory has to be altered or a qualifier should be added, looking through the collective sense of memory. The term "urban memory" more commonly indicates the city as a tangible site and a collection of physical objects and practices that enable recollection of the past, embodying history through traces of the city's constant alteration and transformation. Urban memory appears to identify cities as places where people have lived and have physically marked the place with their presence, manifesting themselves in the memory of the city. Their engagement shapes what is remembered beyond the discourses of architecture and planning. ${ }^{4}$

\subsection{Collective Memory}

The discourse of collective memory emerged when Emile Durkheim wrote The Elementary Forms of the Religious Life in 1912. Although he did not explicitly use the term "collective memory", he suggested that societies require continuity and connection with the past to ensure social cohesion. While he discussed the commemorative rituals used to transmit traditional beliefs in early societies, he addressed the notion of social memory as a common experience that was shared by the group. He argued that totems and objects that have been designated as sacred have enormous spiritual power, providing individuals with tools to individually remember the

3 Ibid.

4 Mark Crinson, Urban Memory: History and Amnesia in the Modern City (London, New York: Routledge, 2005) 
integrity of the group experience. ${ }^{5}$ His perception of social memory offers significant approaches to decipher processes of remembering in contemporary societies.

Maurice Halbwachs, a student of Durkheim's, was the first sociologist to use the term "collective memory" and his work is considered the foundational framework for the study of societal remembrance. Halbwachs suggested that every act of recollection happens in relation to a social group. In other words, collective memory is defined as the summation of personal recall or parts of that recall that are more socially perceived rather than individual and idiosyncratic. In this regard, the collective memory necessitates a personal experience and perception of the material or immaterial spaces surrounding us. Individual memories that are supported by a certain group perform as fragments within a larger socially constructed system of collective memory. Individual experiences are adapted through this system, linked with family and social conventions, language, customs, and religious beliefs. The endurance and vitality of collective memory depend on a social group, which leads to attaching even the most personal memories to one another. Along with transferring these memories to subsequent generations that make remembering possible, memories become accessible through a process of mapping that localizes these recollections. Within this framework, these realms act as the foundations of collective memory against the passage of time. Halbwachs affirms that the construction of collective memory requires a place as a physical artifact, as human experience is bound to a certain social framework. $^{6}$

Unlike Durkheim, Halbwachs adopted an instrumental presentist approach to collective memory which affirms that social frameworks of memory are dominated by the needs of the present. In order to explain the present, leaders of a group rebuild the past logically in order to decide which events are remembered and which

5 Émile Durkheim, The Elementary Forms of the Religious Life, Free Press paperbacks (New York: Free Press, 1965)

6 Maurice Halbwachs and Lewis A. Coser, On Collective Memory, The Heritage of sociology (Chicago: University of Chicago Press, 1992) 
are excluded, and reorganize historical events according to the social narrative. For Halbwachs, memory was constructed through lived experiences, unlike history which consists of abstract reiterations. ${ }^{7}$

"Collective memory, moreover, is a current of continuous thought still moving in the present, still part of a group's active life, and these memories are multiple and dispersed, spectacular and ephemeral, not recollected and written down in one unified story.... History on the other hand gives the appearance that memory persists in a uniform manner, being handed down from one period of time to another and passing successively from place to place."

Pierre Nora expands upon Halbwachs' instrumental presentism by defining Lieux de mémoire as entities "where [cultural] memory crystallizes itself". 9 He considered these sites as lieux in material, symbolic, and functional terms. In Nora's view, a constructed history replaces true memory. Sites of memory are not authentic, being intentionally fabricated. They exist to help us recall the past and yet these memories become disjointed from the past. He argues that by physically marking the sites of memory, collective amnesia occurs since the notion of a lieu that embodies memories would replace active remembrance. In other words, externalizing memory prevents us from experiencing memories internally. ${ }^{10}$

Similar to Halbwachs' study of collective memory, James Wertesch is concerned with the distinction between the objective and subjective representation of the past. Despite Halbwachs' aim for a universal history, Wertesch illustrates that both memory and history can be regenerated in unique ways according to the needs of the society. He states that memory is a form of narrative, thus, it can be interpreted in many ways. He seeks to raise awareness of the

7 Ibid.

8 M. C. Boyer, The City of Collective Memory: Its Historical Imagery and Architectural Entertainments (Cambridge, Mass.: MIT Press, 1994), p.67

9 Pierre Nora, "Between Memory and History: Les Lieux de Mémoire," Representations, no. 26 (1989)

10 Pierre Nora and Lawrence D. Kritzman, Realms of memory: Rethinking the French past, European perspectives (New York: Columbia University Press, 1996) 
manipulation of memory by media or politicians, which inevitably influences our perception of the world. ${ }^{11}$

\subsection{Difficult Memories and Reconciliation}

As Huyssen notes, "Inevitably, every act of memory carries with it a dimension of betrayal, forgetting, and absence." ${ }^{12}$ Acts of remembering and forgetting are inextricably intertwined. The possibility of remembering is conditioned by forgetting and the relationship between the two constitutes memory. Traumatic memories associated with past events are impossible to erase but are buried deep within the subconscious, waiting to resurface. The forceful desire to deny traumatic events and their memories rarely succeeds in healing deep wounds. Instead, without expressing remorse and sorrow, the emotional conflict of intentional amnesia leads to dissociation and loss of identity. Remembering and telling the truth about terrible events are necessary for the restoration of social order, just as necessary as they are for healing the victims of trauma.

Other theories of trauma suggest that those individuals who have encountered a catastrophe long for a sort of experiential return to the incident. In other words, coming to terms with the past requires the idea of an event to be ingrained in the memory. As Nietzsche stated, "If something is to stay in memory it must be burned in: only that which never ceases to hurt stays in memory." ${ }^{13} \mathrm{~A}$ powerful exhibition in a museum has the capacity to invoke an intuitive desire in survivors to emotionally re-enact a traumatic experience from the past. However, this re-enactment is not because of the power of the horrific incident, rather it happens as a result of the incapacity to ascribe meaning to the event. Trauma is not seen as an experience at the time of occurrence. Instead, it merely remains stored in the eyes

11 James V. Wertsch, Voices of Collective Remembering (Cambridge, U.K., New York: Cambridge University Press, 2002)

12 Huyssen, Present Pasts, p.4

13 Paul H. Williams, Memorial Museums: The Global Rush to Commemorate Atrocities, English ed. (Oxford, New York: Berg, 2007), p.98 
and minds of the survivors relived time and time again as they fail to articulate it in a meaningful way.

Huyssen argues that the success of a monument paying tribute to political trauma comes from its role as a linking object between the viewers and the past, extending the life of the memory beyond the life of those with direct experience of the event. In addition, the monument needs to function as part of a network of urban relations, rather than standing disconnected from city life and ultimately referring only to itself. Once integrated into memorial sites as active parts within an urban fabric, remembrance of traumatic events becomes more effective in order to reconcile with the past. ${ }^{14}$

However, the criteria informing the decisions about which sites to mark and the formal characteristics of the memorials are often substantially politicized and controversial, since such decisions implicitly predicate other decisions about what sites are left unmarked. Similarly, the authoritative voice behind certain acts of remembrance is of great importance in shaping the historical narrative that is materialized in public space. ${ }^{15}$ An important question arises here: whose memory are we going to preserve? Whose voices are we going to interpret in memorials and monuments? A thoughtful point here is that the landscape and the memories attached to it have different meanings for different social groups. The political intentions of commemoration in certain cases might be in sharp contrast with local historiographic narratives. ${ }^{16}$ More significantly, one single past is remembered differently across nations. In the case of Israel/Palestine, for example, while the geography may be in some ways shared, each group remembers the landscape differently. ${ }^{17}$ These sites are in nature paradoxical and are as much about recollection as they are about oblivion. As such, the border condition - whether a tangible border or a metaphoric one - of a historical landscape draws

14 Huyssen, Present Pasts, p.4

15 Daniel ]. Walkowitz and Lisa M. Knauer, Memory and the Impact of Political Transformation in Public Space, Radical perspectives (Durham, N.C.: Duke University Press, 2004)

16 Michaela Schääuble, "How History Takes Place: Sacralized Landscapes in the CroatianBosnian Border Region," History and Memory 23, no. 1 (2011)

17 Barbara E. Mann, "'An Apartment to Remember": Palestinian Memory in the Israeli Landscape," History and Memory 27, no. 1 (2015) 
on various historical revisions. In this regard, memories are more than recollections of the past, rather they are interpretations influenced by local narrative conventions, cultural beliefs, and the social context of memorialization. ${ }^{18}$

\section{Palimpsests of Memory}

There has been always an endless desire to recreate, re-read and reproduce the narratives of the past at every level of our culture. The experience and memory of humankind are inherent in layers in the built fabric. Every attempt to recreate or even alter a memory leads to revealing historical layers as well as creating new temporal layers.

A palimpsest can include three different meanings to be interpreted: prior meanings, the new meaning, and the synthesis created when reading the old with the new. As previous fragments emerge partially through the new, the new work is perceived as an overlay of the old, forming a concurrent account of both the old and the new work. In other words, a palimpsest is suggestive of a condition where layers of an earlier entity can be recognized, allowing for reinterpretation and rediscovery. "A palimpsest can also serve as an artifact that embodies history and memory, reminding us that we are constantly building upon the past."19 This metaphor provides architects, urban planners, and designers with an opportunity to examine the layers of history ingrained within a site to understand not only the historical narrative of the place but also how to approach to generate a sense of place. This acknowledgment and awareness are imperative in dealing with a traumatic site with different layers of memory and history that has gone through an extensive reconstruction and reformation, resulting in a complex web of historical markers. We read cities and buildings as palimpsests of space. From a temporal perspective "an urban imaginary may well put different things in one place: the memory of what there was before,

18 Paul Antze and Michael Lamberk, eds., Tense Past: Cultural Essays in Trauma and Memory (Nueva York, Londres.: Routledge, 1996)

19 Ke L. Tran, "Architecture as Palimpsest: a Strategy of Intermediacy," (Master's dissertation, Ryerson University, 2011), p.8 
imagined alternative to what there is." ${ }^{20}$ Traces of the past, erasures, and losses are embedded in the present space. "Similar to the act of erasing something on a piece of paper, a hint of the old work remains, persistently on the paper." ${ }^{21}$ Although its influence could be reduced, the past can never be fully obliterated. 

4
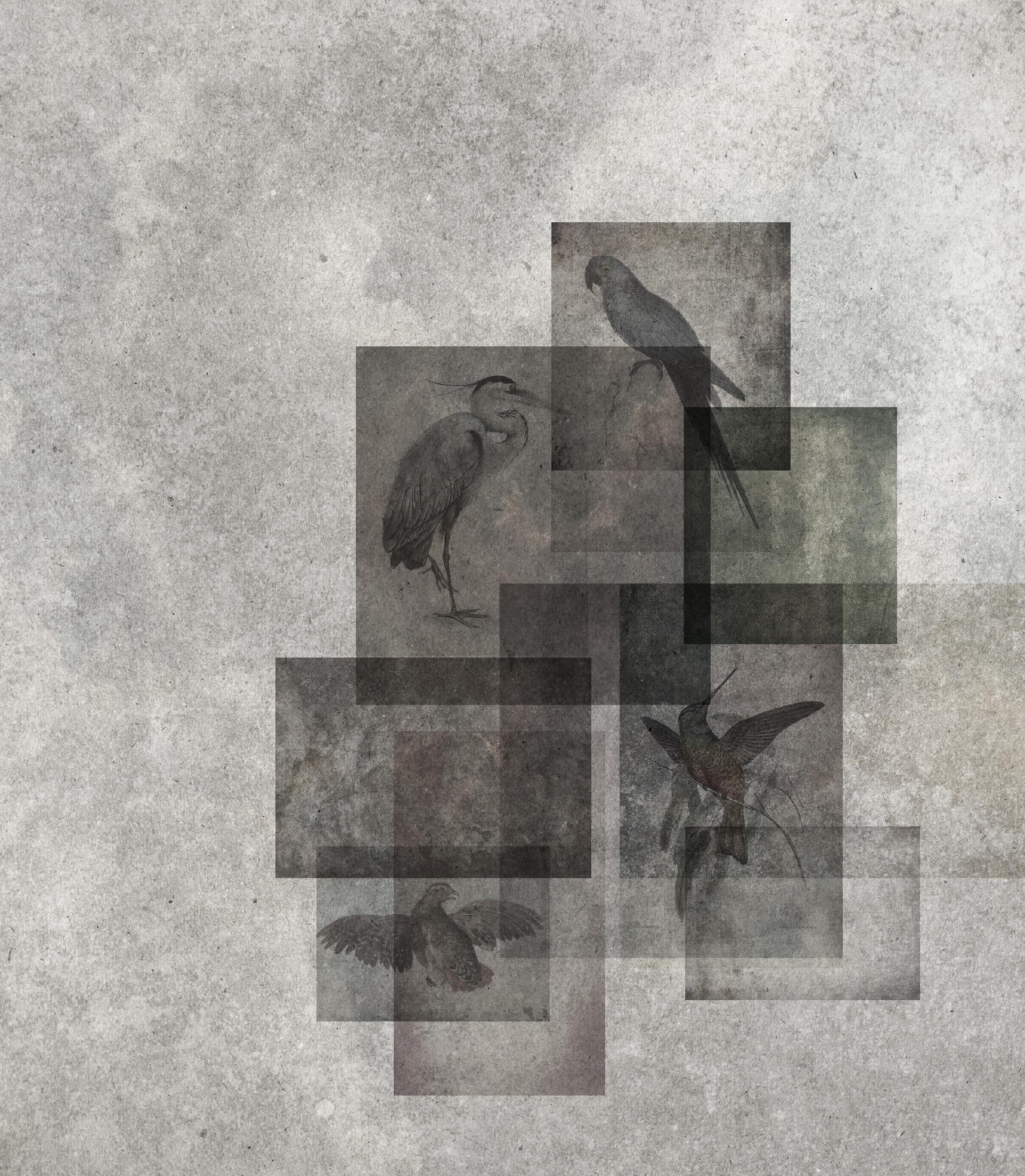


\section{PART TWO}

\section{ARCHITECTURE AS MNEMONIC}





\subsection{Carved Memories}

"What is contained in place is on its way to being well remembered."

Social processes are essentially defined by spatial perception. History and past experiences are associated with a specific place as well as a specific time. Time cannot be remembered or conceived as a mere physical dimension; rather it can be grasped through its materializations. ${ }^{2}$ As landscapes and buildings are the most powerful manifestations of human memory, they can be designed in order to engage people in ways that stimulate the collection of memories. Architectural structures or landscapes may provoke memories; however, based on their function, construction or alteration over time, they embody memories, handed down to the next generation of visitors. This process involves an interchange between the environment, the individual, and the society as a whole. ${ }^{3}$

Our attachment to places affirms the human ability to identify and recollect the landscape. "Place attachment" is defined as a psychological process analogous to a baby's bond with his/her

\footnotetext{
1 Edward S. Casey, Remembering: A Phenomenological Study, 2nd ed. (Bloomington, IN: Indiana University Press, 2009), p.214

2 Marc Treib, ed., Spatial Recall: Memory in Architecture and Landscape (New York, London: Routledge, 2009)

3 Eleni Bastéa, Memory and Architecture (Albuquerque: University of New Mexico Press, 2004)
} 
parents. Place attachment can also develop social, cognitive, and behavioral aspects as individuals establish a sensory connection to a particular community. "Place Memory" refers to "the stabilizing persistence of place as a container of experiences that contributes so powerfully to its intrinsic memorability." ${ }^{4}$ Place memory is suggestive of the ability of human beings to establish a link with the fabricated and natural environments.

Place facilitates the ability to evoke traumatic incidents, reviving memories triggered by qualities of light, sound, and smell. It is a sense of place that contextualizes memories within a certain spatial framework, offering a groundwork for those who visit memorial sites without having an actual experience of the event to reconstruct imaginative memories. Landscape with all its various layers and textures of memory becomes a site of symbolic representation, encompassing the components that are crucial in constructing and manifesting the identity of the place. Therefore, the sense of place is created by the mental images of the individuals and the community who attribute a particular identity to a place. Internal and external processes of identification both contribute to forming place images. These processes are internal because of being specific to a certain group and yet they are external as they are enforced by outside agency. ${ }^{5}$ Osborne illustrates this point as follows:

"[T]the material rendering of social memory in a mythologized landscape transforms landscape from an external phenomenon to be engaged visually, to a psychic terrain of internalized symbolic meaning: homeland; motherland; land of our fathers."

The cultural landscape in tandem with embedded characteristics and memories becomes of great importance in validating political and social systems, leading to the construction of group identity. Furthermore, urban landscape plays an important

4 Dolores Hayden, The Power of Place: Urban Landscapes as Public History (Cambridge, Mass.: MIT Press, 1995), p.46

5 G. J. Ashworth and B. J. Graham, Senses of Place: Senses of Time (Aldershot, England, Burlington, VT: Ashgate, 2005)

6 Brian S. Osborne, "Constructing landscapes of power: the Ceorge Etienne Cartier monument, Montreal," Journal of Historical Ceography 24, no. 4 (1998): p.433 
role in representing public history as a result of its capacity to provoke visual memories. As Ashworth and Graham put it:

"It is argued that the dynamic relationship between history and geography is demonstrated when, for example, national monuments, public buildings, and streets celebrating national heritage are inserted into the landscape in a manner that maps history onto territory."

A city is recollected through its buildings, therefore the preservation of the old urban fabric acts as a catalyst for the preservation of memories in the human mind. The selective process of preservation or destruction of built fabric mobilizes our collective memory of the space. The notion of identity as the assemblage of all traces in the city is at risk if many or significant buildings are demolished, causing memory loss and cultural crisis. The city loses its distinctiveness and can no longer continue to function as a guide or paradigm for the people living in it. Through individual memory or that of a social group a certain location is recognized as unique and significant, which would otherwise become an undifferentiated space. Treib argues that "we understand and remember who we are through our constructions, both material and mental." Examining unfamiliar and historic cultures is also facilitated through their architectural structures that embody their identity and ideology. Urban space is identified by the collective expression of architecture, carrying remnants of memory embedded in earlier architectural forms, city plans, streets, memorial sites, and monuments. As cities evolve, the way they are perceived also changes. The name of the city may never change; however, its physical manifestation is constantly transforming, being eradicated or forgotten, converted to suit other needs or destroyed for other purposes, leading to the generation of palimpsests of memories. ${ }^{9}$

\footnotetext{
7 Ashworth and Craham, Senses of Place, p.62

8 Treib, Spatial Recall, p.17

9 M. C. Boyer, The City of Collective Memory: Its Historical Imagery and Architectural Entertainments (Cambridge, Mass.: MIT Press, 1994)
} 


\subsection{Uncertain Topographies}

"Between salt and stone, between the ephemeral and the permanent, between dissolving personal memory and hardened official histories, I will eventually situate memorial museums." ${ }^{\text {mo }}$

Generally, the distinction between memorials and monuments is based on their political purpose. Memorials serve as representations of grief and lamentation, while monuments evoke honour and heroism. However, any individual structure contains elements of both, making this distinction blurry. Furthermore, memorials are considered to visually establish a dialogue with the audience, whereas in museums history is interpreted through scientific and descriptive textual strategies, tending to the didactic rather than the commemorative. Williams approaches this distinction differently, arguing that formal expression and physical appearance are far better distinguishing factors. In other words, he identifies monument as "a sculpture, structure or physical marker designed to memorialize"11, perceiving it as a subcategory of memorials. Moreover, he describes a museum as "an institution devoted to the acquisition, conservation, study, exhibition, and educational interpretation of objects with scientific, historical, or artistic value." ${ }^{12}$ He coins the term memorial museum to describe a particular museum "dedicated to a historic event commemorating mass suffering of some kind." ${ }^{13}$ He then ascribes the term memorial site to certain locales with commemorative functions which do not necessarily include a built structure. Despite these specific definitions, Williams asserts that the distinctions between museums, memorials, and monuments are not rigorous; rather he seeks to illustrate that the traditional formal differences between these classifications have been blurred in recent decades. ${ }^{14}$

\footnotetext{
10 Paul H. Williams, Memorial Museums: The Global Rush to Commemorate Atrocities, English ed. (Oxford, New York: Berg, 2007), p.1

11 Ibid., p.8

12 Ibid.

13 Ibid.

14 Ibid.
} 
The consolidation of museums with memorials is suggestive of a need to both contextualize the narrative of traumatic events within a moral framework and to add more detailed accounts to commemorative rituals. The fact that many recent memorial museums are seen as controversial indicates that respectful remembrance and critical interpretation cannot be easily achieved together, often when there is a tendency to gloss over one side of the story. Memorial museums simultaneously contain dual qualities. Although they are often dynamic and palpable places in disparate locations where visitors can experience the space in their own personal terms without any rigid and determinate framework, visitation often encompasses a strong ritual component. As Williams puts it:

"Crave and often official impositions of meaning also firmly situate memorial museums as perpetual, reliable city spaces, perhaps as functional as any other. Hence, memorial museums are especially interesting in the way they seek to support a wide, open-ended variety of practices in visitors, yet also aim to make some authoritative statement about where and how to remember the past. They will continue to remain interesting and controversial spaces precisely because they uncommonly represent structures associated with serious historical narratives and institutional permanence, yet also offer a personal freedom of response, interpretation, and use."'5

In memorial museums, there is often a constant tension pertinent to the rational and sentimental perception of the relationship between the architectural and curatorial goals laying the foundation for the incorporation of images, objects, and spaces, and the particular narrative to which they refer. The design principles of museums or memorials are based on two measures: on the one hand, the objects in the space serve the programmatic or didactic purpose of the museum; on the other hand, architectural strategies are implemented in order for visitors to construct mental visions of the subject to which they relate. More than the objects and the descriptions included in museums, visitors establish a meaningful 
dialogue with the historical narrative in response to the scale and character of spaces, facilitating a particular experience for visitors while moving through the museum. Here, architecture plays a critical role in creating an atmosphere conducive to contemplation and reverence. Thus, the museum can be considered as a cultural project in which "spaces, histories, and social activities are being materially and symbolically remade."16

In order to illustrate the significance of emotional experience in the memorial museum, Williams draws an analogy with the experience of going to church. People usually attend not because of the didactic aspects, rather they aim to be in a spiritual environment "that rehearses and affirms a sense of being in place."17 Therefore, memorial museums become similar to churches in terms of the notion of sacredness and drawing people together under a certain theme. Other similarities exist such as their emphasis on morality and our general tendency toward unethical acts, and promoting the need for constant self-reflection. As Williams puts it:

"What now deserves attention is the slippery topic of an individual's quality of feeling that stems from being in a certain place, around others interested in exercising the same moral concern. An accent on the physical is in line with the idea, central to the study of trauma that we remember not so much in a cognitive, declarative fashion, but in one that is bodily and sensory. This is especially pertinent when the themes related to us by memorial museums are those of physical discomfort, pain, and alienation. ${ }^{m 8}$

Architectural design elements act as catalysts to create particular conditions in memorial museums, providing visitors with moments of contemplation on these issues. In addition, regarding their didactic objectives, they foster a future-oriented culture to avoid similar catastrophes.

\footnotetext{
16 Ibid., p.77

17 Ibid., p.98

18 Ibid.
} 


\subsection{Architectural Precedent}

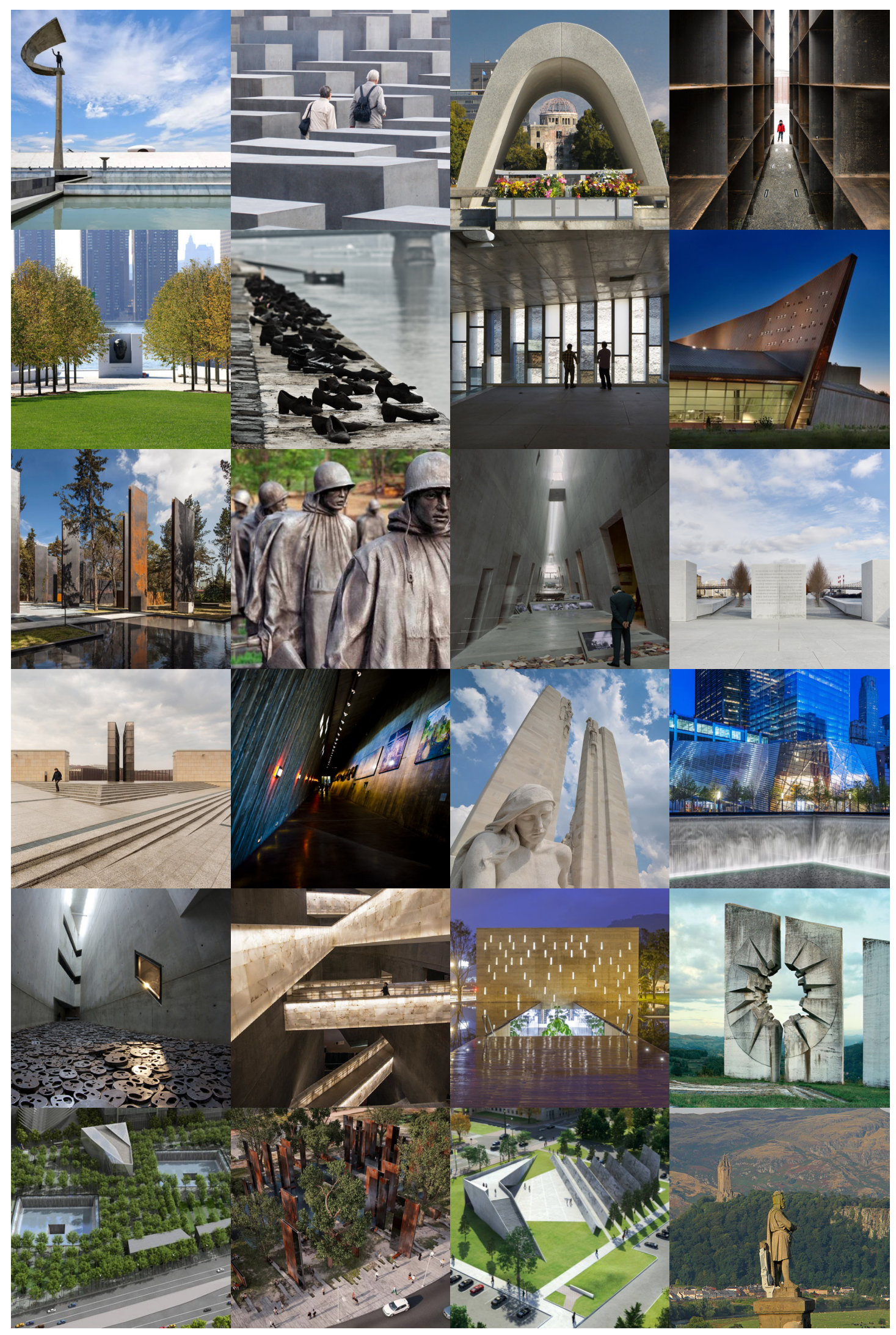




\section{Topography of Terror -Berlin, Germany, 2010}

Heinle, Wischer \& Partner Architects

Topography of Terror is an outdoor and indoor museum that documents and exhibits the crimes of National Socialism in Cermany. The museum was built on a historic site where the headquarters of the Third Reich's Secret State Police, the SS, and the Reich Security Main Office were located during the Nazi Regime, a place loaded with traumatic memories. The original buildings were destroyed and an excavation in 1985 brought forth the remains of this building, which opened a big wound in the heart of Berlin. A new building was designed by Heinle, Wischer \& Partner architects on the remains of a basement containing prison cells. The new building is a neutral, flat, quadratic volume housing archives and exhibitions and intentionally avoids aligning to any lines created by previous structures or streets.

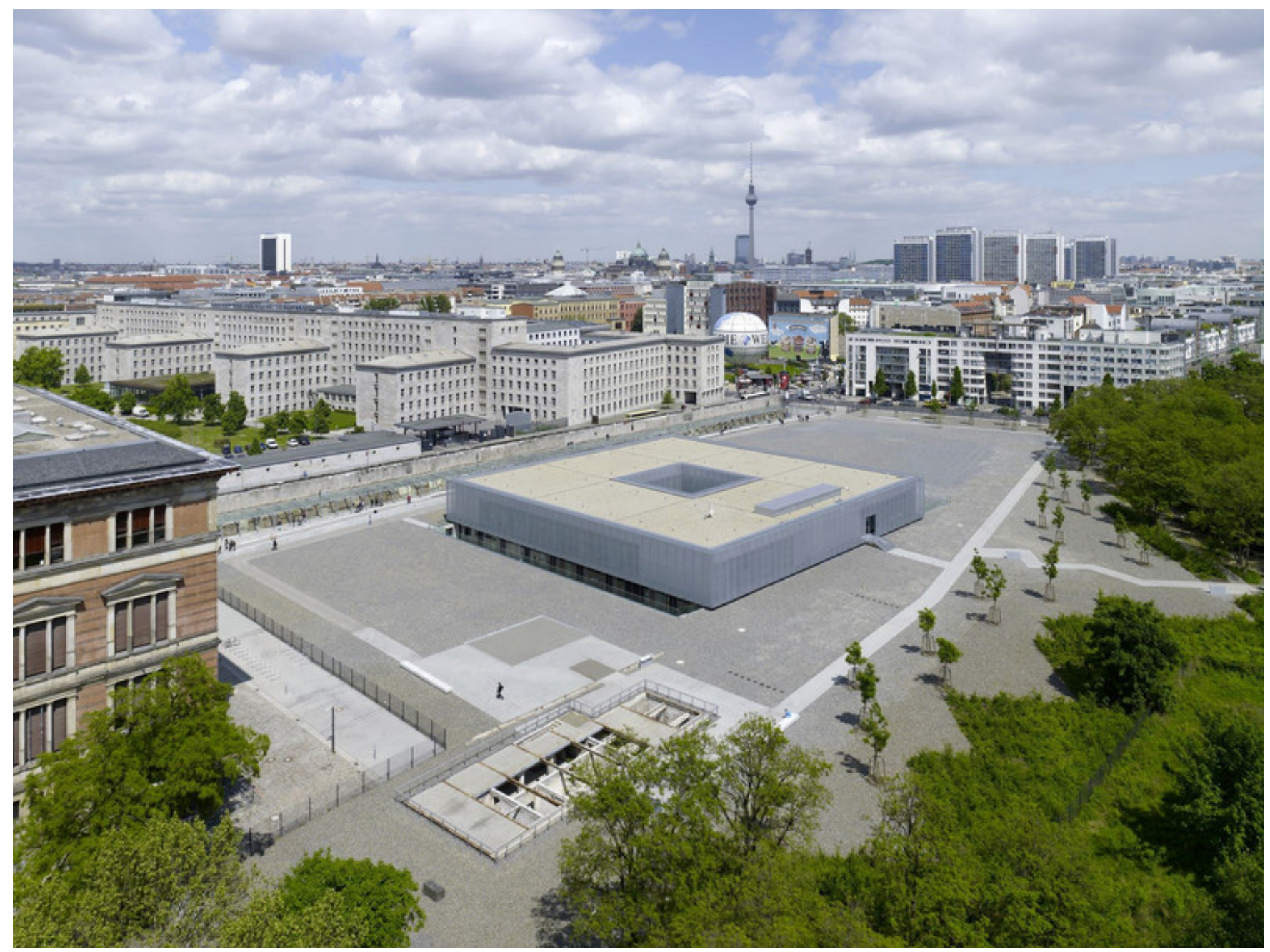

Fig 2.1 View of the grounds of the Topography of Terror 
Adjacent to the documentation centre, part of the basement walls and foundation remnants and one of the last remaining sections of the Berlin Wall are displayed as witness to the dark past of the site. This section of the wall acts as an outdoor exhibition area, detailing the history of repression under the Nazis. A large grove of honey locusts has started to cover the numerous historical layers accumulated on the site.

The landscape around the building is designed to be minimal and simple. The area surrounding the building and the former cellar remnants is covered with a layer of coarse grey gravel. Due to its very emptiness, the site is unsettling in its urban environment and it is filled with a sense of discomfort. It is as if the terror that had once filled in space still lingers in the air.

Physical markers and remnants cannot speak for themselves, however, they do establish a link between the history of this place and the present life of the visitor. The authentic historic site allows for a more immediate and intensive experience, contextualizing history in palpable terms. The new architecture of the site with its neutrality deliberately refrains from choreographing the site and interpreting the historic events associated with this place. It rather seeks to draw attention to the site and its various layers of history.

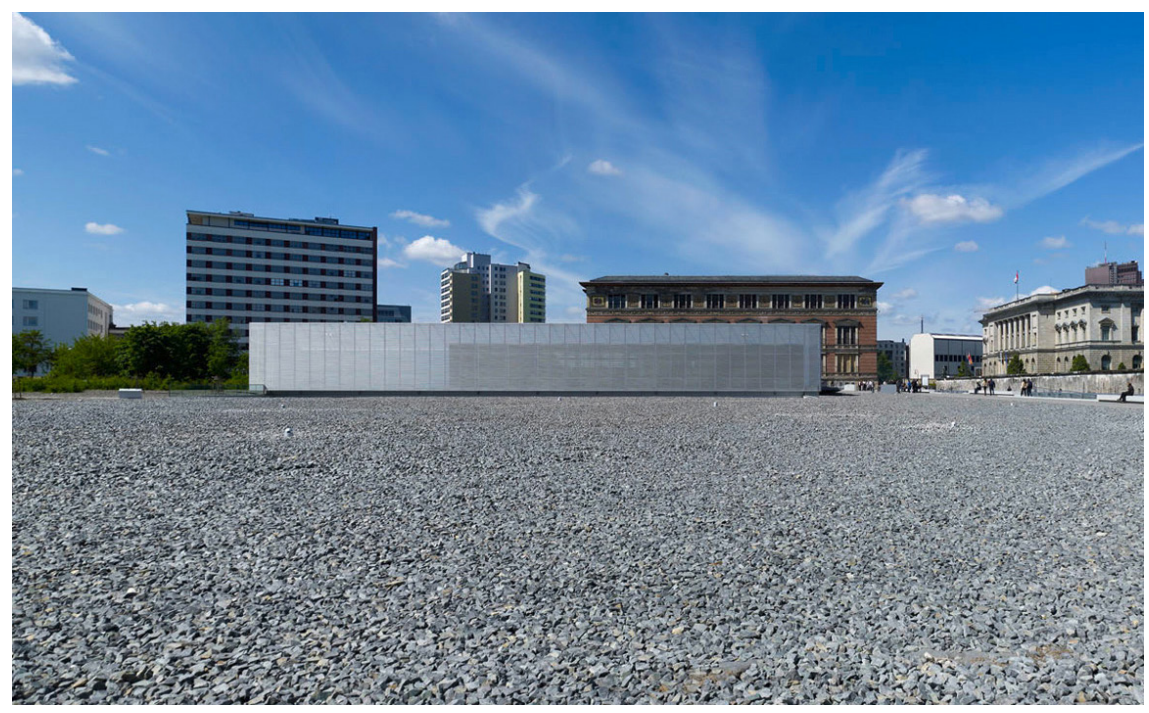

Fig 2.2 The emptiness of the site, Topography of Terror
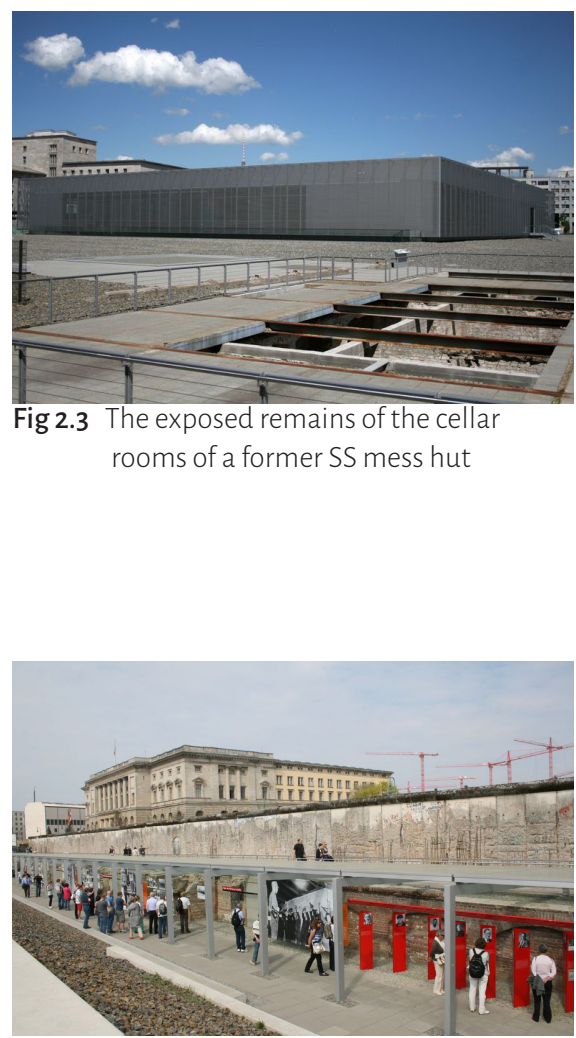

Fig 2.4 View into the exhibition, Topography of Terror

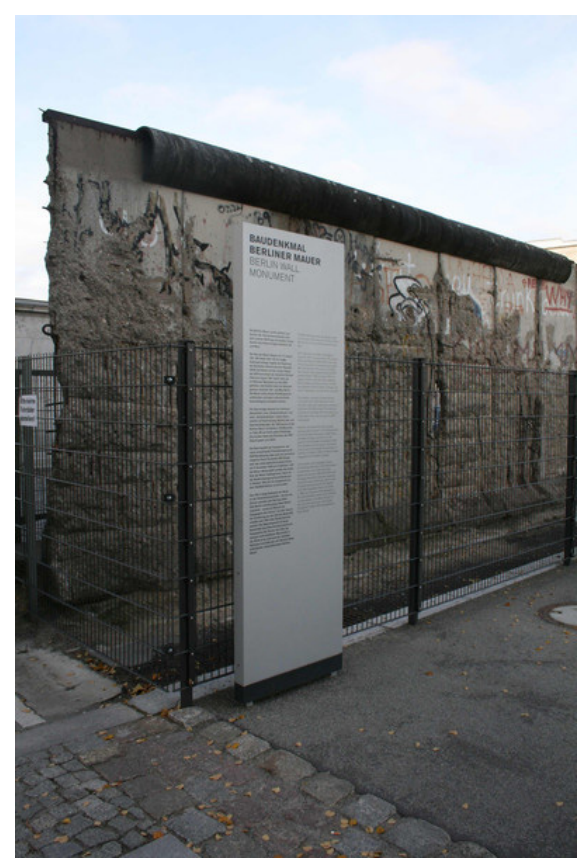

Fig 2.5 The re-designed information panel at the main at the main entrance. Topography of Terror 


\section{Vietnam Veterans Memorial - Washington, DC., 1980}

Maya Lin

Maya Lin's design for the Vietnam Veterans Memorial is simple and yet powerful in evoking remembrance, expressing loss and pain experienced because of the Vietnam War. Maya Lin was very aware of the fact that in response to an inexplicable loss there is a longing to keep the dead alive in memory, to articulate the pain and suffering in space and time. The Vietnam Veterans Memorial is a permanent marker that ensures the remembrance of so many lost lives in the war. It is an object that interacts with visitors on an emotional level.

The V-shaped wall is sunk in the earth representing a wound that time would heal but its trace would be always visible. Although not visible from most vantage points on or near the Washington Mall, it responds to the setting, its eastern arm points directly to the Washington Monument, while its western arm points directly to

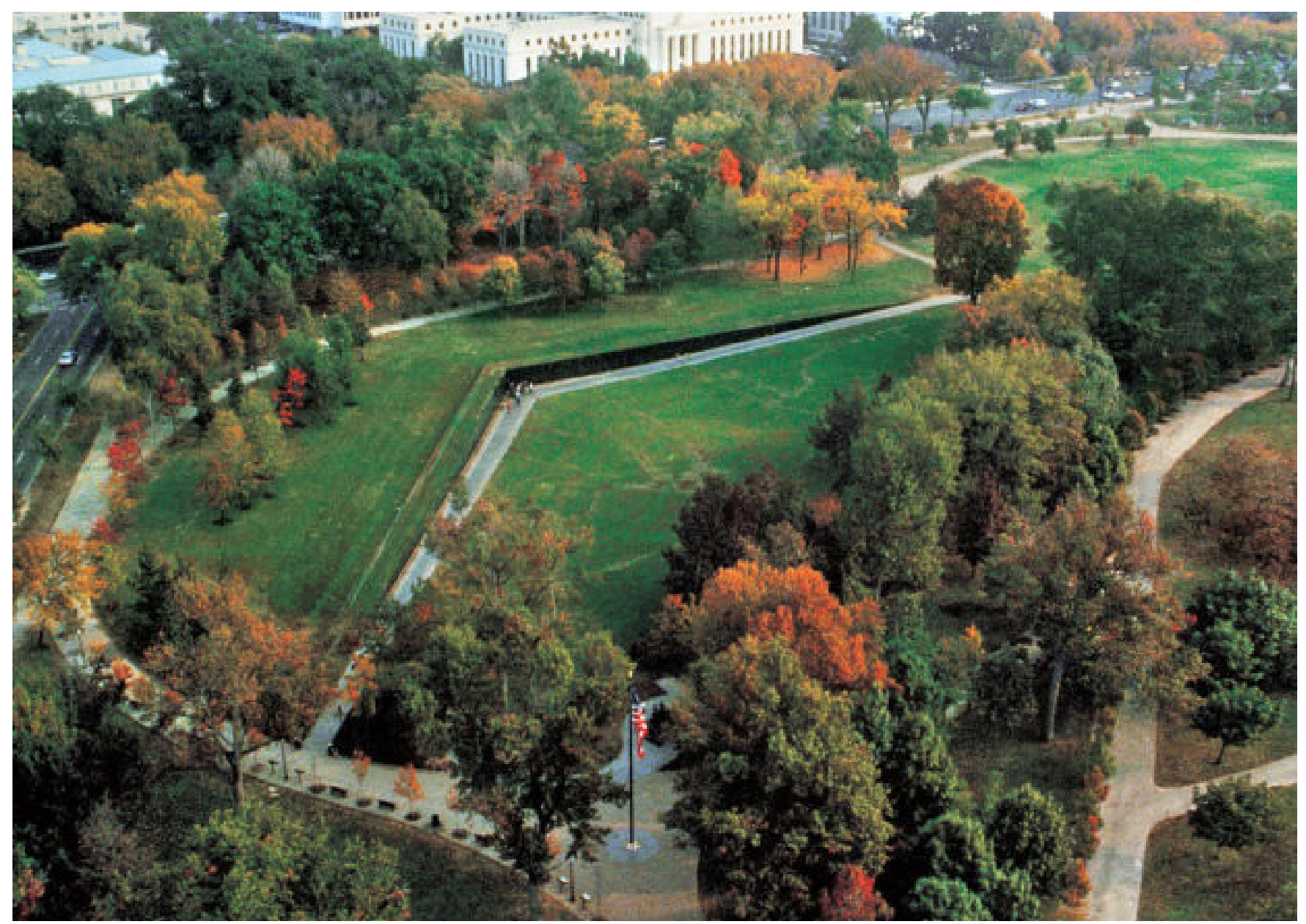

Fig 2.6 An aerial view of the $v$-shaped design, Vietnam Veterans Memorial 
the Lincoln Memorial, incorporating these monumental structures in its design in a subtle way. Yet, it approaches the nation's past in a different way from those neighboring monuments. Consciously avoiding glorifying the controversial Vietnam War, Maya Lin believed that:

"Many earlier memorials were propagandized statements about the victory, the issues, the politics, and not about the people who served and died. I felt a memorial should be honest about the reality of war and be for the people who gave their lives" (National Ceographic, May 1985, p. 557). ${ }^{19}$

The walls bring a sense of detachment by their V-shaped form, embracing the visitors in a distinct time and space. On the two granite walls, 57,939 soldiers' names are inscribed in the order in which they died. By excluding the soldiers' hierarchy or rank, this timeline emphasizes the individuality and reality of each loss. As one walks along the wall, the years emerge and then recede. In this sense, one experiences a circular journey through time, a peculiar journey that

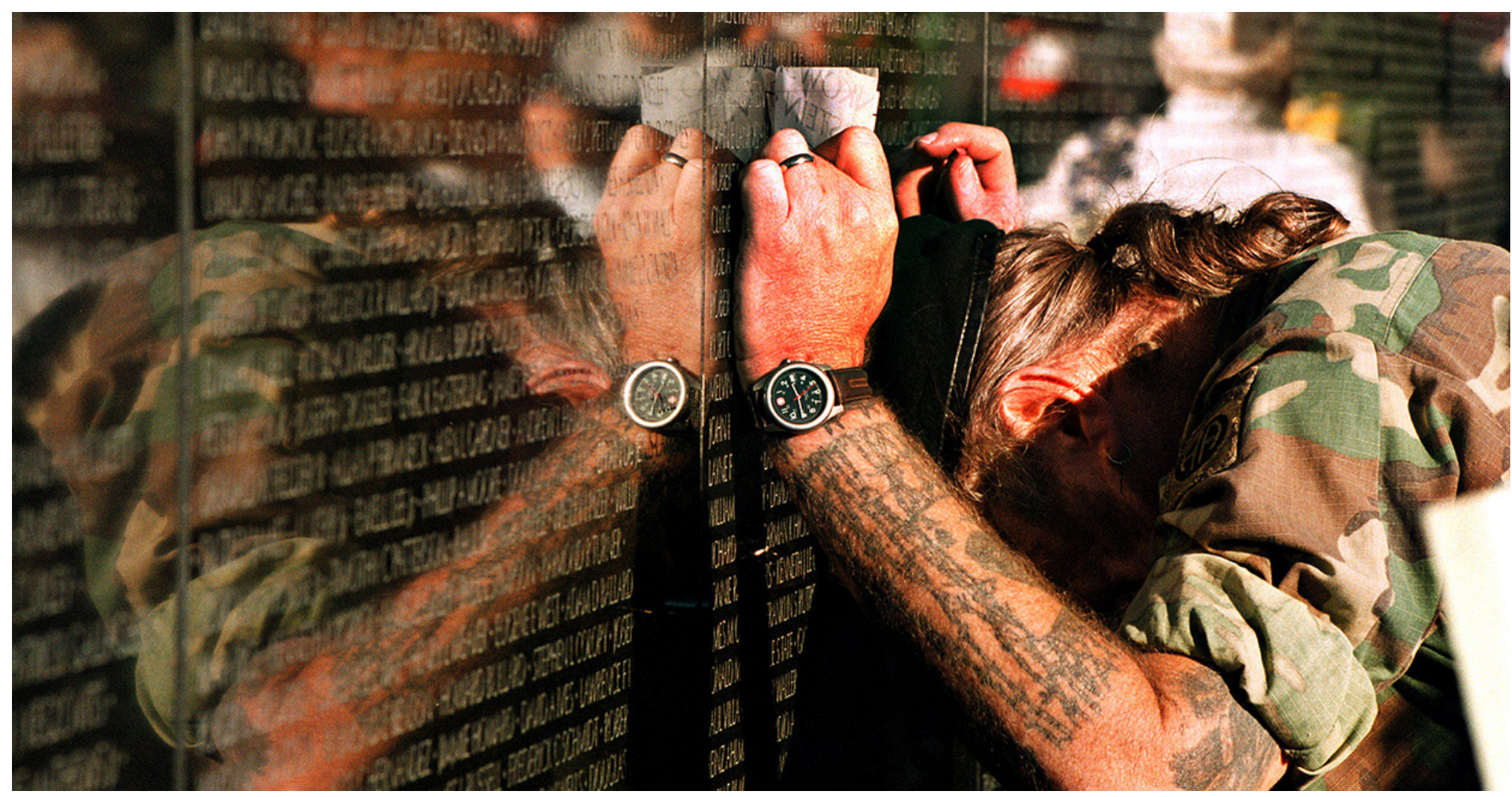

Fig 2.7 Connection and Separation, Vietnam Veterans Memorial

19 As quoted by Robin Wagner-Pacifici and Barry Schwartz, "The Vietnam Veterans Memorial: Commemorating a Difficult Past," American Journal of Sociology 97, no. 2 (1991): p. 400 
helps us realize the immense number of casualties. Visitors touch the names on the wall, tracing the letters with their fingers. This symbolization ensures that the sacrifices of the soldiers will never be forgotten or denied as they have been etched in the nation's memory.

The memorial as a symbolic site provides a place where death can be mourned, a place to recognize the loss and the pain and a place to finally begin to heal. Here, the walls act as a linking object within which the deceased person is not found, rather the walls create a medium through which our own memories and the related feelings become accessible and hence the lost person becomes alive again. The reflective black granite plays a major role in creating a space of absence, emphasizing the loss of individuals as well as the presence of the painful memories. It creates two worlds like a mirror, one that we are living in and one that is only visible but is long gone, bridging the gap between the nation's past and the present. The reflective surface simultaneously connects and separates and establishes an interpersonal human connection of the living and the dead. ${ }^{20}$

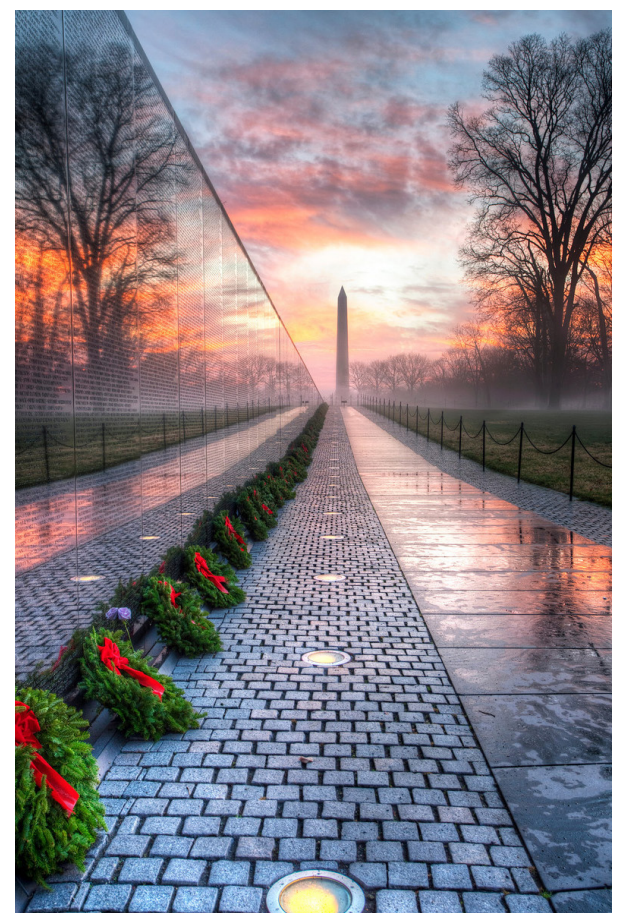

Fig 2.8 Reflective granite wall, Vietnam Veterans Memorial

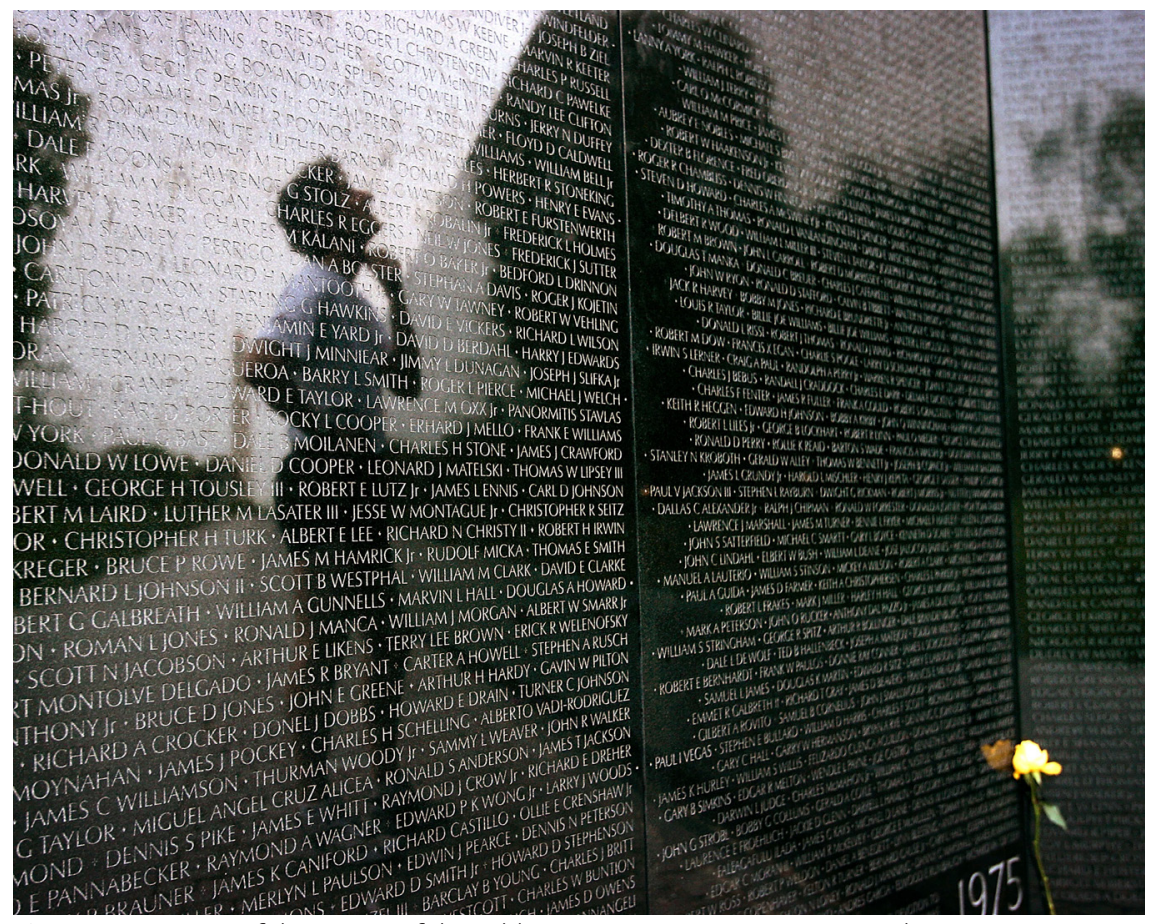

Fig 2.9 Inscription of the names of the soldiers, Vietnam Veterans Memorial

20 Jeffrey K. Ochsner, "A Space of Loss: The Vietnam Veterans Memorial," Journal of Architectural Education 50, no. 3 (1997) 
Memorial to the Murdered Jews of Europe -Berlin, Cermany,2010

PeterEisenman

Characterized by a strong verticality, the Memorial to the Murdered Jews in Berlin designed by Peter Eisenman constitutes an undulating topography with a rigid grid structure of concrete stelae arranged to create walkable passages. The ground and the top planes of the memorial are defined by the junctions of the voids of the grid of stelae and the gridline of the larger context of Berlin. Modifying the ground plane and the top plane enables the grid framework to develop a series of ambiguous spaces out of an orderly structure. The condensed form of the pillars and the chaos in the field of stelae create a multi-layered experience, one that not only refrains from having a single direction but also causes insecurity in the very orderly structure of the internal grid as well as in the frame of the city grid.

Located in a central urban place in the city, the pillars of the memorial vary in height from a few centimeters to 4 meters, creating a captivating spatial experience. The farther the visitor walks into the field, the higher the stelae become, and the visitor becomes deeply immersed in this waving field of stones. Yet, the visual connection

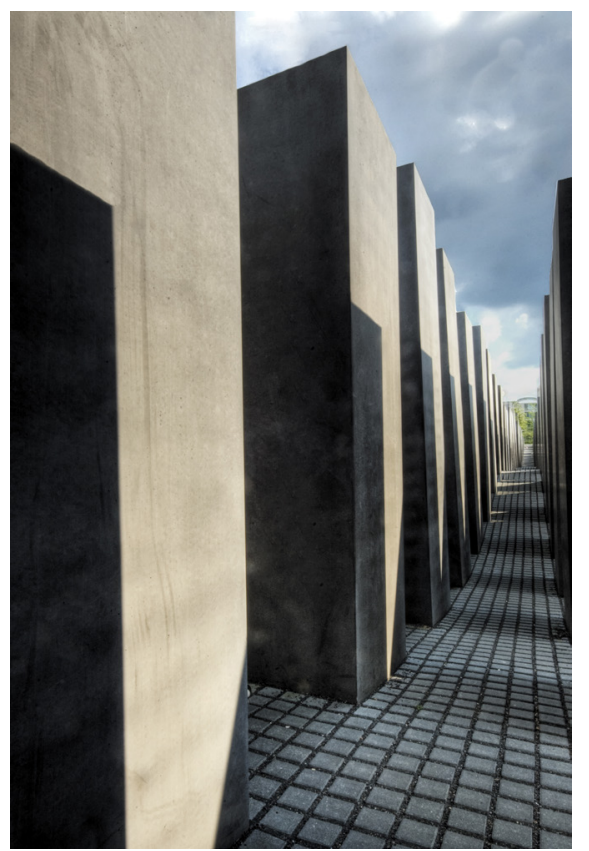

Fig 2.11 The undulating ground, Memorial to the Murdered Jews

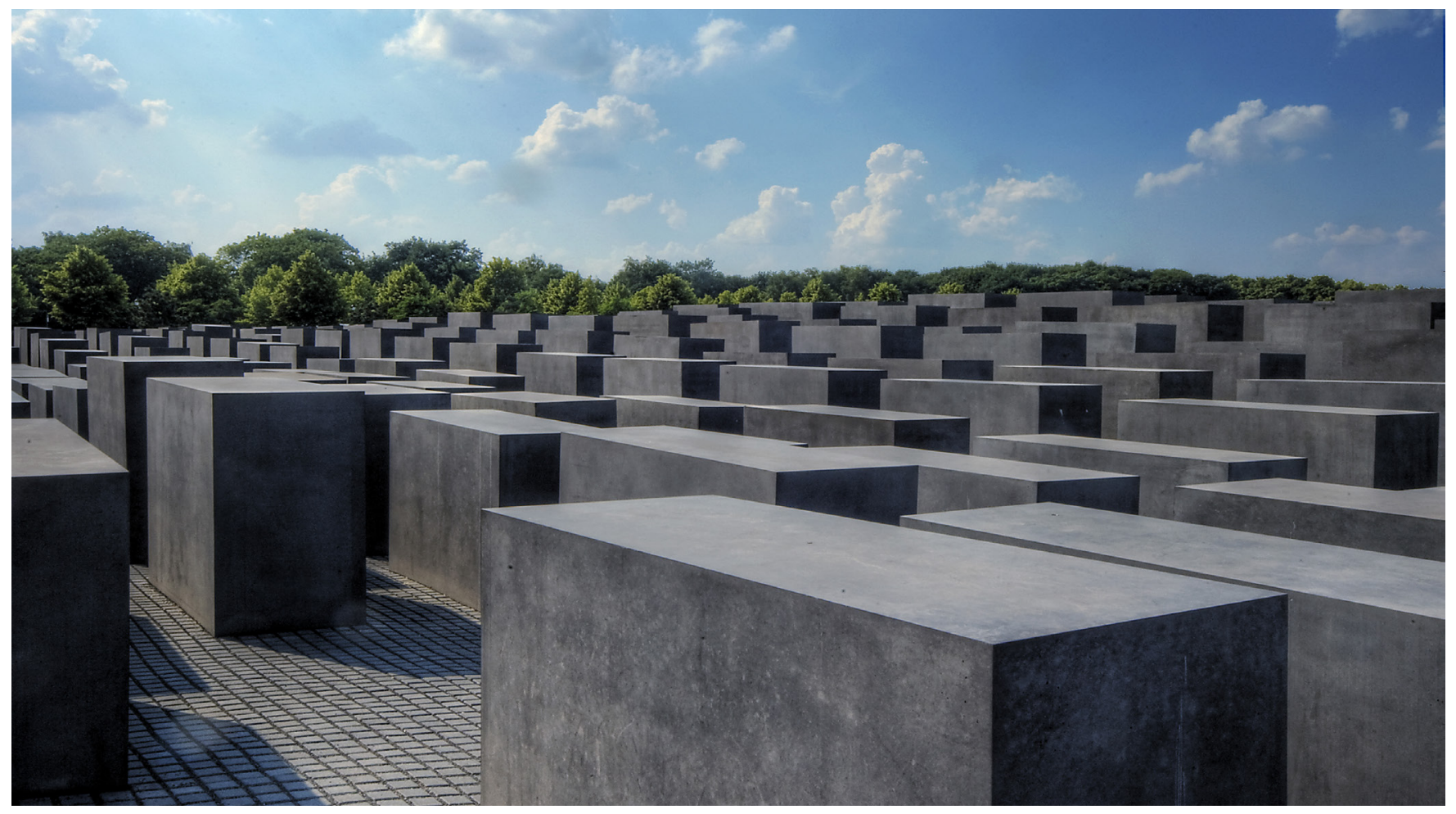

Fig 2.10 Field of stelae, Memorial to the Murdered Jews 
to the urban surrounding is never completely cut off. The stelae are lower at the edges, used by children who playfully jump around on them or by tourists as seats, slowly inviting people in.

The Memorial to the Murdered Jews of Europe is a silent structure that has no single entrances, no start or end point, no descriptions or names. The memorial does not encourage a certain interpretation of the past, nor does it urge its visitors to remember. The pillars are neither symbols of loss nor gravestones. Yet, this type of anonymity is not fixed. It is both present and absent. The memorial seems to be free of memory and at the same time the voids, the variations in height and surface, the destabilization of the individual sense of space and time all retrace an unspeakable loss.

For a more literal understanding of the past, there is an underground visitor's centre that documents and displays information about all the murdered Jews in Europe. Descending into the ground and leaving the grid of concrete pillars, the above ground structure still follows in the building and the exhibitions. The grid of hollow stelae is visible on the ceilings, reproducing the concave ground, and the display panels of the exhibitions also follow the same geometry in the form of concrete blocks.

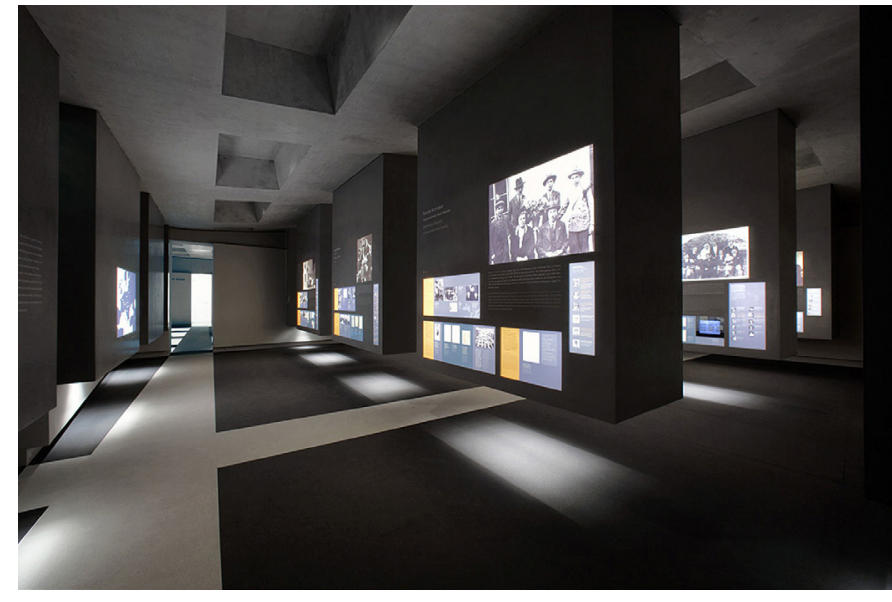

Fig 2.12 Information panels as concrete blocks, Memorial to the Murdered Jews

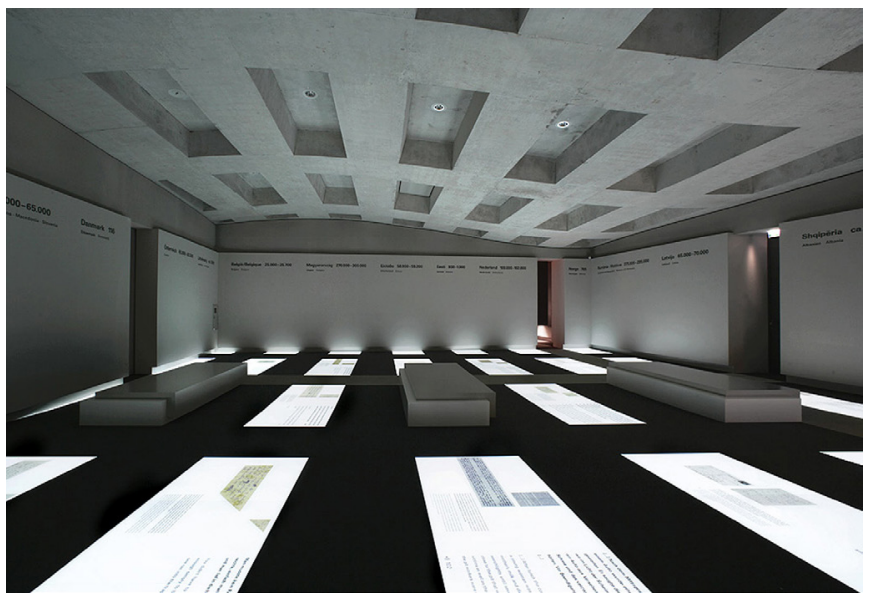

Fig 2.13 Crid of rectangular concrete blocks seen in the ceiling, Memorial to the Murdered Jews 


\section{Jewish Museum Berlin -Berlin, Germany, 2001}

\section{Daniel Libeskind}

Daniel Libeskind's extension to the Jewish Museum in Berlin intends to articulate the suffering of the Jews in Europe. According to Libeskind, this acknowledgement of the erasure of Berlin's Jewish life was necessary in order to move forward. More than a container for relics of the horrible past and a narrator of the history, the museum seeks to optimistically emphasize the continuation of Jewish life in Berlin.

Seen from above, the building adopts a zigzag form that was developed by dislocating the Star of David. The zigzag represents the continuous life of Jews broken into many fragments. The discontinuous straight line cutting through the zigzag shapes the voids in the building, suggestive of the erasure and absence of Jewish life in Berlin. According to Libeskind, these voids refer to what can never be exhibited in the museum. As Young puts it,

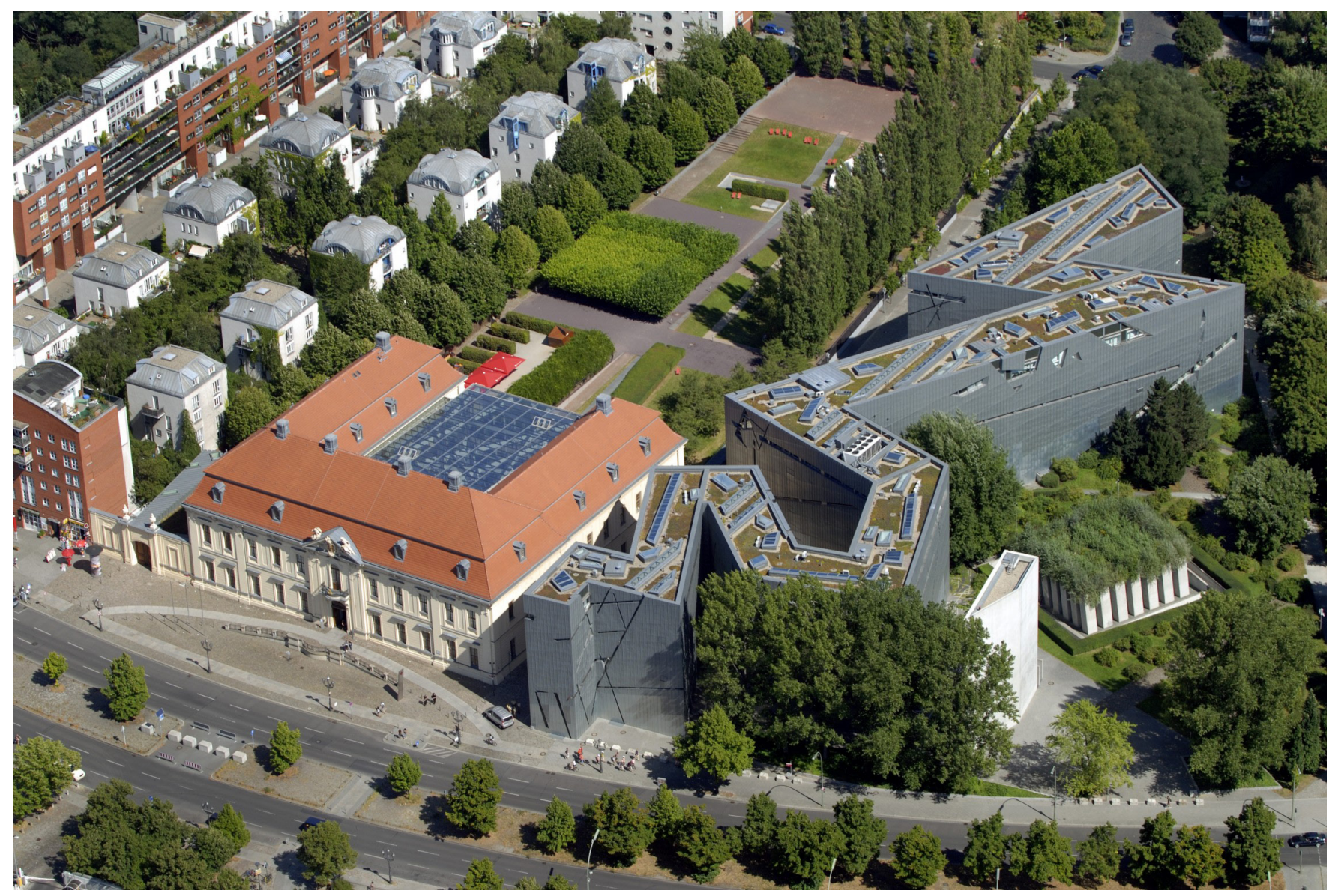

Fig 2.14 Zigzag form of the building, Jewish Museum Berlin 


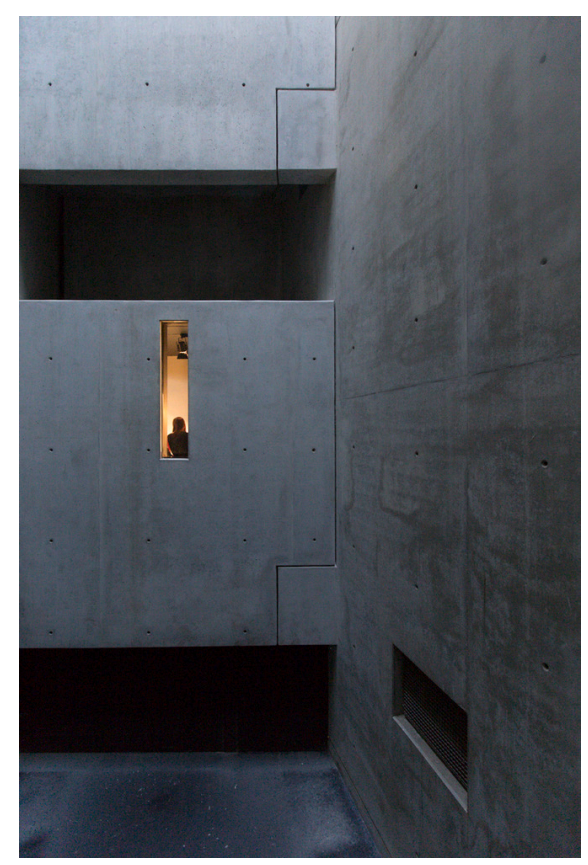

Fig 2.15 The voids, Jewish Museum
"It is the void "between the lines" that Libeskind seeks to capture here, a void so real, so palpable, and so elemental to Jewish history in Berlin as to be its focal point after the Holocaust-a negative centre of gravity around which Jewish memory now assembles." ${ }^{21}$

The voids intentionally create disruptions in the narrative of the interior exhibitions, constantly reminding the visitors of the stories that cannot be told.

Entrance to the Jewish museum happens from the adjacent 18th-century building, the Berlin museum. Although there is no apparent link visible between the two structures from the street level, the existing building is closely tied to the new extension underground. The journey in the Jewish museum actually starts by descending into the ground, more than ten meters under the foundation of the old building. From the entrance, the visitor encounters three different roads.

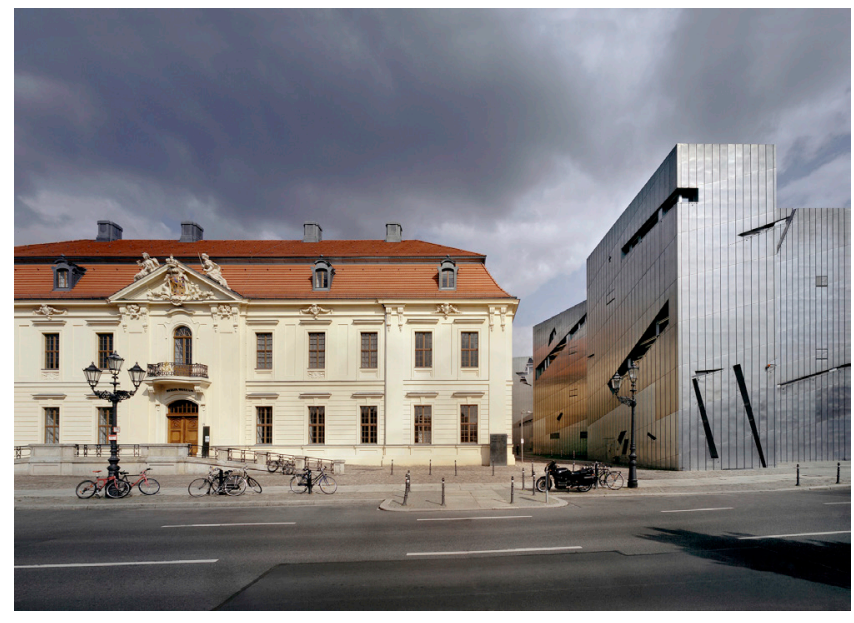

Fig 2.16 The old and the new with no apparent connection, Jewish Museum

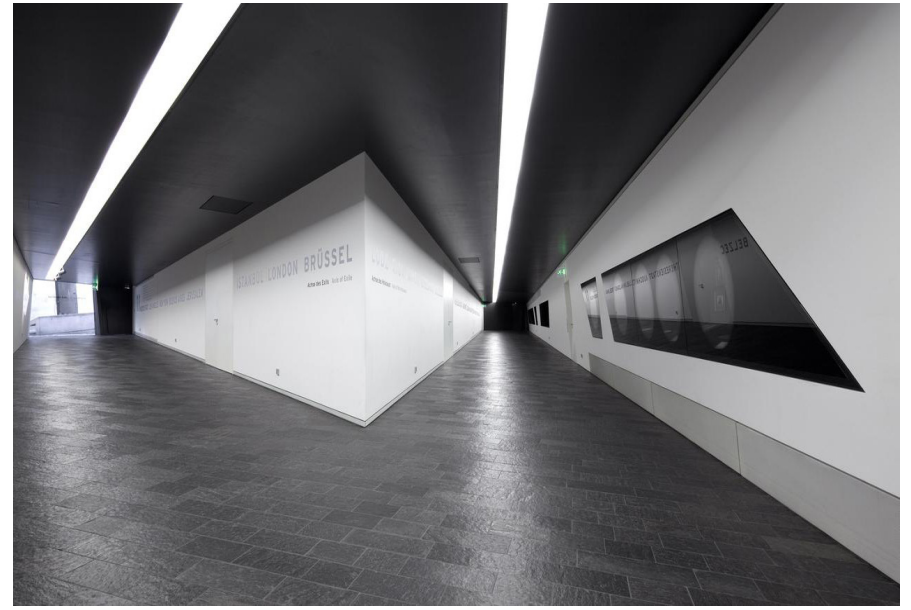

Fig 2.17 Intersections between the routes, Jewish Museum

The primary path is the Axis of Continuity intersected by two other routes: the Axis of Holocaust, and the Axis of Exile, each narrating a particular historical destination for Jews of Berlin. The first road is the longest one that leads to a staircase going up to the exhibitions on the upper floors. The Axis of Continuity metaphorically speaks to the continuation of Berlin's history. The second Axis ends at the tower of Holocaust, accessed through a heavy door, a huge void

21 James E. Young, "Daniel Libeskind's Jewish Museum in Berlin: The Uncanny Arts of Memorial Architecture," Jewish Social Studies 6, no. 2 (2000): p.11 


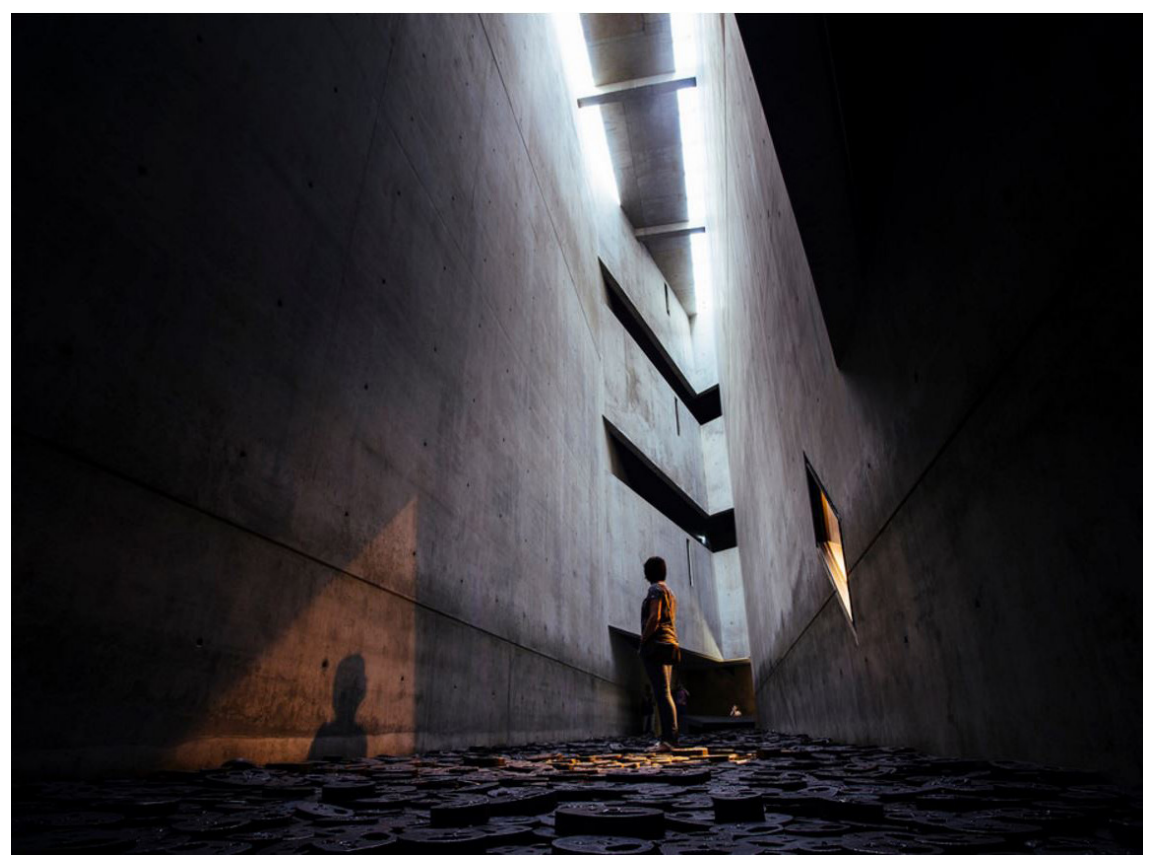

Fig 2.18 The dark Holocaust Tower, Jewish Museum

commemorating the victims of the holocaust. Inside the high concrete tower, one analogically experiences the confinement and misery of those who were deported and then murdered. The emptiness of the tower along with a narrow ray of light coming into the darkness and all the voices of the outside world create a powerful and unsettling experience of being trapped in a tomb.

The third axis leads to the exterior of the museum, the Garden of Exile. The garden is placed on a tilted plinth with 49 slanted columns, each with a tree growing out of it. Moving through the garden on a slanted surface, the visitor experiences the unsettlement and disorientation felt by those who were exiled.

Libeskind's main goal in designing the Jewish museum is not to reassure or alleviate the pain, rather he aims to haunt visitors with the undesirable feeling of recalling that which has been previously obliterated. He attempts to call for an active and hopeful engagement with the dark past, reminding Berlin, Germany and Europe to remember what was easier to forget.

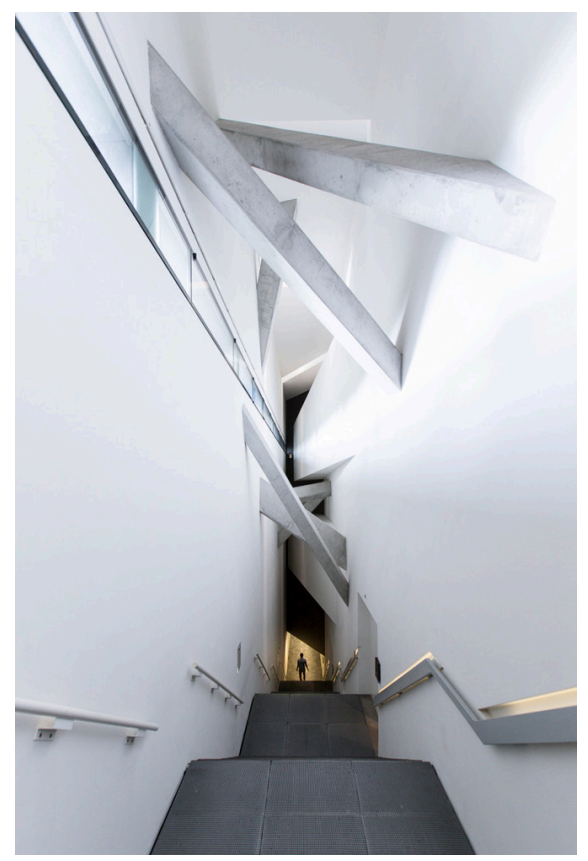

Fig 2.19 The Axis of Continuity, Jewish Museum

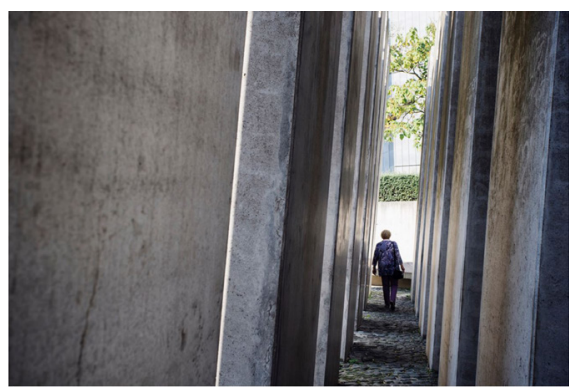

Fig 2.20 Disorientation in the Garden of Exile, Jewish Museum

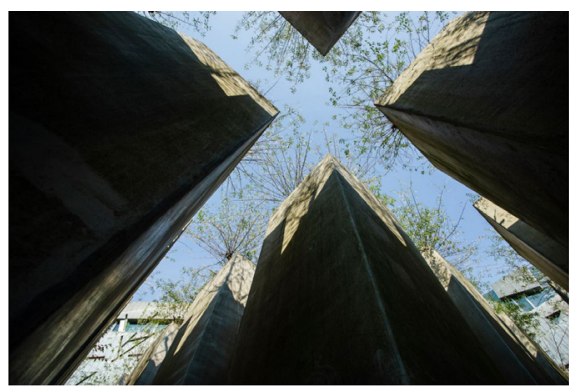

Fig 2.21 49 Columns with growing trees, Jewish Museum 
National Museum of Afghanistan - Kabul, Afghanistan, 2012

Matteo Cainer Architects

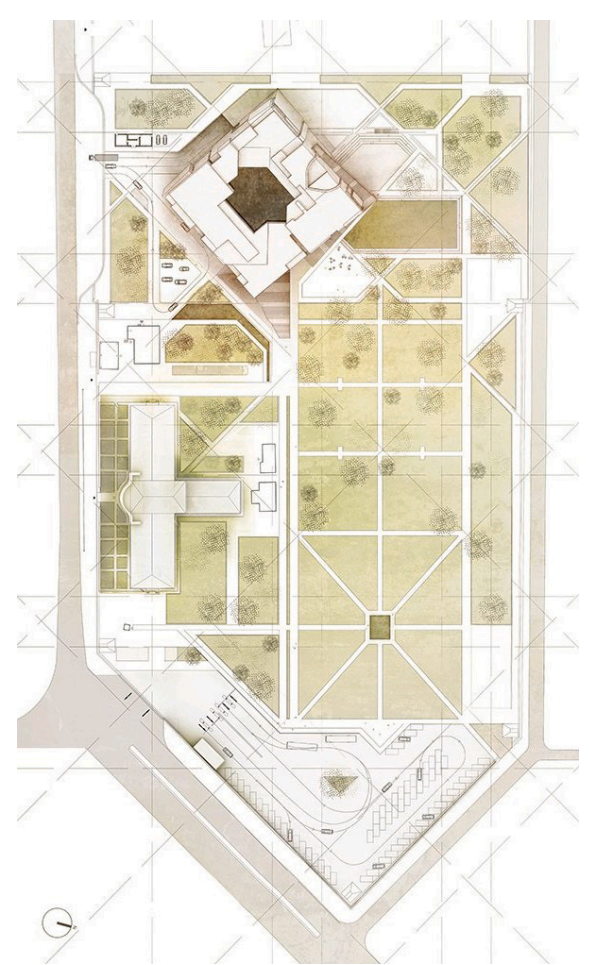

Fig 2.22 Site Plan, National Museum of Afghanistan
The construction of the National Museum of Afghanistan intends to celebrate the country's rich cultural heritage that transcends war and terror. Proposed by Matteo Cainer Architects, "Timeless Cube" is a monolithic cubic structure invoking the nation's cultural heritage through contemplative symbolic references relevant to an Islamic state. Even though the country is devastated by turmoil and conflict, its rich cultural context and the spirit of its people remain intact, embedded in the earth and emerging out of it. The inclination of the building refers to the gradual revealing of the underlying strengths of the nation as well as its current unstable condition.

The building is carefully oriented in response to the solar path and the prevailing breeze in Kabul. The planning of the museum allows for shady areas for outdoor promenades. The garden setting is characterized by the site geometries and configuration, incorporating water features in order to create a desirable microclimate during the summer months. Landscaping comprises a stepped garden

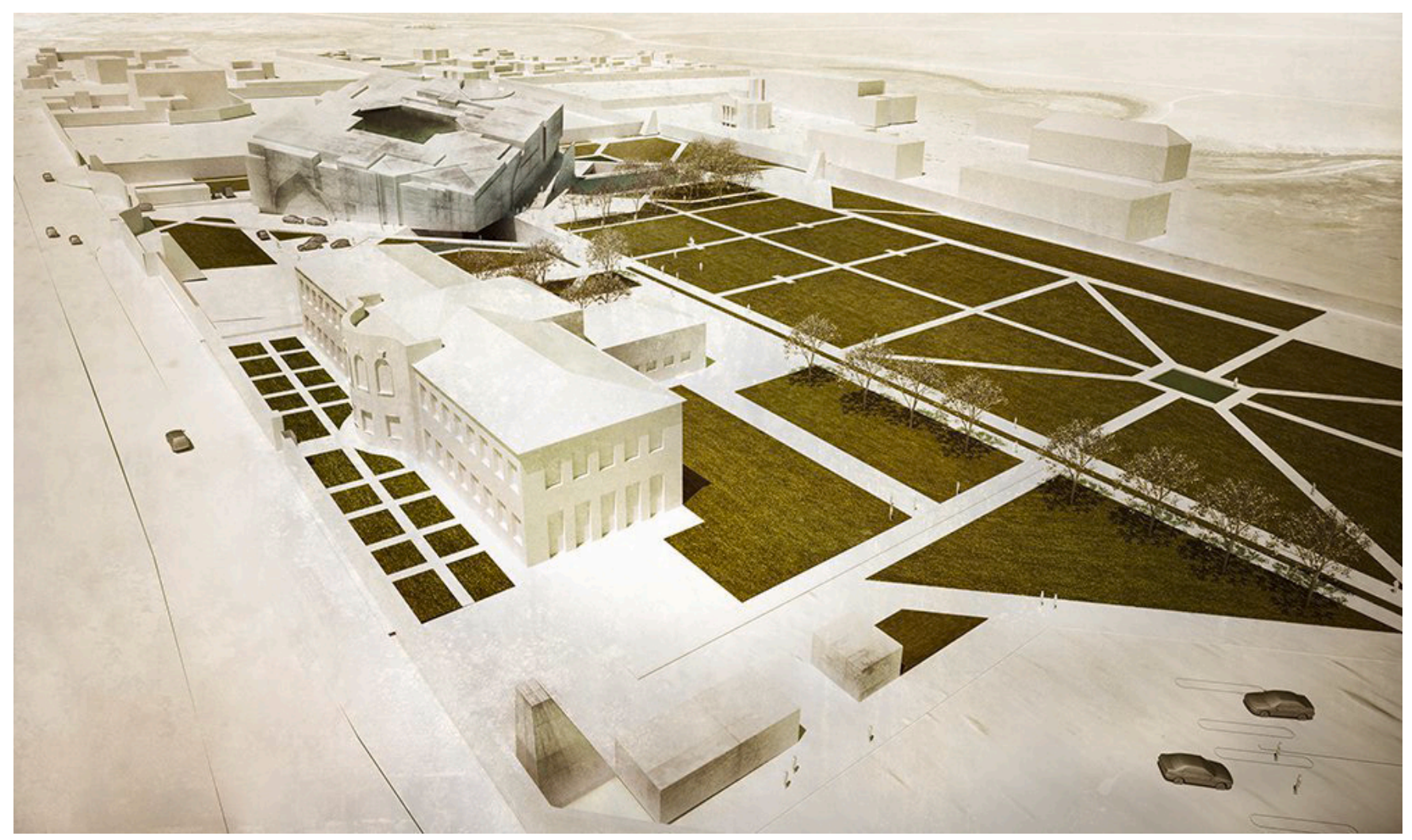

Fig 2.23 Bird's-eye View from the south, National Museum of Afghanistan 
with covered seating areas as well as additional spaces dedicated to the museum's outdoor education programs, including outdoor performances, garden lectures, and tours.

In an attempt to highlight the presence of an absence, the overshadowed rich history of Afghanistan, a void is carved out of the volume, creating an inner courtyard that serves as a foyer which is a serene and peaceful space with water and plants. In this regard, the experience of the museum begins at the heart of the building by ascending the monumental stairs from the foyer. The sculptural staircases lead to a sequence of exhibitions showcasing both traditional and modern Afghan collections. Stairs and carved ramps overlook the foyer with the succession of galleries unfolding in an intriguing and complicated geometry. The large opening at the centre of the exhibitions allows for light penetration while operable shutters control excess heat gain.

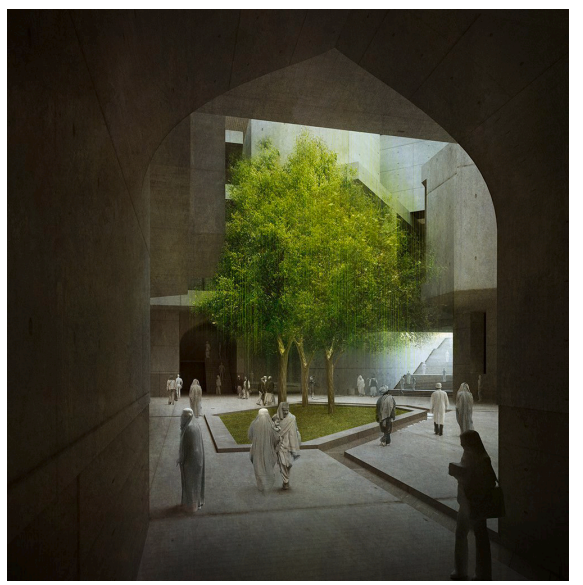

Fig 2.25 Interior foyer, National Museum of Afghanistan

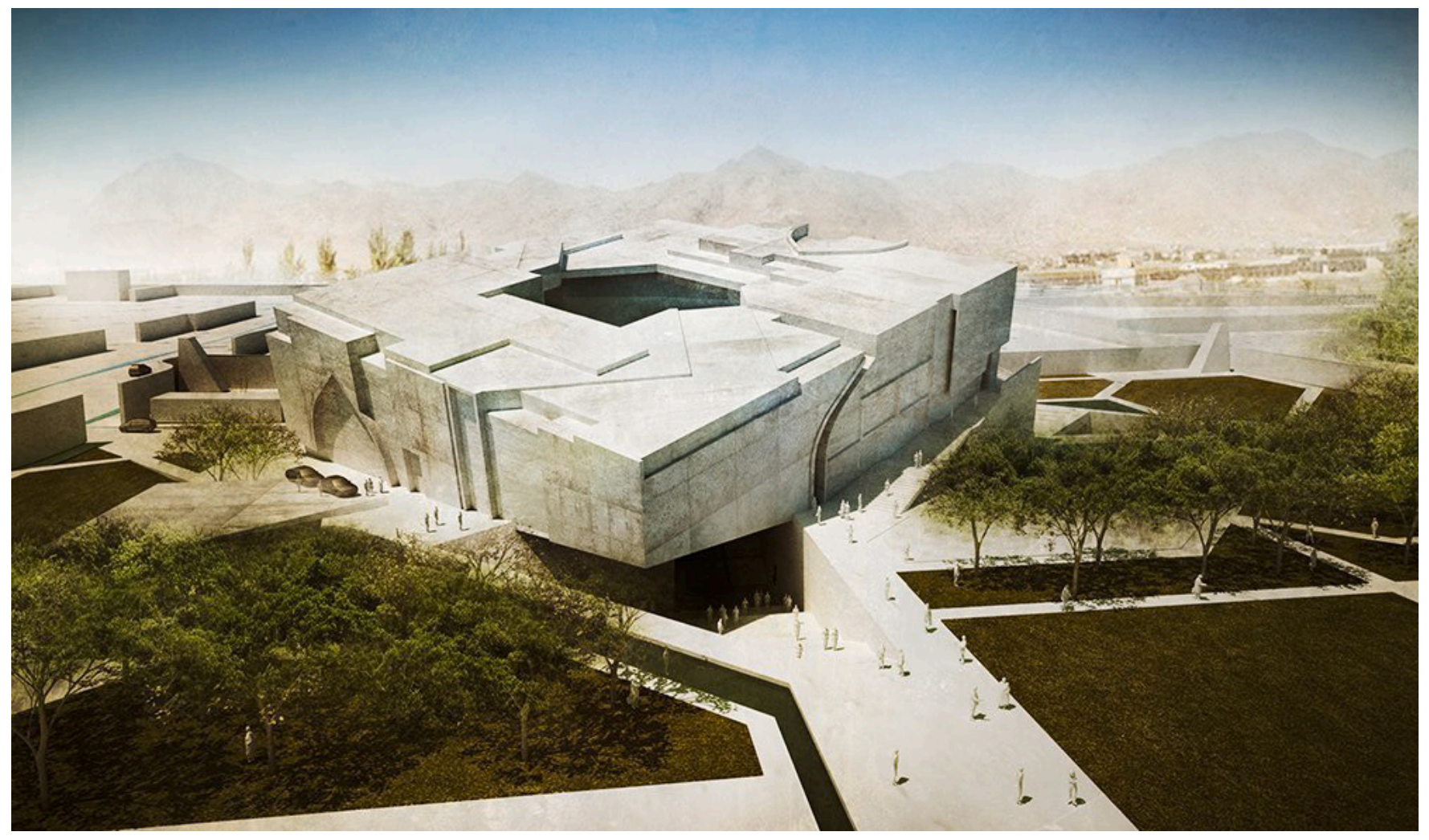

Fig 2.24 Main entrance to the building, National Museum of Afghanistan 
The Timeless Cube exemplifies the culture, pride, and traditions of the Afghan people, offering a better understanding of the nation to move toward a saner future. The new museum provides a platform for remembrance of the rich history of Afghanistan and reconciliation by creatively engaging visitors in traditional and non-traditional didactic programs. The identity, history, and shared values of its people as represented in the museum contribute to establishing social cohesion and provide a foundation in order for future generations to understand and learn about the past.

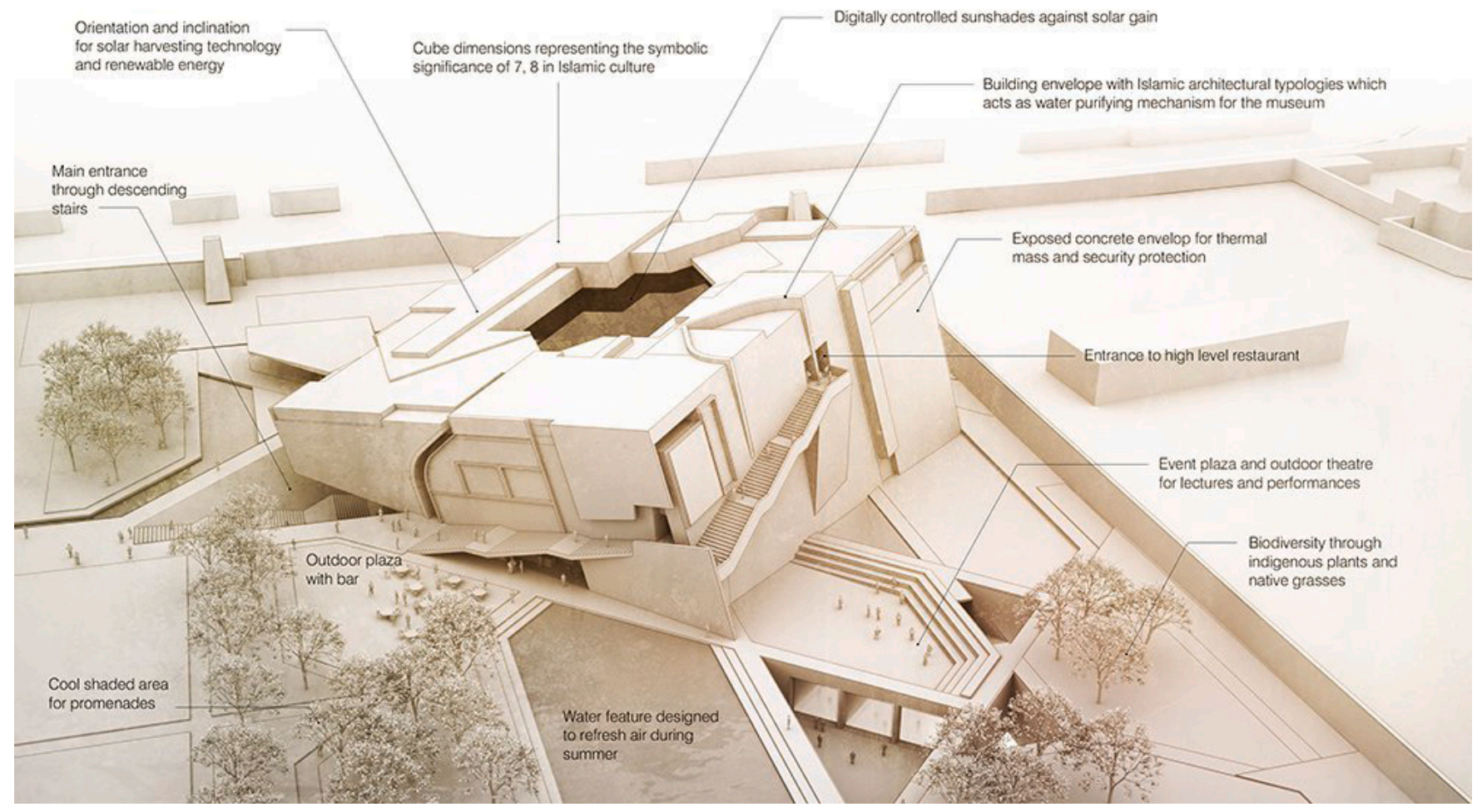

Fig 2.26 Function diagram, National Museum of Afghanistan
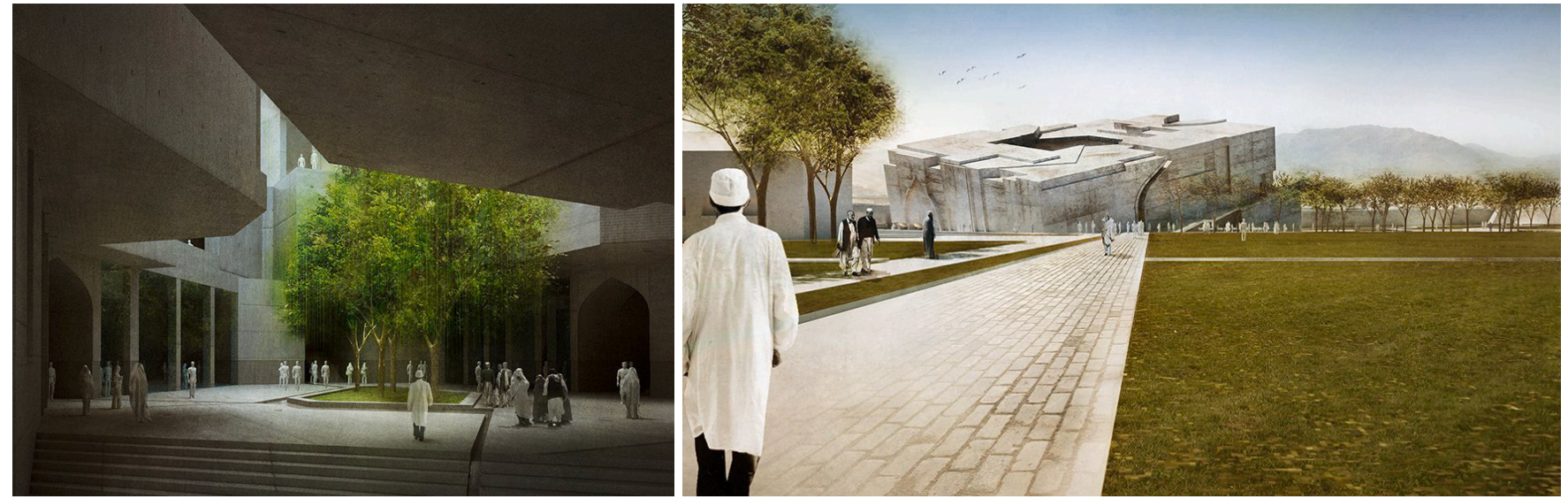

Fig 2.27 Interior foyer, National Museum of Afghanistan

Fig 2.28 Approach to the building, National Museum of Afghanistan 
The Holy Defense Museum of Tehran - Tehran, Iran, 2013 Jila Norouzi

The Holy Defense Museum of Tehran is built on a 22-hectare site in one of the major cultural hubs of Tehran, seeking to remember and commemorate the bravery of the Iranian soldiers during the Iran-Iraq War. Placed within a vast garden, the low-rise building merges into the landscape with a gently sloped roof. Influenced by the natural setting and the topography of the hills, the building is formed by a folded metal cladding. Iranian artillery pieces are also on display across the grounds.

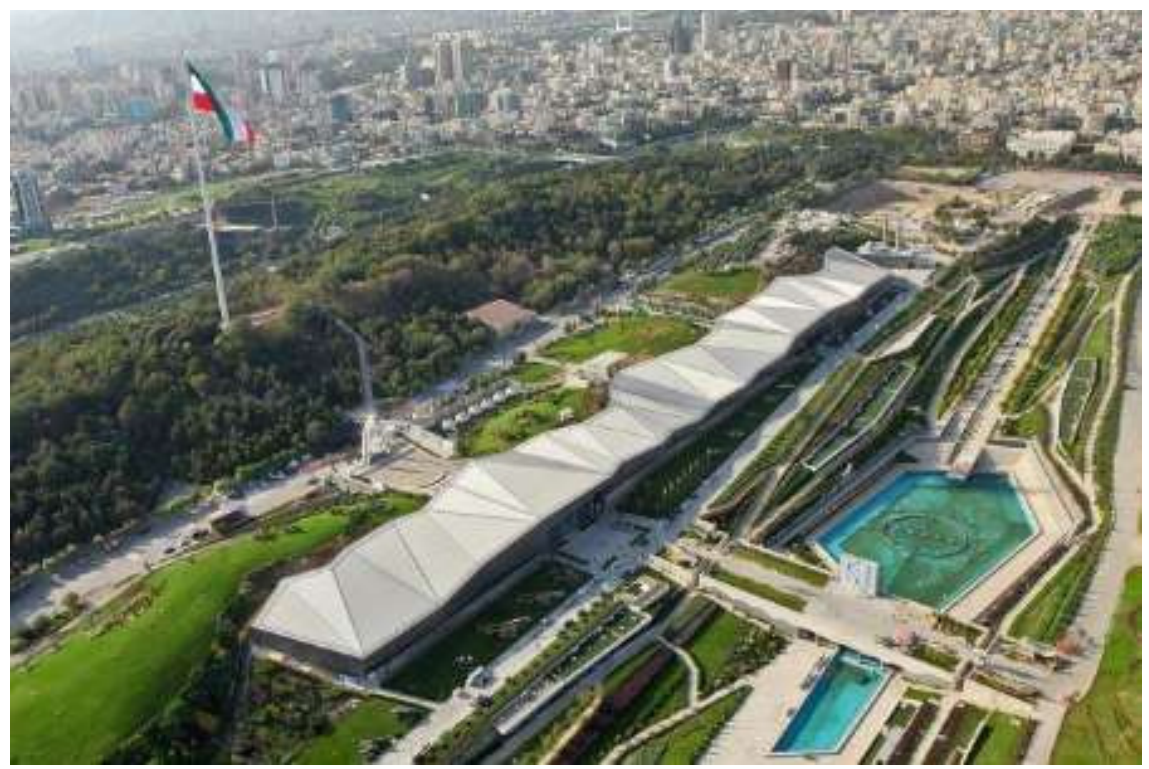

Fig 2.29 The building merges into the landscape, The Holy Defense Museum

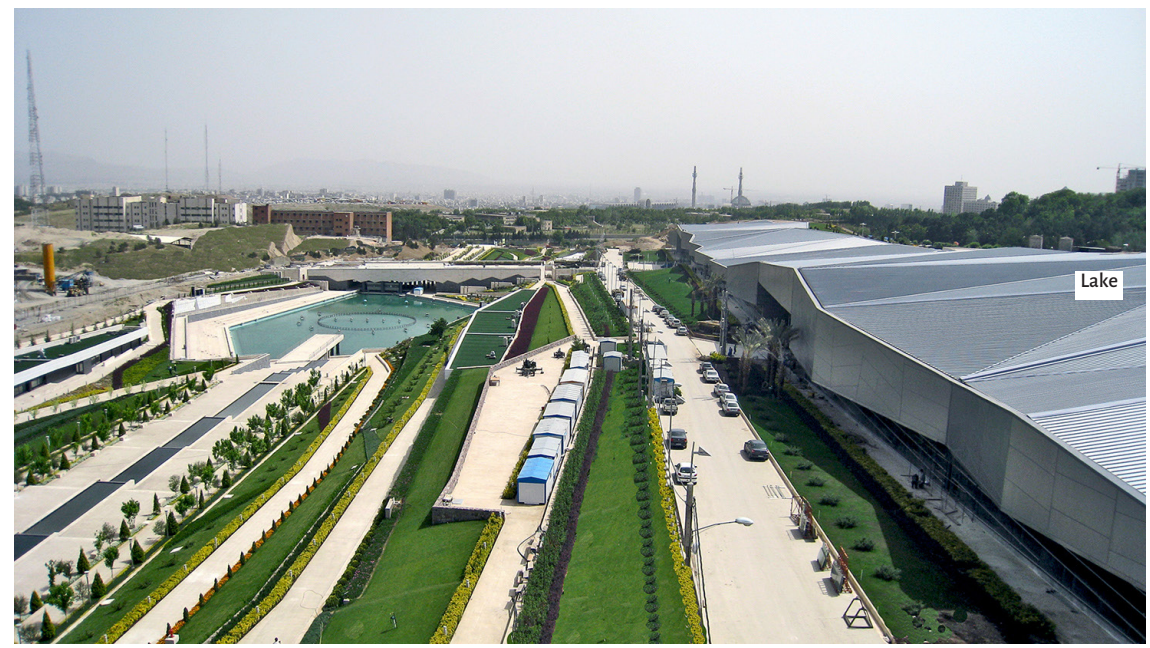

Fig 2.30 The surrounding context, The Holy Defense Museum

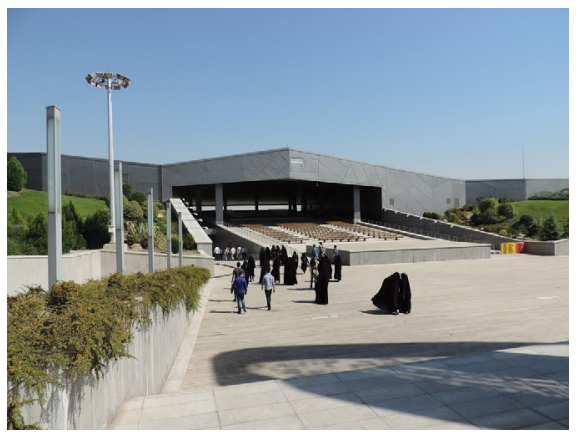

Fig 2.31 Main entrance

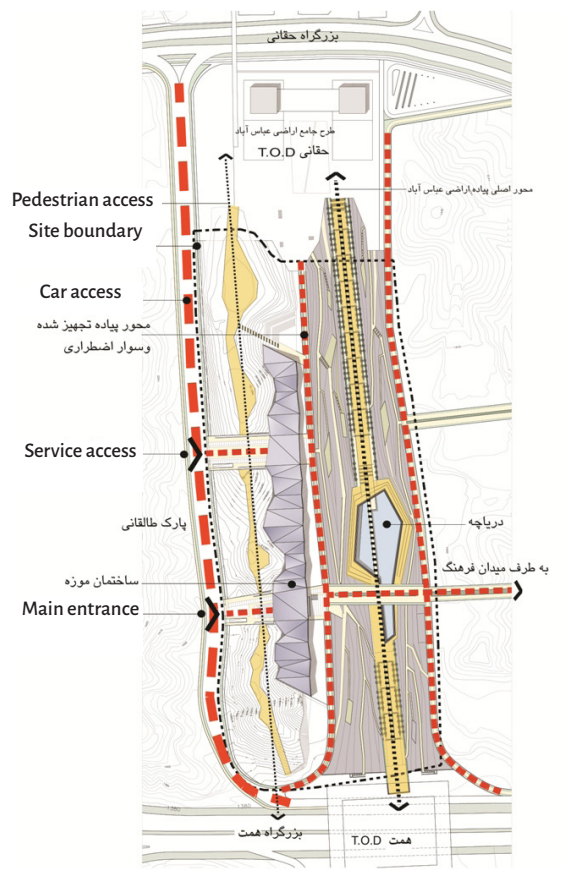

Fig 2.32 Site analysis, The Holy Defense Museum 


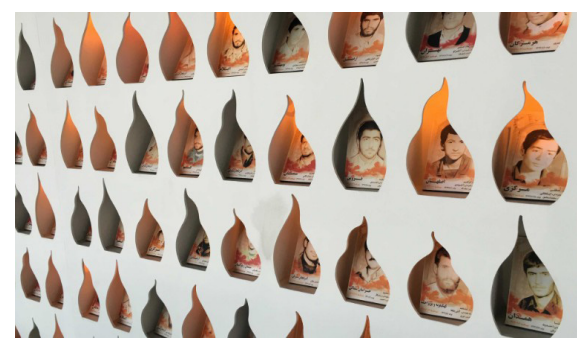

Fig 2.33 The "Hall of Butterflies", The Holy Defense Museum

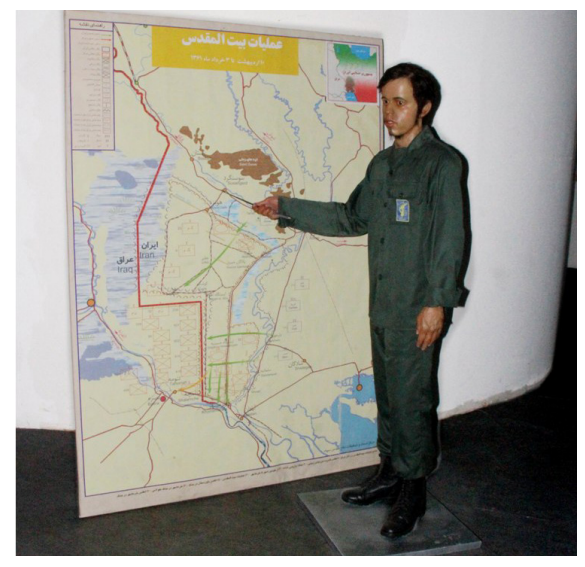

Fig 2.34 Human sculptures, The Holy Defense Museum

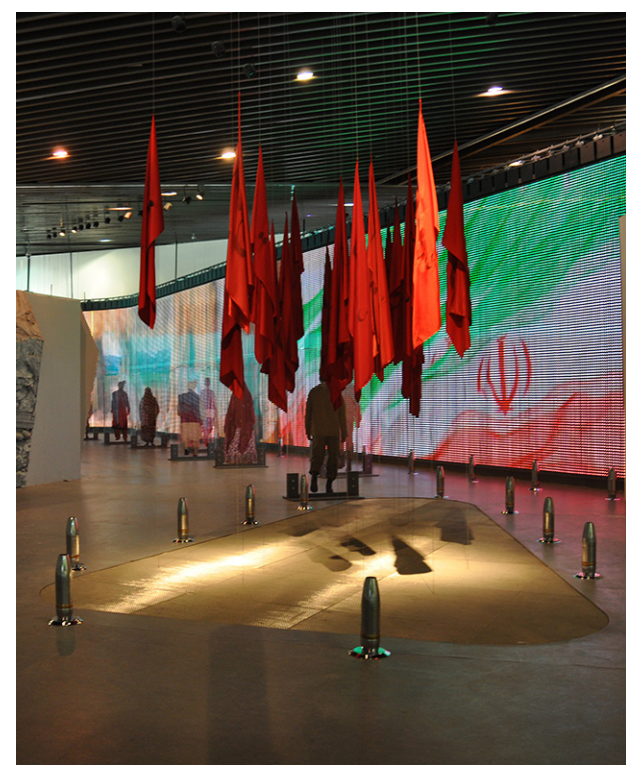

Fig 2.35 The "Hall of Prelude", The Holy Defense Museum
The museum includes eight sequential exhibitions on different levels that are connected by ramps, referring to the 8-year Iran-Iraq War. The "Hall of Butterflies" is a space that greets visitors when entering the building which is a memorial to soldiers killed during the Iran-Iraq war. The hall incorporates several casket-like display boxes, showcasing the personal objects and belongings of the martyrs. It also includes life-size sculptures of the influential figures of the war as a respect to their memory.

By entering the "Hall of Prelude", the visitors begin their journey through the museum and so into a timeline of Iranian history since the 1979 Revolution. The timeline is broken into consecutive exhibitions, and different historical events are represented through a state-of-the-art visual system including video walls, projections, and holograms. In addition, audio recordings are played in the exhibitions with regard to each period. The temperature of the place also changes relevant to the narrative in order to create an experience closer to the reality of the war events.

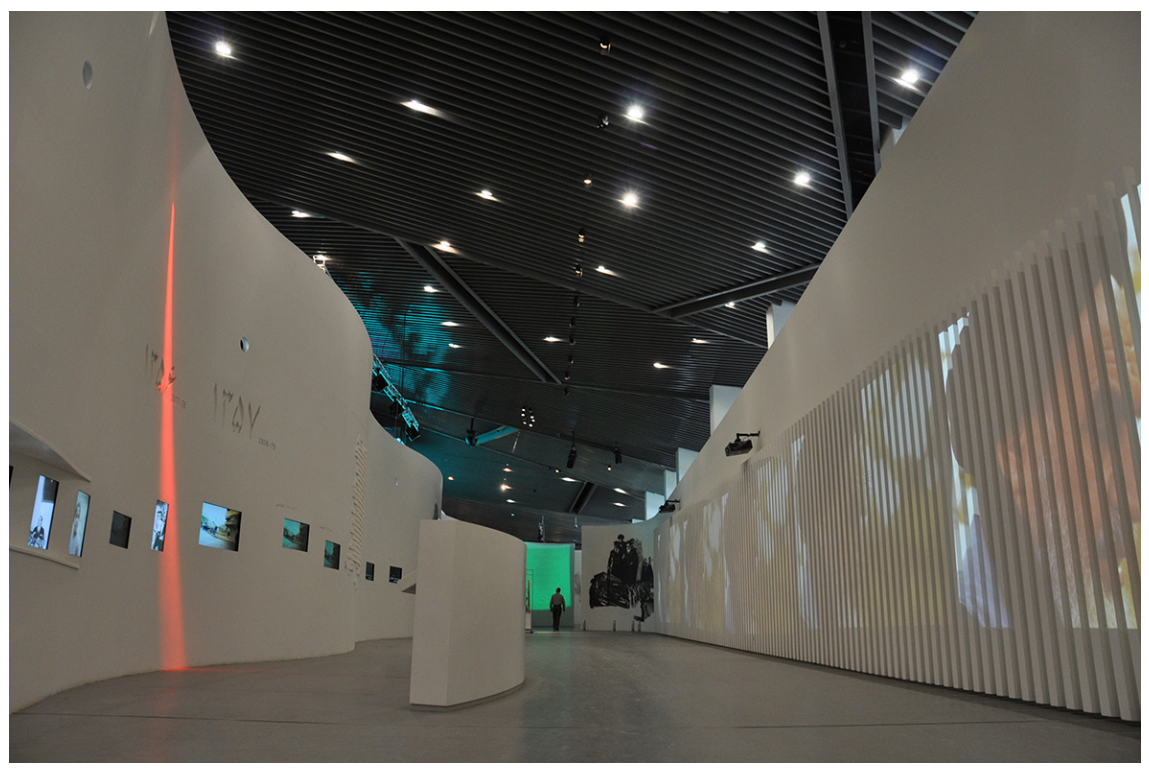

The main objective of the museum is to materialize a difficult time in Iranian history of which many people still bear the scars. In the second exhibition, the "Hall of Amazement and Rectitude", part of the city of Khorramshahr is recreated. Khorramshahr as a strategic port city, located on the border between Iran and Iraq, was captured during 
the war and was extensively ravaged by Iraqi troops. This recreation allows the visitors to walk through parts of the city, providing them with a visceral experience as they pass the abandoned homes and half-demolished schools all bearing the scars of the war. Crying and screaming voices and gunshot sound effects add to the immersive experience.

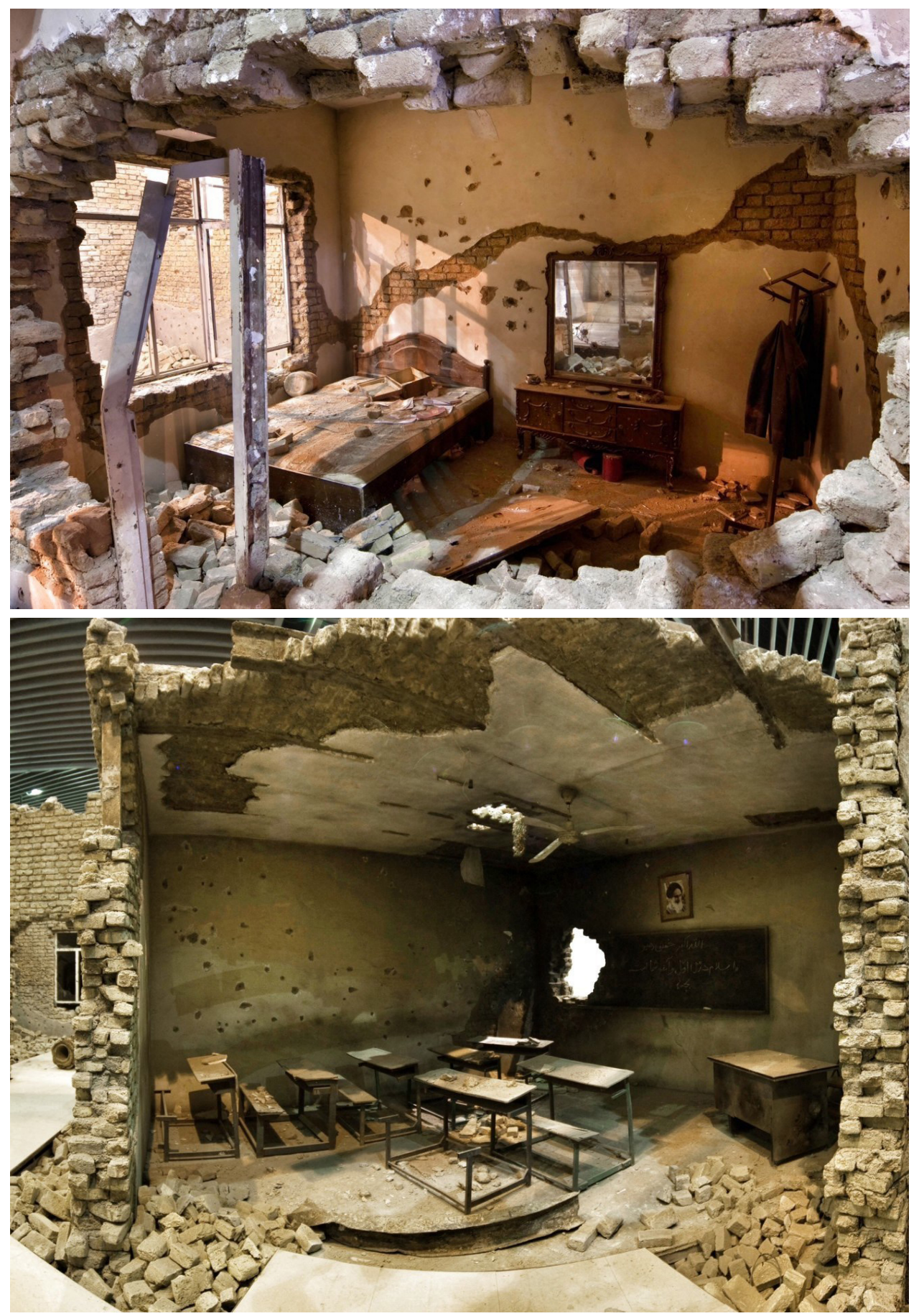

Fig 2.36 Life-size recreation of Khorramshahr 
Although each exhibition incorporates imaginative and innovative aspects, the way the symbolism is approached in some parts of the museum is heavy handed and tacky, lost in the digital technologies and projections. This has led to an inarticulate experience that makes it easy for the visitors to lose the narrative thread.
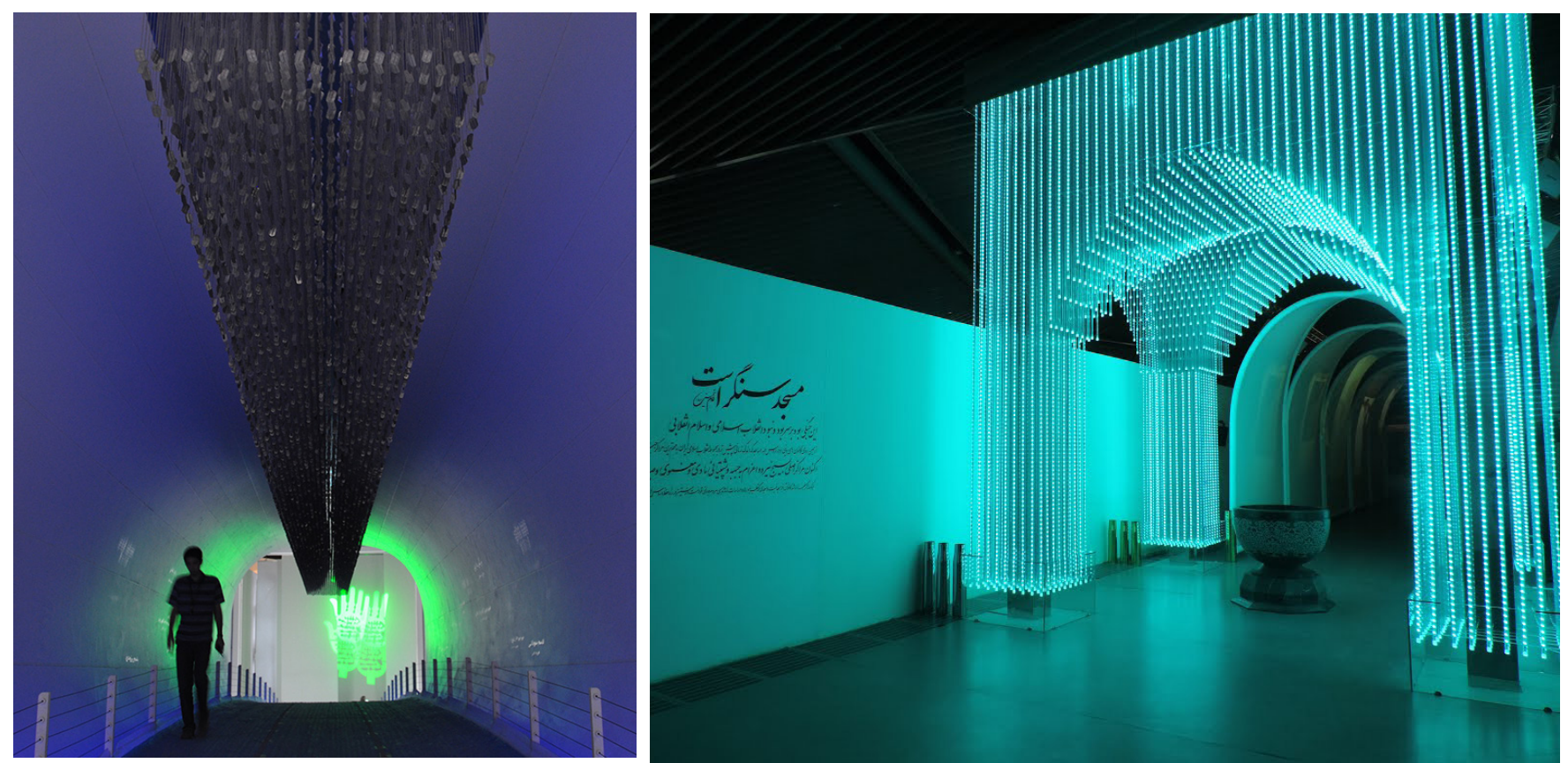

Fig 2.37 The Bridge of Martyrdom in the "Hall of Martyrdom", The Holy Defense Museum

Fig 2.39 Symbolization of Mosque in the "Hall of Defense", The Holy Defense Museum

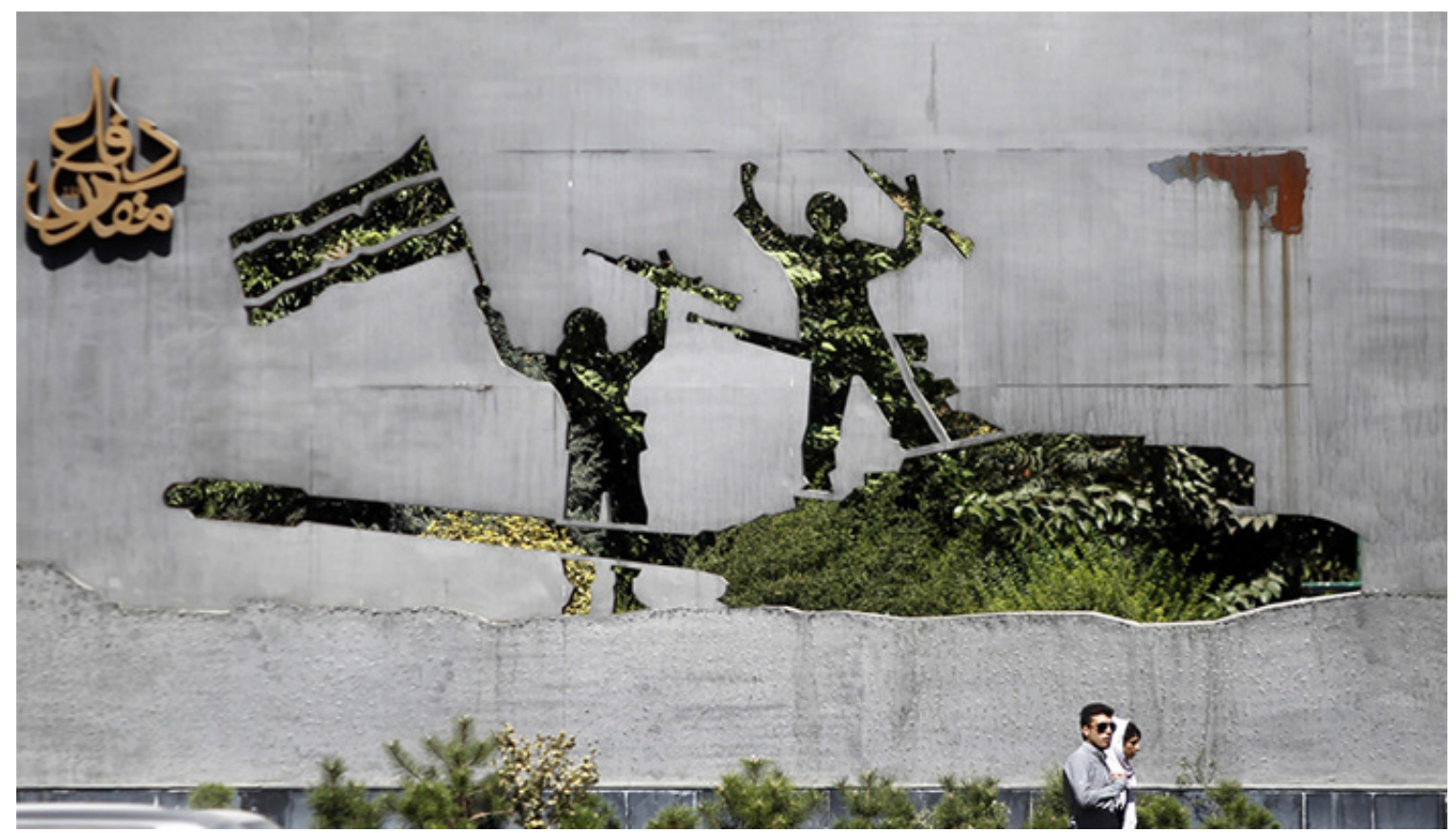

Fig 2.38 Sculptural element outside the museum, The Holy Defense Museum 


\section{Echoes of War}

Battle sites are among the most archetypal places in any nation's repository of tourist attractions, adding to the fascination and enchantment of history by situating the narrative in its physical context. The materialization of historic realities in authentic places caters to a unique experience that can enhance the tourist visit. The physical presence in the original place of a historical battle is the key reason to visit, trying to picture the field at the time of the battle. ${ }^{22}$ There is a generally palpable sense of place in these battlefields which creates a spiritual ambiance experienced by visitors. Warfare tourism presents locales of cultural memory "where memory becomes institutionalized through cultural means, such as commemorative rituals, memorials, and museums." ${ }^{23}$ Memory is considered as the cornerstone of battlefield visitations, facilitating the articulation of war in a meaningful way, allowing visitors to digest a traumatic past. Furthermore, it provides an outlet for difficult emotions through ritual and commemoration as well as being "an attempt to provide a sense of perspective if not closure on painful memories." ${ }^{24}$

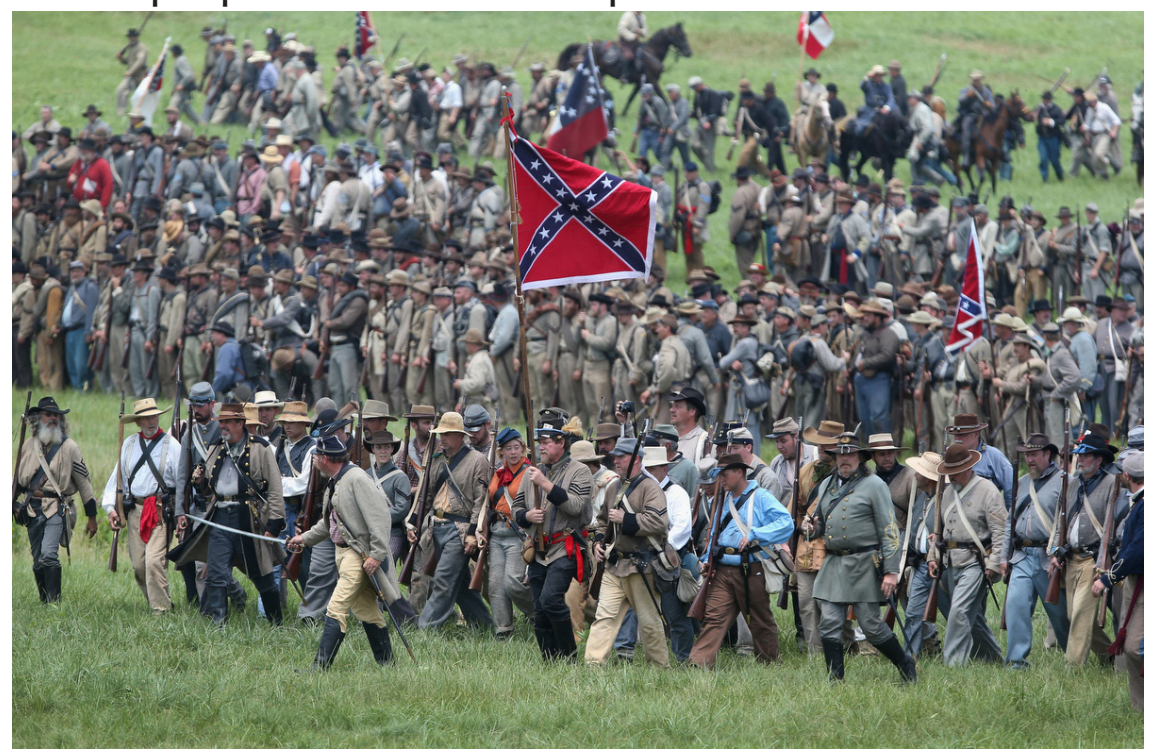

Fig 2.40 Battle of Cettysburg re-enactment

22 Richard Butler and Wantanee Suntikul, eds., Tourism and War (New York: Routledge, 2012)

23 Ria Dunkley, Nigel Morgan and Sheena Westwood, "Visiting the trenches: Exploring meanings and motivations in battlefield tourism," Tourism Management 32, no. 4 (2011): p.861

24 Stephen T. Miles, "Battlefield tourism: meanings and interpretations," (PhD thesis, University of Clasgow, 2012), p.45 


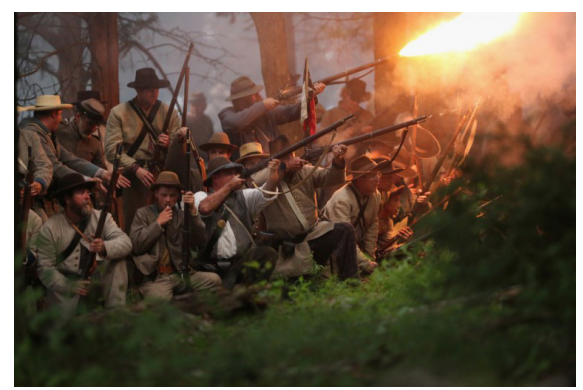

Fig 2.41 Confederate Civil War re-enactors launch an evening attack, Cettysburg

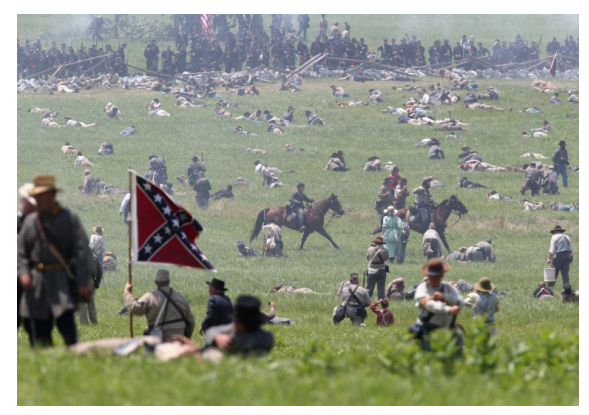

Fig 2.42 "Wounded" Civil War re-enactors, Cettysburg

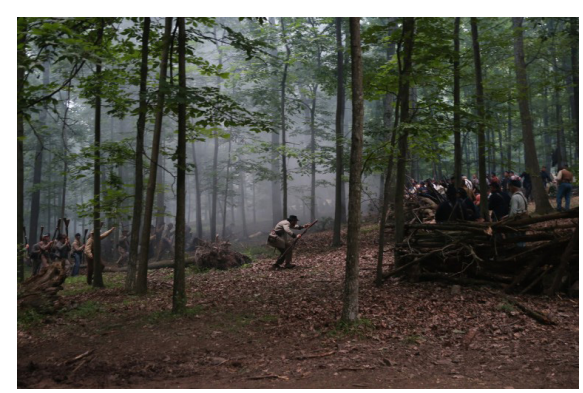

Fig 2.43 Surrender to Union troops, Cettysburg
As symbols of group identity, battlefields are loaded with exceptional weight especially for political groups. Nationalistic or patriotic association with battlefields induces layers of meaning that can contribute to the process of peace and reconciliation. However, there could be occasions when this association can have an opposite effect, used as a vehicle that incites call for vengeance. Individuals travel to these sites of combat in order to attest to tragic events which are too agonizing to comprehend. Thus, it is believed that tourists visit battlefields, "not so much to see what it was like, as to celebrate what they already knew."25

Awareness and elucidation are seemingly the main impetus for most visitors to battlefields, which might either refer to a desire for individual understanding or a more typical appeal for historical facts. Also, these sites are usually concerned with ethical qualities and sacredness, rendering visitation as a respectful and honorable ritual. There are other groups of people who are less enthusiastic about education and commemoration and instead wish to satisfy a sense of curiosity aimed at sinister and horrible objects related to death and suffering. For these tourists, the strong sense of reality at the authentic places of battle amplifies the sense of taboo. Williams argues that despite the various motivations, all visitors share a sense of determination to reflect on the meanings and lessons inherent in these locations. A critical aspect of their influence lies in the fact that battlefields and memorials provide visitors with a tangible case to think about life-threatening situations and moral decisions which most people never experience in everyday life. ${ }^{26}$ In addition to a palpable sense of realism, there is another dimension to battle sites: a deep engagement or transcendence. As a visitor to such sites commented,

\footnotetext{
"Regardless of where you walk on the battlefield, I am very aware that I may be standing on the ground where men have spilled their blood or even died"27
}

\footnotetext{
25 Dunkley, Morgan and Westwood: p.862

26 Williams, Memorial Museums

27 Miles, op. cit., p 42
} 
In Iran, battlefield tourism achieves new dimensions as a local phenomenon. By visiting war remnants, specifically those associated with the relatively recent war with Iraq of 1980-88, "war tourists" attain a spiritual experience and new insights into recent history, contributing to the establishment of a new framework for a tourism which is considered "resistance tourism" rather than "war tourism" reflecting the Iranians' interpretation of the eight-year Iran-Iraq war. In this sense, rather than being conceived as tourism, visitation to

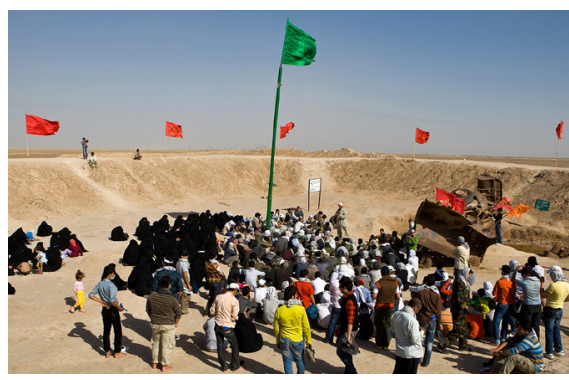

Fig 2.44 A mullah delivering eulogy for the martyrs in Talayieh, Iran sites of warfare is commonly recognized in Iranian communal beliefs as battlefield pilgrimage.

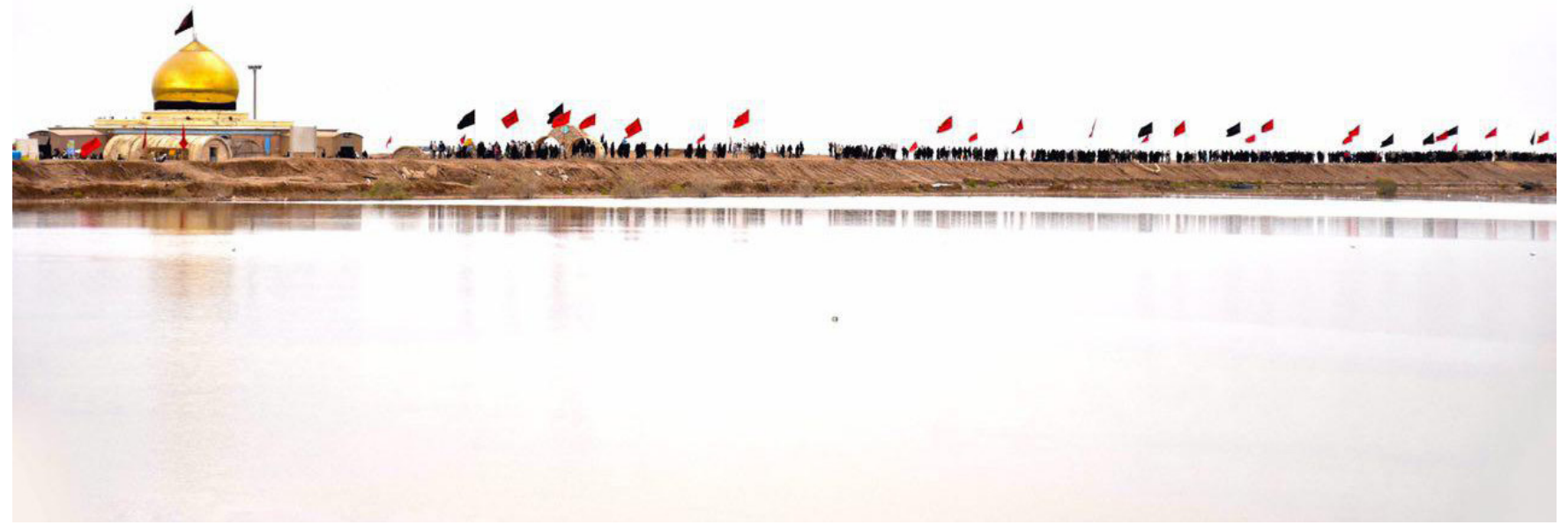

Fig 2.45 Martyrs of Talayieh memorial 


\subsection{The Sacred Journey}

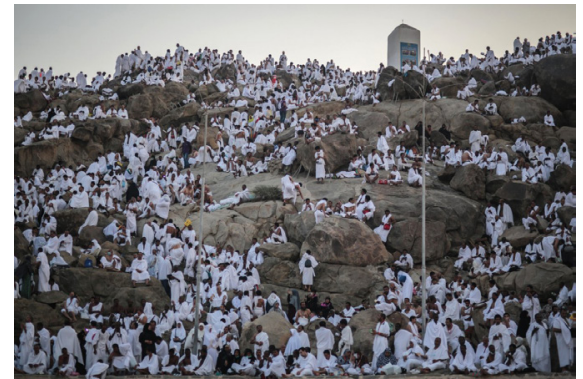

Fig 2.46 Muslim pilgrims in Hajj, Mecca

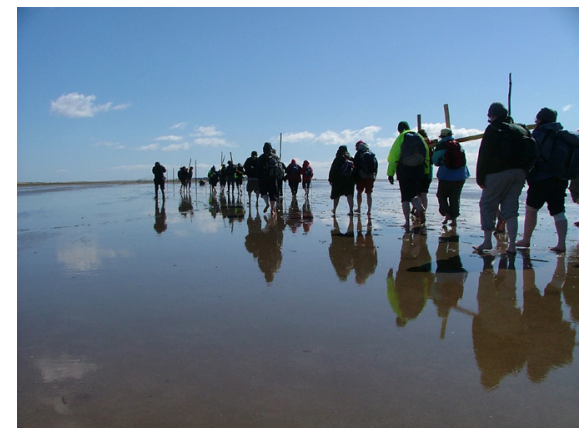

Fig 2.47 Pilgrimage Holy Island on the Northumbrian coast of England

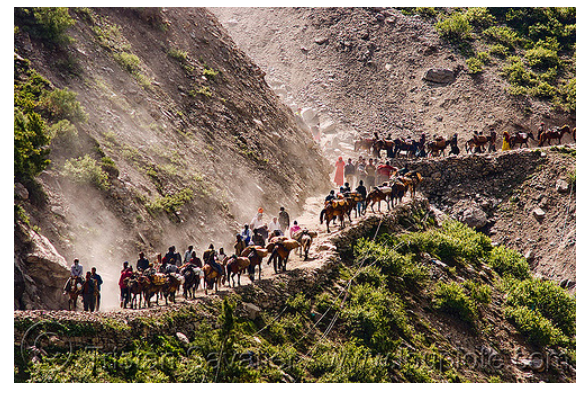

Fig 2.48 Pilgrimage to Amarnath Cave, Himalaya mountains, Kashmir
Journeying is regarded as an experience that can transform individuals psychologically or socially. Pilgrimage or, in Persian Ziyaret as a spiritual journey refers to a voluntary movement seeking to pay tribute to a person or shrine that is commonly believed to be sacred and praiseworthy. According to anthropological studies, pilgrimage happens as a result of an overlap between "journeying" and the search for some ideal. ${ }^{28}$ However, the unique experience of the journey is extremely powerful, so much so that the interest in the destination is almost lost. Although the notion of pilgrimage has expanded to encompass non-religious activities such as visiting the sites of important battles or the memorials of deceased heroes of history ${ }^{29}$, its fundamental characteristics have remained the same, in that it is "a journey with a deep and intense personal meaning to the participant which often brings about a renewed insight or revelatory metamorphosis." ${ }^{30}$ Sacred sites often provoke strong emotions in pilgrims who perceive a palpable certainty while being present at the site, feeling that the past has come into the present and can be touched directly. ${ }^{31}$ In this regard, sacred topographies and architectures provide appropriate material and symbolic settings.

Movement is identified as key to understanding pilgrimage. Movement whether consciously or unconsciously can have an impact on social and cultural transformations. However, the notion of pilgrimage needs to be contextualized within the local perception of mobility, as certain styles of mobility can have different meanings in different cultures. Particular styles of motion illustrate how pilgrimage can open up doors for reflection on the nature of the journey, transforming a bodily experience into a cultural performance. Walking as a common mode of mobility allows for a

28 William S. Schmidt, "Transformative Pilgrimage," Journal of Spirituality in Mental Health 11, 1-2 (2009)

29 Ian Reader, "Pilgrimage growth in the modern world: Meanings and implications," Religion 37, no. 3 (2007)

30 Miles, Battlefield tourism: meanings and interpretations, p.45

31 N. Collins-Kreiner, "Researching Pilgrimage: Continuity and Transformations," Annals of Tourism Research 37, no. 2 (2010) 
pilgrimage that involves a form of self-sacrifice and austerity that contributes to a more intimate connection with the past. Coleman and Eade further illustrate this point by borrowing Michel de Certeau's notion that "walking can be constitutive of social space in the way that speech acts constitute language."32

"[Many people]... are seeking to engage in bodily and temporal modes that subvert or transcend the rushing, mechanized world of modernity and postmodernity. They are choosing to move, but in a way that emphasizes a slowing down rather than a speeding up of life."33

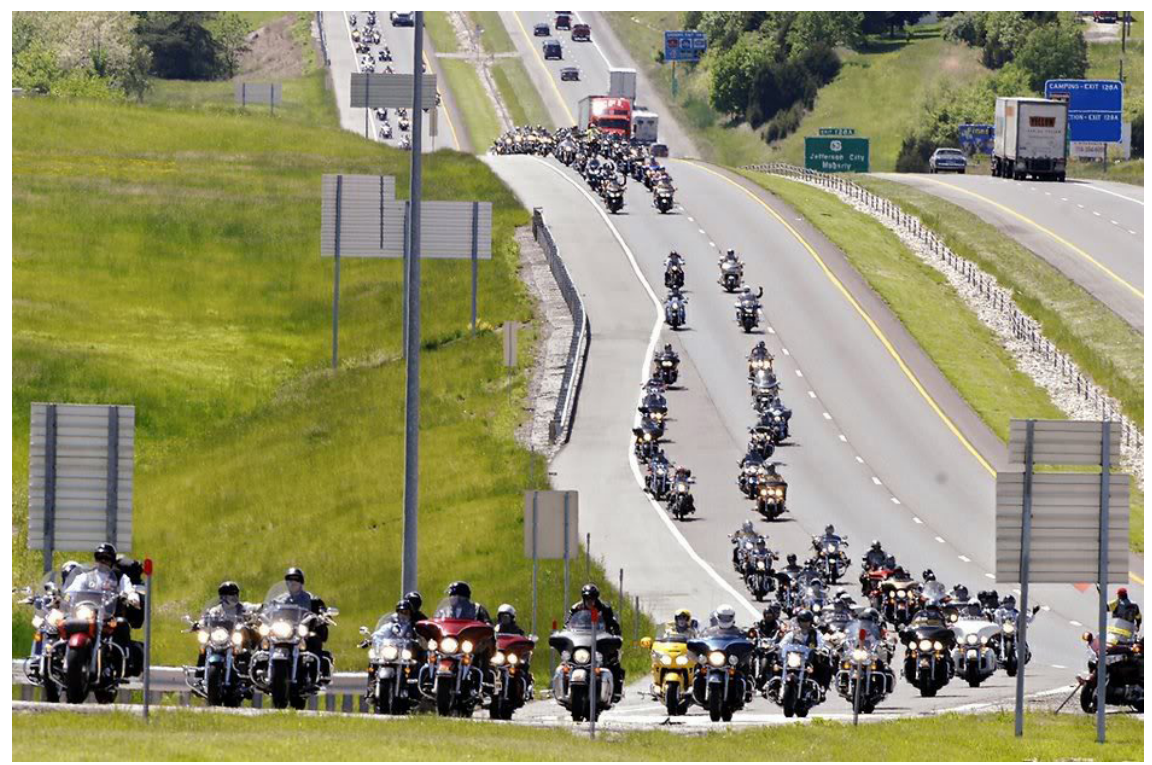

Fig 2.49 "Pilgrims not bikers" in The Run for the Wall

Pilgrimage can be used as a catalyst for constructing a particular meaning in a place or landscape which in turn has the capacity to assist in the healing process of individuals or groups that are concerned with a horrific past. Each year Vietnam veterans and their supporters ride their motorcycles to participate in a pilgrimage known as the Run for the Wall, journeying across the United States to reach to Vietnam Veterans Memorial in Washington, DC. The pilgrimage through the heartland of America creates an opportunity for veterans to reframe their personal and collective memory through

\footnotetext{
32 Simon Coleman and John Eade, eds., Reframing Pilgrimage: Cultures in Motion (London, New York: Routledge, 2004), p.16

33 Ibid., p.11
} 
the parade, receiving the greeting they believe was never offered to them after they returned home from the war. However, these greetings do not occur at the end of the journey, rather the veterans are welcomed all along the way by hosts and supporters. Therefore, the warrior is recognized as a hero rather than a forgotten or disregarded participant in a conflict that was not supported by many Americans. ${ }^{34}$

The Run for the Wall is considered a pilgrimage with a sacred terminus, combining the personal quest for healing and identity with constructing a collective narrative formed by the motorcyclists' journey across the country. This ritual journey illustrates that movement is central to the constitution of cultural meanings. As Dubisch notes:

"The participants in the Run for the Wall, by using the culturally familiar ritual pattern of a pilgrimage, have shaped this ritual into a 'vector of memory', not merely to reflect but to shape culture, memory, history and concepts of 'home' for both individual and collective ends. In this sense, the Run does not merely traverse the 'heartland of America'; it constitutes it as well." ${ }^{35}$

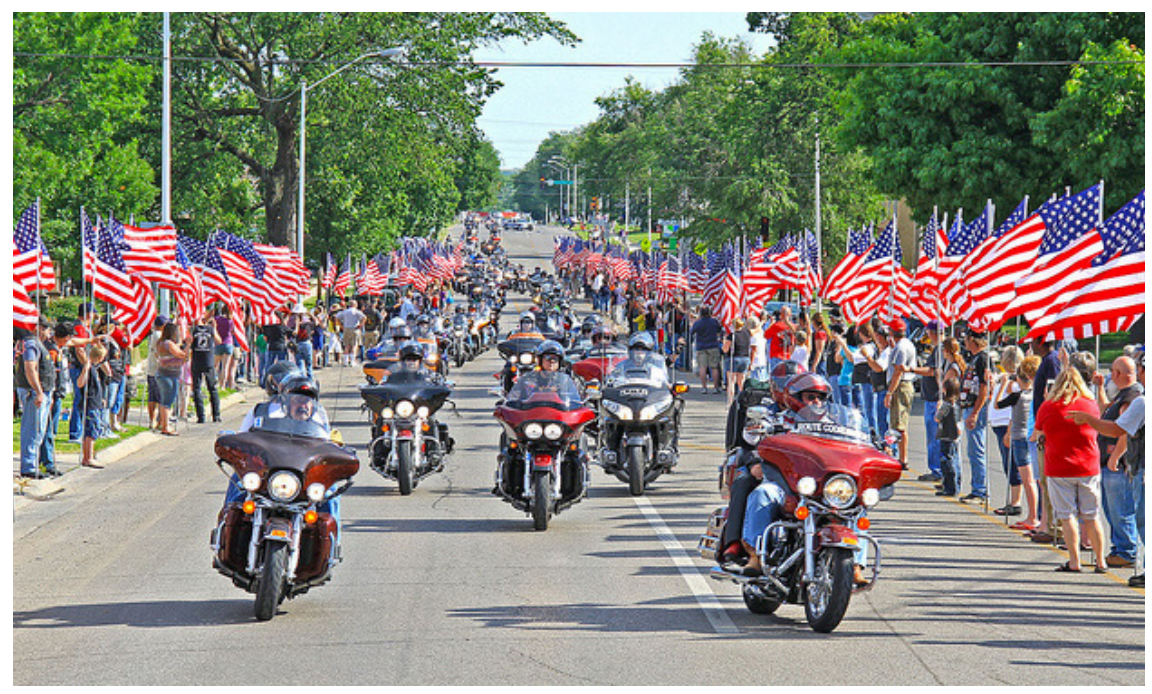

Fig 2.50 Reception of the veterans along the route, The Run for the Wall

34 Jill Dubisch, "'Heartland of America': Memory, motion and the (re)construction of history on a motorcycle pilgrimage," in Reframing Pilgrimage: Cultures in Motion, ed. Simon Coleman and John Eade, 107-34 (London, New York: Routledge, 2004)

35 Ibid., p.132 


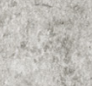
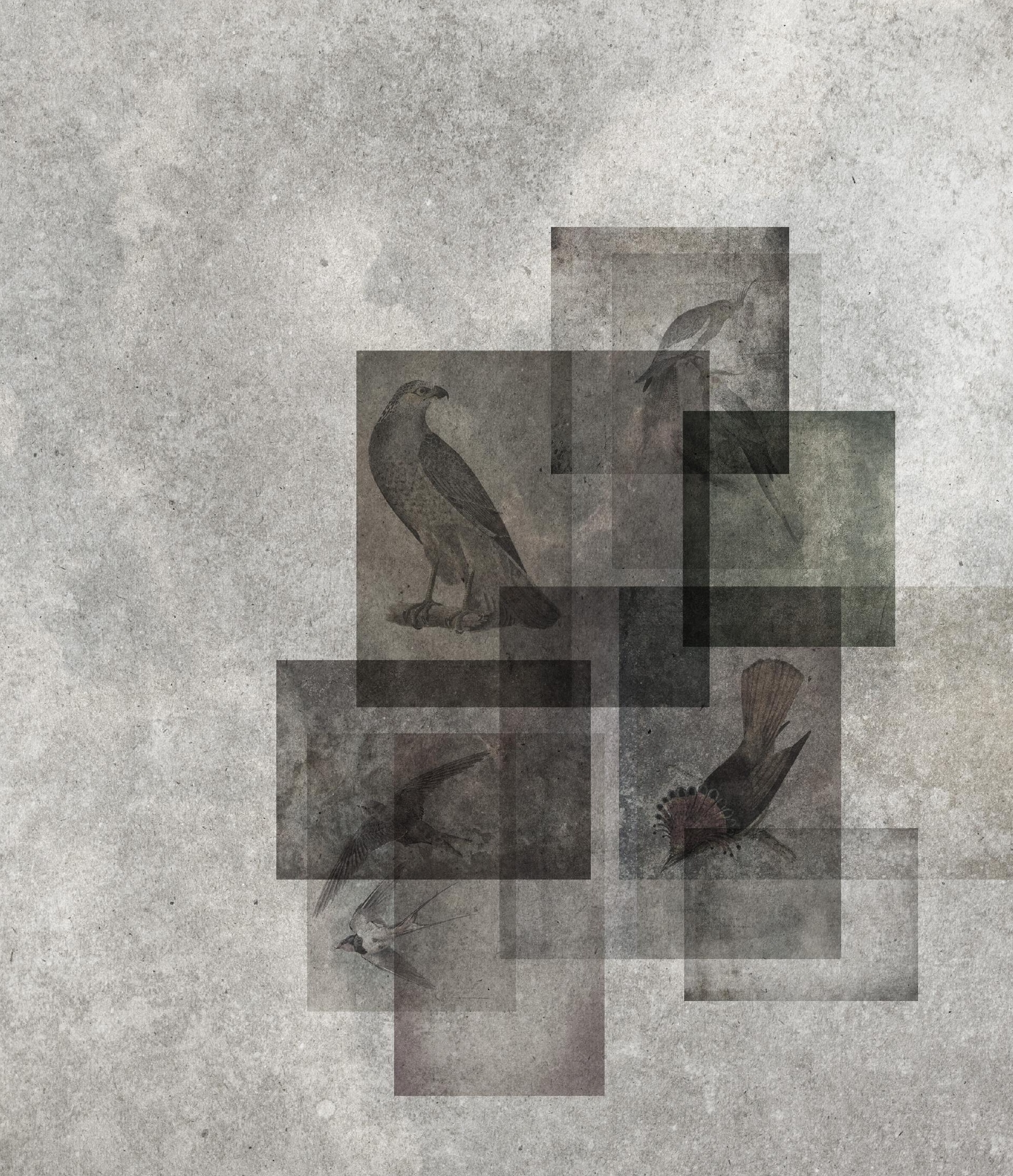
PART THREE

IN SEARCh of the HidDEN 

In the morning, in the parterre of (the red streaked) tulips, to the breeze,

I spake, Saying: 'Martyrs for whom are these, all of bloody shrouds?'

He (the breeze) said: "Not informed of this mystery are we, I and thou,

'The tale of the ruby wine, and of those silver of chin, mention.'

- Hafiz
This section aims to elaborate on the conceptual framework that forms the basis of the design project. It establishes the concept of martyrdom which speaks to a mentality central to the thesis project and contextualizes it within various cultural beliefs and ideologies. The way this experience is expressed through mystical poetry is further analyzed in order to shed light on the architectural interpretations that are going to be discussed subsequently.

\section{3.l Martyrdom in the Islamic Tradition}

The notion of martyrdom in Islamic beliefs is closely tied to the concept of Jihad known as a struggle or striving. However, due to its distortion by political and religious extremists to legitimize savagery, in Western culture jihad is widely misinterpreted as violence and aggression. Yet, the true concept of Jihad in the Quran refers to a fundamentally ethical belief central to the religion of Islam, described as internal or external endeavors to preserve and practice Islamic principles. As stated in the Quran, the Major Jihad is believed to be an inward struggle to control the lower self, not necessary a military attack against nonbelievers. As Jalal puts it:

"Equating jihad with violence and terror makes a sheer travesty of a concept that, for all the distortions and 
misinterpretations, remains the core principle of Islamic ethics."

Martyrdom is defined in light of the struggle in the cause of Allah and for the sake of the truth. The word that is used to denote a martyr -Shahid-originally comes from a Quranic word meaning "witness" or "paradigm". In this sense, a martyr is one who testifies and sees the truth by which he or she stands firmly inasmuch as he or she is ready not only to fight for the truth but also to sacrifice his or her life for it. Thus, he or she becomes a model, a paradigm that deserves to be respected and followed. In Islamic culture, the "truth" (Haqq) and the willingness to declare it even in the face of death, is the core of religious practice. The end goal of Islam (terminologically meaning surrender to the will of Cod) is the establishment of the truth, facilitated by Jihad and the struggle for seeking the truth. Those who die in the cause of the truth are recognized as martyrs who have the highest reward from Allah². This does not necessarily imply that Jihad has to take place on a battlefield or martyrs are merely those who have been killed in war, rather the notion of martyrdom and Jihad encompasses any continuous struggle in the cause of Allah (the Ultimate Truth) which may lead to death.

Initially, the concept of martyrdom in Islam emerged from the Quranic tenets and later on it became a significant force in Islamic ideology, gaining symbolic value. According to the Quran, a martyr is one who rejects abandoning the Quranic principles, dying for the sake of upholding the Quran (Haqq, the truth). The Quran says:

"Think not of those who are slain in Allah's way as dead. Nay, they live, finding their sustenance in the presence of their lord."

These Quranic verses on martyrs being alive incorporate a dual meaning in Islam. Initially, they suggest that martyrs do live in the presence of Cod in the afterlife, on a level that cannot be perceived

\footnotetext{
1 Ayesha Jalal, Partisans of Allah: Jihad in South Asia (Cambridge, London: Harvard University Press, 2008), p.304

2 A. Ezzati, "The Concept Of Martyrdom In Islam," Al-Serat 12 (1986)

3 The Quran (3:169)
} 
by human beings. In addition, the truth and the ideal which martyrs testify by their death continue to live and be reinforced. Hence, death is not conceived as a tragic and depressing event, on the contrary, it fosters the perseverance and morality of the believers, encouraging them to become united with the truth. Furthermore, the notion of martyrdom renders death as a meaningful act of choice and purpose, an act which can be commemorated, admired, and emulated by others.

Since the Quran has both inward and outward meanings, the Prophet and the Imams were attempting to reveal the true meaning of the verses. If an individual approaches the Quran with a purified intention and intellect, he becomes capable of perceiving the true origin, the reality behind the mundane material world. He learns to see with the eye of his heart, to look towards Cod and to see the Divine in every aspect of this earthly world. Similarly, when the martyr encounters severe opposition that may lead to death, he sees Allah before him with the eye of his heart and, therefore, the material world loses its significance, and he embraces death and reaches to the presence of the Divine. Humanity's attachment to this world is the main factor that obstructs the revelation of Cod. His limited existence itself is a veil which obscures the true gnosis from him. By sacrificing his life for Cod, he has destroyed all the veils and submits to Allah truthfully, achieving the ability to perceive Cod and the true essence of Islam. Thus, martyrdom is considered an evolution from the inner comprehension of the Truth to the outer attainment of it.

The actions of a martyr are a microcosm of the Quranic doctrines. Martyrs, through their blood, emphasize these principles, revealing the vitality of the Islamic doctrines, so much so that life becomes worthless. They might have lost their physical bodies but they have revitalized the Islamic truth-seeking impulse, becoming a paradigm for later generations. 


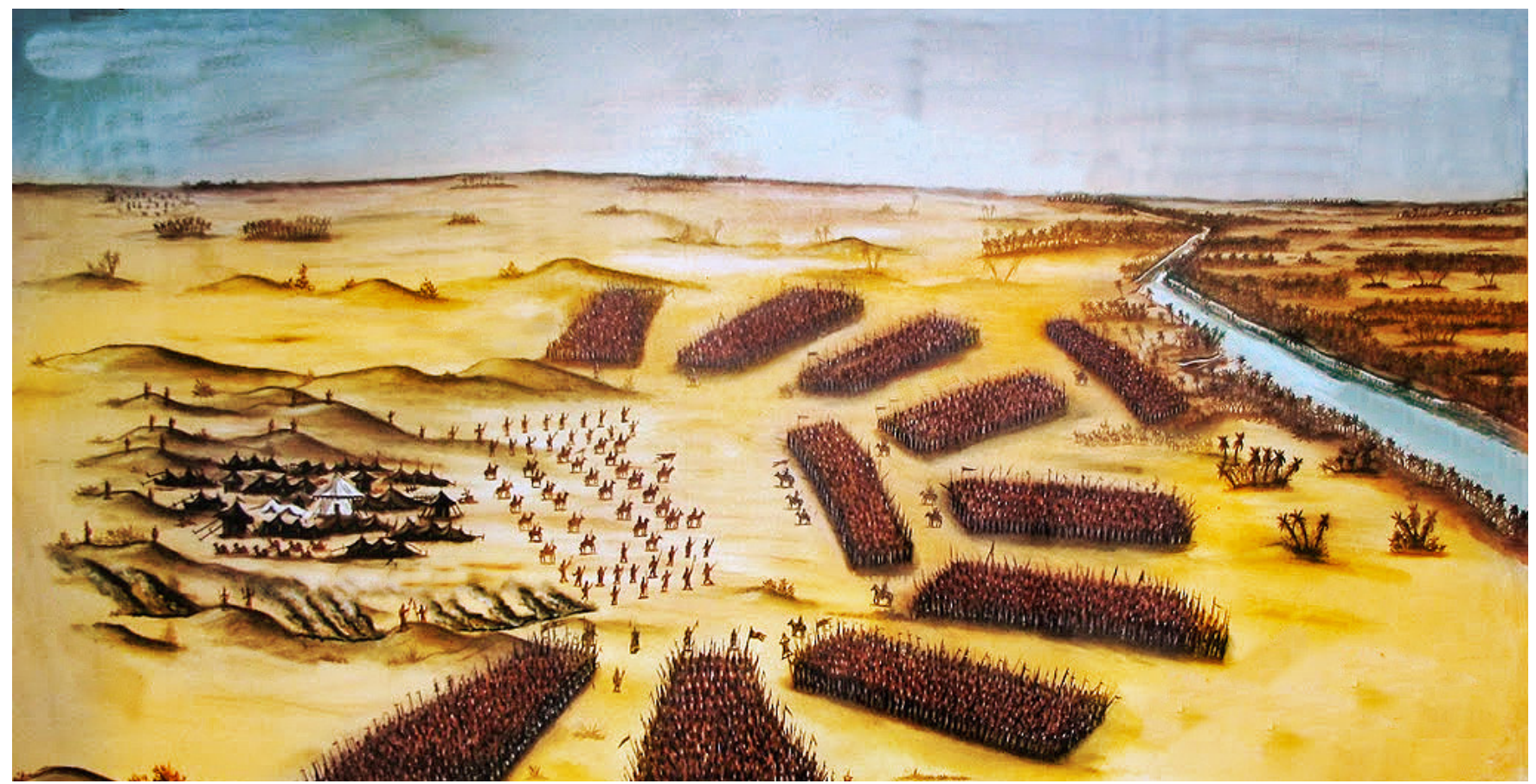

Fig 3.1 Imam Hussain and his followers surrounded by the enemy on the Karbala plain

\subsection{The Battle of Karbala}

Events early in Islamic history laid the foundation for a more in-depth philosophy of martyrdom. The martyrdom of the Prophet's family and his companions further strengthened this philosophy and the significance of Quranic verses, saturating martyrdom with an emotional tone that still strongly affects Muslims. In particular, the martyrdom of Imam Hussain, the grandson of the Prophet, added more force to the notion of martyrdom, imprinting in the Muslim mind and heart on a deeper level. The battle of Karbala and the martyrdom of Imam Hussain and his family on "Ashura" ${ }^{4}$, is recognized as an influential paradigm in the history of Shi'ism, inspiring Muslims to continuously follow Hussain's path. The famous saying often quoted "Every day is Ashura, and every place is Karbala", very well represents the dynamic and revolutionary essence of this event throughout history. ${ }^{5}$

\footnotetext{
4 Meaning tenth, referring to the tenth day of Muharram

5 Ezzati, Op. cit.
} 
Hussain died with the aim of convicting abusers of Islam in order to rejuvenate it. As a person who bore witness to the truth of the Quran, he firmly and eagerly chose to resist the destroyers of the truth, those who were using Islam as a means to gain more wealth and power, distorting the Quran for the benefit of their regime. In order to rescue the truth of Islam, Hussain with his 72 followers went to Karbala to fight with Yazid's ${ }^{6}$ army of 5,0007. Even though Yazid had more troops, he was so afraid of the strong motivations of the Imam and his followers that he blocked the Euphrates River, preventing them from accessing water in the desert for a whole week up to the end of the battle. Being very aware of his eventual death, Hussain did not turn back, sacrificing himself and his followers to expose the tyranny and oppression prevailing in the Islamic world. Indeed, the very fact that there was a slim chance of overcoming the 5,000 troops with only 72 is suggestive of the additional layers of intention beyond merely taking over the government. ${ }^{8}$

The main purpose of the uprising of Imam Hussain was for delivering a message of bidding the good and forbidding the evil. These two correlated principles are frequently mentioned in the Quran as the obligatory duties of true Muslims. By testifying to the very core of Islam, the Divine Unity or "lā ilaha illā Llāh Muhammad rasūl Allāh", Hussain himself becomes the spiritual cornerstone of the religion of Islam, rupturing the previously held sectarian characteristics of this struggle. Hussain is rendered as a cosmic archetypal figure, "a cloud of mercy akin to his Prophet-grandfather, above and beyond sectarian strife and appeals to history." ${ }^{10}$ In this sense, regardless of Shia or Sunni doctrine, the opposition between Hussain and Yazid is more associated with "the inner human conflict

6 The then Umayyad caliph

7 Some sources estimate this number to be $4,000,12,000$, or 30,000 . It is likely that these numbers are metaphoric, indicating a vast force of men compared to the small group of Hussain's companions.

8 Ibrahim Ayati, A Probe Into the History of Ashura (Accra, Karachi: Islamic Seminary Publications, 1984)

9 The Islamic creed which declares that "there is no Cod but Allah and Muhammad is his messenger."

10 Syed A. Hyder, Reliving Karbala: Martyrdom in South Asian memory (Oxford, New York: Oxford University Press, 2006), p.141 


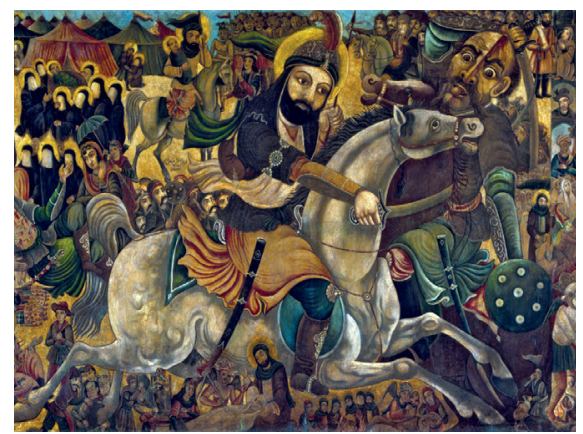

Fig 3.2 Imam Hussain at the Battle of Karbala than with any outward political agenda."1 As Hydar argues, "the suffering that Hussain himself had to undergo to nourish the garden of truth transformed him into the very foundation of monotheism."12 Despite the fact that Hussain and all his companions savagely perished, the battle of Karbala indeed indicates a victory of blood over sword:

"Remember me not through the shedding of the blood of others but remember me when you seek to save the truth from the claws of falsehood.... Remember me in your tears when the meek and lowly are oppressed...and when the corrupt among you are set up in government over the destiny of men of faith.... when the poor complain and the pockets of the rich bulge, remember me... Remember me when all these things take place and rise up...to lift high the emblem of justice and truth.... But if you hold your peace amidst deception and accept humiliation, then I would be slain anew." ${ }^{m 3}$

The persistence of Karbala's legacy goes hand in hand with its malleability, contributing to its emblematic resilience. The trope of Karbala has been portrayed and reinterpreted in countless ways by many poets, devotees, mystics, and chroniclers. The Battle of Karbala with all its brutality might seem a great tragedy, however, it is a timeless incident perpetually encouraging believers to fight for establishing the truth, a Jihad against all kinds of injustice and repression. After the battle of Karbala and Imam Hussain's martyrdom, Ibn Ziyad'14 asked Hussain's sister, Zainab, 'How did you find the way Allah treated your brother and your family?' She said, 'I saw nothing but beauty. ${ }^{15}$

\footnotetext{
11 Ibid., p.144

12 Ibid., p.141

13 Mahmoud M. Ayoub, Redemptive Suffering in Islam: A Study of the Devotional Aspects of Ashura in Twelver Shi'ism, Religion and society 10 (Berlin: De Gruyter, 1978), p.233

14 Umayyad general and the governor for the Umayyad Caliphate in Kufa

15 Ayati, A Probe Into the History of Ashura, Sermon of Lady Zaynab in the court of Yazid
} 


\subsection{Martyrdom in the Modern Context}

This 7 th-century tragedy still resonates within the cultural contours of the contemporary Muslim world. Every year, Shiite Muslims around the world mourn and commemorate the martyrdom of Imam Hussain and his followers during the two months of Muharram and Safar, perceiving "what happened 13 centuries ago on the plains of Karbala ... as if it were happening here and now."16 Karbala as a multivalent allegory is configured within various contexts, ideologies, and memories, going beyond the boundaries of history and religion. Many socio-religious movements of the 2oth century adopted and interpreted the trope of Karbala, further broadening the definition of martyrdom. Hussain became a symbol in the constant battle between good and evil. In addition to the localized and religious interpretations of the Karbala event, nationalist movements made it a present-oriented worldwide concept, "an outlet for ideas of universal justice, resistance to colonial and postcolonial categories, and the building of transnational solidarities."17

The symbolic significance of the Battle of Karbala was taken on in the Iran-Iraq war of the 1980 s in which Iranians aligned themselves with the revolt of Hussain. The invocation of the Karbala event and its themes and motifs played an important role in mobilizing the masses to go to the frontlines. Emulating the Battle of Karbala, Iranians of all ages volunteered to sacrifice themselves in order to preserve their Islamic identity and values. The notion of the war for Iranians shifted to become a "sacred defense" against the tyranny and cruelty of Saddam Hussein whose goal was to annex Khuzestan Province to gain more political power, taking advantage of the chaotic situation in post-revolutionary Iran. On the contrary, however, Saddam's invasion created an opportunity for the Iranian regime to become more unified and stabilized. As Mitchell states:

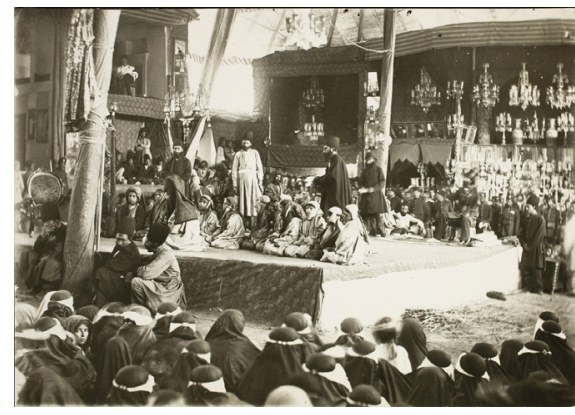

Fig 3.4 Ta’ziya Performance in Tehran in Qajar period

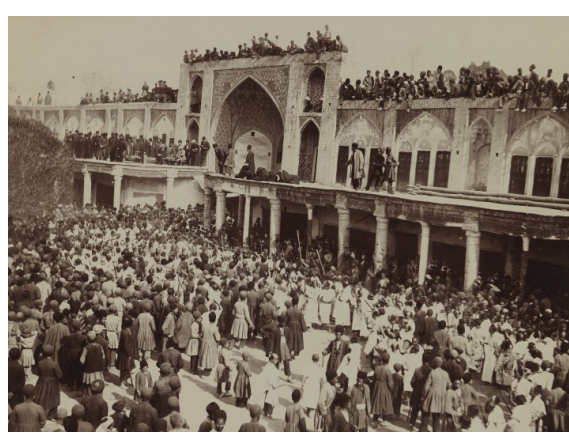

Fig 3.5 Came-zani in Muharram mourning ceremonies, Qajar period

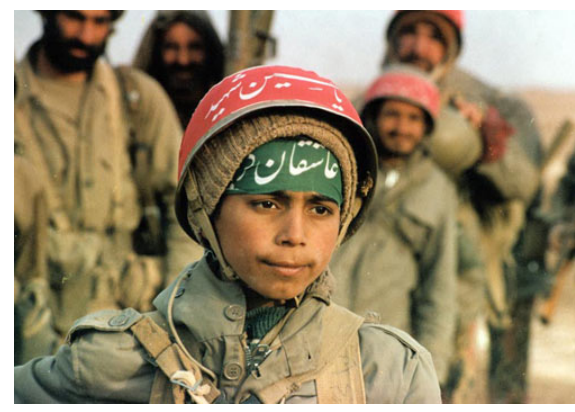

Fig 3.6 The red headband addresses the martyred Imam Hussain

16 Jolyon P. Mitchell, Promoting Peace, Inciting Violence: The Role of Religion and Media (London, New York: Routledge, 2012), p.60

17 Hyder, Reliving Karbala, p.11 


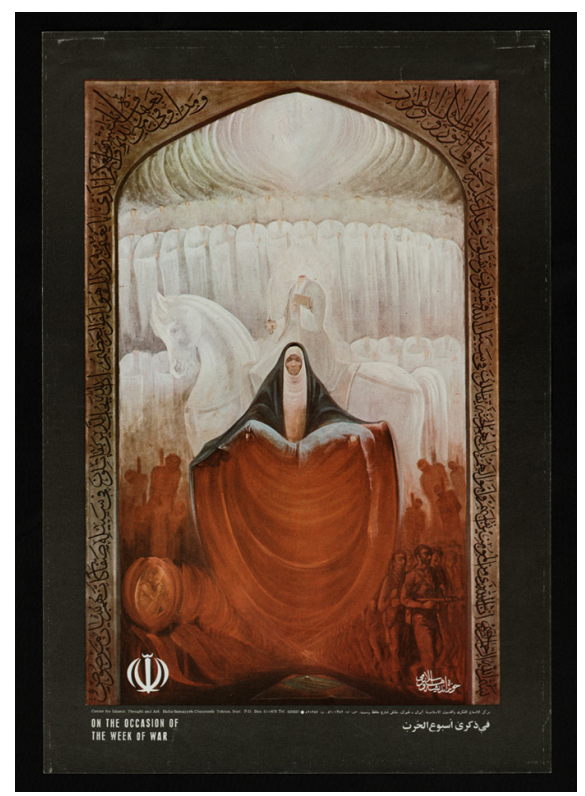

Fig 3.7 A dead soldier's body transforms into a tulip

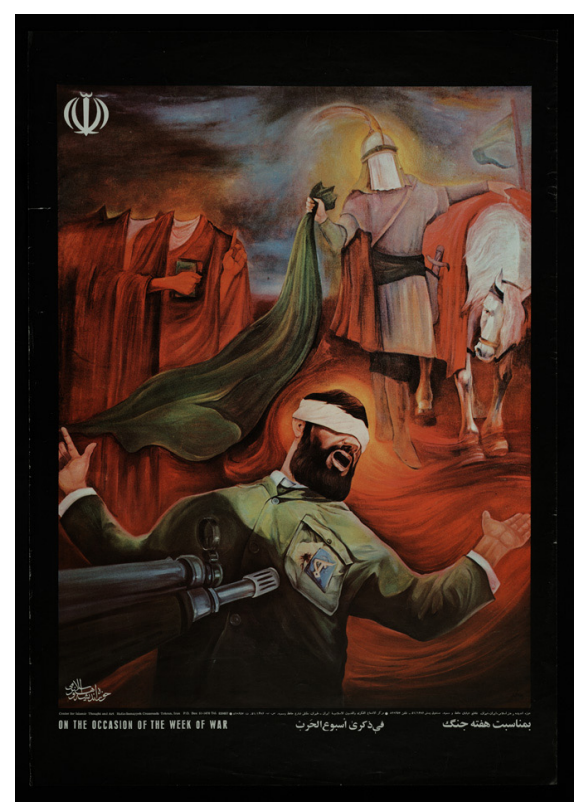

Fig 3.8 Visual association of martyrs of the Sacred Defense with Imam Hussain
"Iranians were united together in a war of supposed selfprotection. Several accounts underline the righteous quality of the local martyrs fighting against Iraqi infidels. This characterization of the enemy as infidels allowed the Iranian leadership to define the conflict as a Jihad, or Sacred War, and place martyrdom at the center of the state's wartime policy.".

In such a context, Saddam as an aggressor became the symbol of Yazid in an unequal battle parallel to the Battle of Karbala, while Iranians became the symbol of the oppressed nation, fighting for establishing the right values rooted in the Karbala paradigm. In addition, the attack of the Sunni-led Arab army against the Iranian Shiites added more tension to the hostilities between the two sects. Emphasizing the association with the Battle of Karbala, operations were named Karbala One, Karbala Two, Karbala Three, and so forth. ${ }^{19}$ It seemed that "battlefields became a place to re-enact or reexperience what happened at Karbala." ${ }^{20}$

Imam Hussain signified the notion of standing against an oppressive established order. As such, the battle gained mythical quality, provoking the masses on the sidelines to plunge into the fight and to embrace the ideology of martyrdom. The loss and death on the side of the oppressed reinforced their strength to continue, becoming more determined to overcome the evil. They considered themselves as part of an ethical movement, as a reaction to Hussain's call for withstanding persecution on both physical and spiritual levels.

During and after the war, various kinds of media were employed to intensify and preserve the memories of the Sacred Defense martyrs, tying them in with the Karbala narrative. In addition to countless murals in Tehran as well as in other cities, references to these devotional martyrdom stories were frequently found in school textbooks, university lectures, political speeches, radio broadcasts, and public sermons. In the realms of visual art and iconography, the red tulip became the most common motif of martyrdom after the

18 Mitchell, Promoting Peace, Inciting Violence, p.61

19 Pedram Khosronejad, Unburied Memories: The Politics of Bodies of Sacred Defense Martyrs in Iran (London: Routledge, 2013)

20 Mitchell, Promoting Peace, Inciting Violence, p.54 


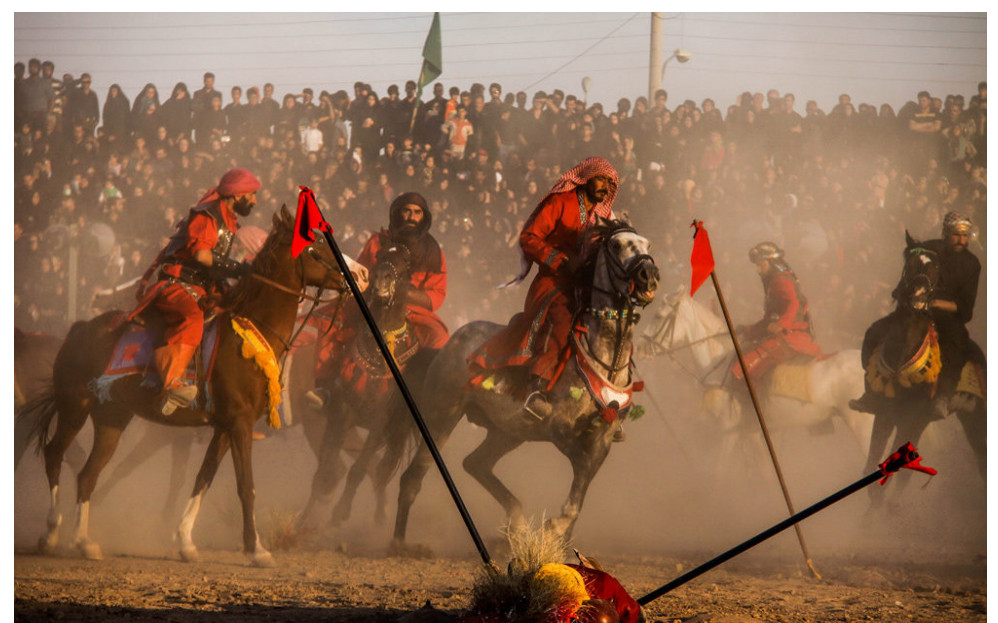

Fig 3.9 Re-enactment of the Battle of Karbala as a Passion Play on the day of Ashura

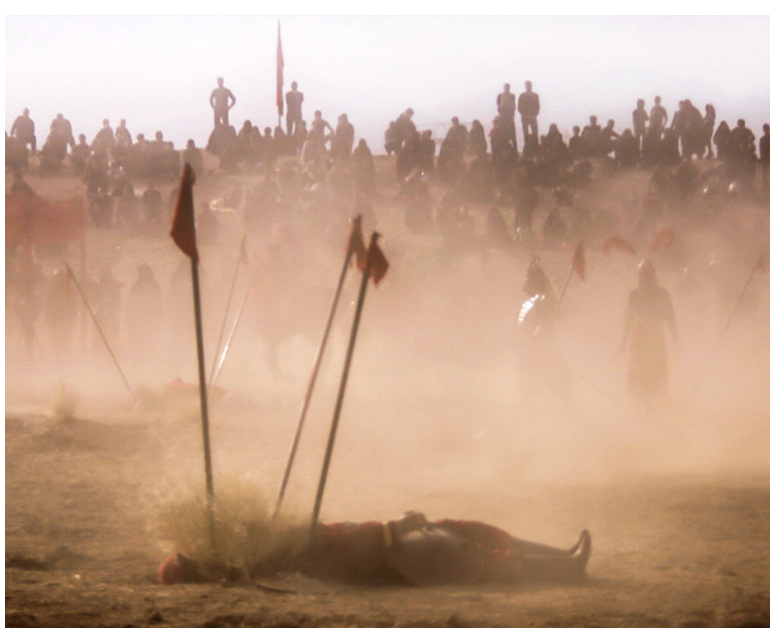

Fig 3.10 Narration of the Battle of Karbala as a form of theater

1979 Revolution and Iran-Iraq war. In the Shia tradition, tulips are the common symbol of martyrdom rooted in the legendary belief that a red tulip will bloom where the blood of a martyr is spilled. ${ }^{21}$ Referring to the martyrdom of Imam Hussain, there is a poetic belief that "it was Hussain's blood that rained upon the desert of Karbala and left the red tulips there"22, representing the devastated condition of the Karbala plain after the battle. Hussain's blood is depicted here as a raincloud, contrasting significantly with the dryness and thirst of the actual desert of Karbala. The metaphor of red tulips symbolizing the bloodstained garments of the martyrs has also a long history in Persian poetry and literature, illustrated in the Siavash narrative in the epic poem Shahnameh. The red tulip not only prevailed as a depiction of martyrdom in murals and posters but also, it found its way into the national emblem of Iran after the Revolution. The current logo on the Iranian flag designed by Hamid Nadimi features the Arabic word Allah, shaped in the outline of tulip petals, commemorating the people who died for Iran. The five parts of the logo refer to the five Islamic principles. ${ }^{23}$

Iranians perceived the imposed Iran-Iraq war as a battle in the cause of the truth of Islam for the purpose of standing against the

\footnotetext{
21 Ibid.

22 Annemarie Schimmel, "Karbala and the Imam Husayn in Persian And Indo-Muslim literature," Al-Serat 12 (1986)

23 Mitchell, Promoting Peace, Inciting Violence
}

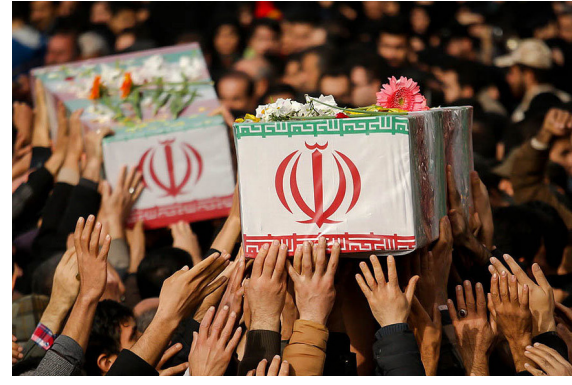

Fig 3.11 The national emblem of Iran on the coffins of the Unknown martyrs of the Sacred Defense in a funeral ceremony in Tehran 


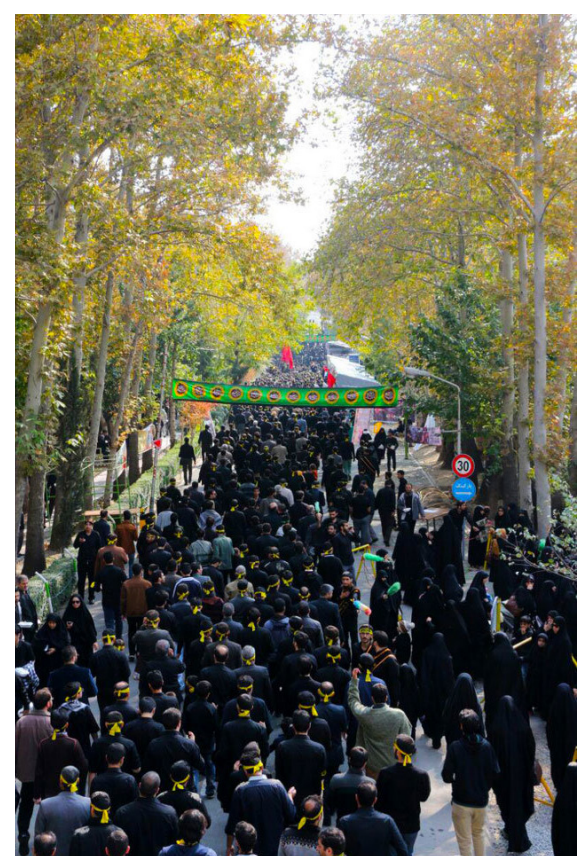

Fig 3.12 Mourning parade as a form of commemorating the Karbala event abusers of Islam. The concept of martyrdom achieved new political dimensions, reflecting a culture which had been cultivated during the Iranian Revolution of 1979. Motivated by the redemptive power of Imam Hussain's uprising, millions of Iranian people embraced the mystical notion of annihilation in Allah, metaphorically comparing themselves to moths burned in the candle ${ }^{24}$ to be united with light. To them, Hussain, the Prince of Martyrs was a martyr of love to the Divine who gave his life for saving what he unconditionally loved, the Truth of Islam. ${ }^{25}$

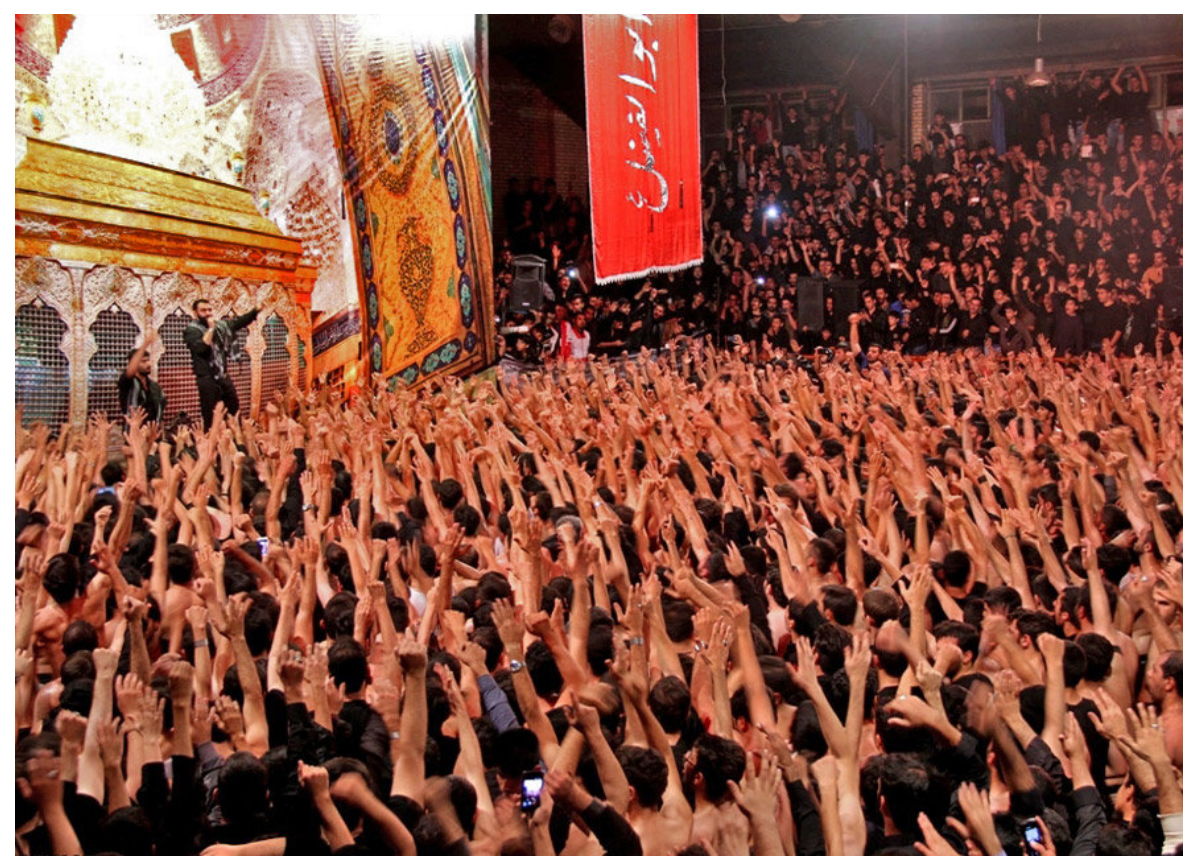

Fig 3.13 Imam Hussain mourning ceremony

24 The famous mystic parable of the moth and the candle is illustrated in a quatrain in Mukhtār-Nāma by Attar in which the moth said to the candle: 'because of the true covenant, because of that first day, would you wash my body with your tears, if I be killed for your head?' The candle answered: 'A martyr needs no washing.'

25 Asghar Seyed-Cohrab, "Martyrdom as Piety: Mysticism and National Identity in Iran-Iraq War Poetry," Der Islam 87, no. 1 (2012) 


\section{Martyrdom in Mystical Sufism}

The story of Karbala and Imam Hussain's sacrifice permeated the broader discourses of Islamic mysticism, manifested by Sufism. Through poetic elegies and mourning rituals, the everlasting memory of Hussain has been constantly articulated and experienced. ${ }^{26}$

The persistence of the Karbala trope in Sufi devotional poetry reflects the honored position of Hussain being praised in these mystical discourses. Famous Sufi poets, such as Mohammad Iqbal, have ascribed a timeless universality to this event by weaving together the mystical features embedded in this narrative and its reformist lessons. ${ }^{27}$ The Karbala event became a mystical model for those who embark on the journey of love. The poets and authors adopted Imam Hussain's martyrdom as an allegory of the demise of the ego and becoming united with the Divine Beloved. In the Sufi tradition, resistance against impediments to spirituality and piety is strongly encouraged. Refusing to pay allegiance to Yazid regardless of the costs, Hussain is portrayed as a manifestation of Islamic belief, which acknowledges Cod as the Ultimate power of the universe. Therefore, the tragic and excruciating aspects of the Karbala narrative seem to be de-emphasized, since the martyred Hussain and his companions have received God's sustenance. "Hussain and his followers are not resigned to martyrdom, but instead, rejoice in martyrdom." ${ }^{28}$ By annihilating the self and achieving a subsistence in the Divine's will, spiritual happiness is gained. Parallel to this concept is the Prophet's exhortation to 'Die before you die.' ${ }^{29}$

"Hussain wages a war and refuses to pay allegiance to separation, opting instead for union with the Beloved. The consistent theme in the mystical works of Rumi as well as Sanai, insofar as it pertains to Karbala, is that of love. Hussain in these works becomes the metaphor for the ideal lover and Karbala becomes the battleground analogous

26 Schimmel, op. cit

27 Syed A. Hyder, "Iqbal and Karbala: Re-Reading the Episteme of Martyrdom for a Poetics of Appropriation," Cultural Dynamics 13, no. 3 (2001)

28 Hyder, Reliving Karbala, p.105

29 Hyder, op. cit 


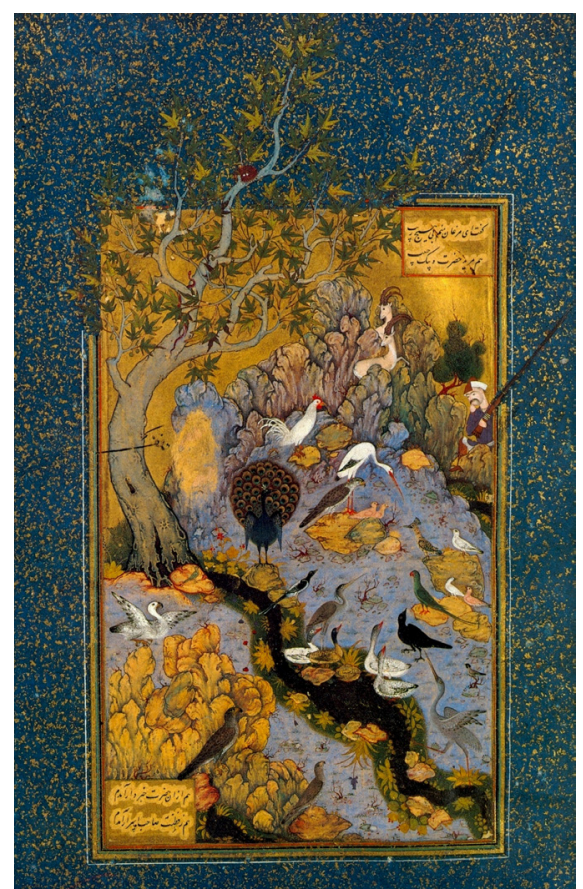

Fig 3.14 Folio from The Conference of the Birds Manuscript to the combative inner self where the lover's love for the beloved is tested." ${ }^{30}$

One of the many mystic poets for whom the suffering of Hussain became an archetype of the Sufi's life, was a $12^{\text {th }}$-century poet, Farid-ud-din Attār who significantly influenced Persian poetry and Sufism. His philosophy and poetry were the main inspiration for Rumi and many other poets. Attar's best-known work on Sufism is called Mantiq-ut-Tayr, or "The Conference of the Birds". In a long allegorical poem, Attar tells the story of a group of birds (exemplifying Sufi pilgrims) embarking on a journey to find a ruler for their kingdom, toward the land of the great "Simurgh"31. Before they find the Simurgh and reach the Divine presence, the birds have to pass seven valleys, including Quest, Love, Cnosis, Detachment, Unity of Cod, Bewilderment, and finally, Oblivion in God. These valleys represent the stages that a Sufi or an individual has to endure in order to attain spiritual perfection. ${ }^{32}$

Throughout the journey, the birds undergo a hundred difficulties in each valley. Some birds die on the way, some give up and decide to go back and one by one drop out of the journey. Eventually, only 30 birds reach the 7th valley, realizing that there is no Simurgh anywhere to be seen. They perceive that they themselves are the SiMurgh (Si=thirty + Murgh=bird). In fact, the thirty birds that manage to reach the last valley have been completely purged of all earthly elements along the way inasmuch as they are merely reflecting the Simurgh (Divine God), losing their own selves and resuscitating by the light of His Majesty. ${ }^{33}$

The story is based on the fundamental principle of Sufism that God is not separate from the universe. God is present in every soul, and each soul exists in Cod. Thus, the search for the divine cannot be undertaken from without. Rather, it can only be achieved from within by self-realization to the point where one's ego is purified and

\footnotetext{
30 Ibid., p.346

31 A mythopoetic Persian bird similar to phoenix, here symbolizing the Lord of Creation and the Divine.

32 Farid u.-D. Attar and Mohammad R. Shafiei Kadkani, Manțiq-uț-Tayr, 9th ed. (Tehran: Sokhan, 2013)

33 Ibid.
} 
liberated from earthly burdens. After this stage, when the Sufi begins to perceive the universe more clearly, he eagerly surrenders himself to the Divine will. The Sufi becomes so selfless that his heart, like a mirror, can only reflect the perfection of the Divinity ${ }^{34}$. Mansur $\mathrm{Hallaj}^{35}$, one of the major mystic figures of Sufism, has very well referred to this notion in a poem:

"I saw my Lord with the eye of the heart

lasked, 'Who are you?'

He replied, 'You'.'36

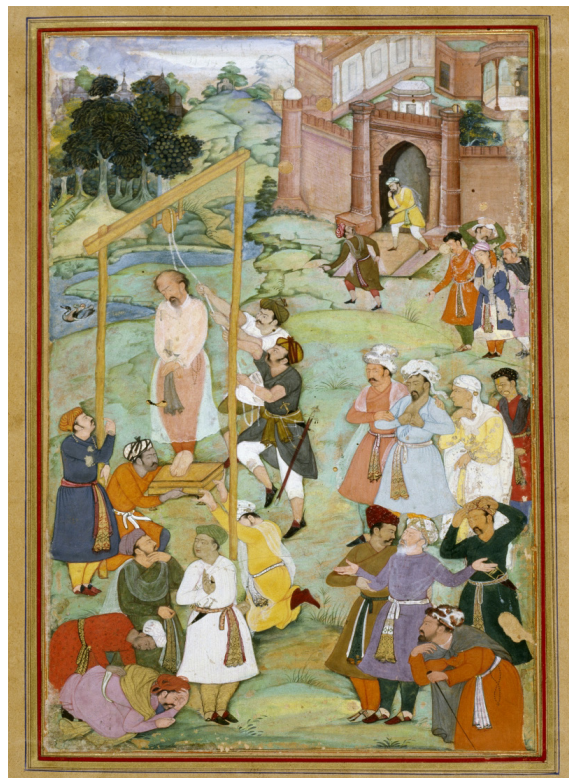

Fig 3.15 The execution of Mansur Hallaj

34 Rustom P. Masani, The Conference of the Birds: A Sufi Allegory: Being an Abridged Version of Farid-ud-Din Attar's Mantiq-ut-Tayr (New Delhi: Asian Educational Services, 2003)

35 Hallaj was executed in 922 because of his famous saying "I am the Truth". He is now considered as a martyr whose claim was not being the Divine, rather he was annihilated in Cod as a result of his spiritual state.

36 Mohammed Rustom, "The Metaphysics of the Heart in the Sufi Doctrine of Rumi," Studies in Religion 37, no. 1 (2008): p.3 


\subsection{Echoes of Paradise}

The construction of formal gardens has a long history in Persia dating back to as early as 500 B.C. After the advent of Islam in Persia, the notion of the Persian garden was developed in conformity with the doctrines of the new religion, becoming the symbol of the heaven promised by the Quran. The Persian word for garden, "pardis" or "firdaws" means both garden and paradise. This etymological duality inspired Persian poets to enthusiastically draw comparisons between the earthly garden and the heavenly paradise. Therefore, driven by imagination and the yearning for the utopian paradise promised by the Quran, Persians attempted to create gardens that would exemplify a microcosm of heaven. ${ }^{37}$ Persians successfully managed to build magnificent gardens that represented earthly embodiments of paradise, even in the relatively hot and arid conditions of most parts of the Persian plateau ${ }^{38}$. In fact, the Persian garden becomes a paradigm, establishing a sharp contrast between the trees and plants within and the dry desert without. The garden in the desert also implies the dichotomy of life and death.

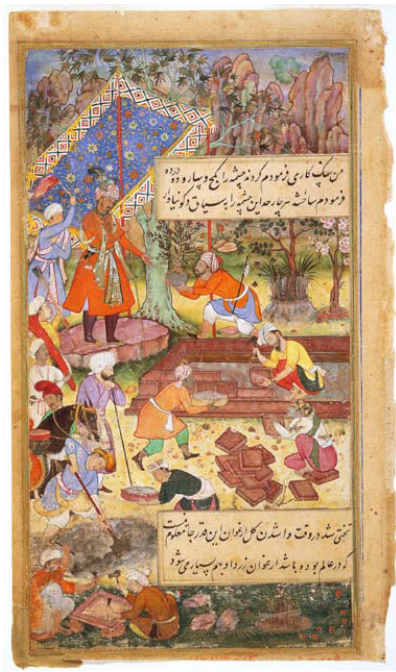

Fig 3.16 Mughal Ruler Babur Supervising the Creation of a Garden

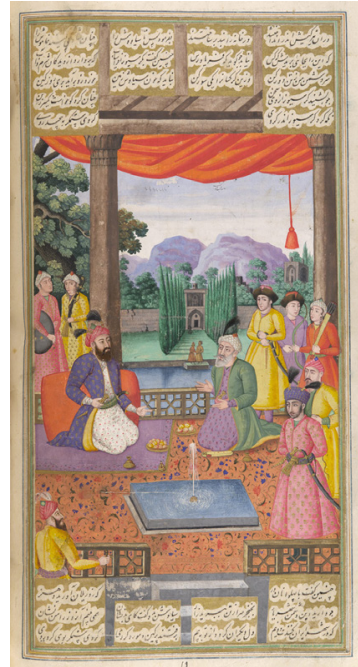

Fig 3.17 Folio from Shahnameh Manuscript. c.1074

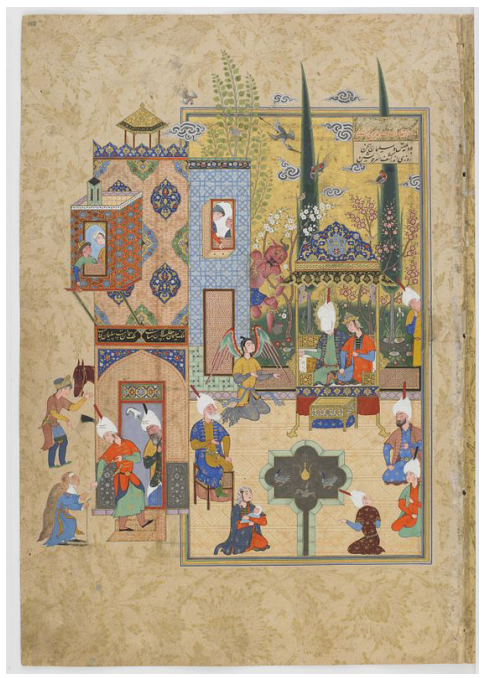

Fig 3.18 Persian garden miniature, c. 1450 S

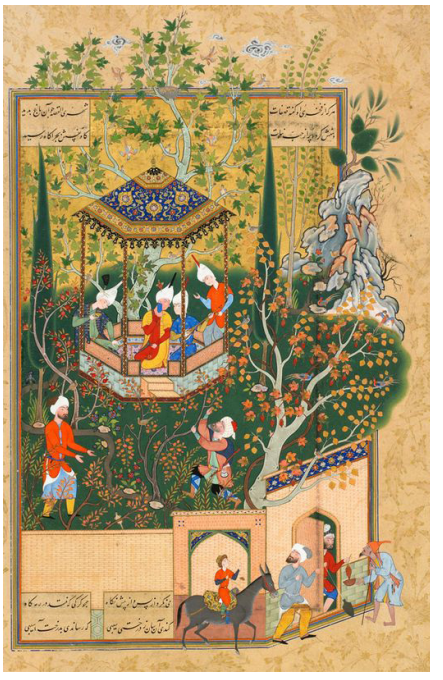

Fig 3.19 Persian garden miniature, c.1450s

37 Donald N. Wilber, Persian Cardens and Garden Pavilions, 2d ed. (Washington: Dumbarton Oaks, 1979)

38 Persia here refers to "Greater Iran" which defined as the regions that have been historically ruled by Persian Empires. 
With Islamic traditions becoming prevalent in Persia, the concept of inward-looking gardens dominated most aspects of Iranian architecture. Persian gardens were built in various forms according to the climate or the purpose of the garden. However, the most general pattern of the Persian garden is a centripetal rectangular plan, segmented by intersecting water channels and pathways. The geometric structure of the Persian garden is mainly rooted in the creation of harmony and integrity. ${ }^{39}$

Space at the center of the courtyard or the garden becomes the hidden gem, enclosed by walls or a building, suggestive of the way the body of a person wraps around the soul. This also illustrates the Sufi tradition that considers the universe to be constituted of macrocosm and microcosm. Accordingly, the notion of the Persian garden exists as both container and as contained (courtyard). This binary relationship exhibits the fundamentals of public/private space in Islamic beliefs. The garden as container is composed of a public building at the center, looking outward into the paradise of nature. Likewise, the garden as a courtyard contains a private inward looking garden. As Shrivani described, "The garden as container is a public place where the hidden

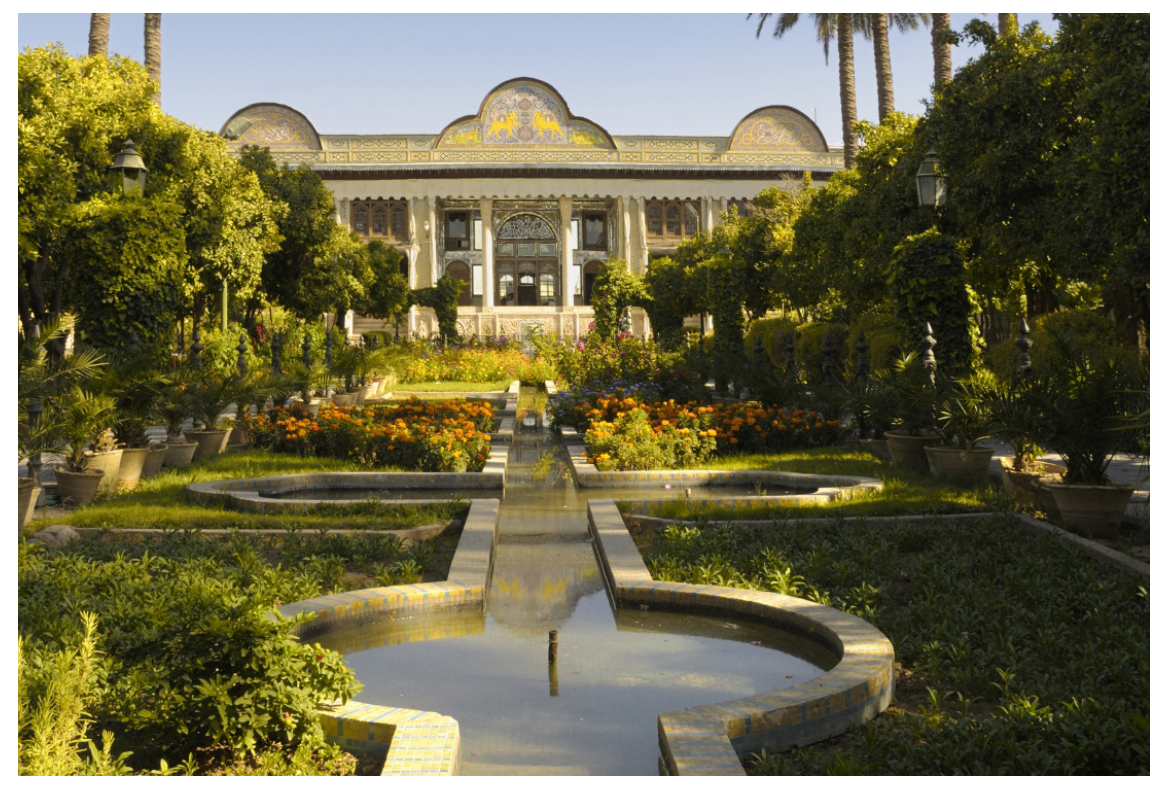

Fig 3.20 Naranjestan-i Qavam, Shiraz

39 Leila Mahmoudi Farahani, Bahareh Motamed and Elmira Jamei, "Persian Gardens: Meanings, Symbolism, and Design," Official Journal of the International Association for Landscape Ecology 46 (2016)

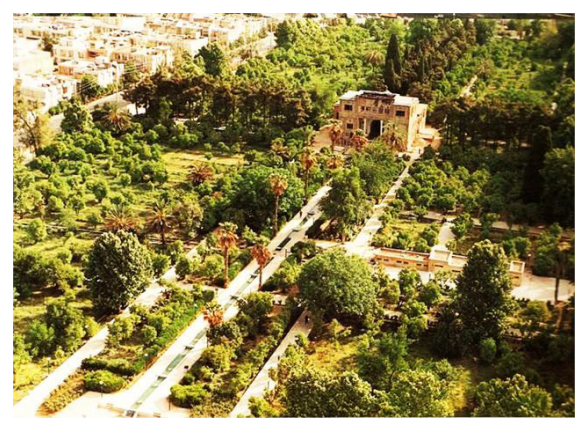

Fig 3.21 Delgosha Garden, Shiraz

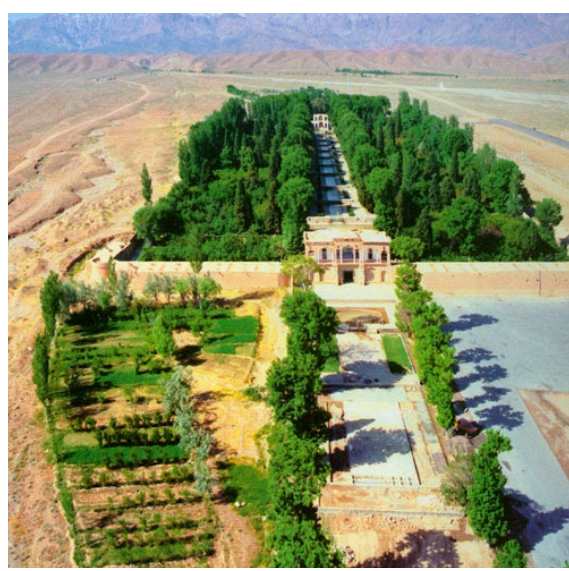

Fig 3.22 Shazeh Garden in the middle of the desert, Kerman

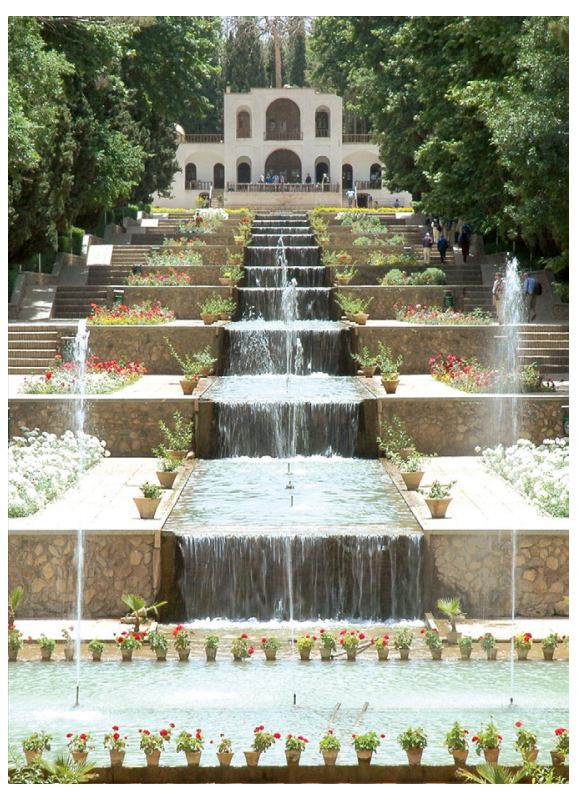

Fig 3.23 Spring in Shazdeh Garden, Kerman 


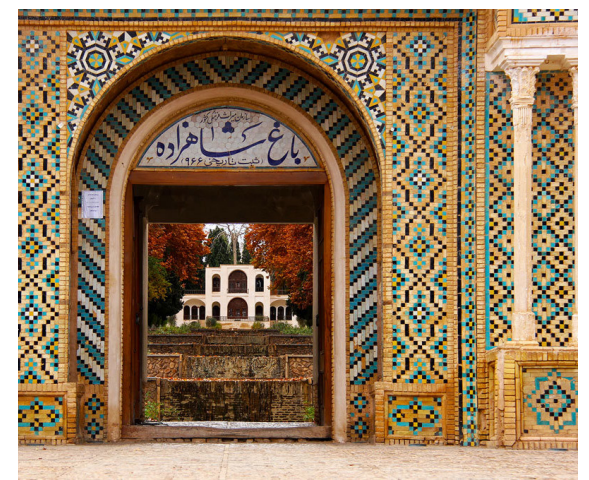

Fig 3.24 Entrance to Shazdeh Garden, Kerman is in infinity, while the garden as contained is a private place where the hidden is contained." ${ }^{40}$

The obsession with the search for the hidden truth in Islamic/ Sufi tradition is also expressed in the elements of a garden. The pool of water at the center of a garden exemplifies the latent in space, the core spirit of the Persian garden. In addition to symbolic aspects of water as life-giver and purifier, the reflective nature of the pool refers to a refined spirit, a metaphor for "those not deceived by the seeming completeness of the ordinary world." ${ }^{41}$ The reflection also signifies the moment when the realm of the earthly is connected to the heavenly. Water is the key element by which spaces are articulated to create freshness, peace and movement into gardens. The channels of water in the Persian garden create visual continuity, bringing a sense of direction and infinity. These channels facilitate water flow from one segment to another, creating the rhythmic and never-ending sound of water. Also, the movement of water from the central pool to the edges of the garden symbolizes the movement of the spirit into the body and vice versa. ${ }^{42}$

The Persian garden is a manifestation of various layers of meaning and symbolism cultivated by mystical traditions. Through

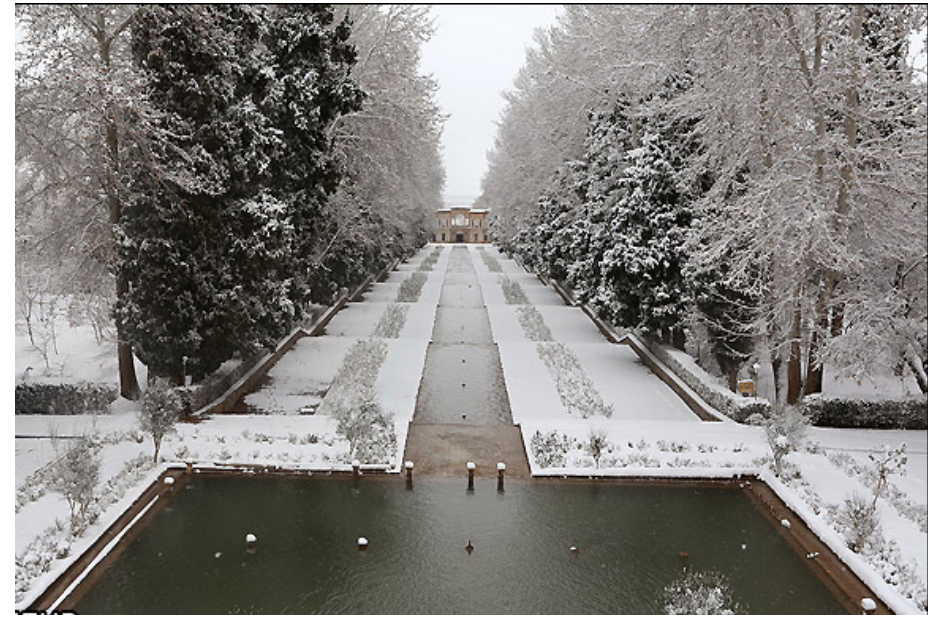

Fig 3.25 Winter in Shazdeh Garden, Kerman

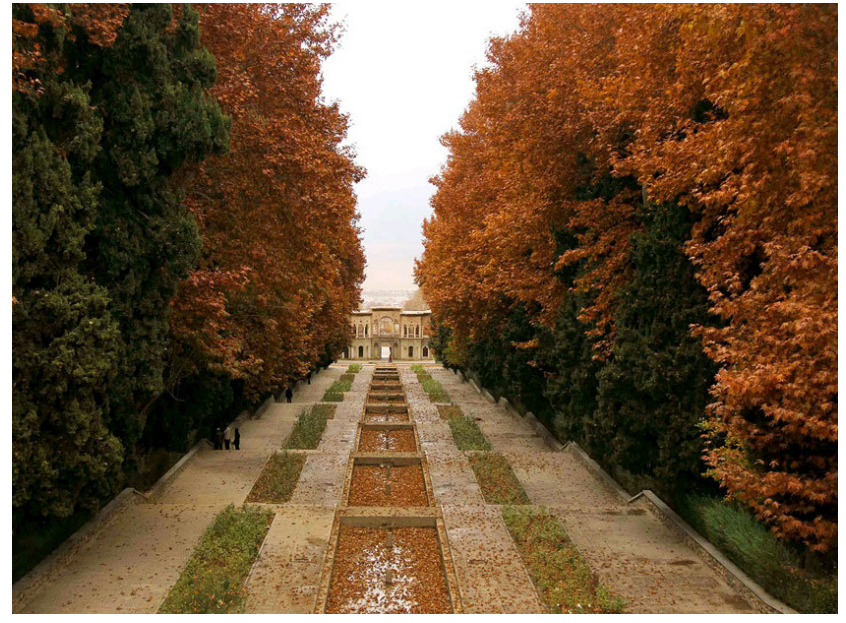

Fig 3.26 Autumn in Shazdeh Garden, Kerman

40 By Rumi, cited in Hamid Shirvani, "The Philosophy of Persian Garden Design: The Sufi Tradition," Landscape Journal 4, no. 1 (1985): p.26

41 Ibid. p.26

42 Ibid. p.27 
thoughtful employment of water features and foliage, an earthly paradise emerges in the middle of the desert, hidden from the harsh world outside. Rumi, a well-known Sufi mystic has reflected on the contrast he saw, which he believed could be reconciled through contemplation:

"Thou art hidden from us, though the heavens are filled With Thy Light, which is brighter than sun and moon! Thou art hidden, yet revealest our hidden secrets! Thou art the Source that causes our rivers to flow Thou art hidden in Thy essence, but seen by thy bounties. Thou art like the water and like the millstone.

... Thou art the Spring, and we the sweet green Garden"43

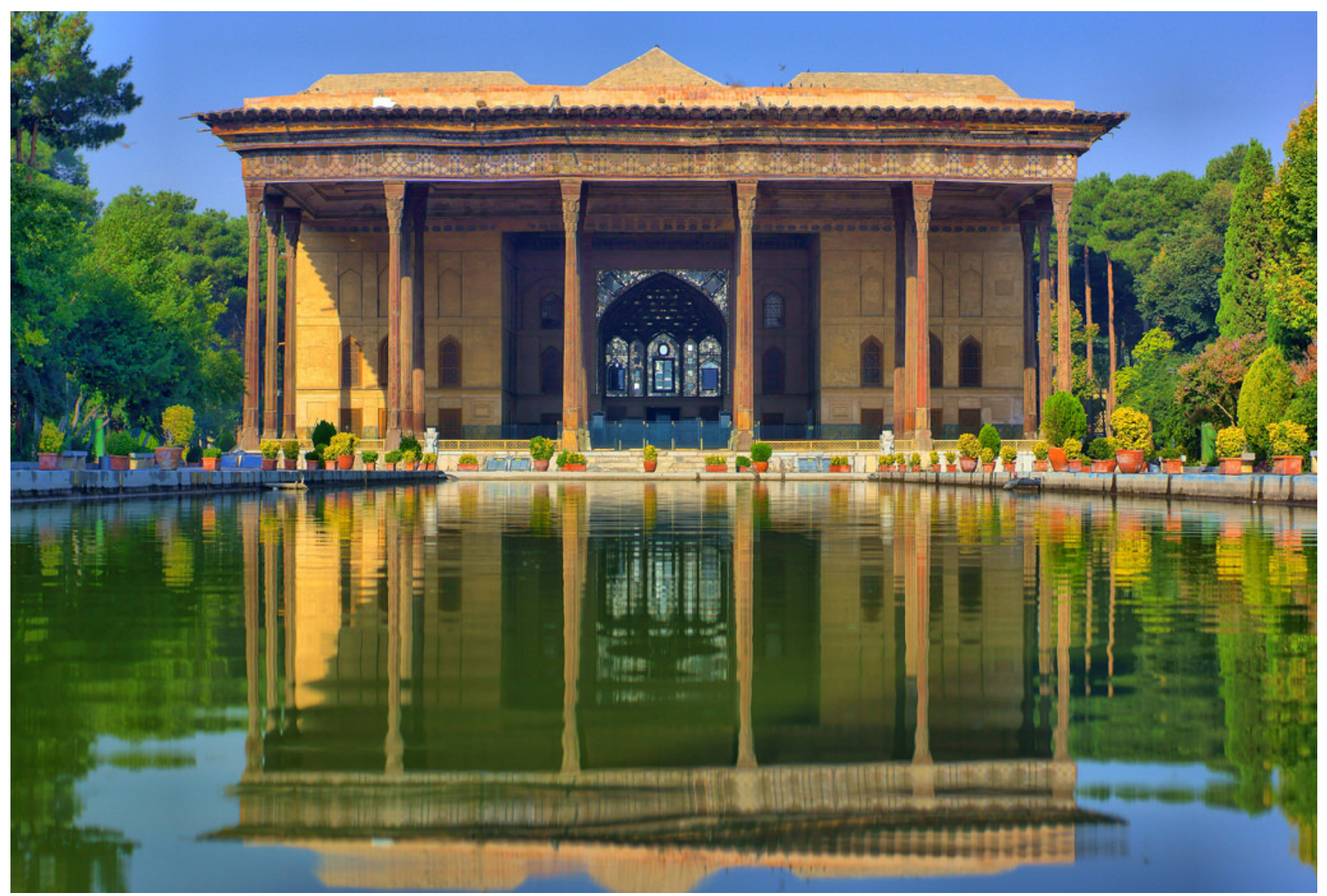

Fig 3.27 Chehel Sotoun Palace, Isfahan 
48

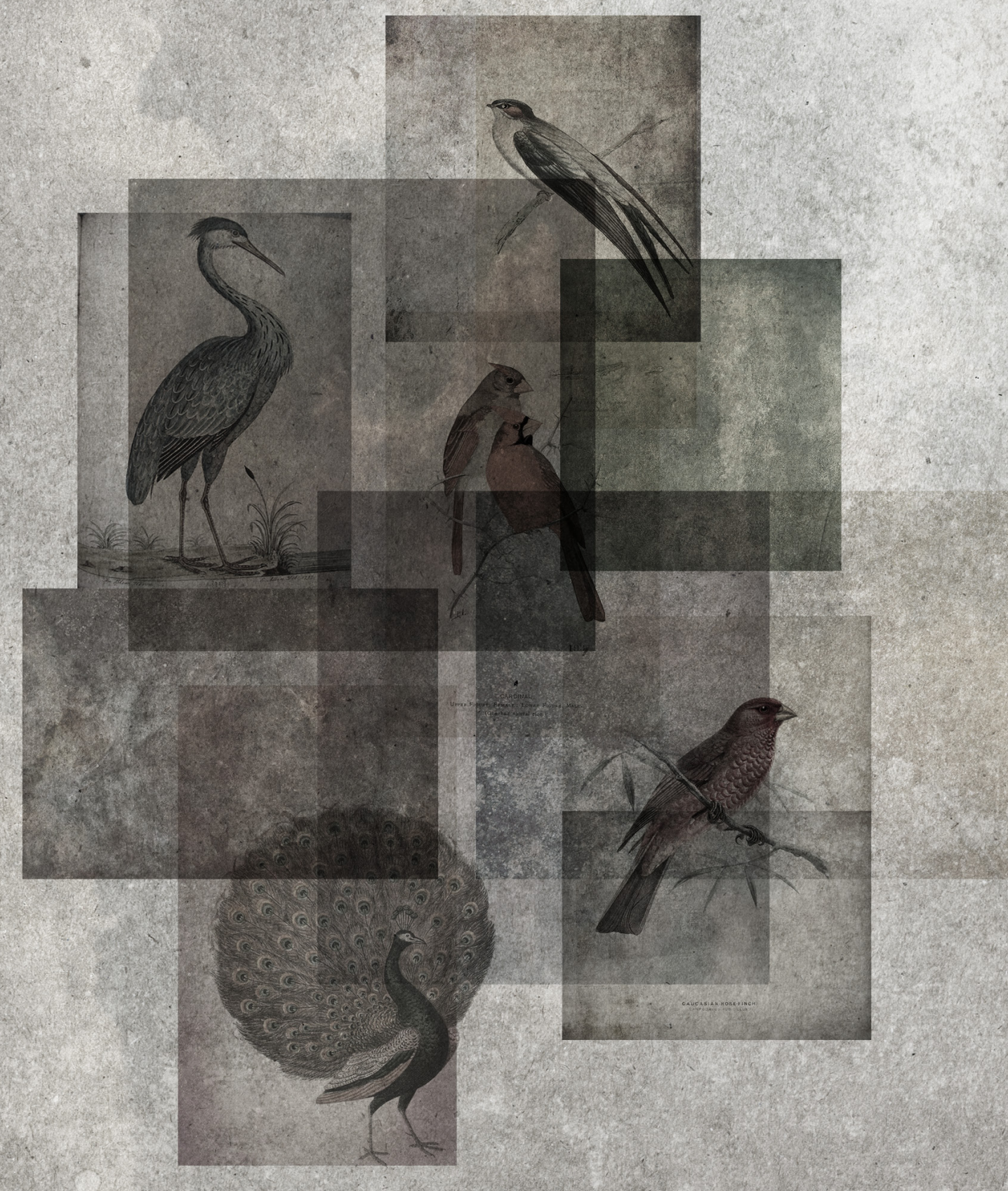


PART Four

THE LIFE AND DEATH OF KHORRAMSHAHR 



\subsection{Site Selection}

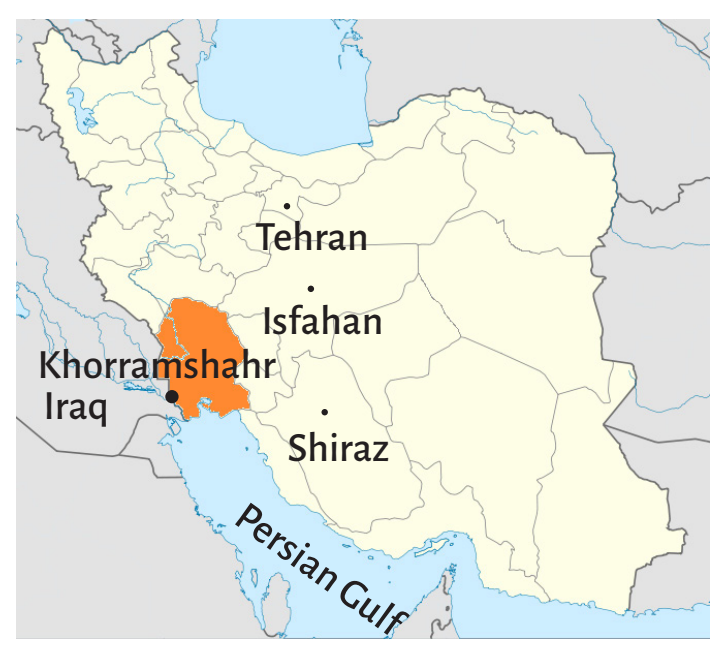

Fig 4.1 Khuzestan Province in Iran

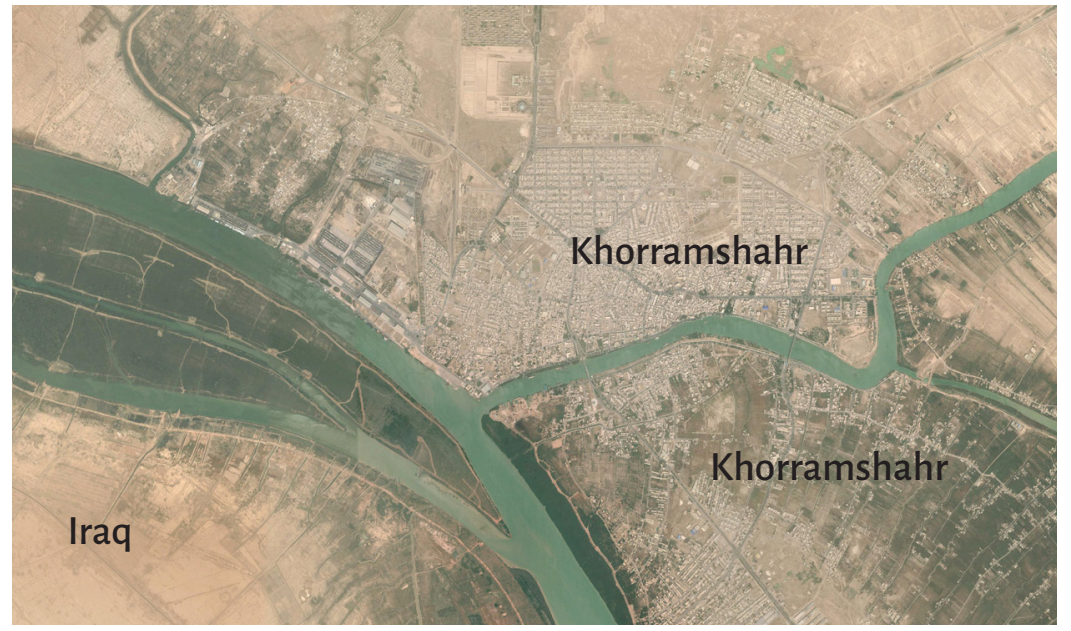

Fig 4.2 Khorramshahr city

The proposed site for the thesis project is located in the southwestern part of Iran. With historical and urban settlements dating back to $4000 \mathrm{BC}$, Iran is home to one of the oldest continuous civilizations in the world. Khorramshahr, formerly known as Mohammareh, is a port city located in Khuzestan Province. Located at the confluence of two rivers (Arvand and Karoun), the city has a history that dates back to the late Parthian period in the 1st Century $A D$. Located in a hot and humid region, Khorramshahr is surrounded by date palm trees. The city is a trading center thanks to its port status. During World War II, Khorramshahr achieved a greater status as the 


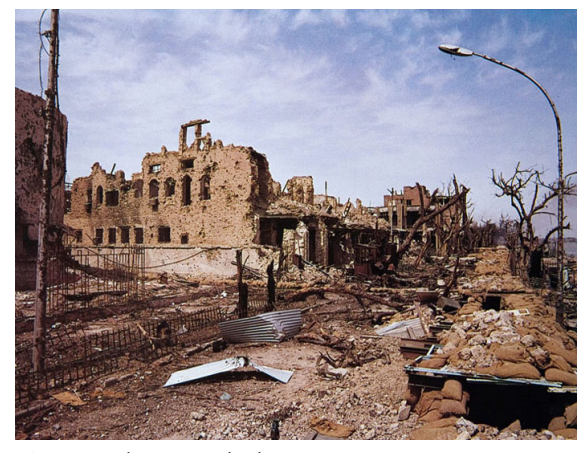

Fig 4.3 Khorramshahr ruins main portal for shipping military equipment from Allied forces to Russia. $^{1}$

\subsection{The Life and Death of Khorramshahr}

Throughout history, Khorramshahr has encountered numerous cycles of destruction and rebirth. During the pre-Islamic period, the small town was known as Barma, which was completely destroyed as part of Alexander's attack on Persia in $331 \mathrm{BC}$. The city was reborn with the new name of Bayan or Piyan, meaning "men" in the Khuzi ${ }^{2}$ dialect. Historians believe that Bayan was located 18 kilometers from the present site of Khorramshahr. The city remained under this name until the early 10th century when it was destroyed again due to unknown reasons. There is no historical record of the city for nearly 900 years. In the place where Khorramshahr is now located, Mohammareh ${ }^{3}$ emerged in the late 18th century. With the rise of the Pahlavi Dynasty in 1925, Mohammareh was renamed Khorramshahr, meaning a prosperous city. ${ }^{4}$

The city of Khorramshahr is known to be the symbol of bravery and sacrifice as it was one of the most important frontlines of the Iran-Iraq war. Despite having such rich layers of historical and political meaning, Khorramshahr has not been considered more than a name from history and its significance is little known to tourists and Iranians. Khorramshahr had been largely destroyed by the end of the war and has never regained its prosperous position. The reconstruction of the city has not progressed much since the war, and there are still several half-demolished buildings as reminders of the conflict. $^{5}$

\footnotetext{
1 Ahmad Kasravi, The 500-Year History of Khuzestan (Tehran: Khaju, 1983)

2 Associated with the western province of Khuzestan as an unofficial royal language

3 Mohammareh means "red water" in Arabic. The reason for this name is seemingly red water in Karun River.

4 Yaser Khalafi, Two Thousand years of Khorramshahr History (Tehran: Asar Afarin, 2015)

5 Murray Fraser and Nasser Colzari, Architecture and Clobalisation in the Persian Culf Region (Burlington, VT: Ashgate Publishing Company, 2013)
} 


\subsection{The Sacred Defense}

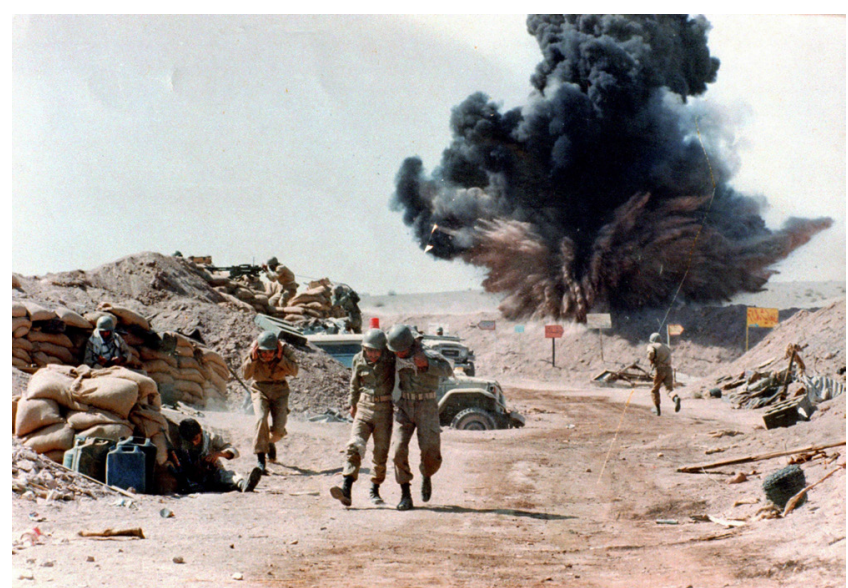

Fig 4.4 Iranian soldiers in Khuzestan

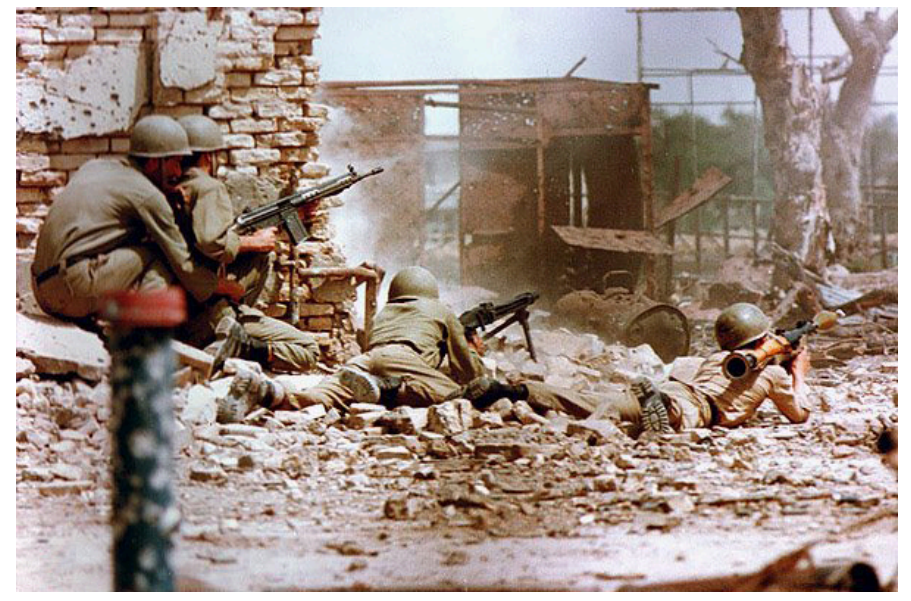

Fig 4.5 A Group of Iranian soldiers defend the city of Khorramshahr

Before the Iran-Iraq war, Khorramshahr had grown extensively to become Iran's primary non-oil port city, home to some of the country's wealthiest people. However, following a long history of border conflict, Iraq invaded Iran in 1980 and Khorramshahr was captured by Iraqi forces after 34 days of resistance by the popular forces especially the youth of the city who formed defense groups with very limited weapons. Iranians fought viciously against the Iraqi troops to defend their soil, but after the fall of the main bridge on the Karoun river, Iraqi forces effectively took control of the city and surrounded the few remaining defenders of Khorramshahr. Khorramshahr was recaptured by Iranian troops after 575 days in 1982. Every year Iranians celebrate the day as the Liberation of Khorramshahr recalling the courage and resistance of Iranians in the defense of their country.

Despite calls for a ceasefire by the United Nations Security Council, hostilities continued for eight years. The war is known in Iran as the Sacred Defense mainly because Iranians perceive it as an imposed war, condemning Iraqi authorities for the invasion

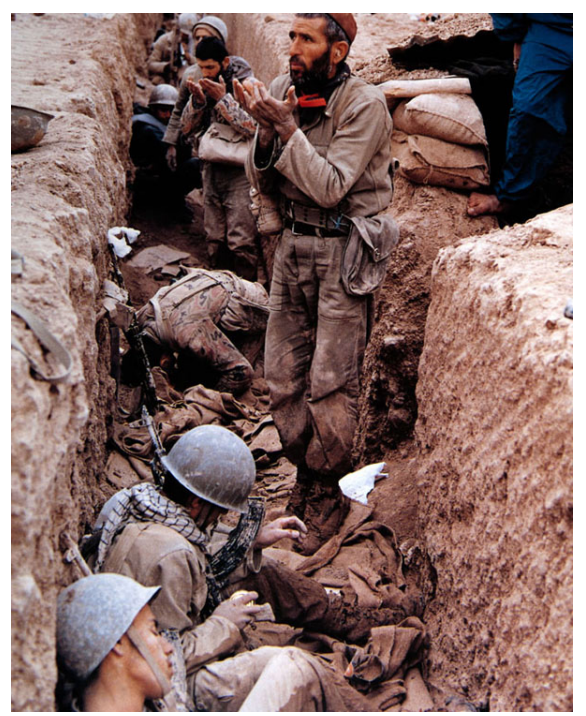

Fig 4.6 Soldiers praying in the trenches 


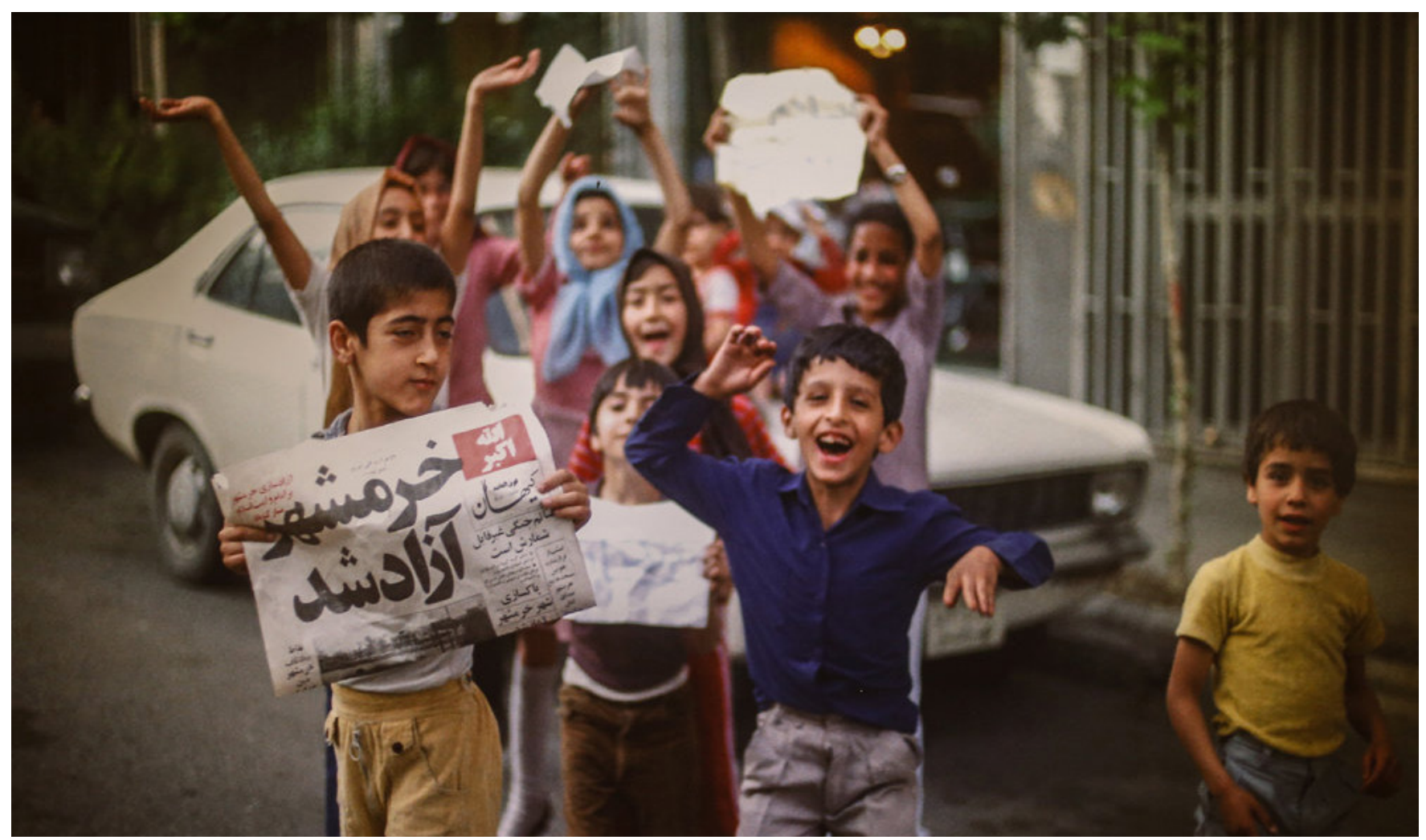

Fig 4.7 Exhilarated children on the day of Liberation of Khorramshahr in 1982, the title on the newspaper reads, "Khorramshahr was liberated."

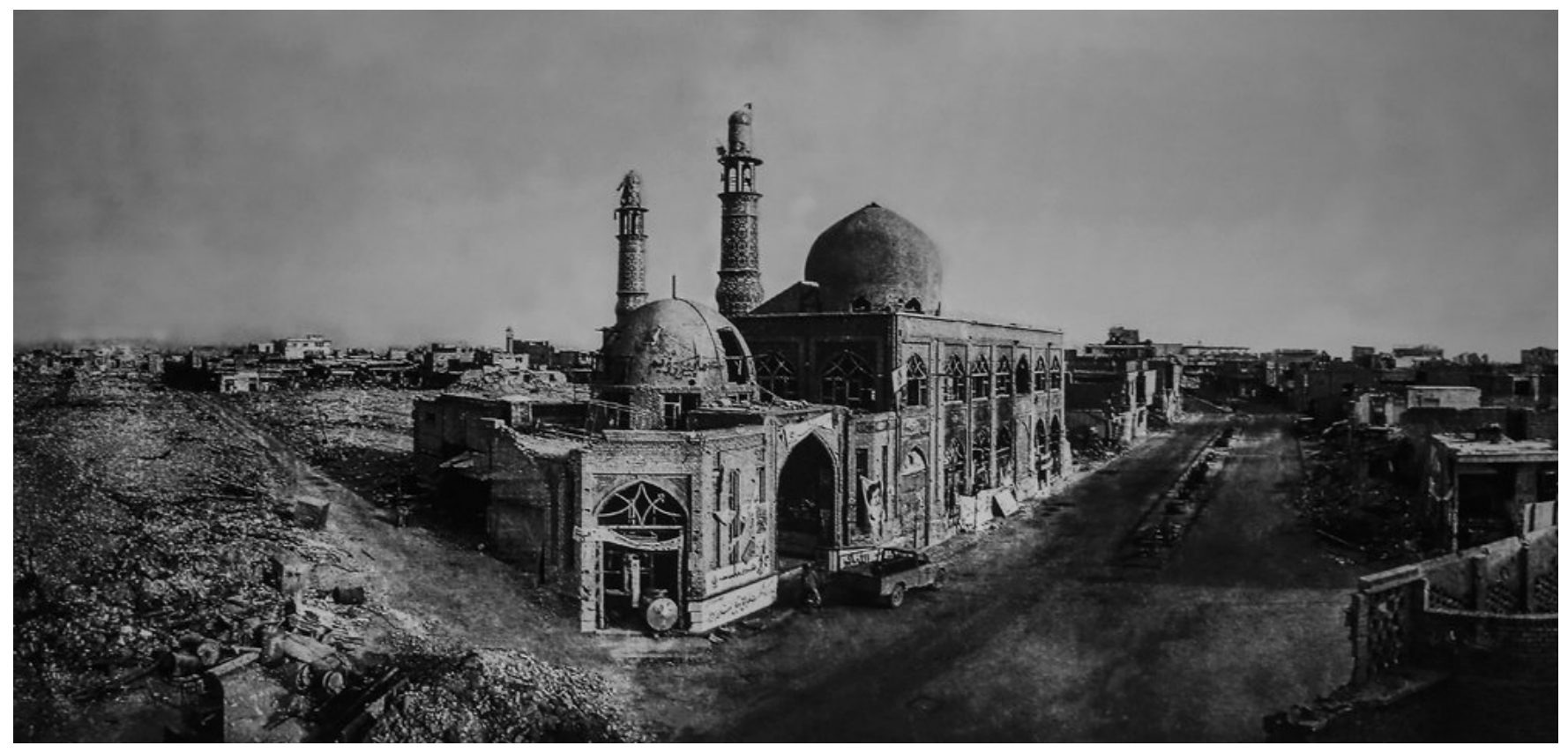

Fig 4.8 Khorramshahr Jame Mosque after bombing 


\section{Repressed Memories}

One of the most anguishing and difficult operations of the Sacred Defense was launched in 1987 after two failed operations. This operation called "Karbala 4" refers to the Battle of Karbala in 610 A.D when Imam Hussain, the grandson of the Prophet Muhammad went to a battle against his opponents. Hussain and all his supporters were killed. Hussain represents the symbol of martyrdom in Islamic tradition. The name Karbala was a motivation for modern-day soldiers as they would embrace martyrdom. This operation was intended to move the Iraqi lines in an effort to capture Iraqi territory. However, because of poor management and execution of the operation, Karbala 4 led to a major failure. 60,000 Iranian troops crossed the Shatt al-Arab River north and south of Khorramshahr to launch a surprise attack against the Iraqi forces. Before the launch of the operation, the details were revealed to Iraqi forces and they were waiting for the Iranian soldiers. In this three-day battle, Iran lost 12,000 troops. Not long after this horrible defeat, the Iranian forces once again launched another offensive attack, Operation Karbala 5, which became the largest battle of the war, with both sides losing tens of thousands of soldiers. Unlike the previous operation, Iran was successful in this attack, pushing Iraqi forces back from the Iranian border. ${ }^{6}$

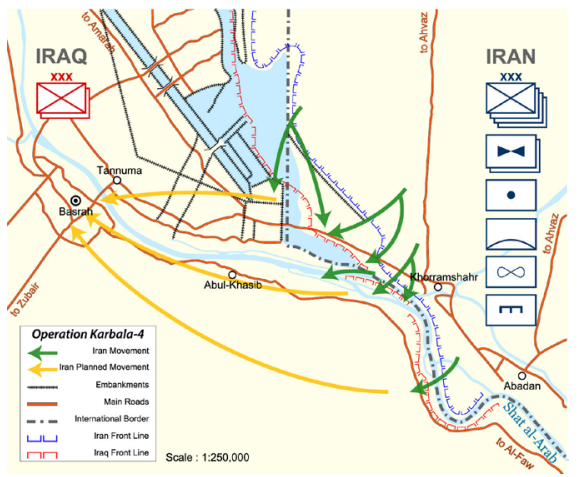

Fig 4.10 Karbala 4 Operation map
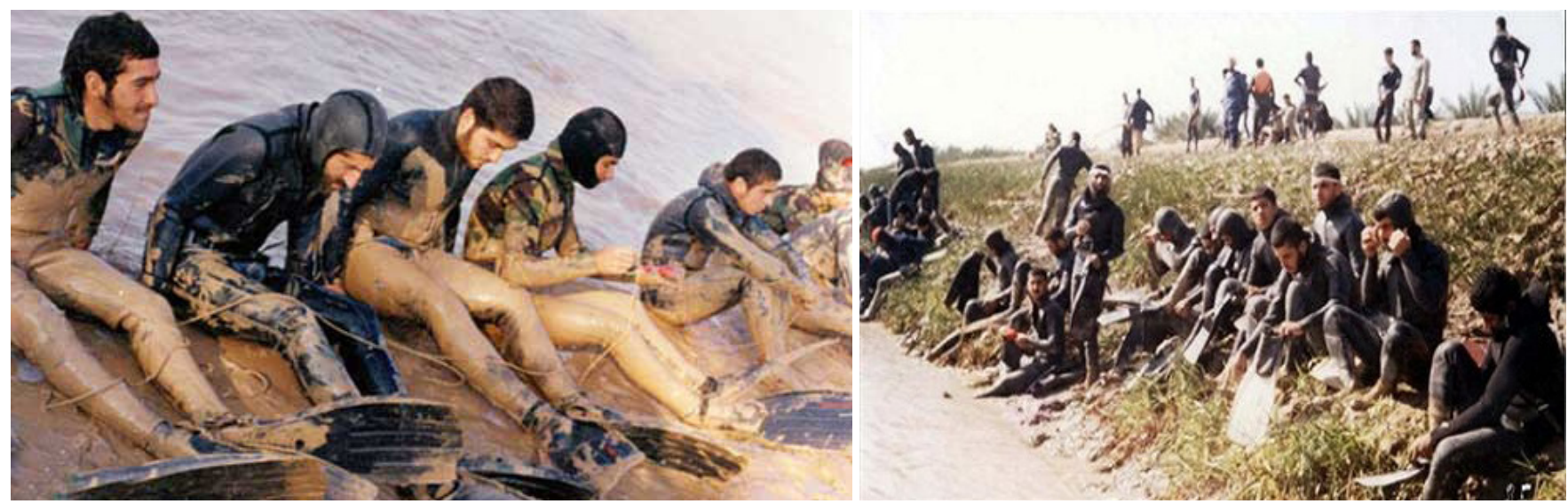

Fig 4.9 Divers preparation for the operation

6 Robert Johnson, The Iran-Iraq War (Houndmills, Basingstoke, Hampshire, New York: Palgrave Macmillan, 2011) 


\subsection{Resurfacing Memories}

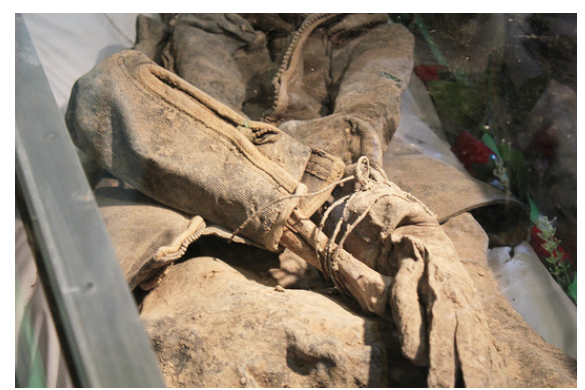

Fig 4.12 Discovery of 175 bodies with their hands tied
In May 2015, the bodies of 175 missing veterans were discovered in Abu Al-Khaseeb in Iraq. The bodies, which displayed no injuries, belonged to the Iranian divers who were allegedly buried alive with their hands tied. The news stirred painful memories of the 8 year Sacred Defense after 28 years. Iranian social media reacted strongly to the news, with people sharing their emotions and feelings. A commemorative event honouring the return of the 175 martyrs took place in Tehran with thousands of Iranians attending this ceremony.

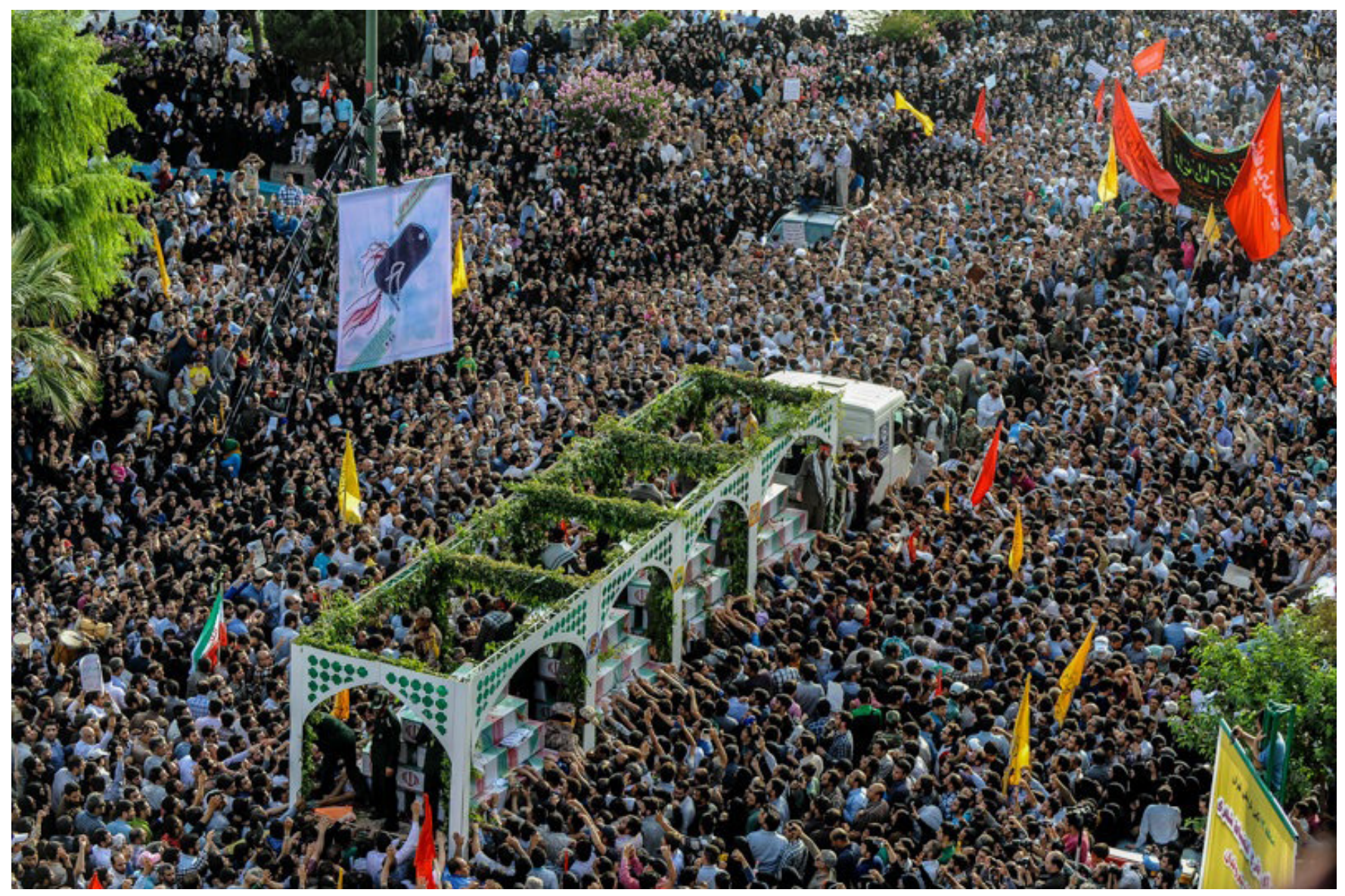

Fig 4.11 Funeral ceremony for the missing 175 martyrs in Tehran 


\subsection{Design Proposal}

In memory of the Sacred Defense and the missing divers as well as acknowledging the several stages of life and death of Khorramshahr, I propose to design a memorial in Khorramshahr on the border between Iran and Iraq, on a site very close to where Operation Karbala 4 was launched. The difficult memories of the suffering during the war need to be remembered as part of Iranian identity. Furthermore, reinterpreting various layers of history and memory in the formation of the city as we know it today can transcend the current condition of urban oblivion.

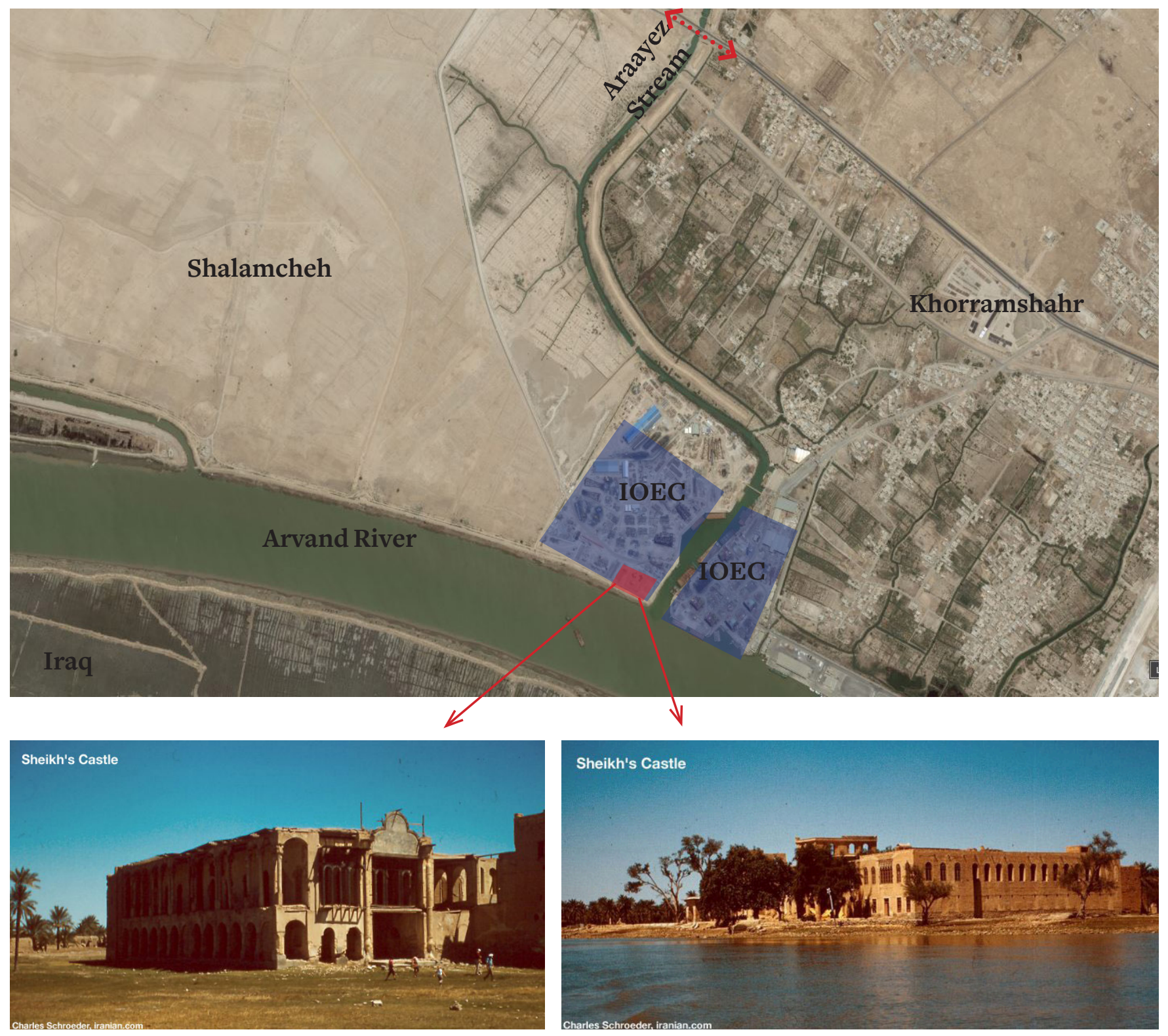

Fig 4.13 The initial proposed site - Sheikh's Palace before demolition 
Initially, the proposed site was located at the intersection of the Arvand River and Araayez stream, which played a major role in Operation Karbala 4. The stream was of great importance during the war as a barrier that prevented Iraqi forces from invading from the west. Also, in Operation Karbala 4, the divers were planning to strategically cross this stream in order to reach Iraq soil. Located on the site was the palace of Sheikh Khaz'al built in 1917 that was demolished by locals in 2012 due to their hostility toward Arabs. However, the possibility of proposing a memorial on this specific site seems difficult; since the site is now considered part of an industrial area belonging to an Iranian offshore engineering and Construction Company responsible for making gas and oil platforms.

An alternative site was proposed. The selected site is located in the southeast of Khorramshahr very close to the river front. Operation Karbala 4 was carried out on a vast region from Minoo Island in the east to Shalamche in the west. The current site is situated in the middle of the axial line of the Operation launching area. Remnants of war still exist in this area such as half-ruined houses and grounded boats.

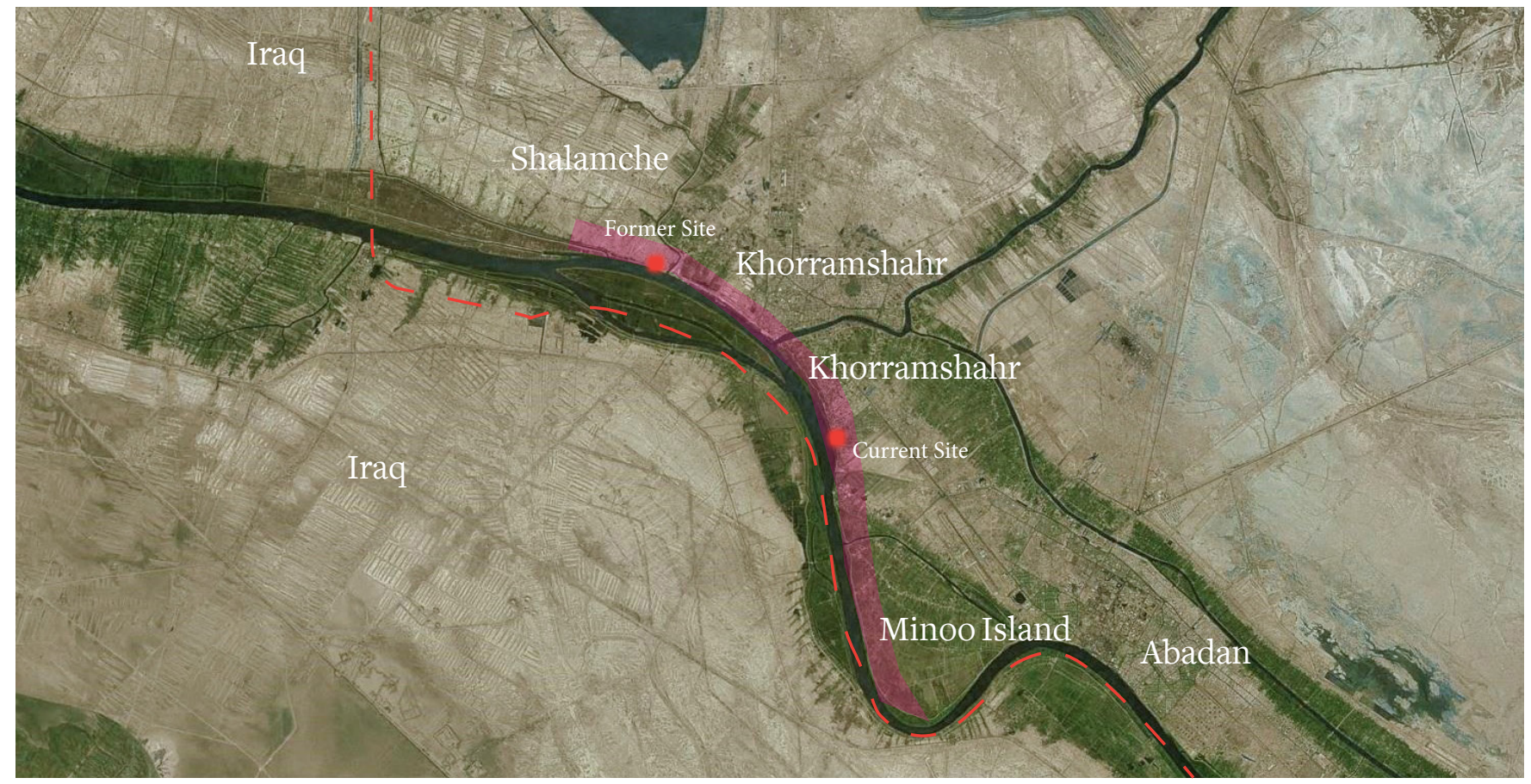

Fig 4.14 The current site is located on the middle of the axial line of the Operation launching area

7 The last Arab ruler of Mohammareh until 1925. 


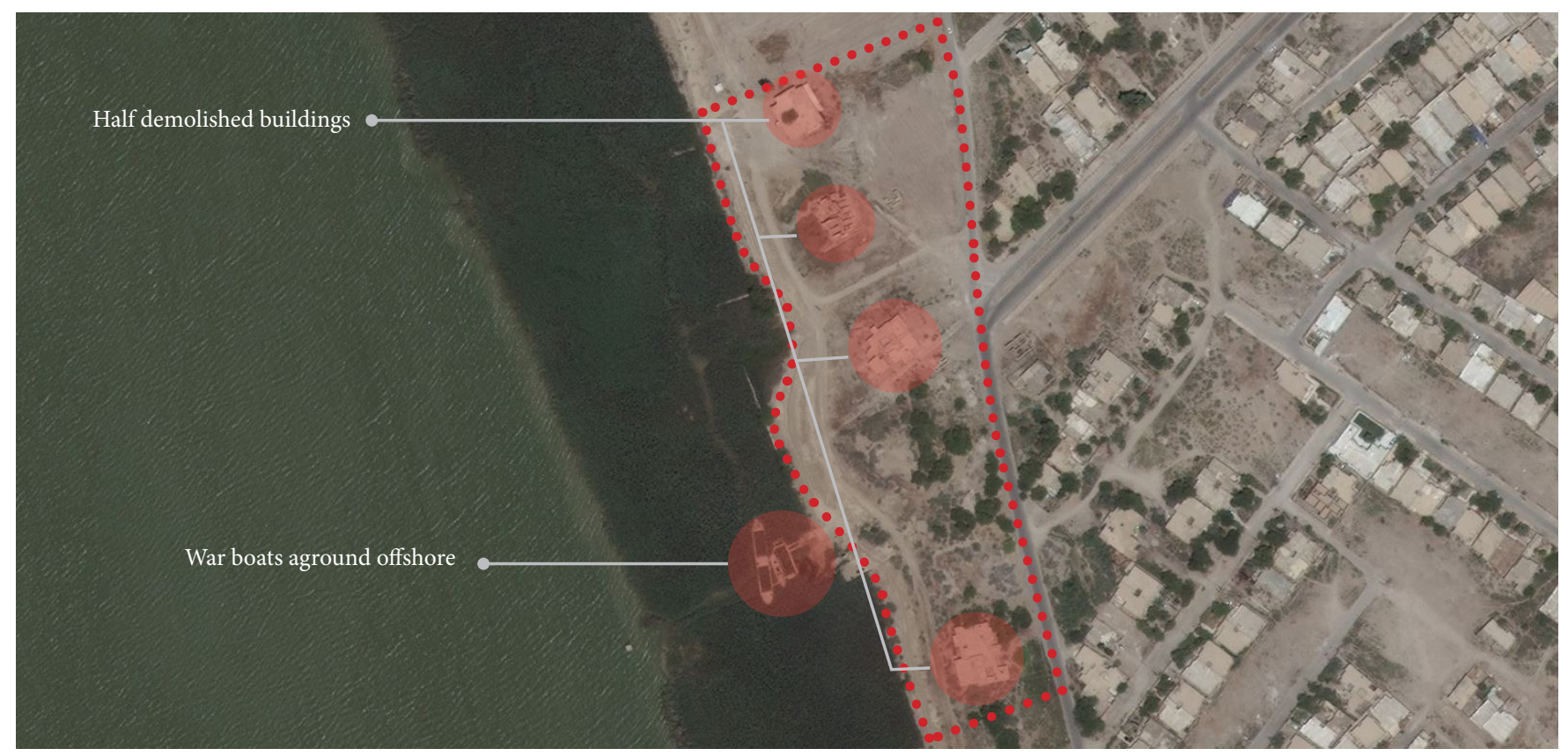

Fig 4.15 A closer look into war remnants on the site

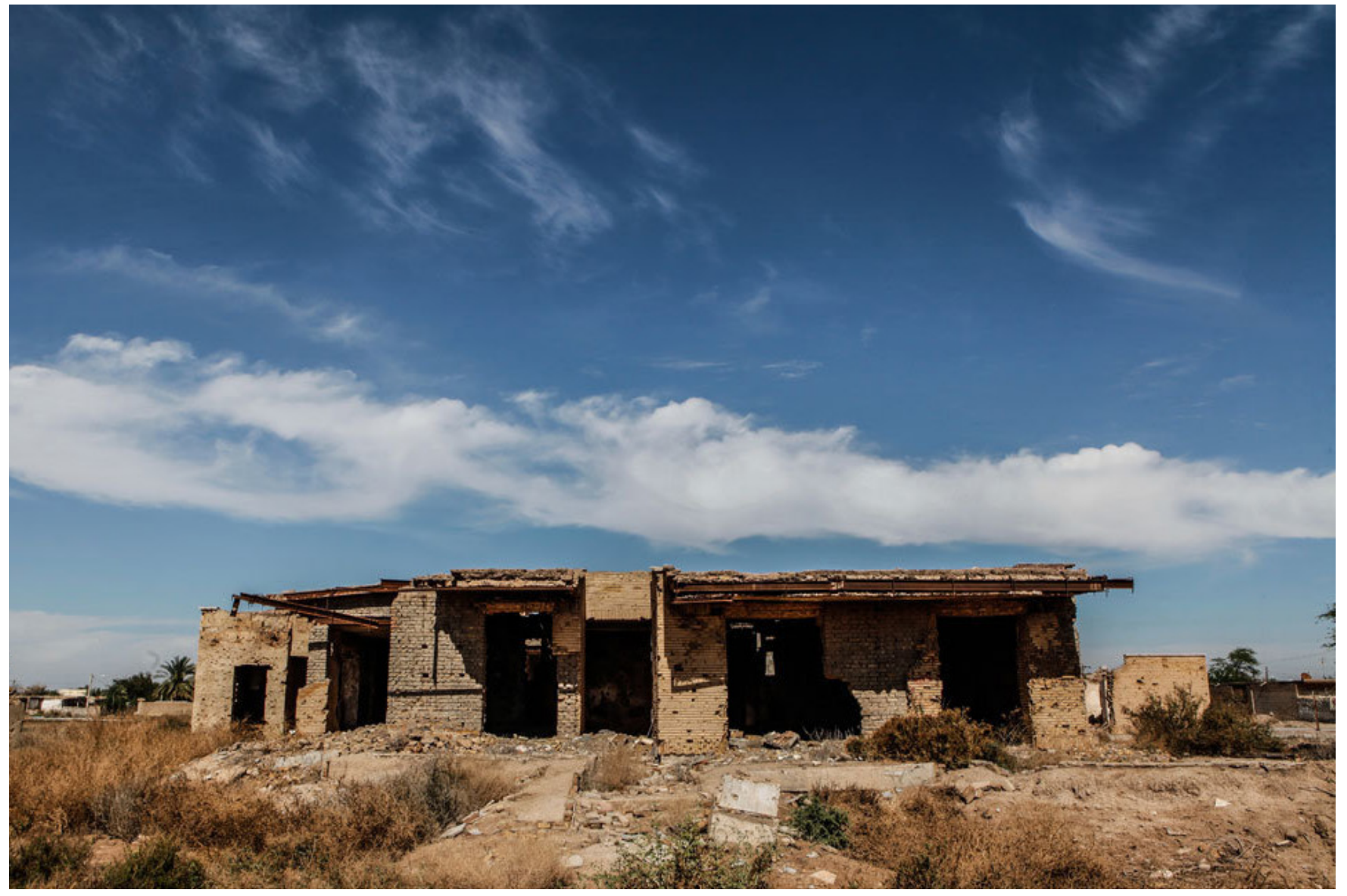

Fig 4.16 Half demolished buildings on site 


\subsection{Passengers of Light}

"Passengers of Light" refers to a large group of religious tours with the aim of visiting battlefields of the Iran-Iraq war in the west and southwest of the country. The group, which is now facilitated by the "Foundation for the Preservation and Publication of the Sacred Defense Values", was formed in 1997 by volunteer veterans and martyrs' family members, gradually gaining more importance with the support of religious authorities. Also, the public embraced the idea of experiencing the battlefield ambiance and traveling as a mark
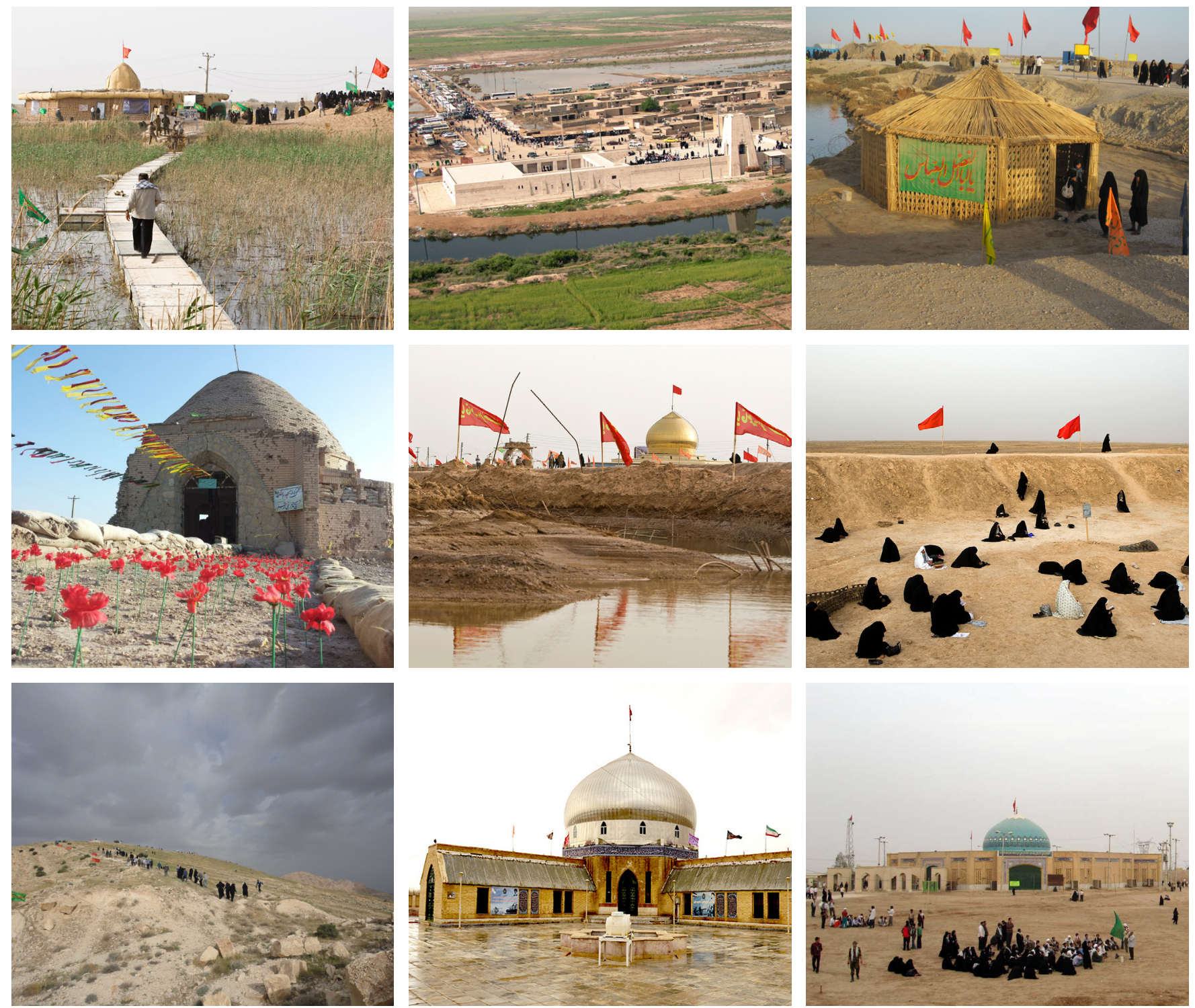

Fig 4.17 Memorials and symbolic markers built all over the west and south-west of Iran on sites of the Iran-Iraq War 
of respect, in order to remember and pay tribute to fellow Iranians who suffered and were martyred in these places during times of war. Each year between 2 to 4 million Iranians travel to visit the often remote places that are not obviously considered as standard tourist attractions.

With increasing popularity among people, especially youths, the Passengers of Light organization began to erect several memorials, mosques, symbolic gateways and signifying elements at different sites as physical markers in addition to war debris that already existed on the sites. At these sites, several veterans and commanders narrate the history of the place, telling the stories of the martyrs' sacrifice and bravery.

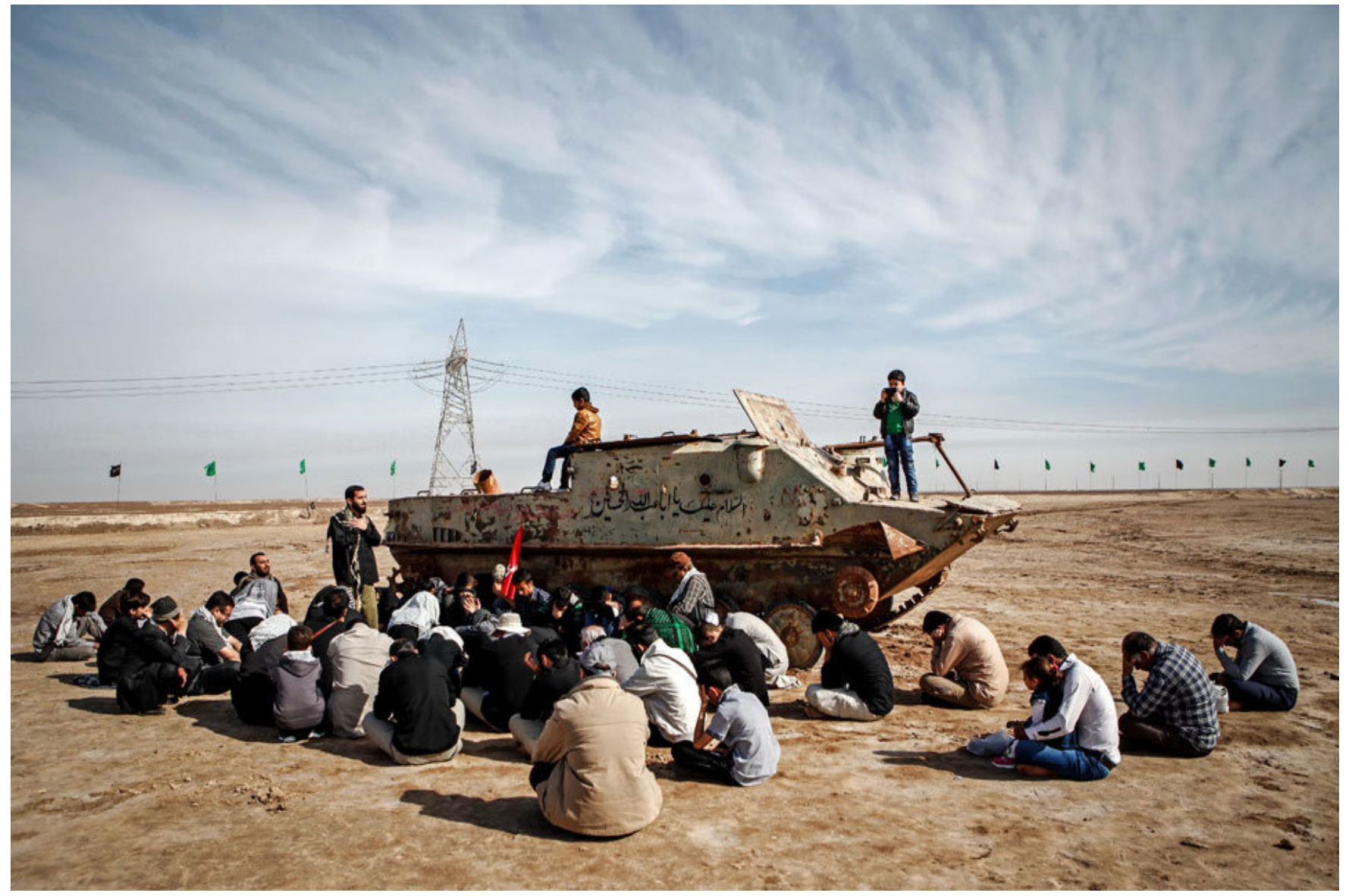

Fig 4.18 Veterans narrating the stories of the war 
The selected site for thesis project, known as "memorial to the martyrs of Alghameh" has recently been added to the Passengers of Light tour out of respect for the martyrs of Operation Karbala 4. A new gateway was built to mark this area, using the slit trench building traditions. The old grounded boats became part of the exhibition and were opened to the public to walk on and experience the space.

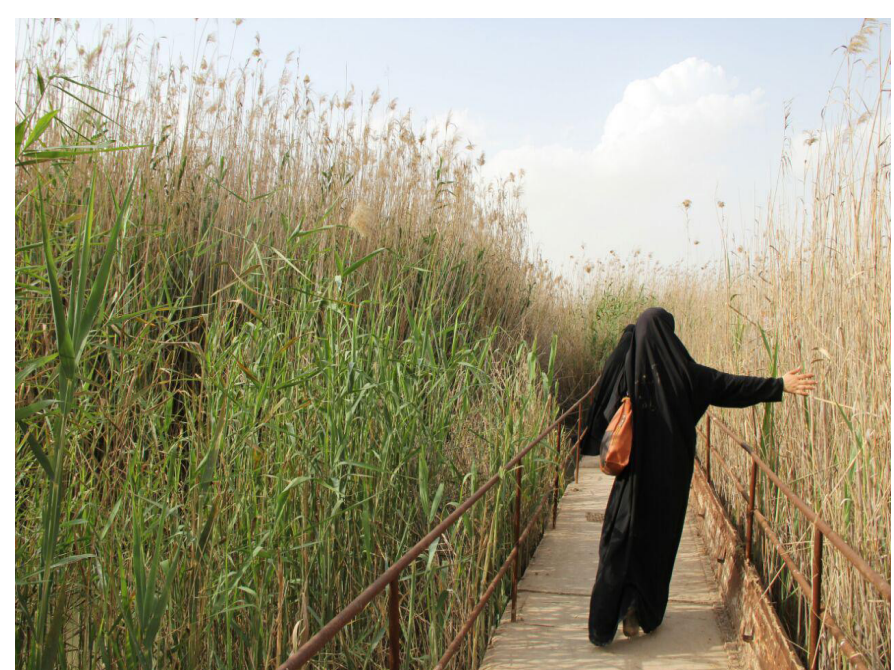

Fig 4.19 Passageway to the riverfront

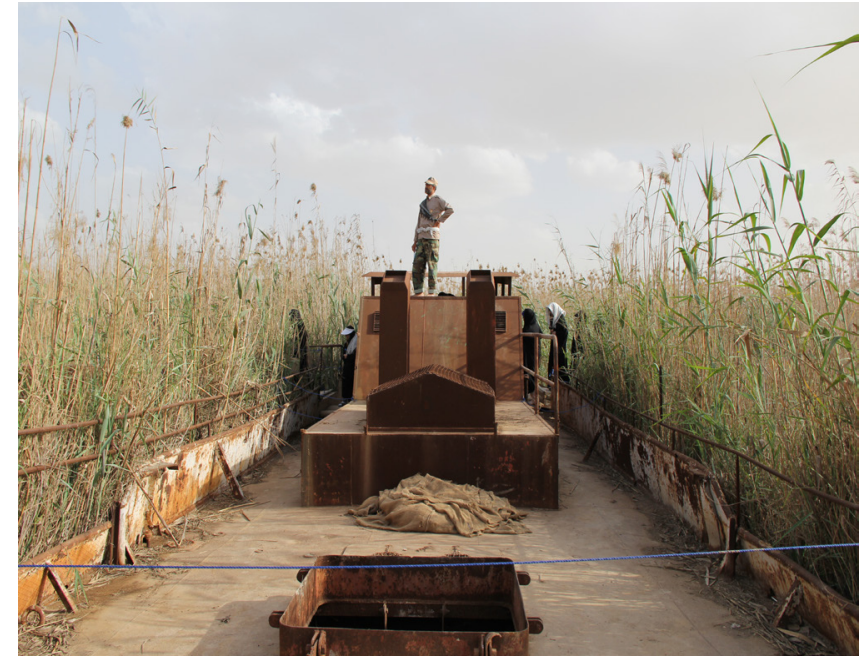

Fig 4.21 Walking on the old boats

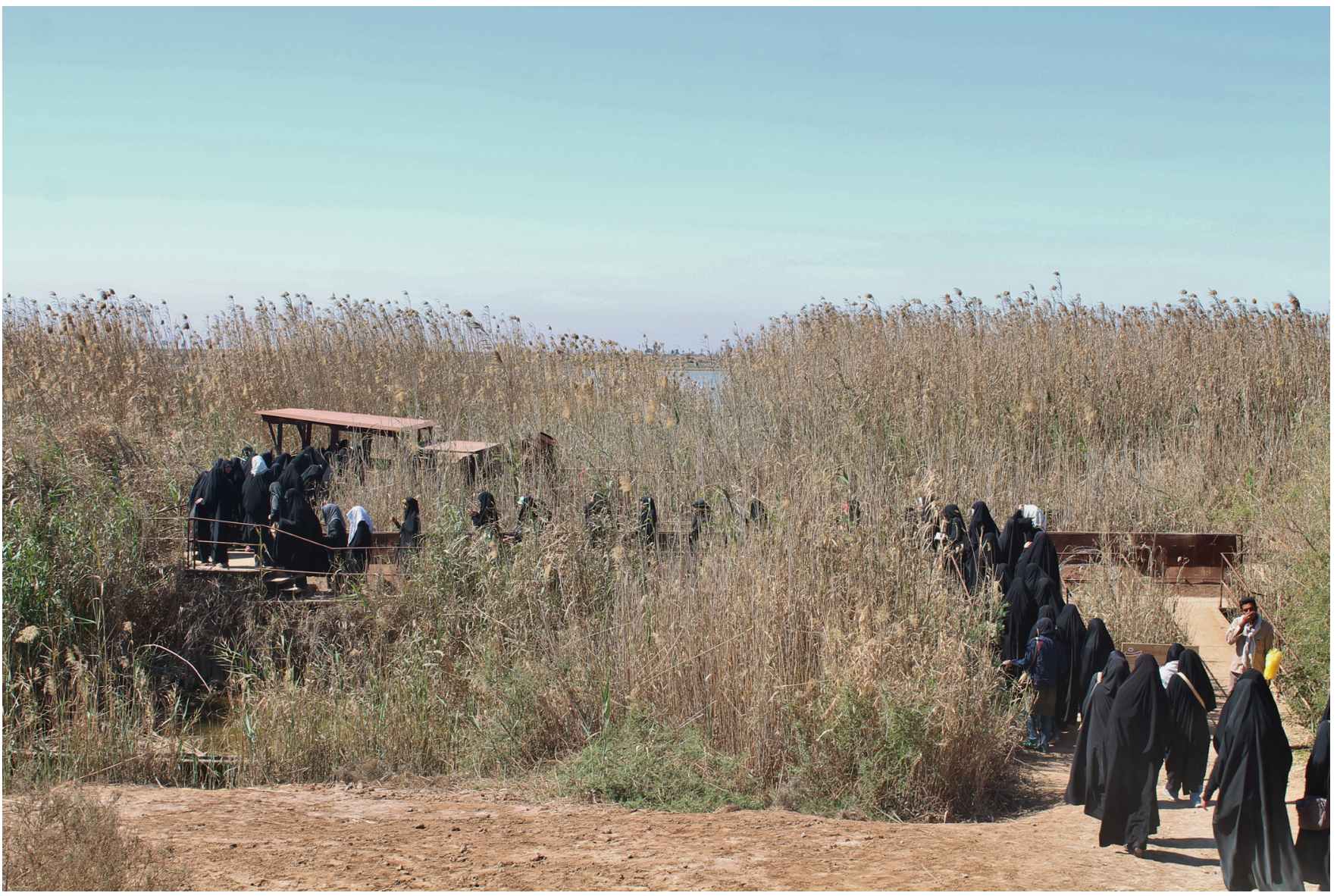

Fig 4.20 Boats aground as part of the exhibition 


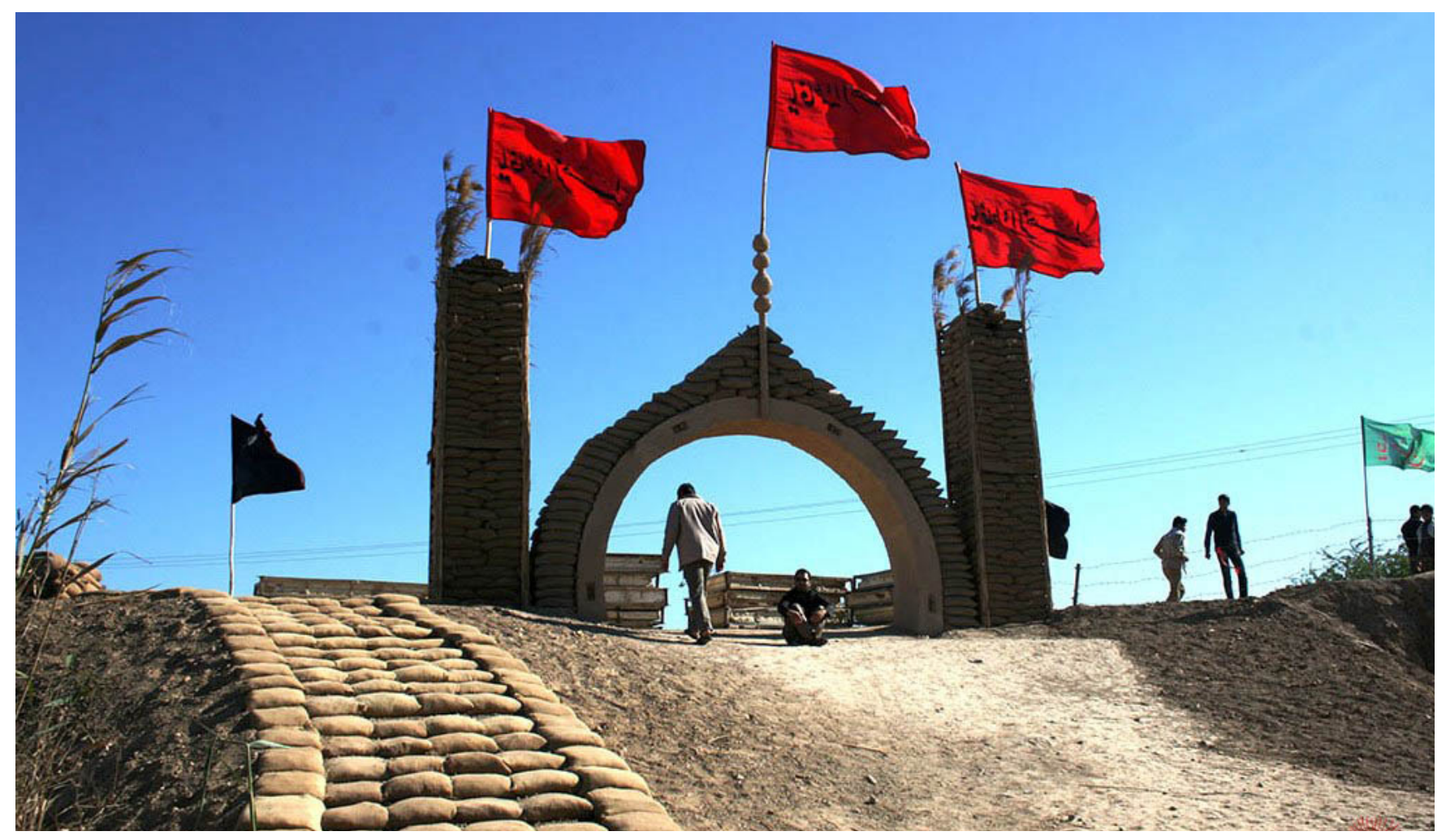

Fig 4.22 The symbolic gateway to the Martyrs of Alghameh Memorial

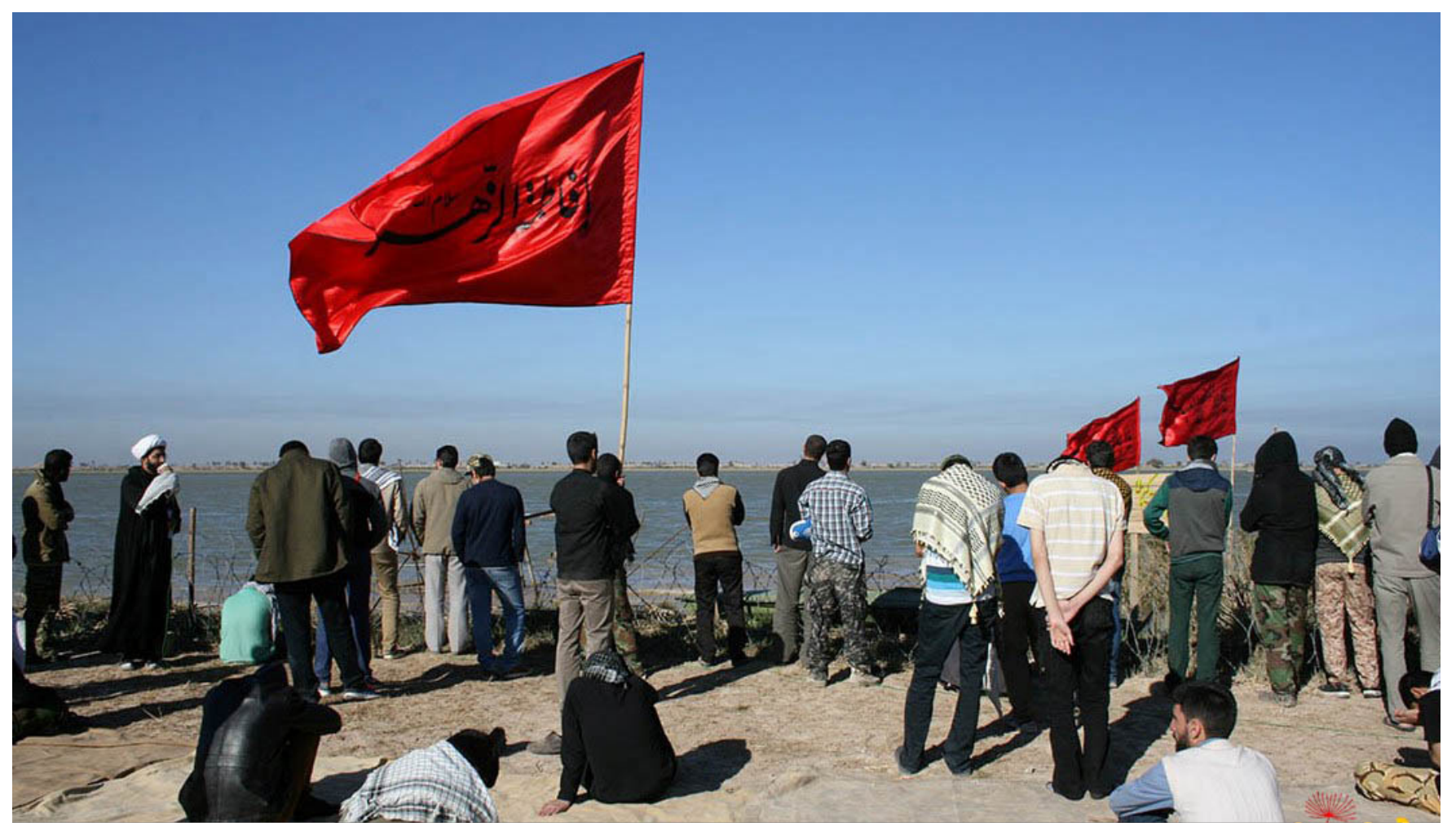

Fig 4.23 Arvand riverfront as a site of mourning and remembrance 
$(3)^{2}$

4h $-x+2=0$

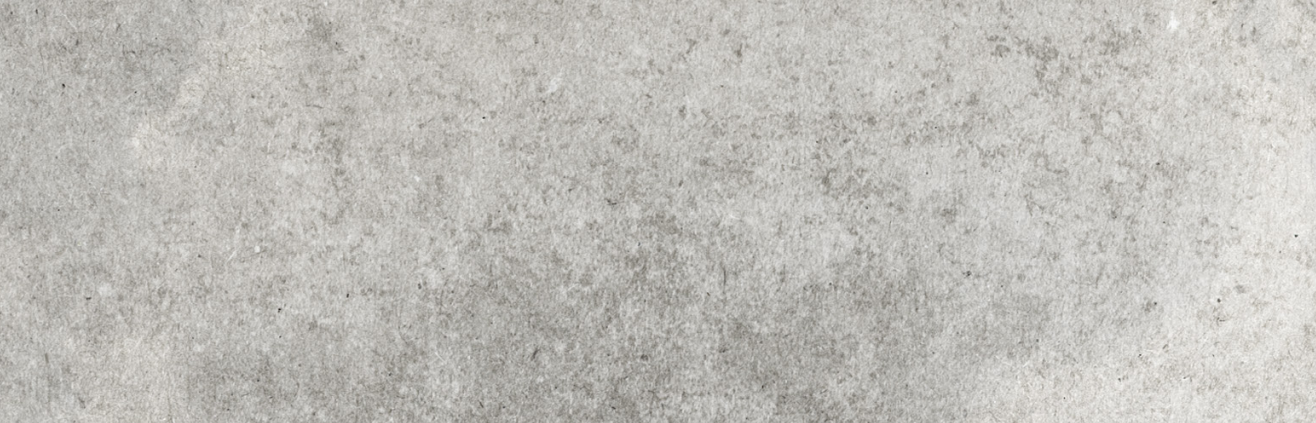

48

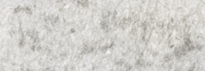

(1) Iin

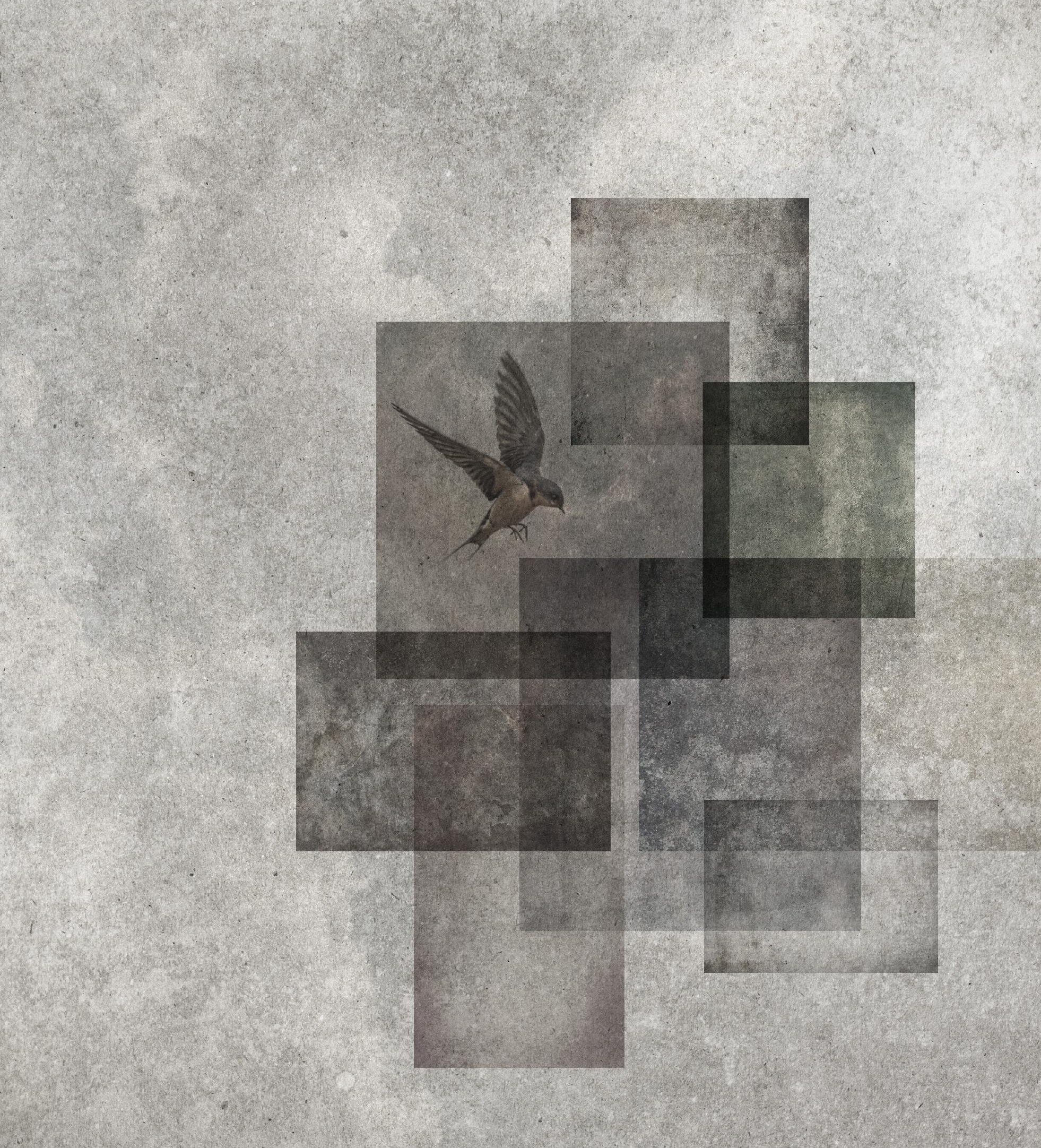




\section{PART FIVE}

\section{A JOURNEY FOR RECOVERY}





\subsection{Design Principles}

"Your eyes have been forever closed.

Seek, because that door is never closed."

Located in a land which has witnessed much bloodshed and devastation throughout its two thousand year history and yet miraculously resurrects out of the ashes, this proposal seeks to create a sensory experience that triggers the memories buried in the contours. With regard to the theoretical foundations discussed in previous chapters, three design principles have been identified in order to develop the thesis project.

\section{Symbolization as Memory}

One of the main purposes of a memorial or monument is to represent the feelings and values of a community for what is being memorialized. These sentiments can be expressed in many various ways at different historical moments in any given society. The chosen form to embody them is conditioned by these attitudes and ideals. Thus, the memorial becomes the symbol of the sentiments of the community. Symbolization lies

1 Farīd a.-D. Atțār and Peter Avery, The Speech of the Birds (Cambridge, U.K.: Islamic Texts Society, 1998), 3330 
at the core of memory, and it is the fundamental component of the life of emotion. Symbols can evoke feelings when they are associated with the cultural values of the social group. In those place where the sentiments are overwhelming and persistent, spatial localization of the memorial symbol is vital for their articulation. Here, symbolization plays a significant role in the healing process. A symbolic site allows for mourning and reflection, providing a place for recognizing our loss, experiencing the pain and starting to heal.

\section{Landscape as Memory}

Storytelling relies heavily on the context and location in which the story has happened. Place facilitates the ability to evoke traumatic incidents, reviving memories triggered by qualities of light, sound, and smell. It is a sense of place that contextualizes memories within a certain spatial framework, offering a groundwork for those who visit memorial sites without having an actual experience of the event to reconstruct imaginative memories. Landscape with all its various layers and textures of memory becomes a site of symbolic representation, encompassing the components that are crucial in constructing and manifesting the identity of the place.

\section{Movement as Memory}

Memories can be materialized spatially and mapped onto the landscape in order to produce new temporal dimensions and juxtapositions. Despite the symbolic character of the architectural expression, it becomes most compelling when it is perceived through a physical experience that engages the body. Creating a meaningful whole from fragmentary memories is facilitated through the movement as a narrative experience. Thus, the movement-related narratives regarded as "ritual processions" ensure the persistence of such historical landscapes as a repository of cultural memory. ${ }^{2}$ Pilgrimage as

2 Amy Russell, "Memory and Movement in the Roman Fora from Antiquity to Metro C," Journal of the Society of Architectural Historians 73, no. 4 (2014) 
a ritual performance with its transformative qualities provides visitors with a symbolic order in which a collective narrative can be created, establishing a shared identity. As such, journeying is redefined as a cultural performance to give the lingering memories meaning and thus to lay the foundation for the healing process.

The project, stemming from these principles, entails a journey within a journey that occurs in the broader context of the Passengers of Light Pilgrimage, seeking to symbolically materialize the journey of all the martyrs of the Sacred Defense, particularly the missing divers of Operation Karbala 4. The proposal aims to reframe the notion of martyrdom with its persistent resonance and ancient history in Iran, establishing it as a spiritual journey towards Divinity in order to meaningfully articulate the memories of a tragic past. The fundamental aspect of the proposal lies in its intention to narrate the memories of Operation Karbala 4 in light of a poetic manifestation of the phenomenon of martyrdom. 


\subsection{Context}

The area known as the "Memorial to the Martyrs of Alghameh" in Khorramshahr is very close to the Iran-Iraq border. The significance of this area is rooted in its involvement in Operation Karbala 4 and it is one of the main launching points of the offensive. The site is also a part of the Passengers of Light tour with old grounded boats and a few half-demolished houses as physical reminders of war. Located in a residential neighborhood, the selected site is roughly $3 \mathrm{~km}$ away from the city's core district along the edges of the Karoun River, and it is usually accessed by the Passengers of Light tour buses or private cars.

Khorramshahr has mild, short winters and long, hot summers with a maximum temperature of $55^{\circ} \mathrm{C}$. There is a limited amount of plant material on the site. However, a vast marsh exists along the edge of the Arvand River that has gradually covered the grounded boats over the years following the war, forming a transitional landscape between the arid terrain and the river.

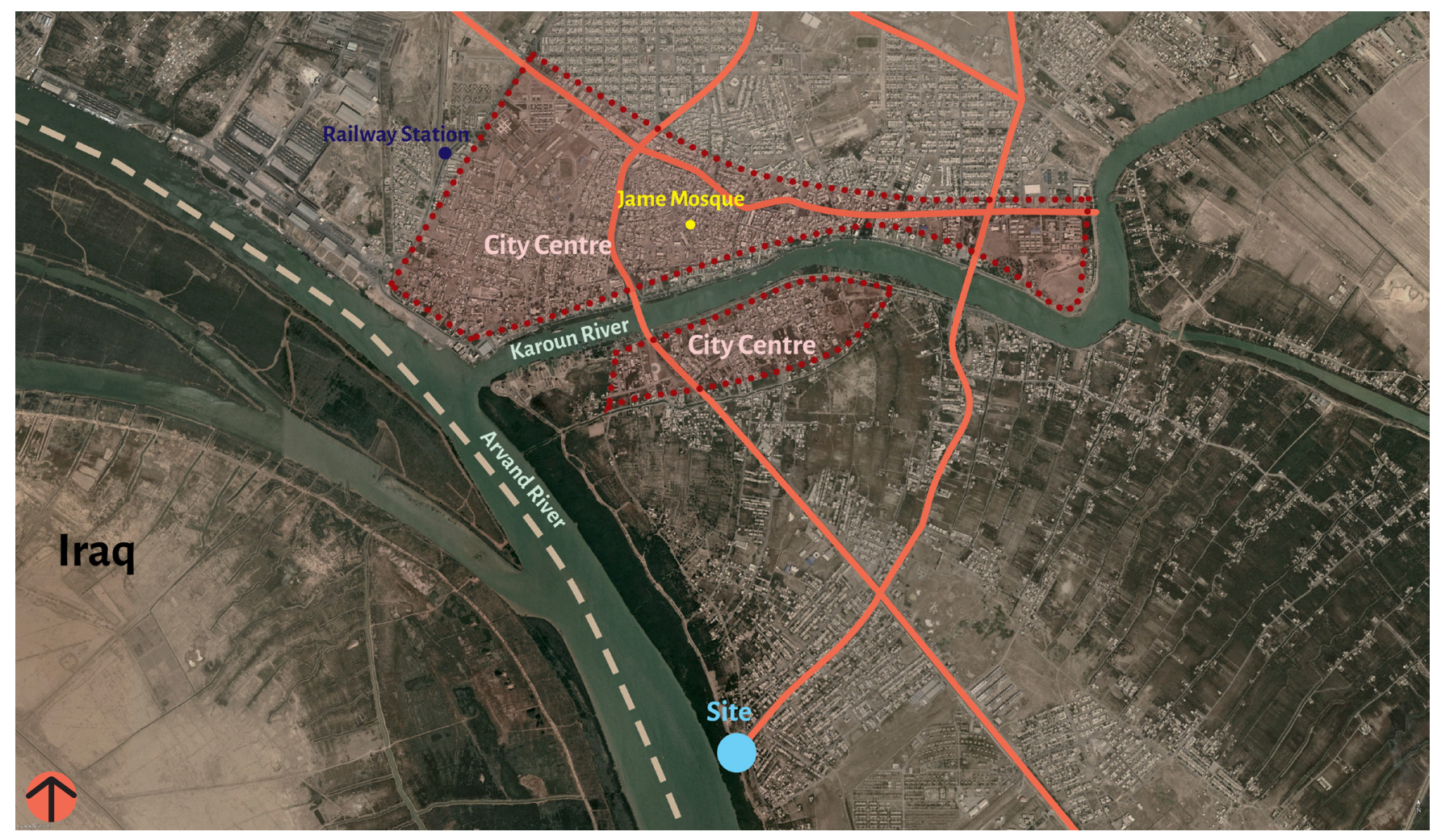

Fig 5.4 The position of proposed site in Khorramshahr city 


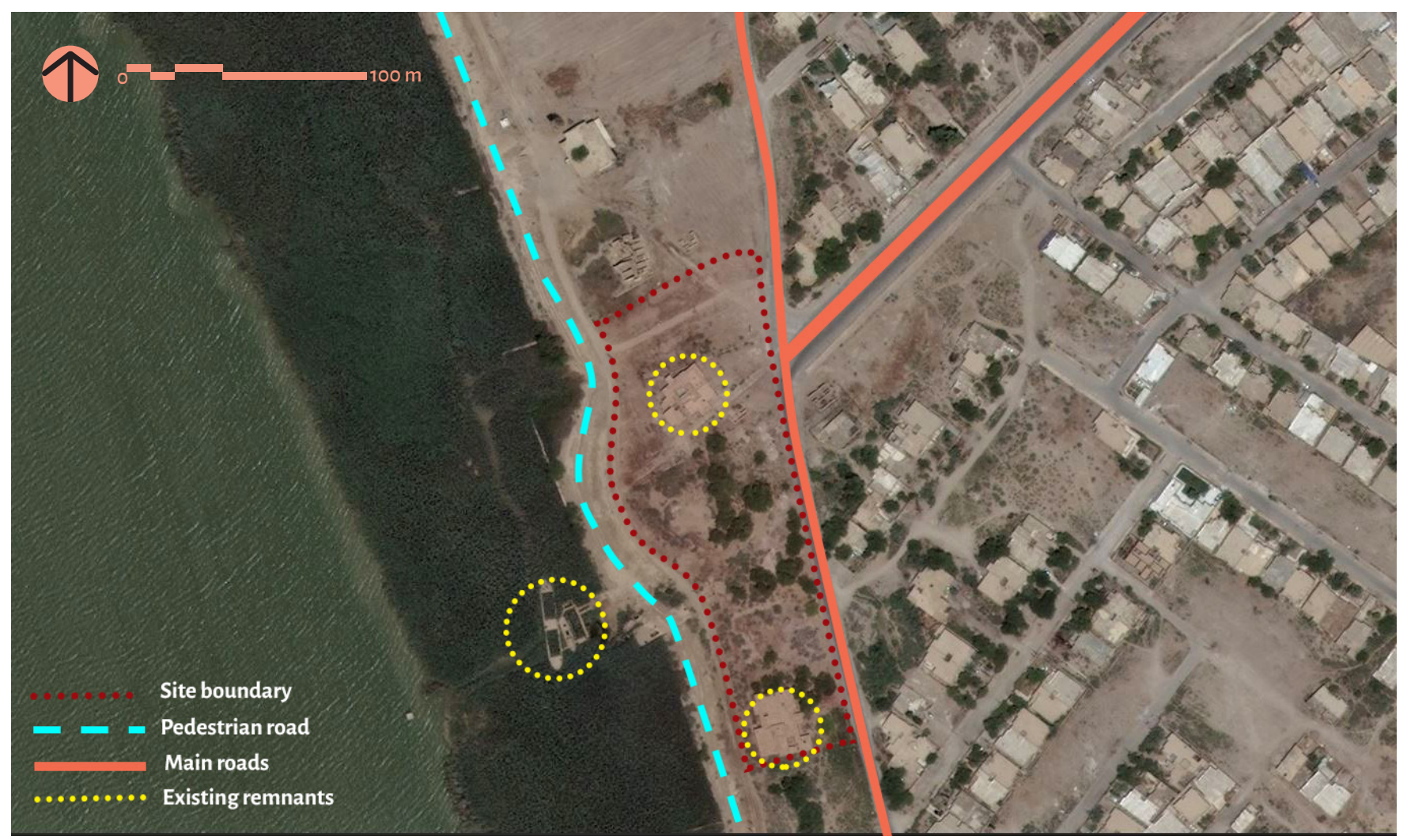

Fig 5.5 The existing condition of the site

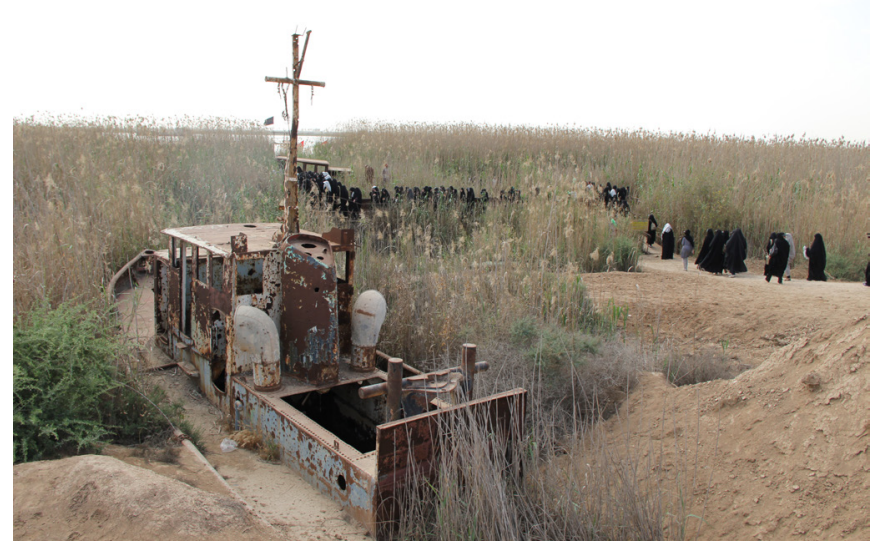

Fig 5.6 Boats aground hidden in marshland

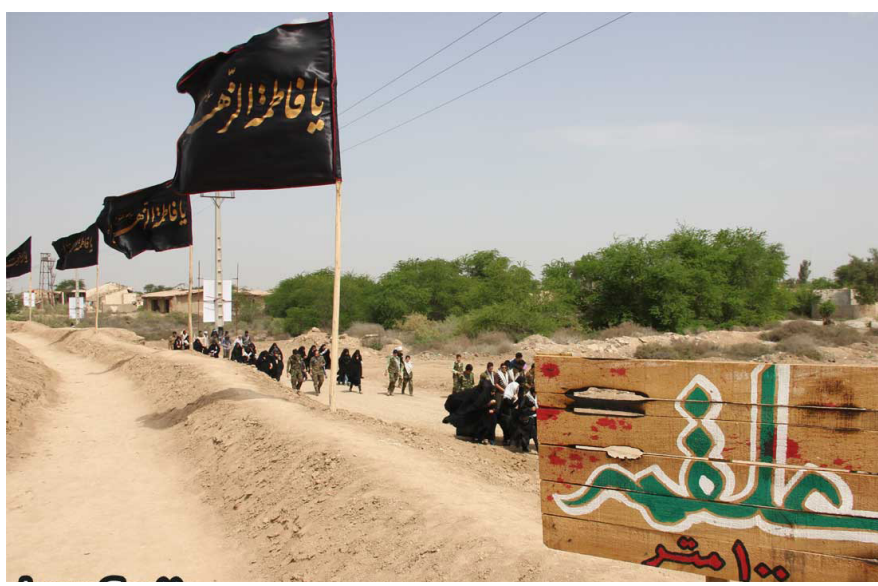

Fig 5.7 The pedestrian route along the edge of marshland on the left 


\subsection{Architectural Expression}

The proposed architecture intends to perform on three levels. Primarily, it analogizes the suffering of the martyred divers through a spatial journey of contemplation. Also, it serves didactic purposes by providing visitors with educational resources and historical archives to build a hopeful insight into the future. Furthermore, as part of the Passengers of Light tour, it acts as a staging point for the pilgrims during the whole battlefield tour. Thus, the project can be seen as a memorial/museum/pilgrimage center.

The specific orientation of the building on the site responds according to climatic considerations as well as the existing war remnants of the place. With regard to Khorramshahr's latitude and the sun direction during the summer and winter, it is preferable to locate the main axis of the building on a north-south axis rotated $15^{\circ}$ to the west. ${ }^{3}$ The other axis directs toward the Arvand river and the grounded boats, facing Iraq on the other side of the border. Inspired by the ancient tradition of the Persian garden, the design embodies an earthly paradise in a desert, speaking to the persistent tension between life and death. Also, the multiplicity of the gardens refers to the successive destruction and rebirth of Khorramshahr throughout history.

The project is comprised of three main components: an outdoor "journey" in a rectangular garden bounded by a series of walls, the interior exhibitions in an elongated rectangle, and the educational section and ancillary spaces wrapped around a courtyard. Another courtyard is used to form the transition between the first garden and the other two components. In addition, a stepped garden is extended along the elongated bar as a transition between the endpoint of the exhibitions and the arrival point.

In an attempt to add a landmark to the whole complex, a third axis was added, facing toward Mecca (Qibla), that indicates the association of the journey through the building with Divinity.

3 Morteza Kasmaei, Architecture and Climate in Khouzestan- Khorramshahr (Tehran: Road, Housing \& Urban Development Research Center, 1991) 


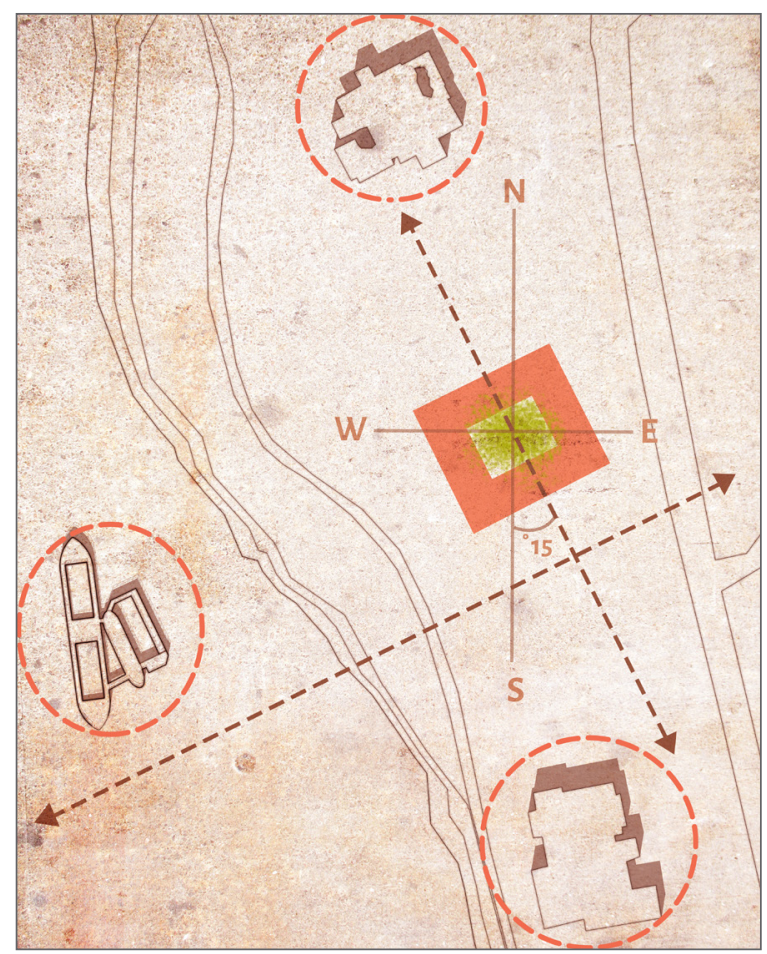

Fig 5.8 Orientation of the building on site

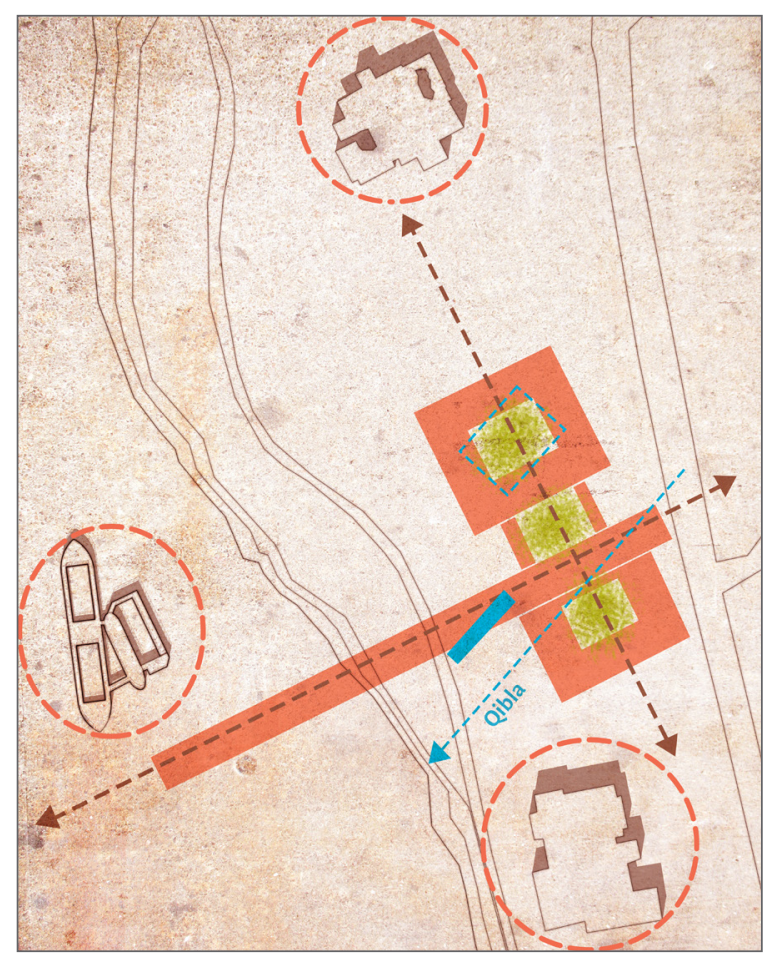

Fig 5.10 Third axis facing toward Mecca (Qibla)

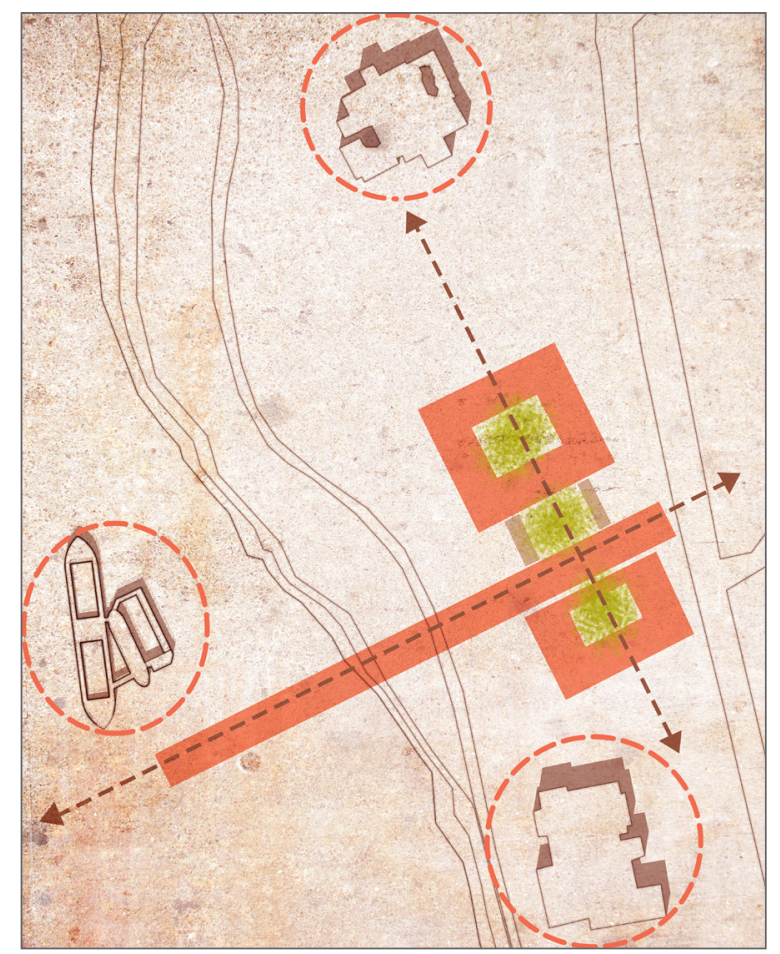

Fig 5.9 Three main components of the building

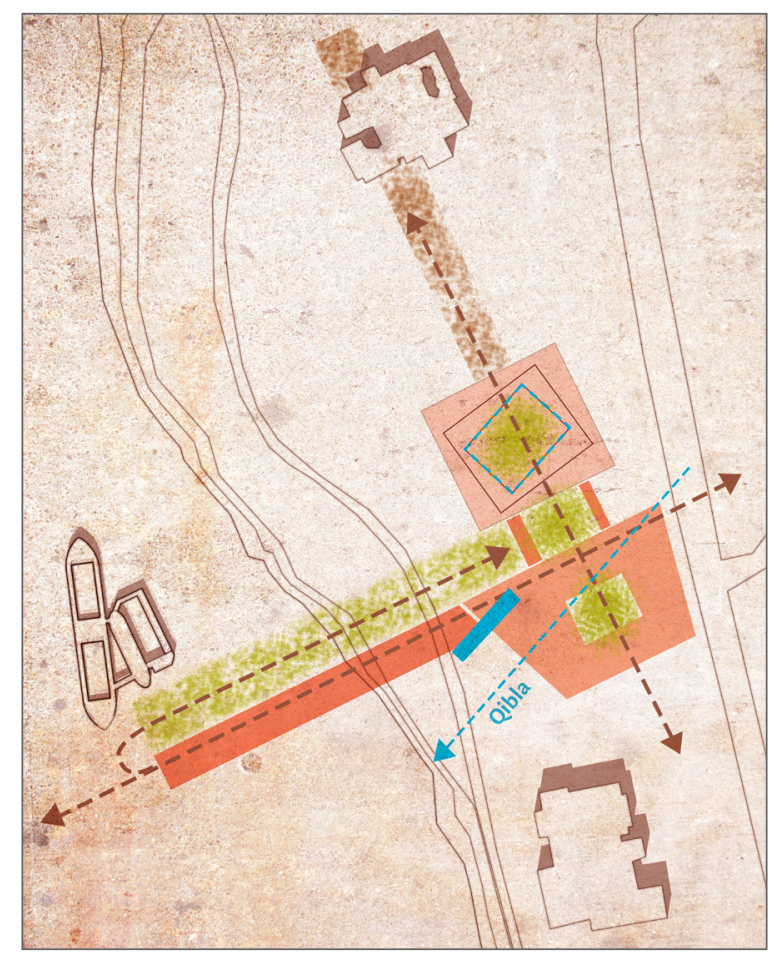

Fig 5.11 The final iteration of design 


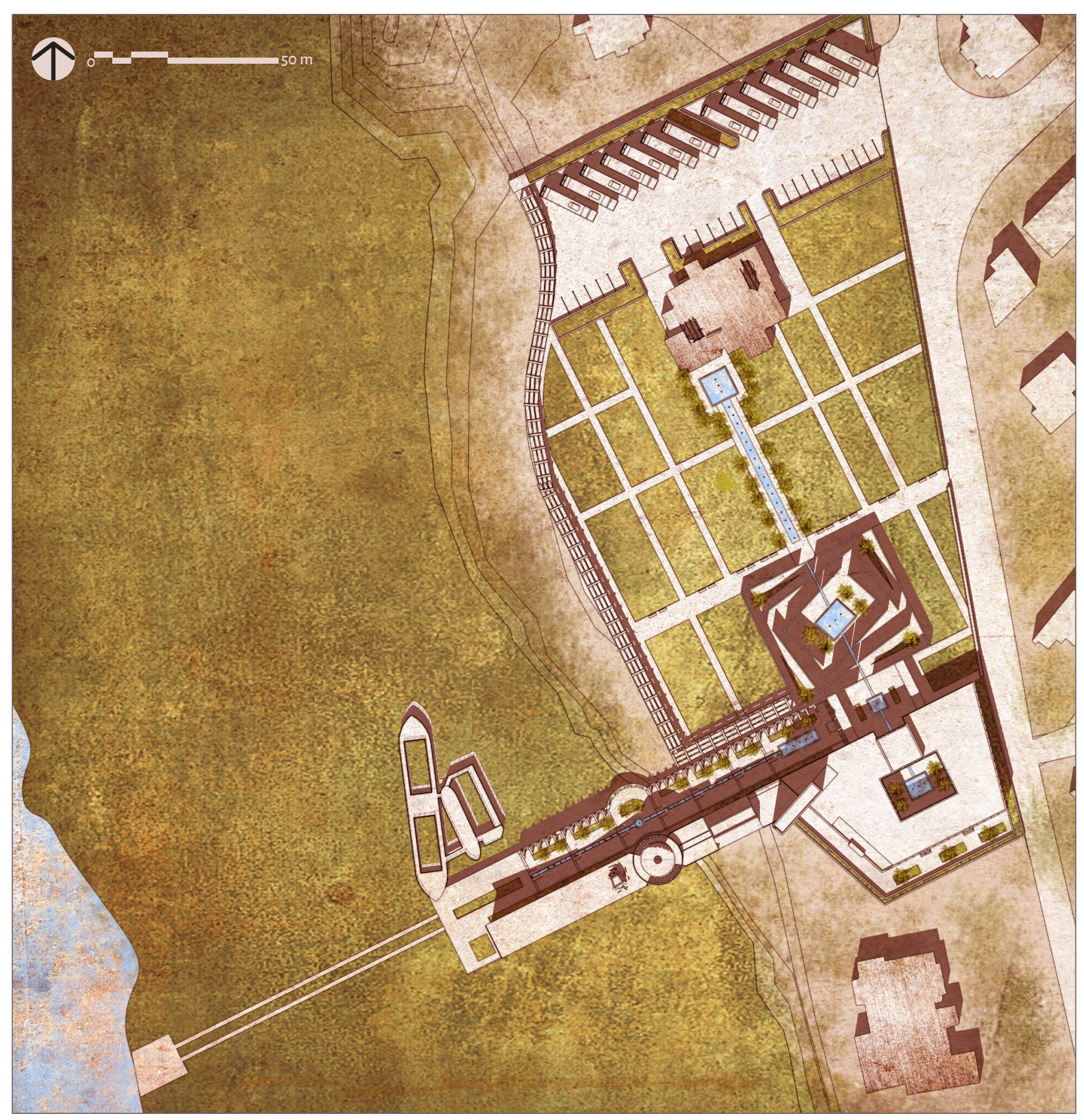

Fig 5.12 Site Plan 


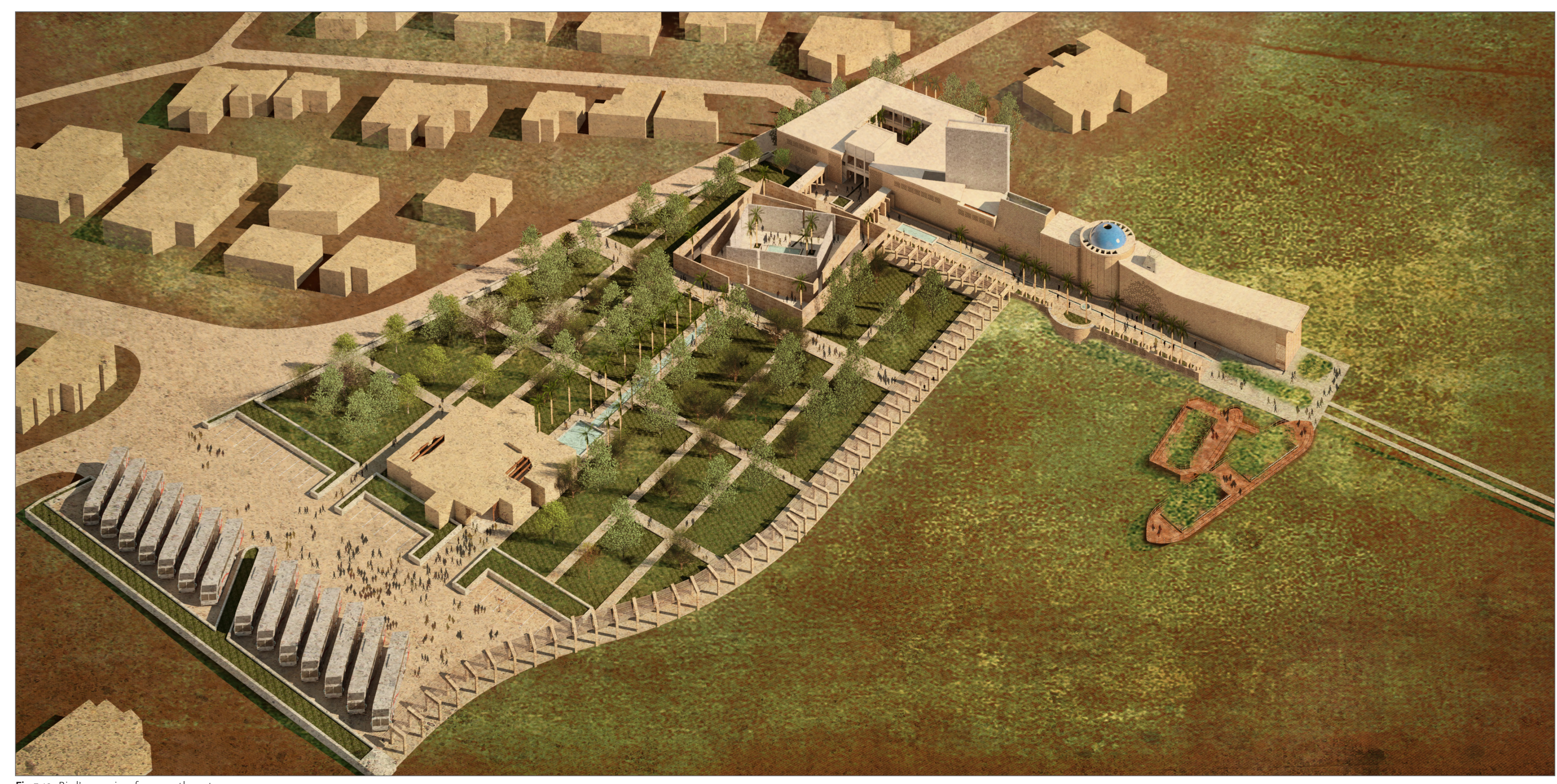




\section{Programmatic Elements}

The exhibitions are housed on one level in an elongated bar which is connected to the two-storey educational section. The exhibitions are divided into seven chambers, each characterized by certain architectural qualities according to their narrative. The entrance to the main exhibitions occurs at the ground floor, and visitors gradually descend into the ground. The educational spaces and the exhibition spaces were intended to have separate access points so that the activities of these spaces do not interfere with each other. Inspired by traditional Persian houses, all the spaces in the educational component of the building face an inner courtyard, establishing a strong connection with the courtyard as the heart of the building. Also, the circulation in the building primarily consists of external stairs and shaded terraces to further reinforce the significance of this relationship.

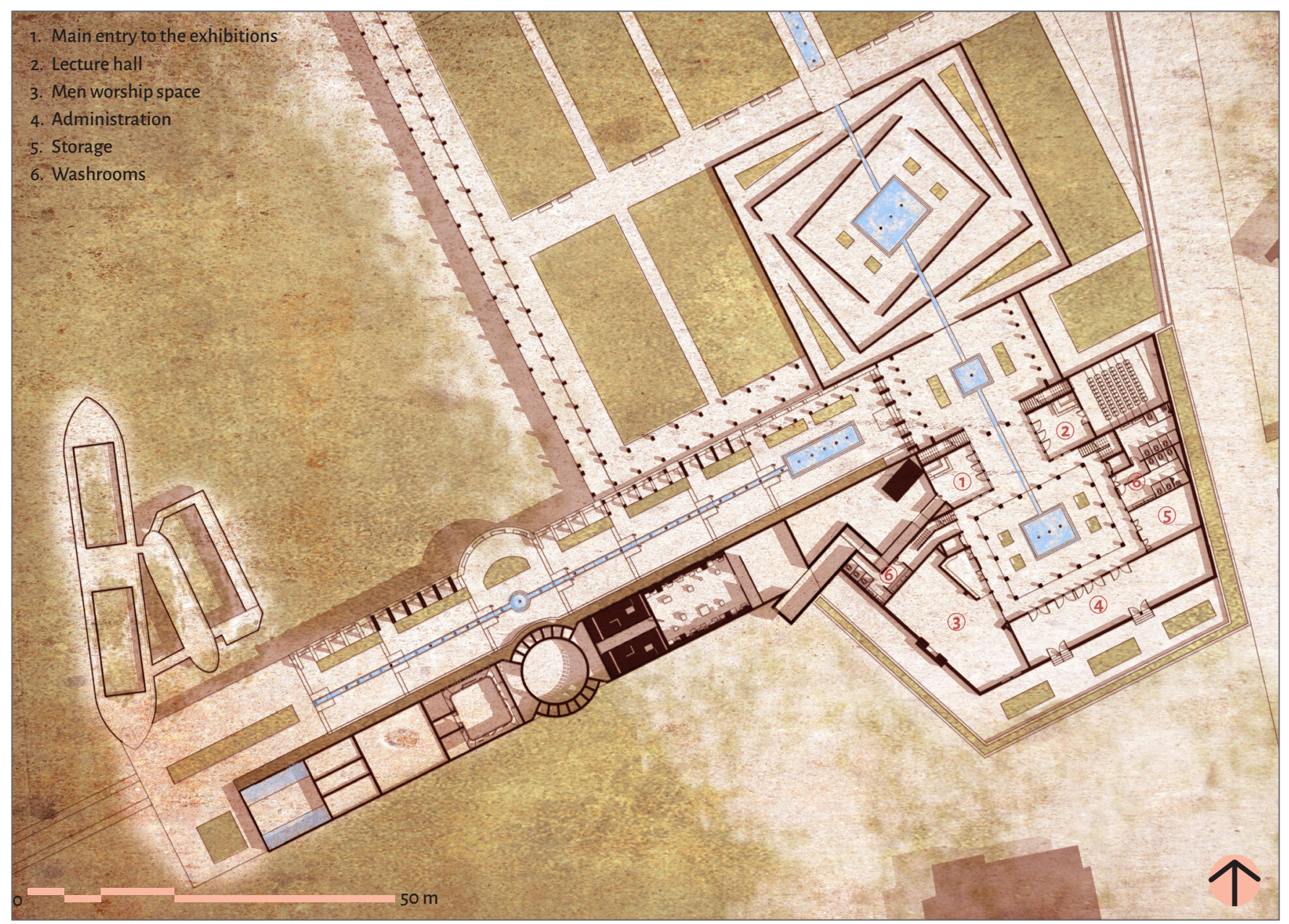

Fig 5.14 Ground Floor Plan 


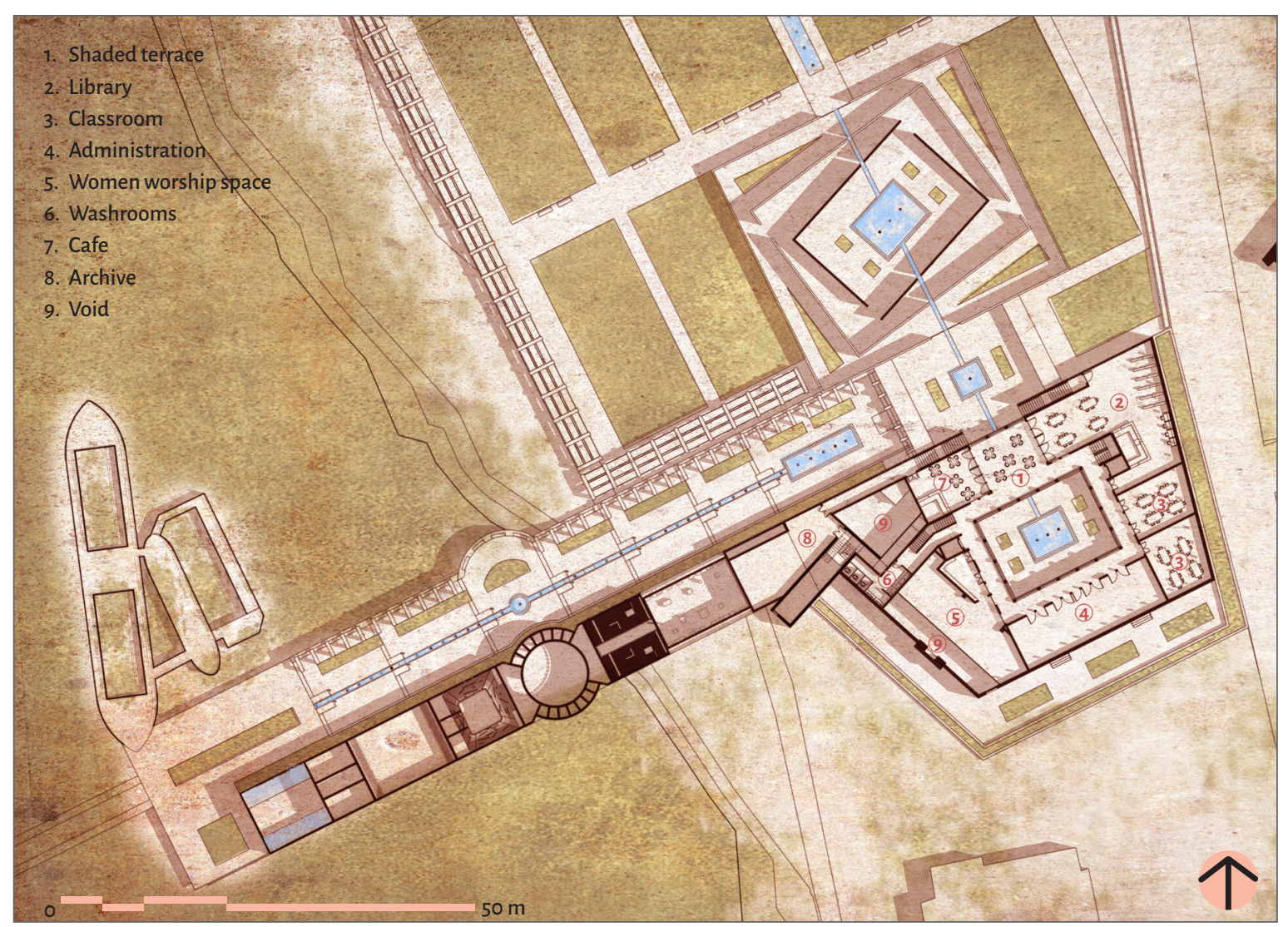

Fig 5.15 First Floor Plan

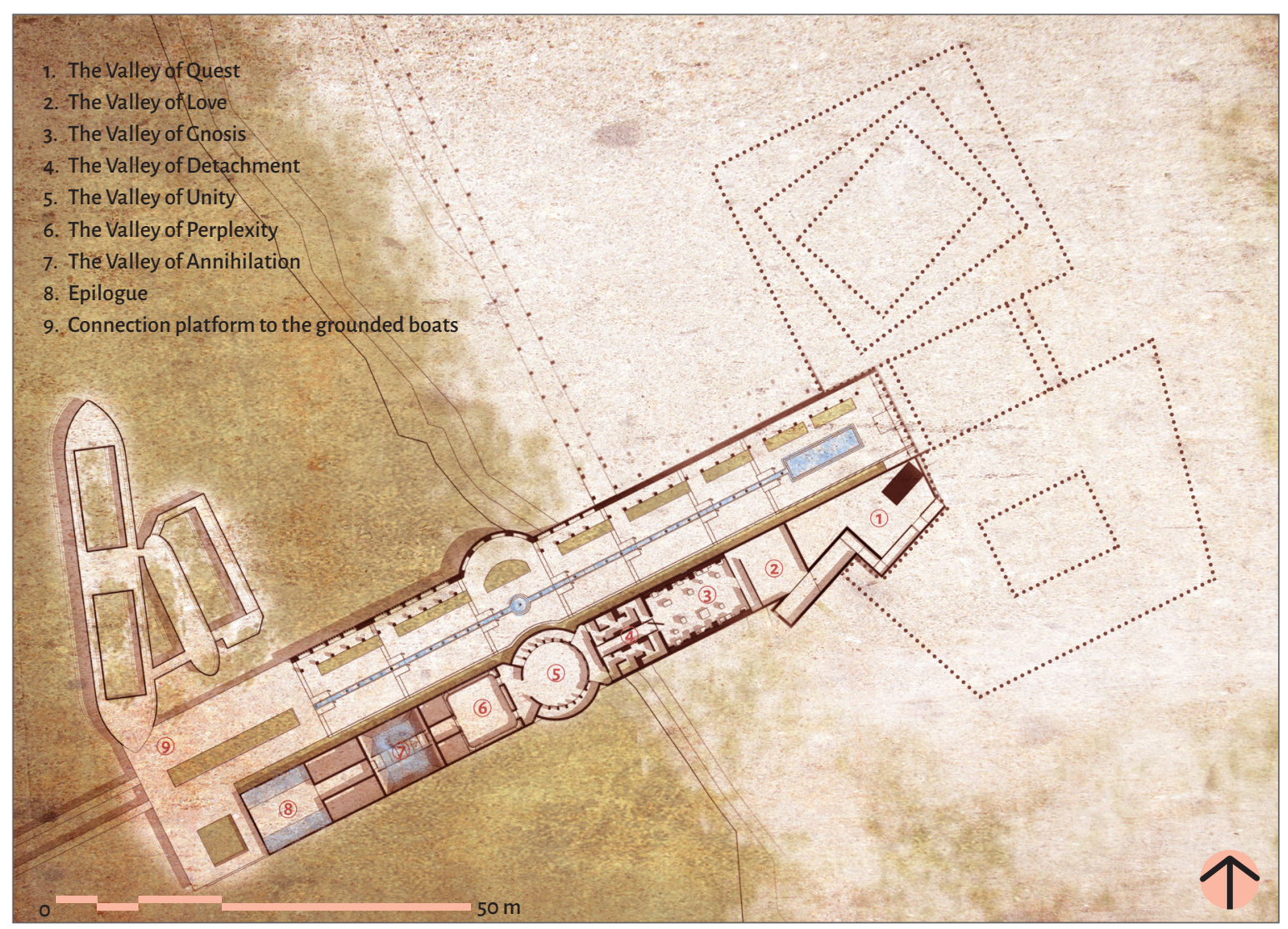

Fig 5.16 Lower Level Plan 


\subsection{Climatic Considerations}

Learning from the old fabric of Khorramshahr, the design attempts to respond to the specific climatic context and cultural identity. Several practical, invisible technologies are implemented to create a sustainable and culturally determined environment. The orientation of the building on the site is primarily conditioned by the sun path and the prevailing sea breezes in Khorramshahr, directed toward north-south axis $15^{\circ}$ to the west with its longest dimension facing the south. Thus, the amount of heat gain in the west and east walls is minimized. Planting trees to the east and west boundary of the building also helps reduce the interior temperature.

The design entails several courtyards with central ponds, emphasizing the role of water as a practical response to the hot climate. The courtyards contain trees and plants to provide shade and create a peaceful space for contemplation. There is a limited number of openings on the outward facades in order to prevent heat absorption while also channeling winds to cool the inside. Instead, all the interior spaces are opened to the courtyard and the shaded terraces on the first floor allowing for cross ventilation. Terraces with deep overhangs and shutters are designed in a way that offers passive cooling.

In terms of materiality, light brown brick is predominantly used in the design, reminiscent of the traditional local architecture of Khorramshahr. In addition to the energy efficiency of brick in such a climate, it allows for various sorts of brickwork patterns and adorned walls which contribute to cross ventilation or creating temperature variations on facades. Wooden doors and windows are used instead of metal door/windows, again preventing excessive heat gain and heat loss.

The brick is contrasted by beige stucco for the educational and ancillary spaces. This formal gesture accentuates the distinction between the two components of the building. The tower and the inner walls of the maze which both face the Qibla are built of the same 
distinguished material to emphasize their association with the Divine. Courtyards are paved with light brown mosaic tiles so that the surface absorbs less heat.

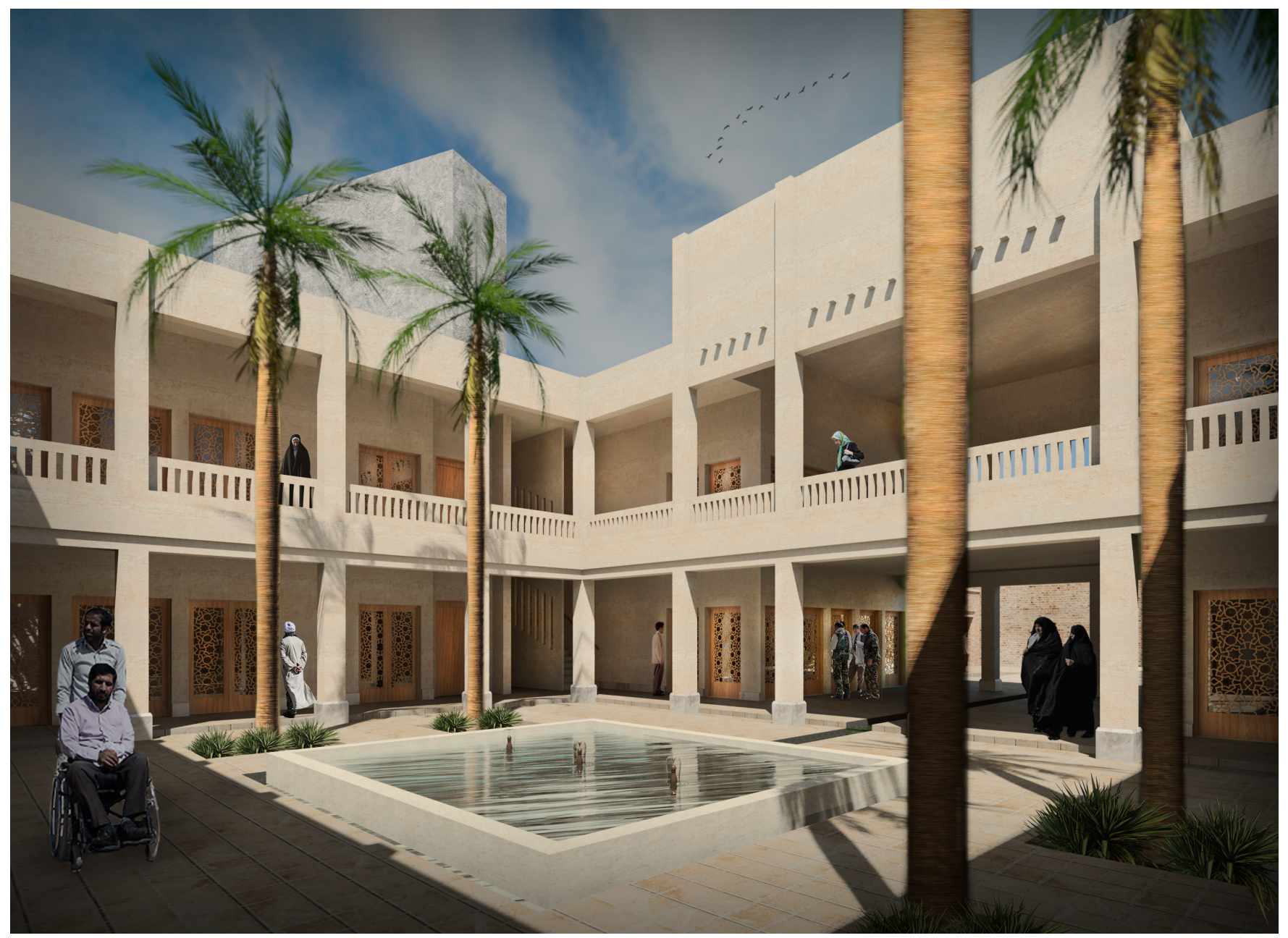

Fig 5.17 Inward looking building with terraces with overhang and wooden shutters 


\subsection{Spatial Sequence and Procession}

The memorial museum is spatially characterized by various phases of movement. Procession from the arrival point to the building is deliberately prolonged to give visitors enough time to disconnect from the outside world. The remnants of the war along the passage act as an entry point and a transition from devastation and loss to restoration and life.

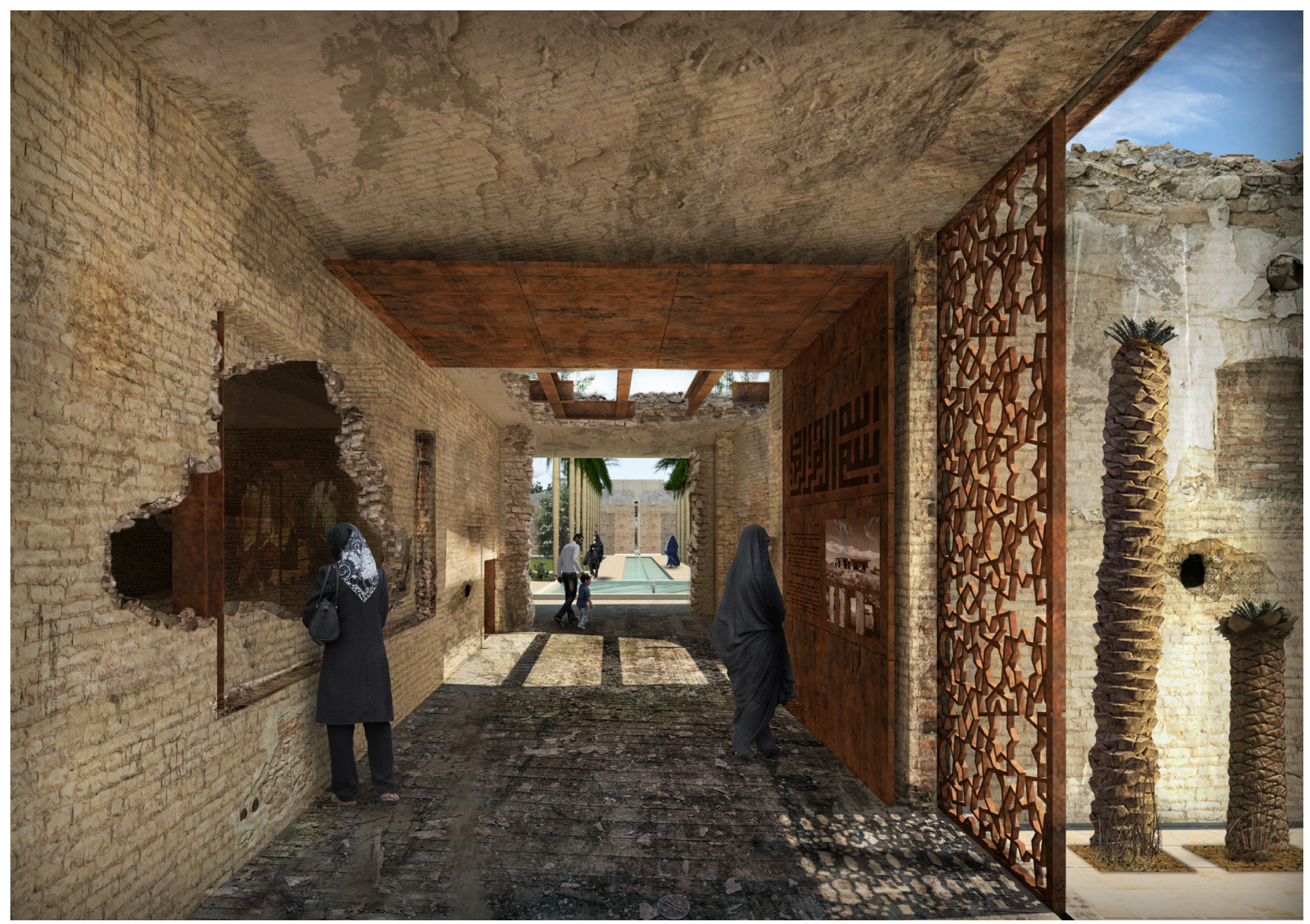

Fig 5.18 Arrival point-Transition from devastation to life

The experience of the memorial museum unfolds through a ritualistic labyrinth, engaging visitors with different spatial moments while moving across a variety of paths. Rather than providing a direct access to the destination, this multicursal maze allows for detours, disorientations, and diversions which contribute to a meandering and slow-paced journey through an array of choices between paths. 


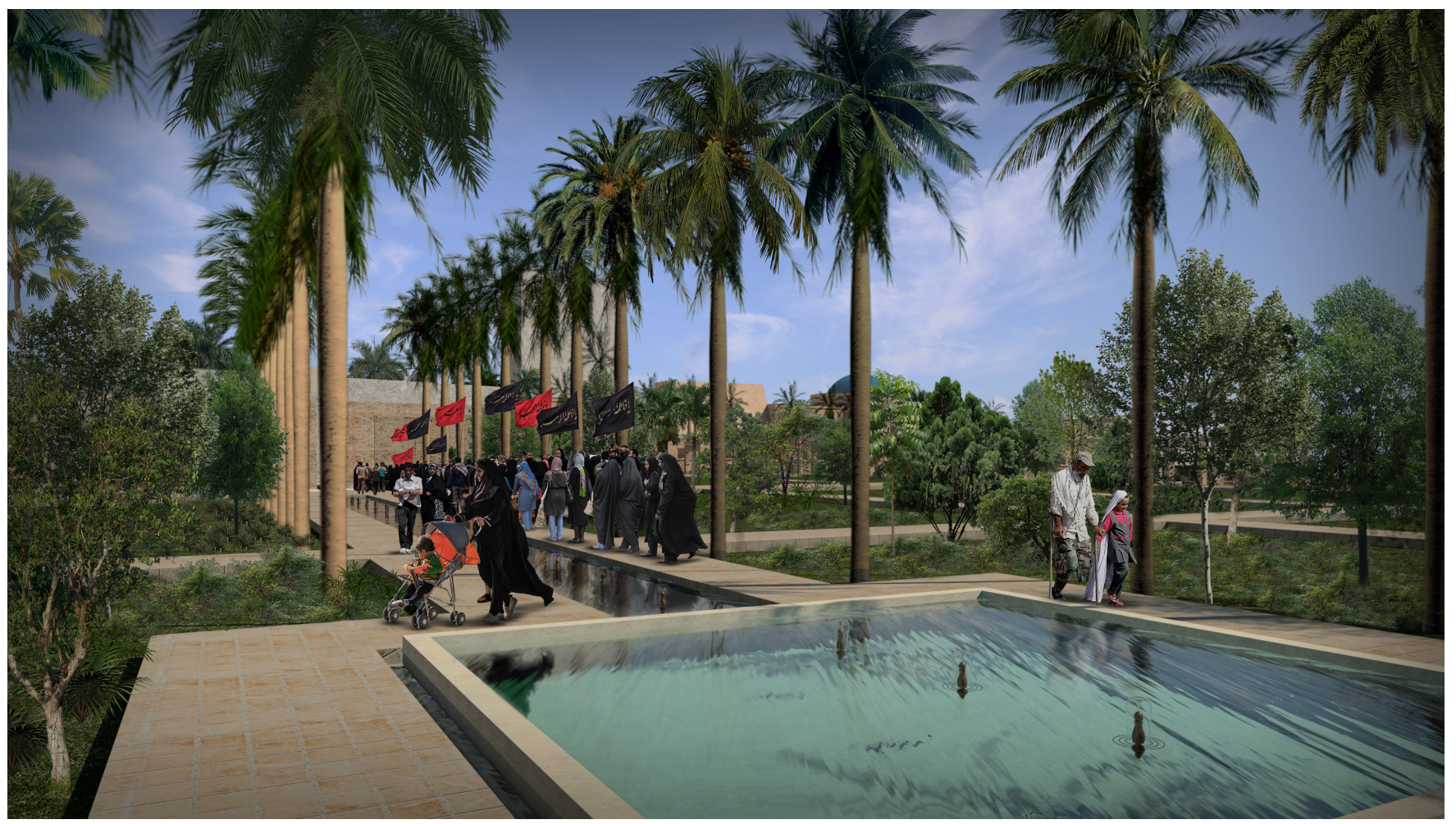

Fig 5.19 Prolonged procession from arrival point to the building

The breaks in the walls provide a glimpse into the inner layers of the journey, motivating visitors to proceed and discover the hidden gem. Thus, movement through this maze is interrupted, repetitive, and disintegrated which requires a moment of contemplation and decision at each corner. The intentional discontinuity of the path forms a unique and emblematic experience, embodying at the same time uncertainty and lucidity, fragmentation and fusion, order and chaos, frustration and optimism.

Placed at the heart of the maze, a courtyard fully emerges as a symbol of paradise rewarded to those who have overcome all the doubts and frustrations of the journey. The perimeter walls of the courtyard are oriented towards Mecca or Qibla as a metaphor for the submission to the Divine. In the garden, the visitors still have visual access to the maze entry point as well as to the gardens that will subsequently be revealed along the journey. 


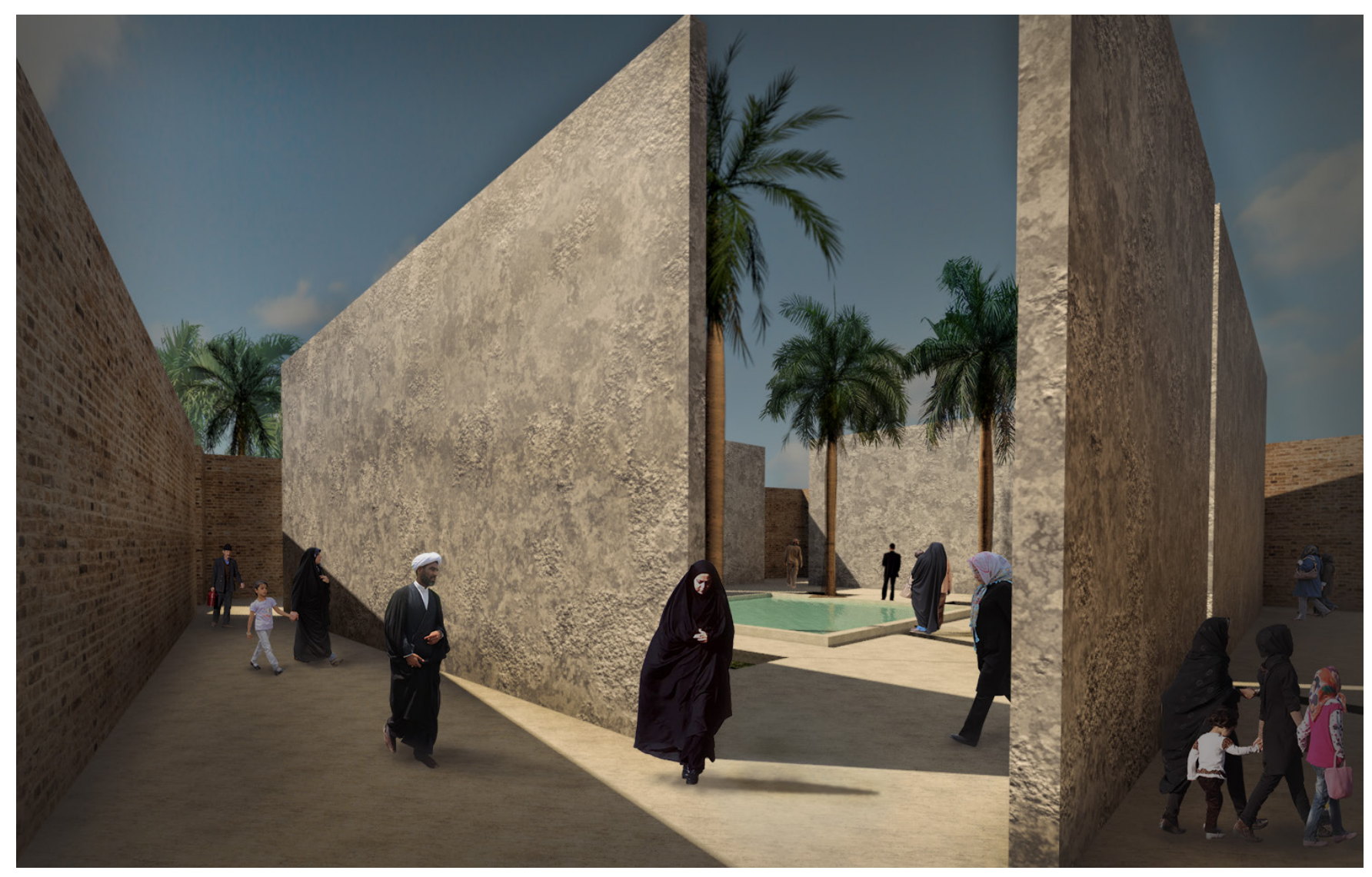

Fig 5.20 Purposeful disorientation in the multicursal maze

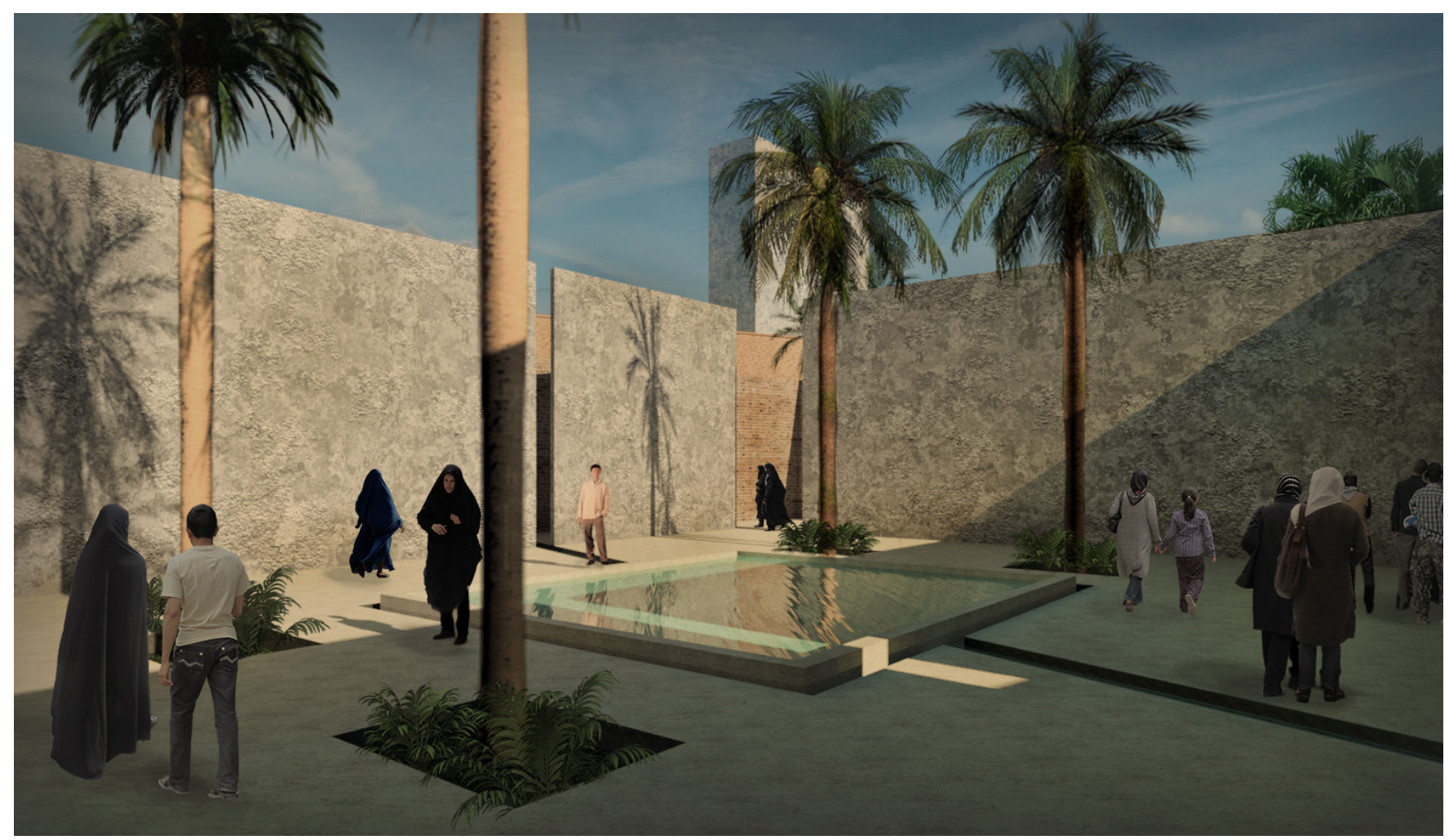

Fig 5.21 Paradise at the center of the maze 
As visitors leave the labyrinth and approach the next garden, the memorial museum building comes into sight formed as a elongated brick bar. The building entrance is articulated by a slight set back of the terrace on the first floor that acts both as a threshold to the third garden as well as a prelude to the interior journey through the exhibitions. The entry is also accentuated by the change in the height of the roof.

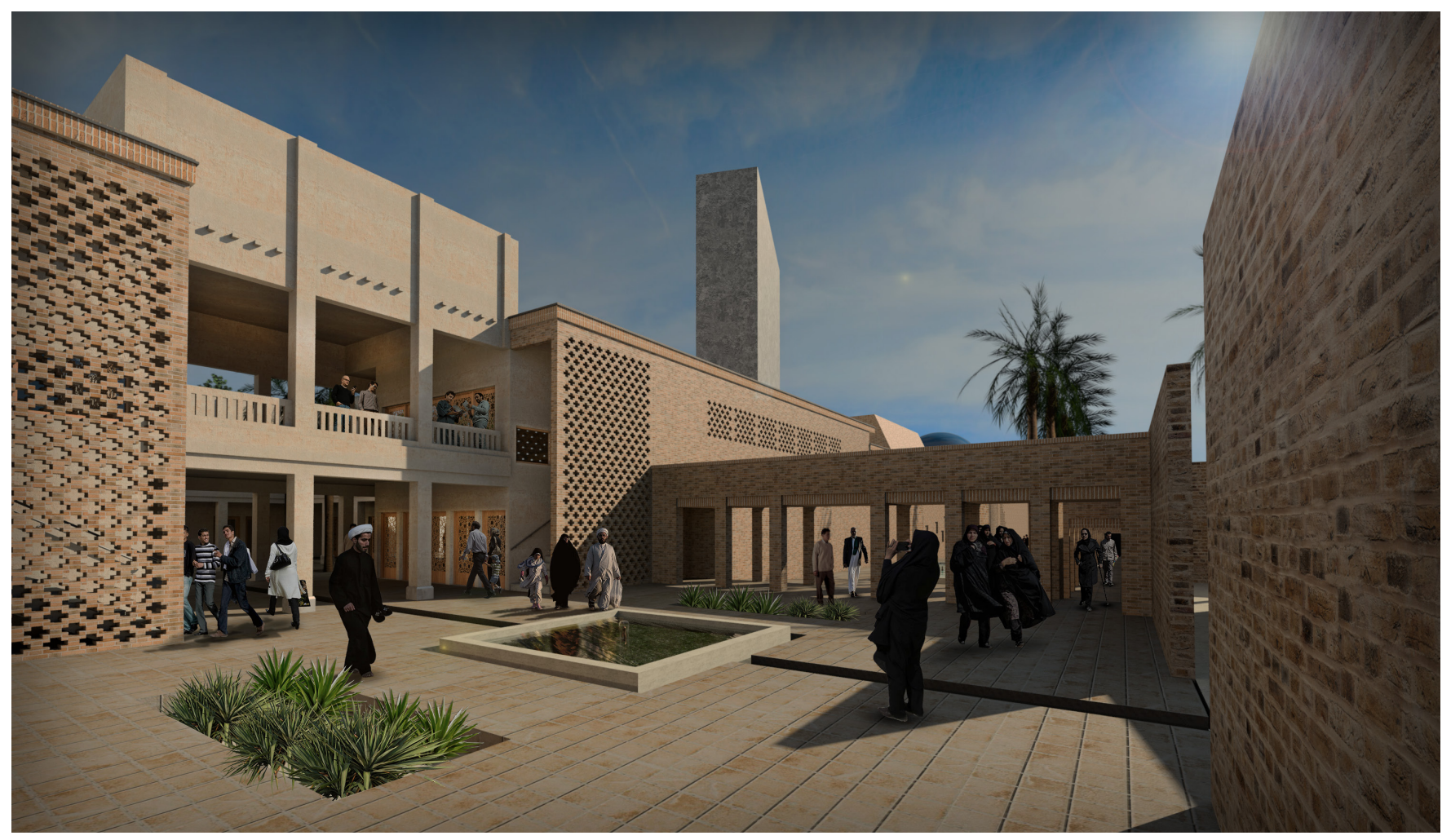

Fig 5.22 Entry to the building 


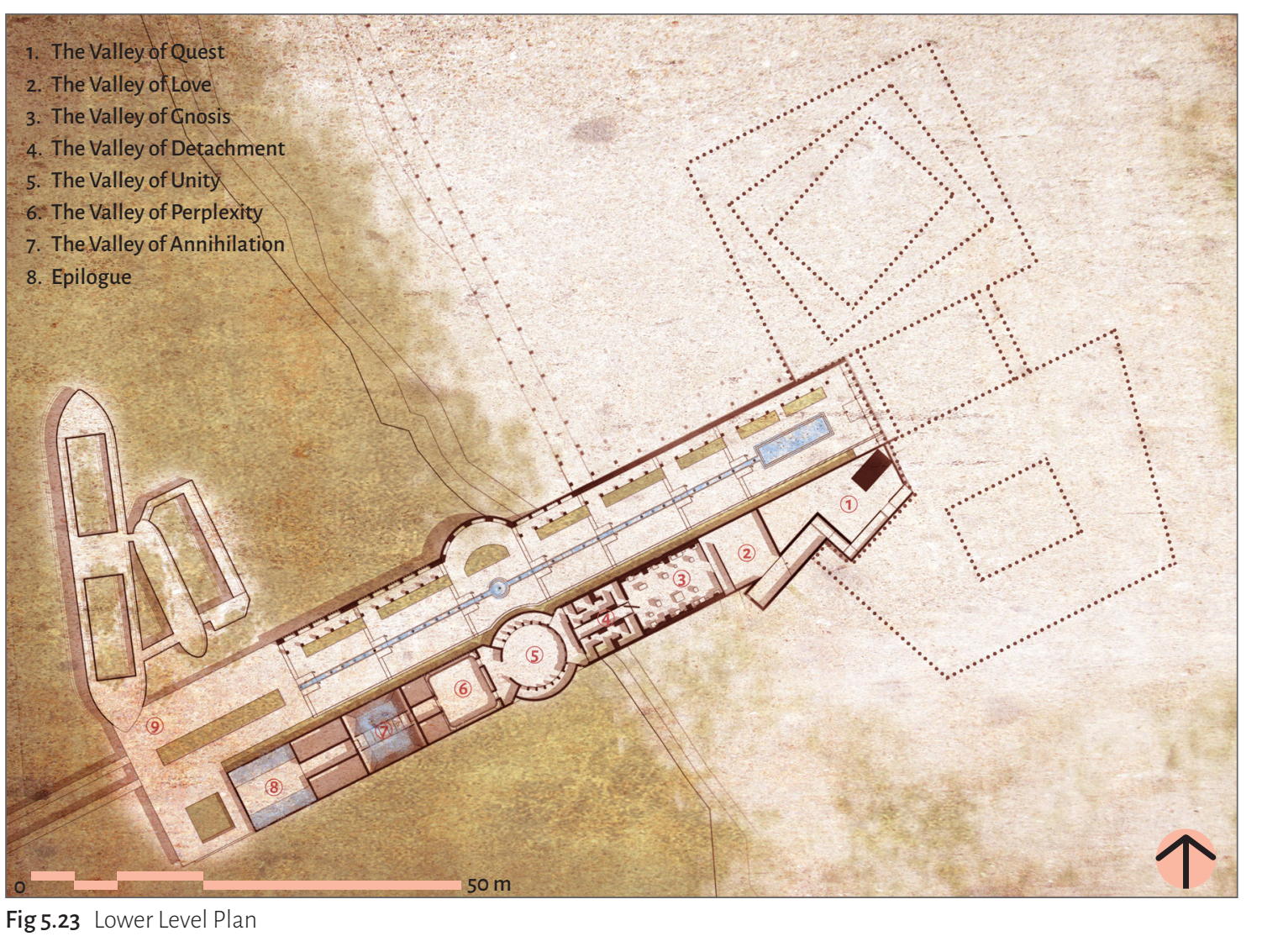

Unlike the first outdoor journey which is more concerned with disorientation and the chaotic sequence of movement, the second journey entails a linear progression through interior spaces and exhibitions. In spite of their organizational differences, the two patterns of journeying share fundamental qualities in that both are rooted in the notion of the "path", a journey from a starting point to a visionary end. This is where the tradition of martyrdom and its poetic expression through the "The Conference of the Birds" come to play a significant role in articulating the memories of the martyred divers, forming the basis for the way the design of the exhibitions is approached.

Similar to the journey of the birds in the poem, the linear experience of the memorial museum unfolds in seven sequential chambers, each one symbolically representing one of the Valleys in The Conference of the Birds while invoking the narrative of the martyrs of Operation Karbala 4.

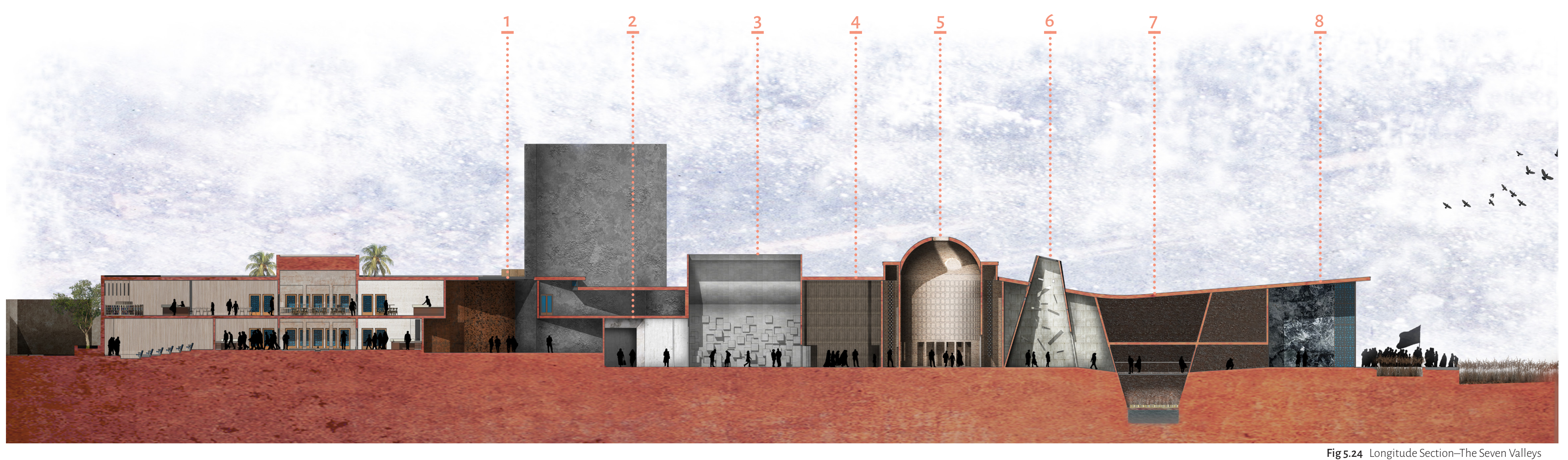


1. The Valley of Quest

"And if the goal seems endlessly concealed,

Do not give up your quest; refuse to yield."

Poetic Expression: The initial step of the seekers' journey is the Valley of Quest or Waady Talaab. The Arabic word, Talaab means "desire", "seek", or "yearn". The Valley of Quest is a metaphor introduced to the birds as the yearning to find their ruler. In this valley, the seeker encounters a hundred difficulties and a great deal of effort and patience is required to pass. The endless suffering of the seekers in this valley and their endurance grant them a sense of realization of the nature of the journey and they become more enthusiastic to pursue the light of the Divine. They become Talib, meaning "seeker", and their desire for seeking multiplies a thousand times. After this exposure and spiritual transformation, they are no longer concerned about any challenges they might face. The experience of yearning becomes intensified, insofar as they eagerly abandon anything that was previously precious to them, forgetting all but the burning desire to reach the Simurgh.

Architectural Interpretation: The first exhibition intends to showcase visual and textual didactic information about the Passengers of Light pilgrimage, introducing the vast geography in the west and southwest of Iran imbued with memories of the Sacred Defense. The information is used to contextualize the site dedicated to the martyrs of Operation Karbala 4 in the larger setting of the Passengers of Light. This exhibition symbolizes the spiritual step in which the seekers discover all the difficulties about their journey, becoming prepared to face any challenges along the path.

During the eight-year war, escorting and greeting the soldiers who had been dispatched to the frontlines was conceived as an honourable act by Iranians, saturated with bittersweet feelings. The image of a passenger bus full of young soldiers bidding farewell to their loved ones, uncertain if they were ever going to see them again,

4 Farīd a.-D. Attār, Afkham Darabandi and Dick Davis, The Conference of the Birds, The Penguin classics (Harmondsworth: Penguin, 2011), p.184

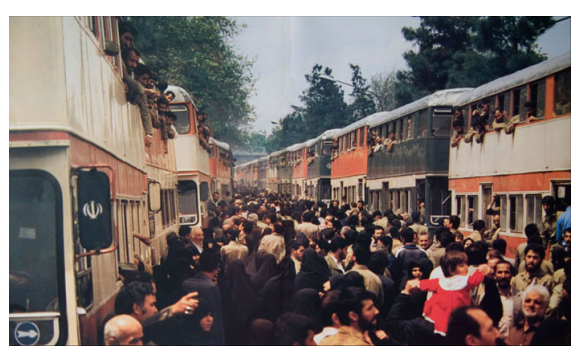

Fig 5.25 Passenger bus as a symbolic icon in the collective memory of the war

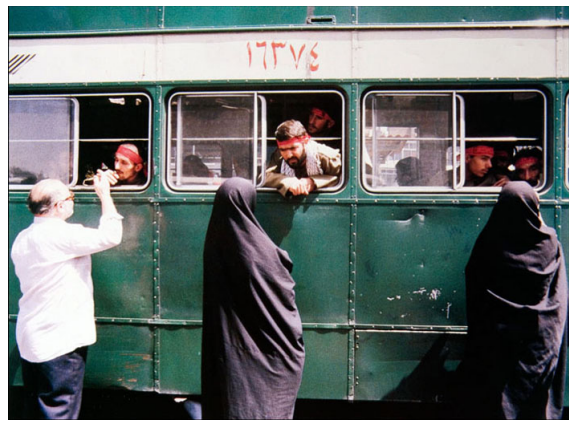

Fig 5.26 Dispatched soldiers escorted by their loved ones

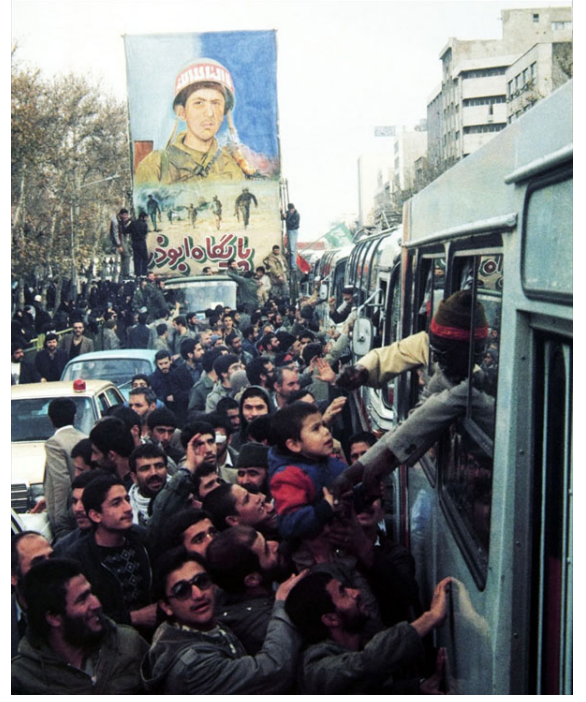

Fig 5.27 Dispatched soldiers escorted by their loved ones 
occupied a central position in the Sacred Defense iconography as a representation of bravery and determination. As a symbolic gesture, the same iconic passenger bus is placed at the exhibition, referring to the departure point of all the soldiers/seekers/martyrs.

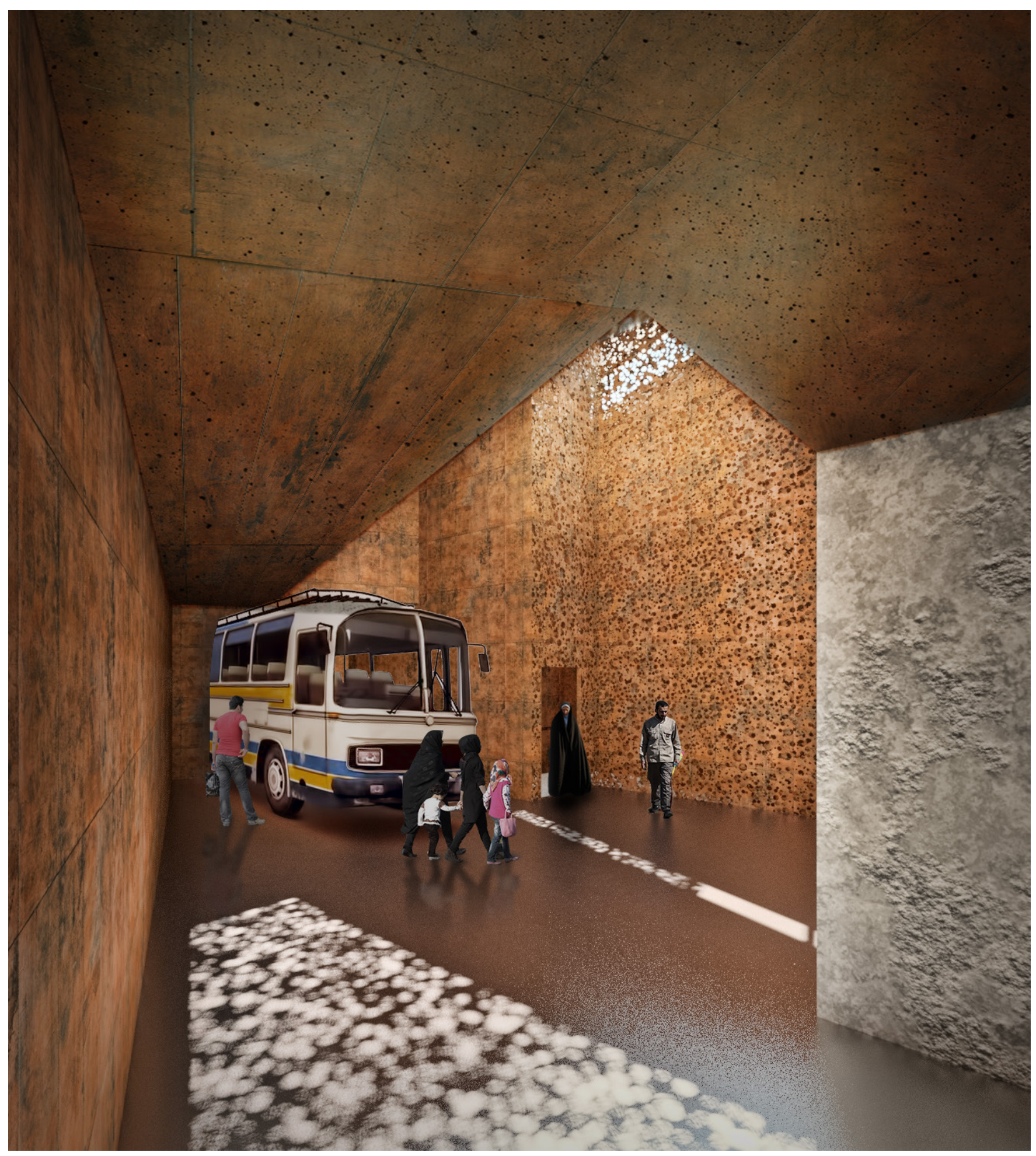

Fig 5.28 The Valley of Quest 


\section{The Valley of Love}

"Until their hearts are burned, how can they flee From their desire's incessant misery?"5

Poetic Expression: The Arabic-Farsi word for "love", Ishq denotes a "strong passion" or "consuming love". The word originates from ashaqa, which describes a kind of parasitic ivy that clings to a tree, grows its roots on the roots of the tree and eventually dries it up. Persian poets have conceived of this process metaphorically to represent love. They believe that when a seeker falls in love with the Divine, the love becomes dominant and nourishes itself by consuming every bits and pieces of the lover inasmuch as there is nothing left but love. In this valley, mystical love is symbolized by the fire and in order for the seekers to pass the valley they must be transformed into fire themselves, burned and revived in the fire of Divine love. When love emerges within a seeker, there is no place for reasoning as the intellect is unable to perceive the depths of mystical love. The seekers become indifferent to all earthly matters as a result of a strong passion for the Divine. Here, smoke is a metaphor of reasoning. The smoke disappears when the flames are intensely burning.

Architectural Interpretation: Descending the disorienting twists and turns of a path from the Valley of Quest, the visitors approach the Valley of Love. Prior to setting foot in this Valley, the visitors enter a remarkable 20-meter tower with a slit that allows for the penetration of daylight. The tower with its intentional alignment toward Mecca sits in contrast to the main axis of the building. The experience of the tower with a tall and narrow opening seeks to symbolize an encouraging moment when the seekers have passed all the difficulties of the Valley of Quest and are determined to embark on the journey to reach the Divine. The visitors then proceed to the Valley of Love, a serene white room filled with the peaceful sound of the ocean. In Persian literature and poetry, there is often a strong association between the ocean and love as they both have the ability

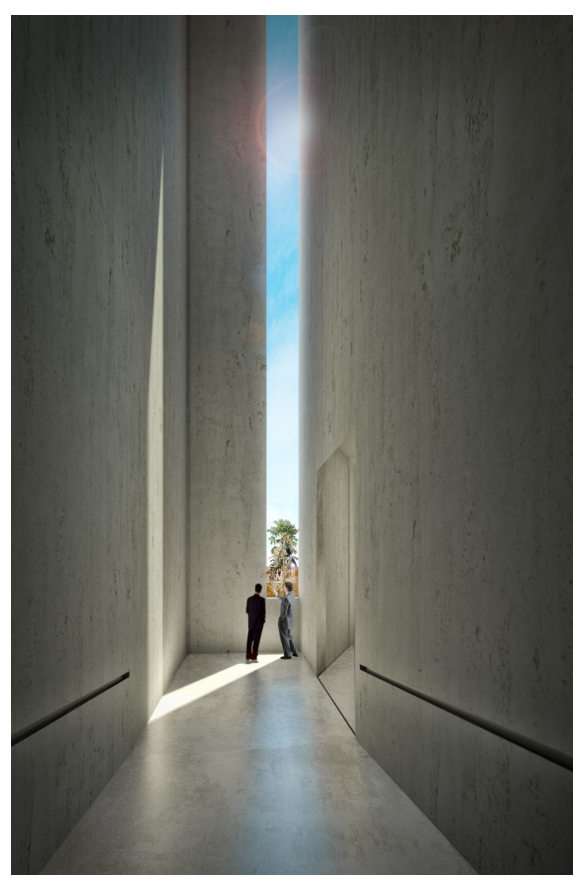

Fig 5.29 The tower facing Mecca

$5 \quad$ Ibid., p.187 
to drown an individual with their power. The room with no objects to display intends to produce a transcendental experience.

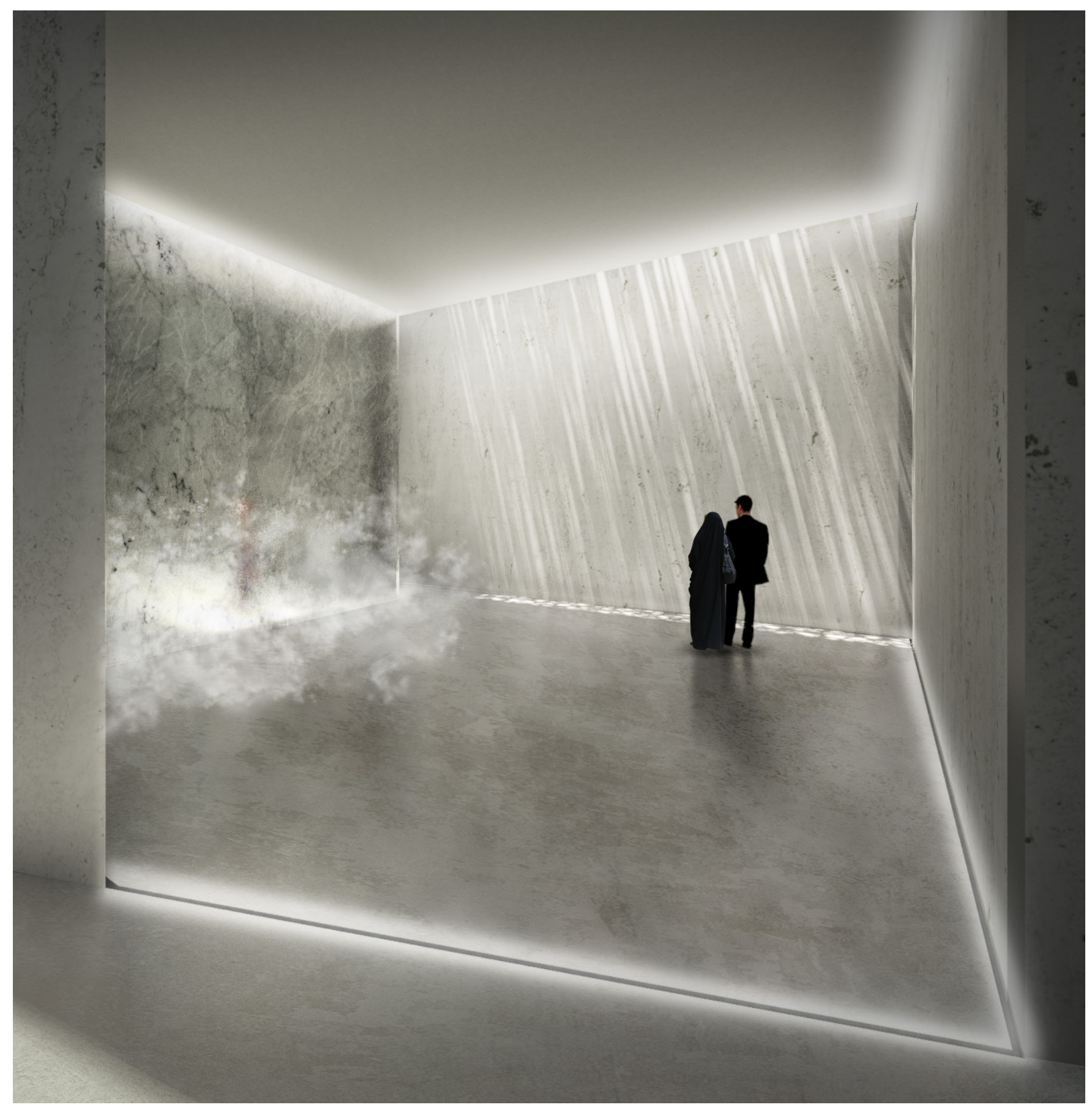

Fig 5.30 The Valley of Love 


\section{The Valley of Gnosis}

"Now let the sea of gnosis drown your mind, Ordust and death are all that you will find."

Poetic Expression: In the valley of Gnosis, the seekers become capable of perceiving the mysteries and meanings of the universe. They realize that all the knowledge they have gained so far is merely a drop in the vast ocean of Gnosis by which they can achieve selfrealization. Cnosis is defined here as "the knowledge of spiritual mysteries" which can be observed only when the inner eyes open. In this valley, the seekers have different capacities to access and comprehend knowledge according to their strengths and weaknesses. As such, there are countless spiritual paths and many variations in the progress which make the experience and the meaning of the journey different for each individual. Under the light of Cnosis, seekers can see beyond an earthly understanding of the matters, which eventually leads them to a true perception of the Divine.

Architectural Interpretation: Before entering this exhibition, visitors pass through a semitransparent partition that separates the Valley of Love from the Valley of Gnosis, shrouded in a veil of mist. The sense of ephemerality and ambiguity created by the partition speaks to the limited perception of the seekers while in the Valley of Love. But this constraint will be overcome as soon as one enters this Valley and is greeted by the immense light coming from the sky, epitomizing heavenly knowledge. In this exhibition, the details of Operation Karbala 4 are depicted in order to offer a holistic understanding of the historical accounts. The wide variety of display cases parallels the different approaches to perceiving the mysteries of Cod.

6 Ibid., p.195 


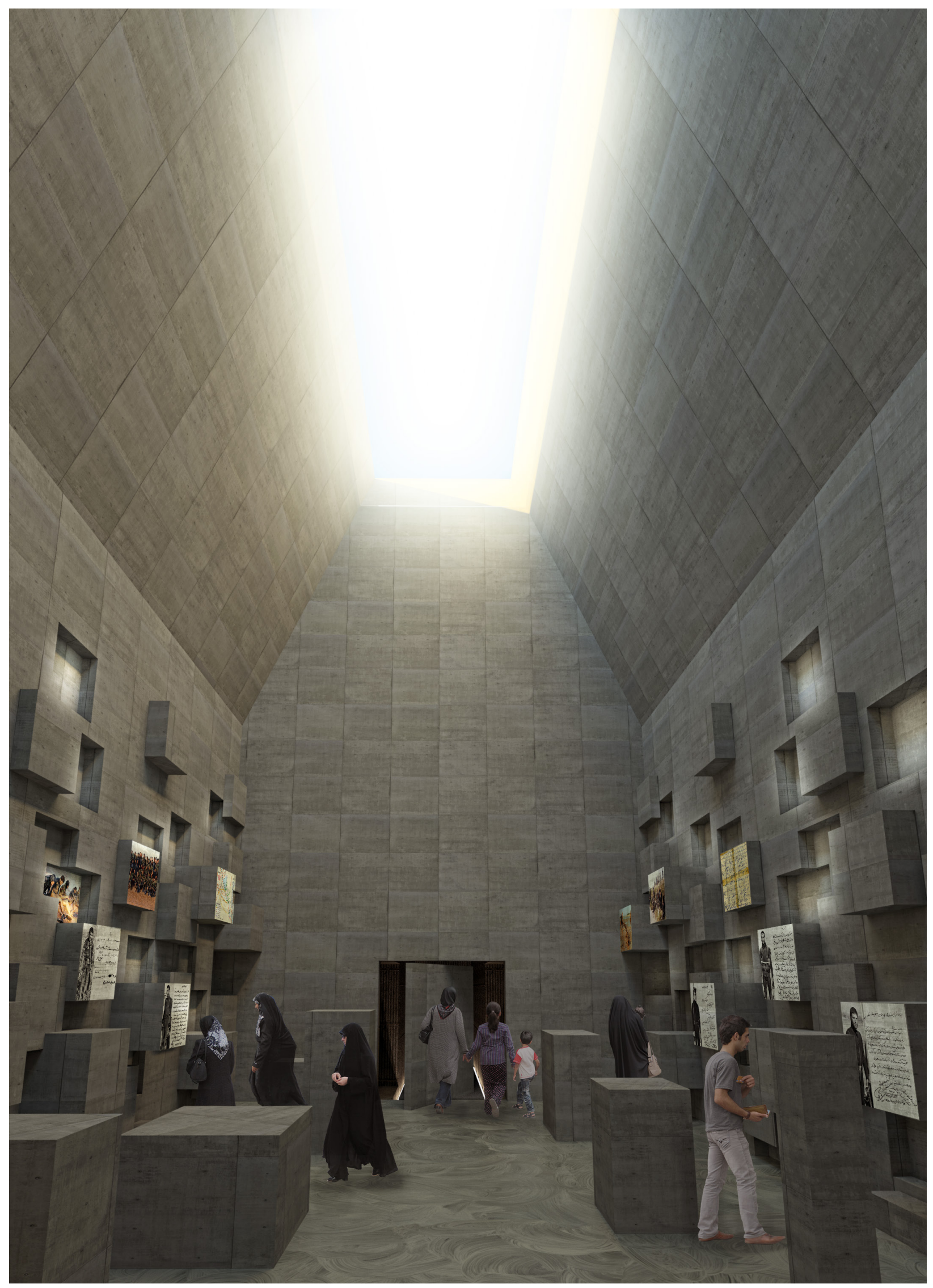




\section{The Valley of Detachment}

"The seven planets seem a fading spark, The seven seas a pool, and heaven's arc Is more like dust and death than paradise; The seven burring hells freeze cold as ice."

Poetic Expression: The fourth valley, the Valley of Contentment or Detachment represents a fundamental characteristic of Cod who has no need for anything since he encompasses everything and lacks nothing. In this stage, the seekers become detached from any earthly wishes or desires insofar as "if the whole world, the entire universe, came to an end, it would not matter." ${ }^{\prime 8}$ Their hearts become purified, once they perceive the true happiness in the presence of God. Esteghna is the Arabic word meaning "contentment" or "self-sufficiency" and ghani refers to an individual who is "wealthy" or "free from want". Attar believes that the liberation and independence from all material attachments are key to realizing the fact that this is only and merely Cod to whom the seekers have to adhere under any circumstances.

Architectural Interpretation: This chamber is characterized by a remarkably high ceiling with rays of dim light coming in. The positions of the ribbed concrete walls converge to create a tight passage, immersed in a contemplative light, generating a feeling of humility compared to the whole universe. The choice of a rough material and the relative darkness of the space is deliberate in order to portray the situations in which obstacles or comfort seem the same in the sense that the individual is free from any feelings and thoughts except the need for reaching to God's presence. The rays of light on the ceiling represent the sublime source which all the seekers crave. Behind the concrete walls are the exhibition spaces with low ceilings and tight dimensions to symbolically reconstruct the experience of the divers when they were surrounded by Iraqi forces during the Operation. In those moments, divers were totally detached from the

7 Ibid., p.199

8 Gity Baxter-Tabriztchi, "Farid ud-Din Attar's The Conference of the Birds: A Study in Sufi Psychology and Spirituality," (PhD thesis, Argosy University, 2003), p.322 
material world, death or survival was the same to them, realizing that only God can spiritually help them in such a difficult situation.
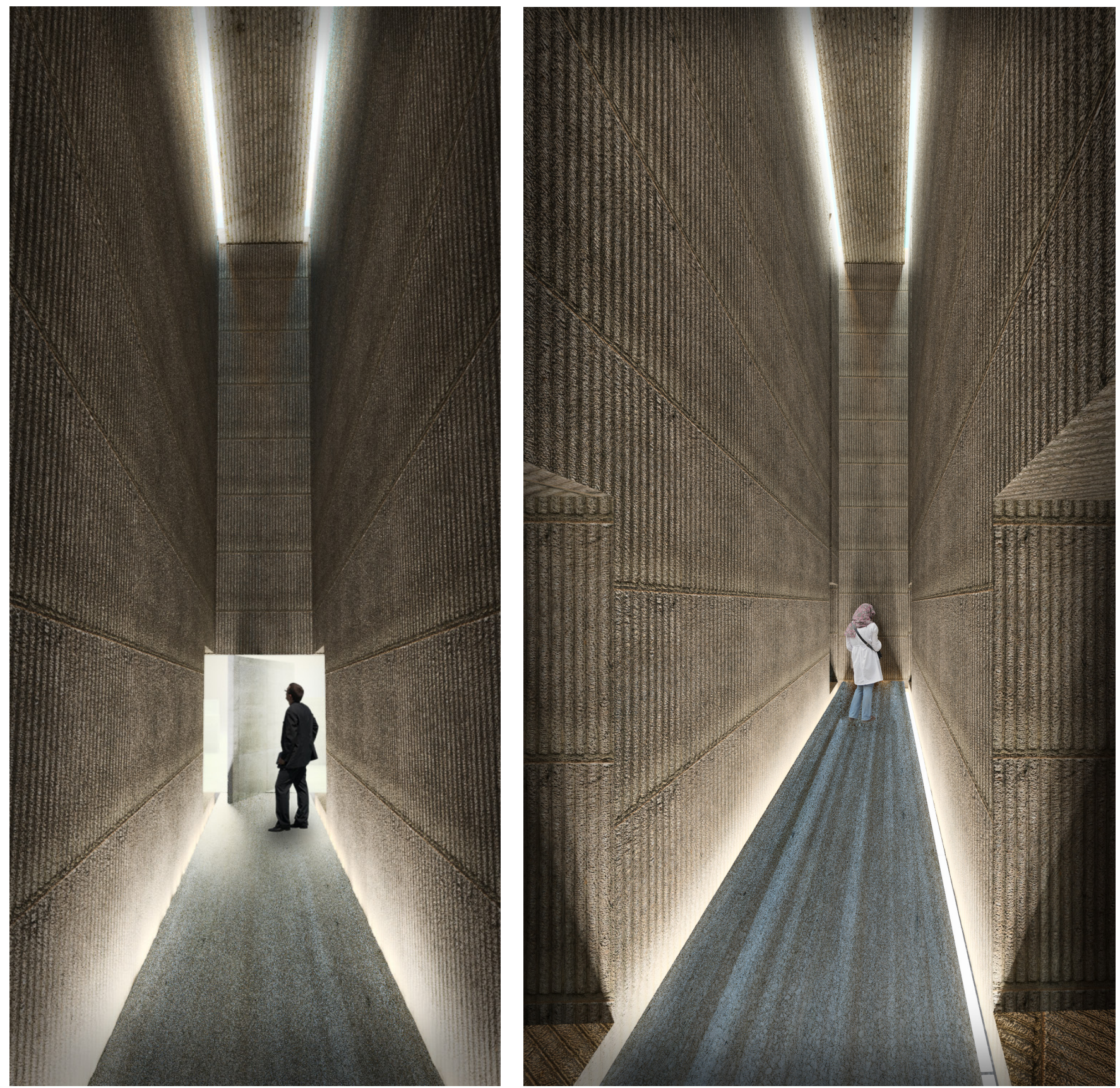

Fig 5.32 The Valley of Detachment 


\section{The Valley of Unity}

"All things are one - there isn't any two;

It isn't me who speaks; it isn't you."

Poetic Expression: This is where the seekers undergo a spiritual transformation, moving from multiplicity to unity and wholeness. They now realize that the creation is comprised of various components, all of which form into a single unique entity as a whole. In this sense, seekers as mentally separated individuals become spiritually unified, experiencing a connection with themselves and with each other. They see the Divine present in all created things. In this valley, there is no differentiation between entities as everything becomes one. Multiplicity and unity are considered the same since the many fragments exist in one and oneness appears in all things.

Architectural Interpretation: Entry to this stage occurs across multiple thresholds but exiting can only happen through a single doorway. This duplicity is suggestive of the notion that in the Valley of Unity multiplicity turns into oneness. Unlike the orthogonal spatial expressions in previous exhibitions, this room features a circular form with a dome at the top as an embodiment of unity and oneness. Images of the soldiers martyred in Operation Karbala 4 are placed on the curved walls of the exhibition, forming a vast cylindrical canvas as a whole. This gesture affirms that thousands of martyrs became unified into a single entity in the presence of God. Digital media also narrate the life of individual martyrs, creating both a personal and collective identity.

9 Attār, Darabandi and Davis, The Conference of the Birds, p.207 


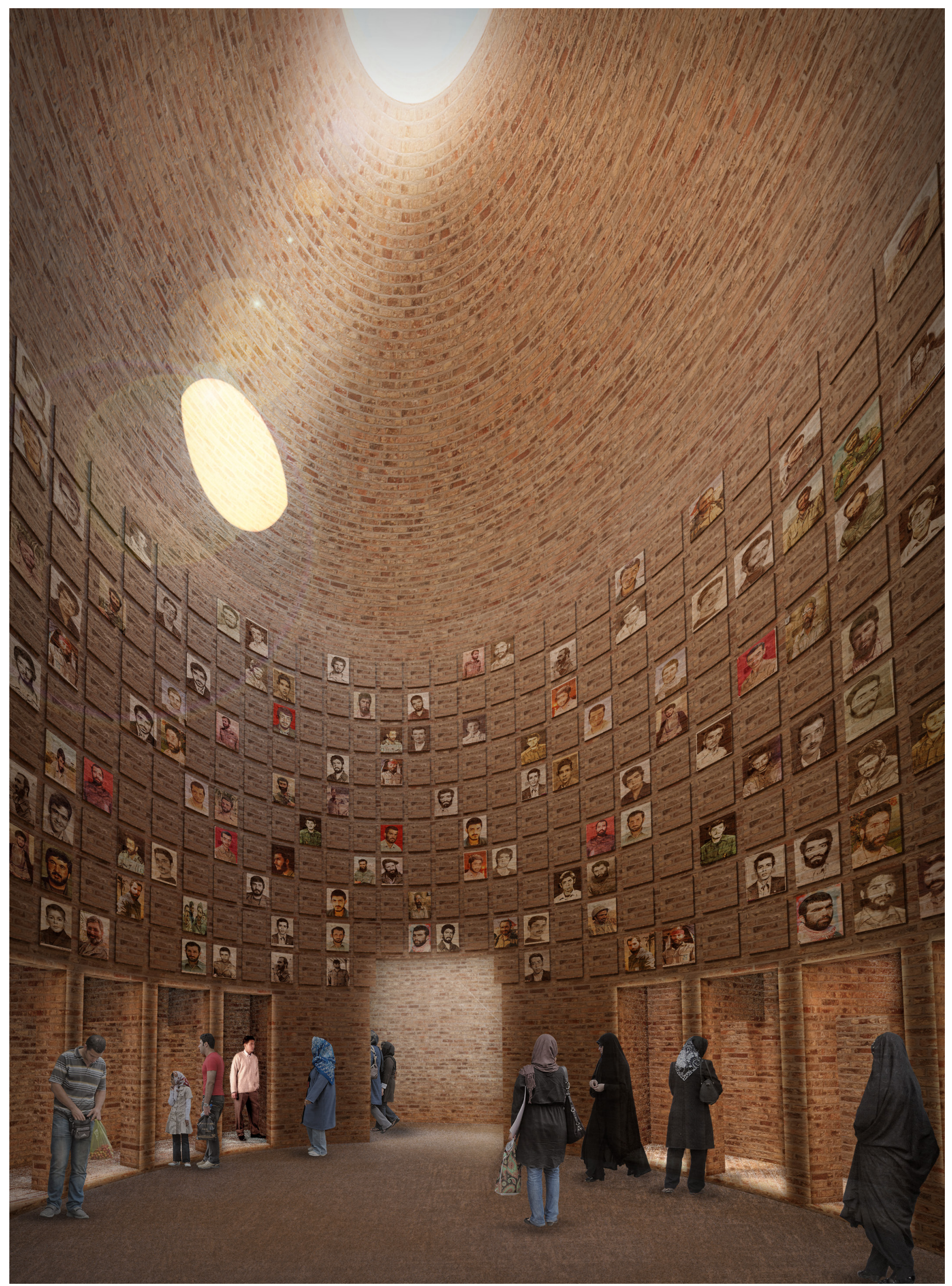




\section{The Valley of Perplexity and Bewilderment}

"In ice you fry, in fire you freeze - the Way

Is lost, with indecisive steps you stray -"'o

Poetic Expression: The Valley of Bewilderment or Perplexity is the place where the seekers are amazed and confused by the beauty of the Divine. Their understanding of the world is transformed drastically, exacerbating their sense of confusion and awe. This overwhelming sense of astonishment comes from the realization that "the path [to Divinity] is greater and more mysterious than they had originally thought."11 Using rationalization in order to understand the essence of this experience would merely add to the confusion. Rather, the seekers have to plunge into the state of bewilderment to realize it from within.

Architectural Interpretation: The form of this chamber stands in a sharp contrast with the rest of the spaces, characterized by a conical shape, intended to induce a sense of amazement and confusion in the visitors. The tilted walls and the significant height of the ceiling evoke a feeling of awe. The irregularly patterned slits on the walls along with colorful lights and shadows intensify this experience of being overwhelmed by the space.

10 Ibid., p.212

11 Baxter-Tabriztchi, Farid ud-Din Attar's The Conference of the Birds, p.370 


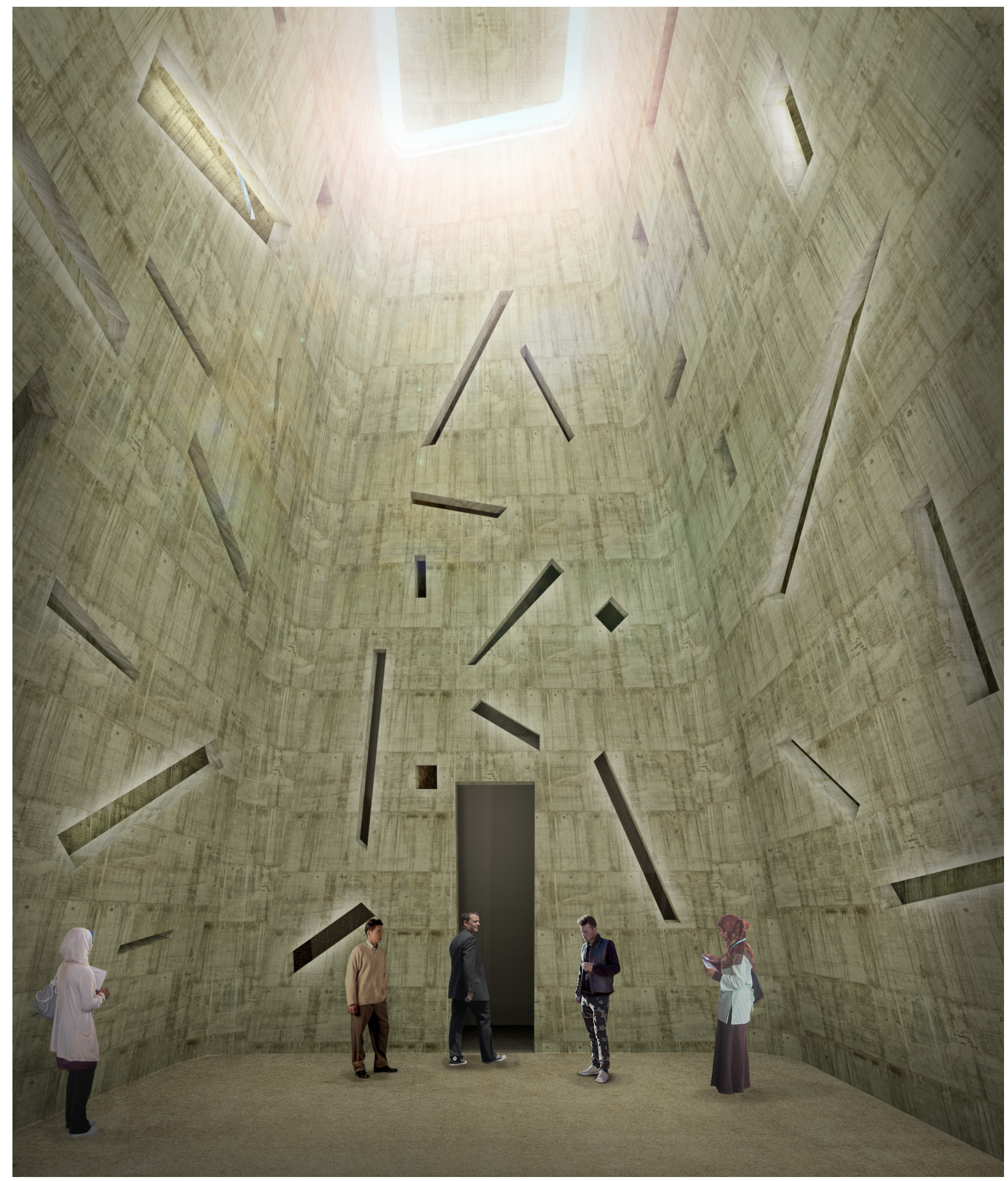

Fig 5.34 The Valley of Perplexity 


\section{The Valley of Annihilation and Oblivion in God}

"No creature's Selfcan be admitted here, Where all identity must disappear."12

Poetic Expression: Ultimately, the seekers reach the final stage, Waady Faqr-o-Fana in which the seekers "face complete dissolution in the experience of poverty, annihilation, and the passing away from the self, which leads to eternal subsistence."13 Faqr which means "poverty" is the state of not possessing anything of the material world, a prerequisite to becoming united with Cod. Also, fana refers to "annihilation", "absolute nothingness" or "death". In this valley, the seekers experience oblivion and annihilation of every aspect that defines their identity, relinquishing their entire being so that they dissolve in God. It is only through the process of self-annihilation that the seekers can immerse themselves in the Beloved and become immortal.

Architectural Interpretation: The visitors finally arrive at the Valley of Poverty and Annihilation where they find themselves in a tomb-like space, making reference to the state of the divers buried alive. This is the last stage of the spiritual journey where the seekers become obliterated in Cod. This is where the soldiers were martyred and gained subsistence in the Divine. Walking on a glass bridge, the visitors are able to traverse a pool of water which is lit with 175 candle-like lights, symbolizing the recently discovered bodies of the divers. From this chamber, the visitors enter a dark corridor while simultaneously grasping a glimpse of the distant light ahead of them. Then, an immensely bright space emerges, signifying the entrance to heaven. On the two sides of the path to the outside are reflective marble walls, referring to the experience of the birds in the poem when they reached the Simurgh and they were purged of all the impurities of the journey so that they were merely a reflection of the Divine.

12 Attār, Darabandi and Davis, The Conference of the Birds, p.222

13 Baxter-Tabriztchi, Farid ud-Din Attar's The Conference of the Birds, p.372 


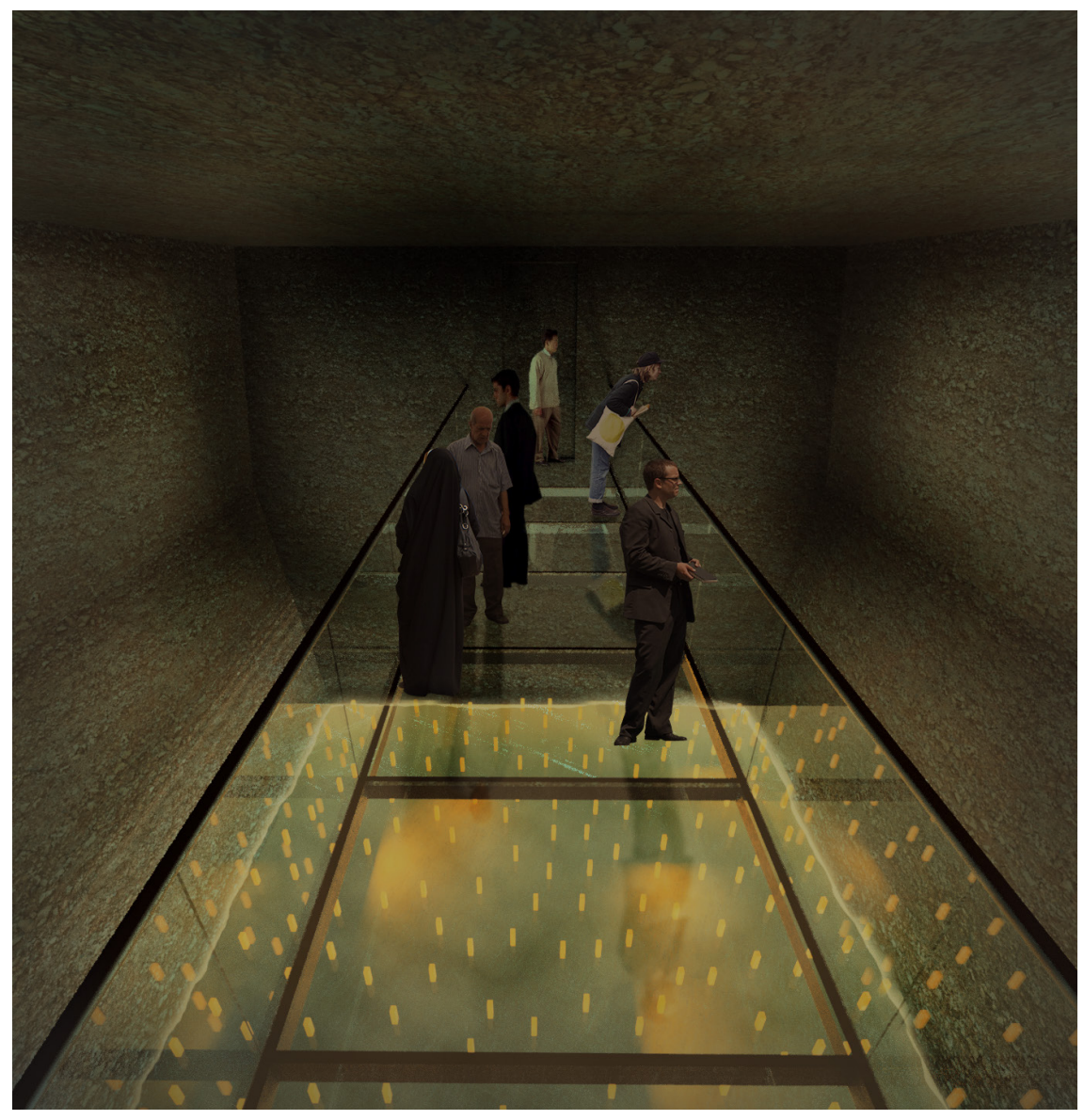

Fig 5.35 The Valley of Annihilation

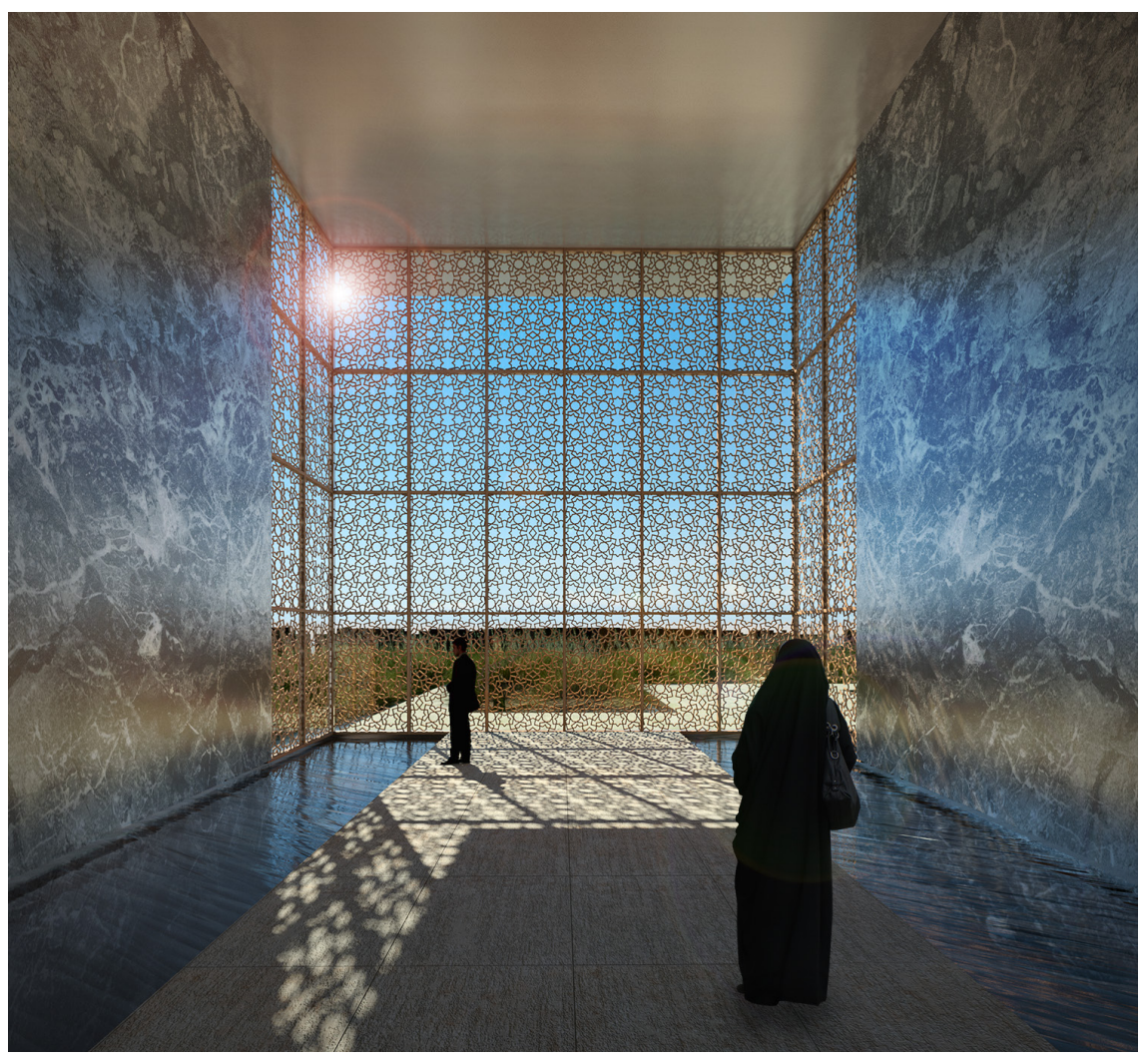

Fig 5.36 Epilogue-Toward Heaven 
After exiting the building, the visitors can proceed into the marshland to arrive at the riverfront or explore the old grounded boats and eventually make their way back to the beginning of the journey. The returning occurs through a contemporary interpretation of the Persian garden, linking to the first garden that the visitors experienced at the point of arrival. In this regard, the whole experience of the memorial museum is expressed through a cyclical journey, beginning and ending in a garden.

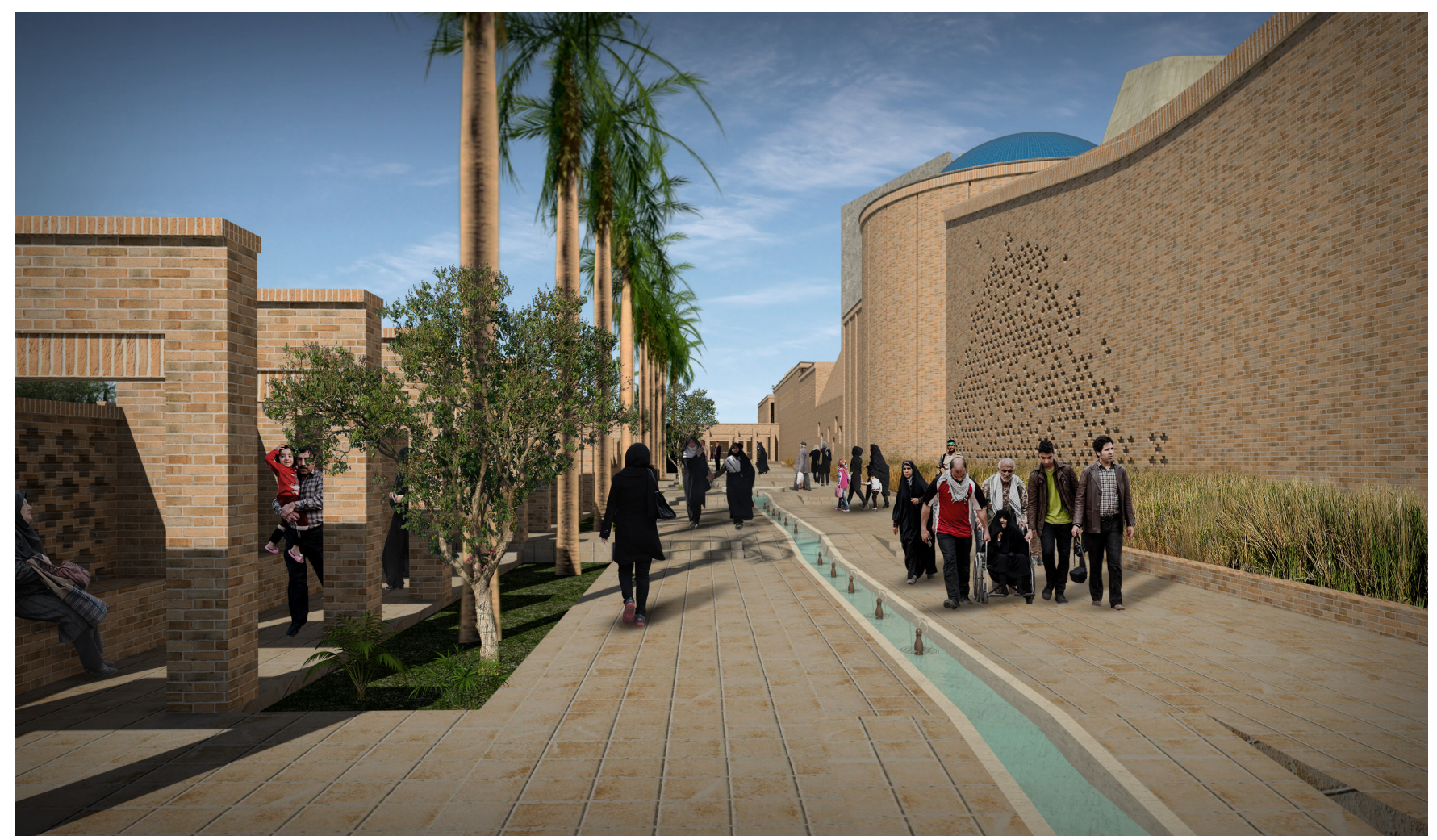

Fig 5.37 Visitors making their way back to the arrival point 


\subsection{Epilogue}

Memory is not an object or a medium for carrying the past into the present; rather it is a changing process which functions differently within different temporal and cultural frameworks. Sites of past atrocity can be revived through memorialization to perform on various levels: first, they can provide a sacred space for mourning and reflection as a form of symbolic experience; second, they can serve didactic purposes, educating future generations to prevent similar failures; and, they can also contribute to group cohesion and serve as a vehicle through which national identities are established and rebuilt in the aftermath of war.

The design for a memorial museum in Khorramshahr acts as a case study to examine the ways memories can be manifested through architecture. The particular journey described in this project not only captures the intensity and solemnity of the Sacred Defense memories but also creates an optimistic and transcendental experience -as discovered by the birds- through the sequential movement in the galleries. Each experience entails particular aspects the fusion of which culminates in a spiritual journey, touching upon the depths of memory and creating a place for remembrance and contemplation.

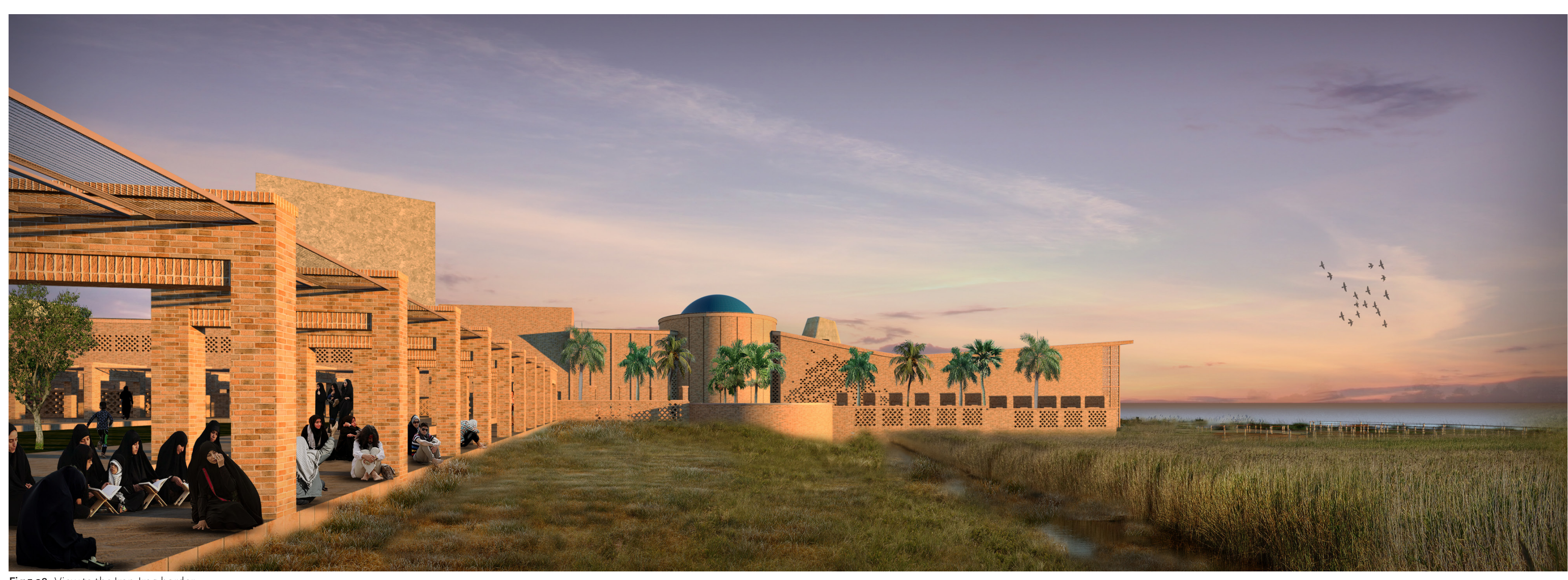

Fig 5.38 View to the Iran-Iraq border 
Though you have struggled, wandered, travelled far, It is yourselves you see and what you are.

Though you traversed the Valley's depths and fought With all the dangers that the journey brought, The journey was in Me, the deeds were mineYou slept secure in Being's inmost shrine. Dispersed to nothingness until once more You find in Me the selves you were before. Neither the pilgrims nor their guide remained. The Simorgh ceased to speak, and silence reigned.

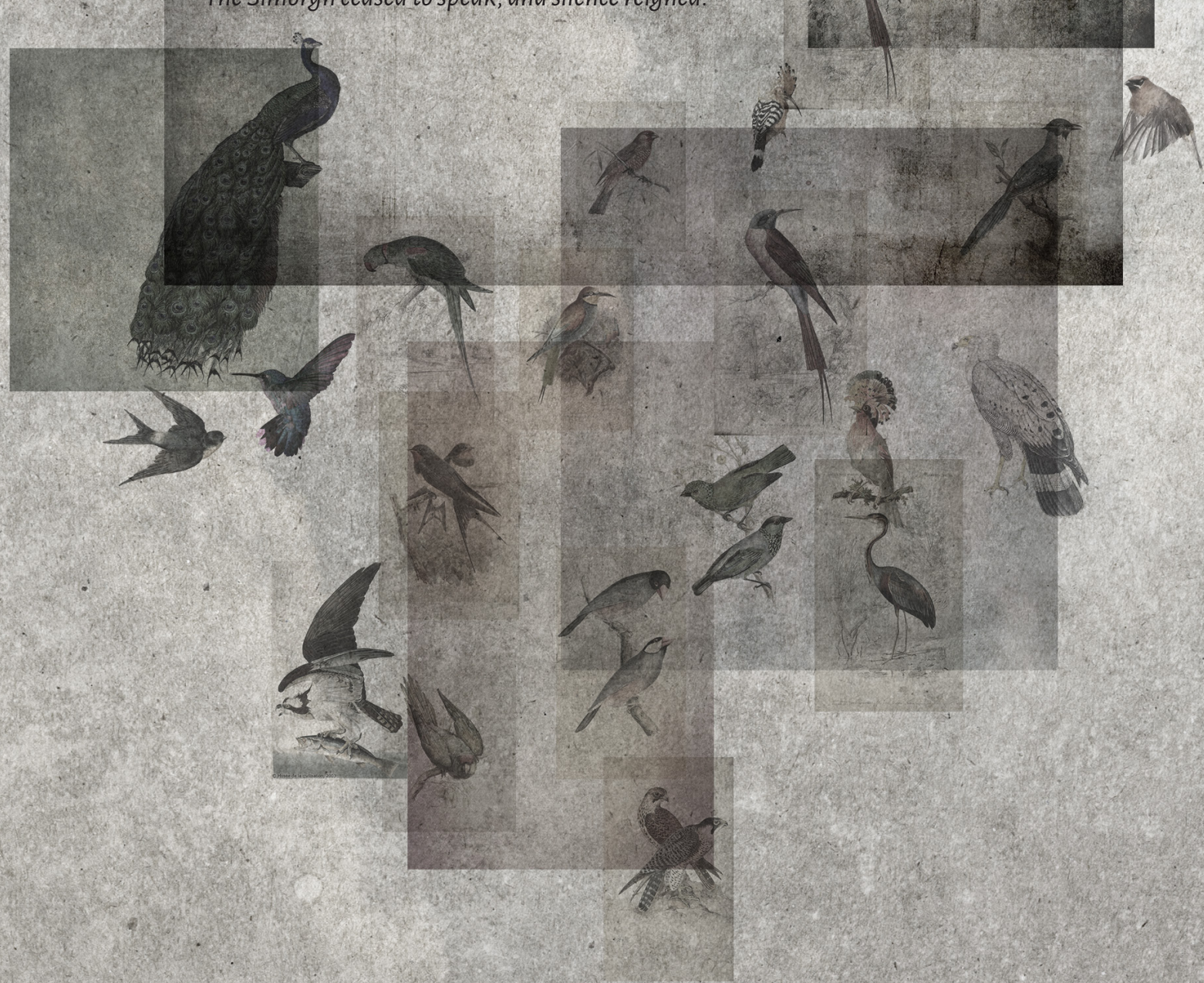





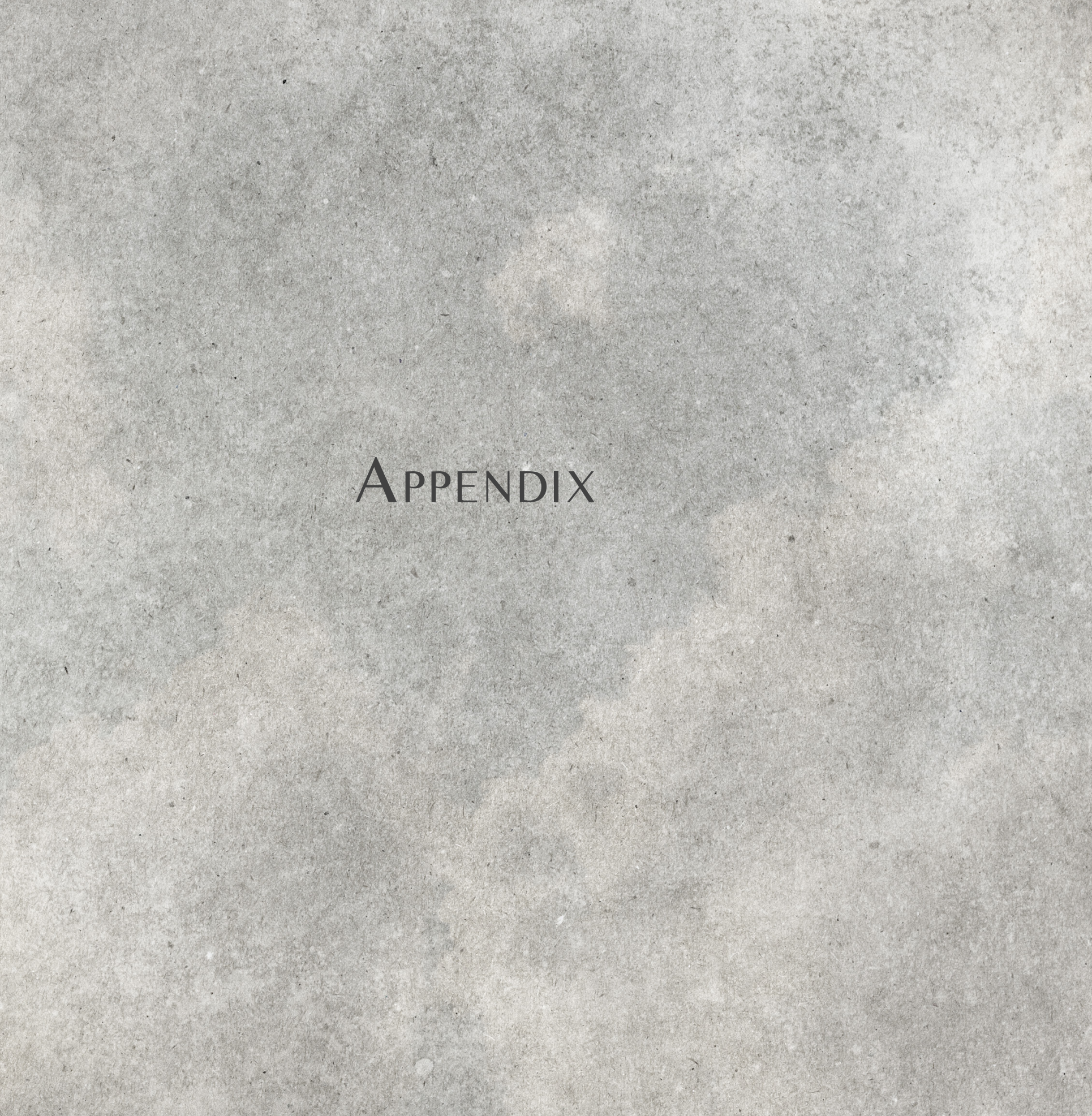




\section{Appendix A}

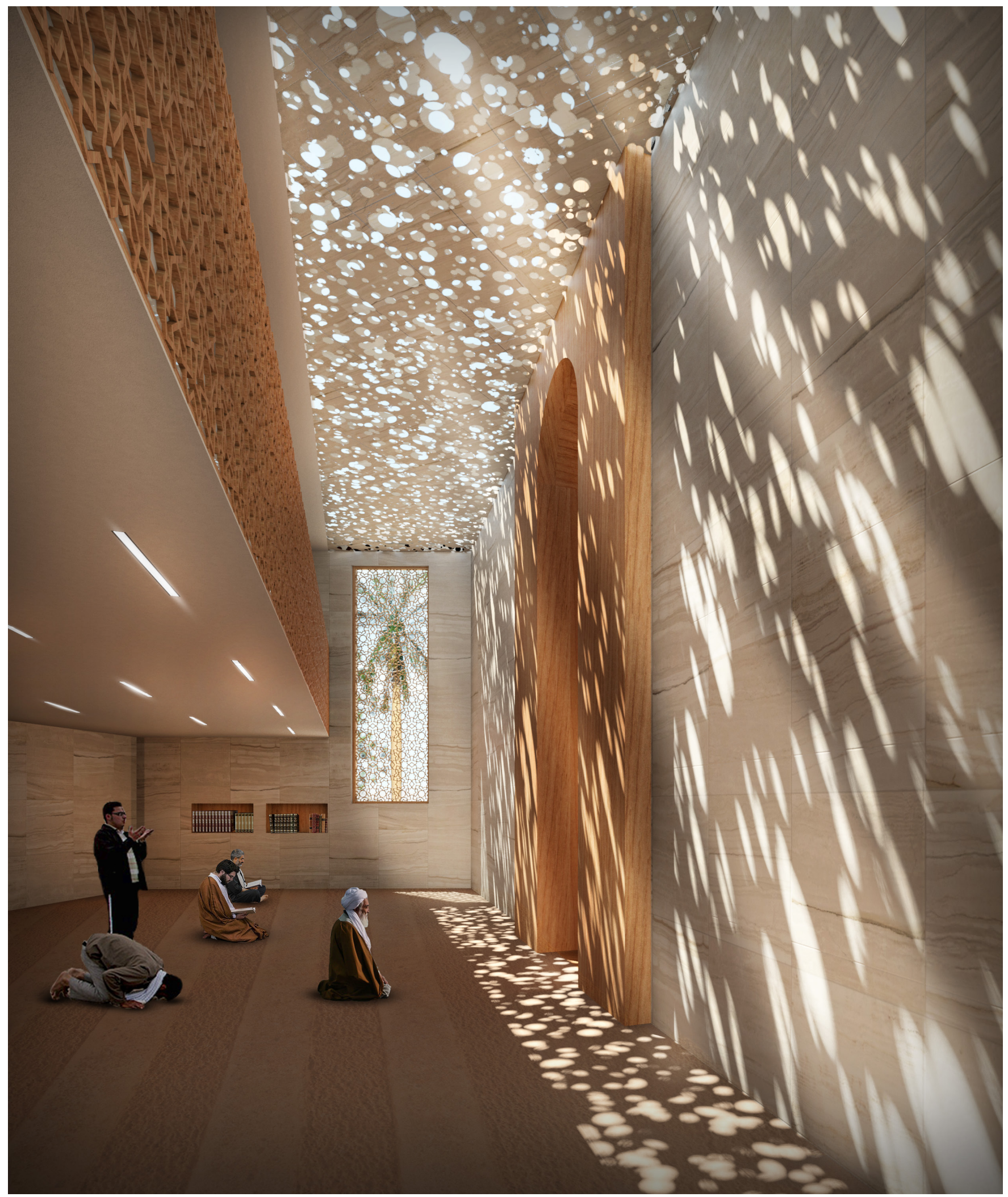




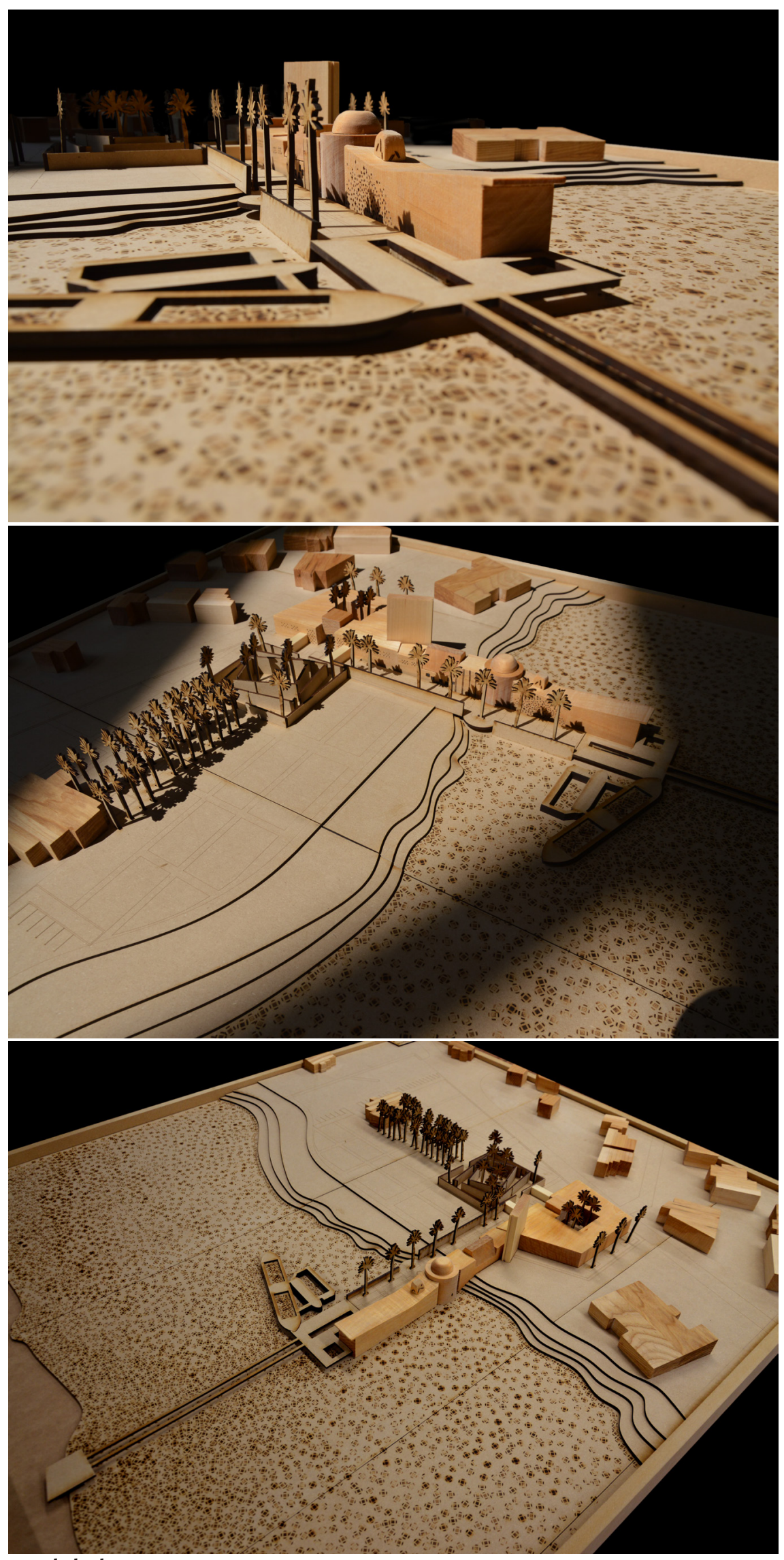

Model photos 


\section{Appendix B}

The following drawings and representations indicate the thesis project at the stage of second Milestone. (December 2015)
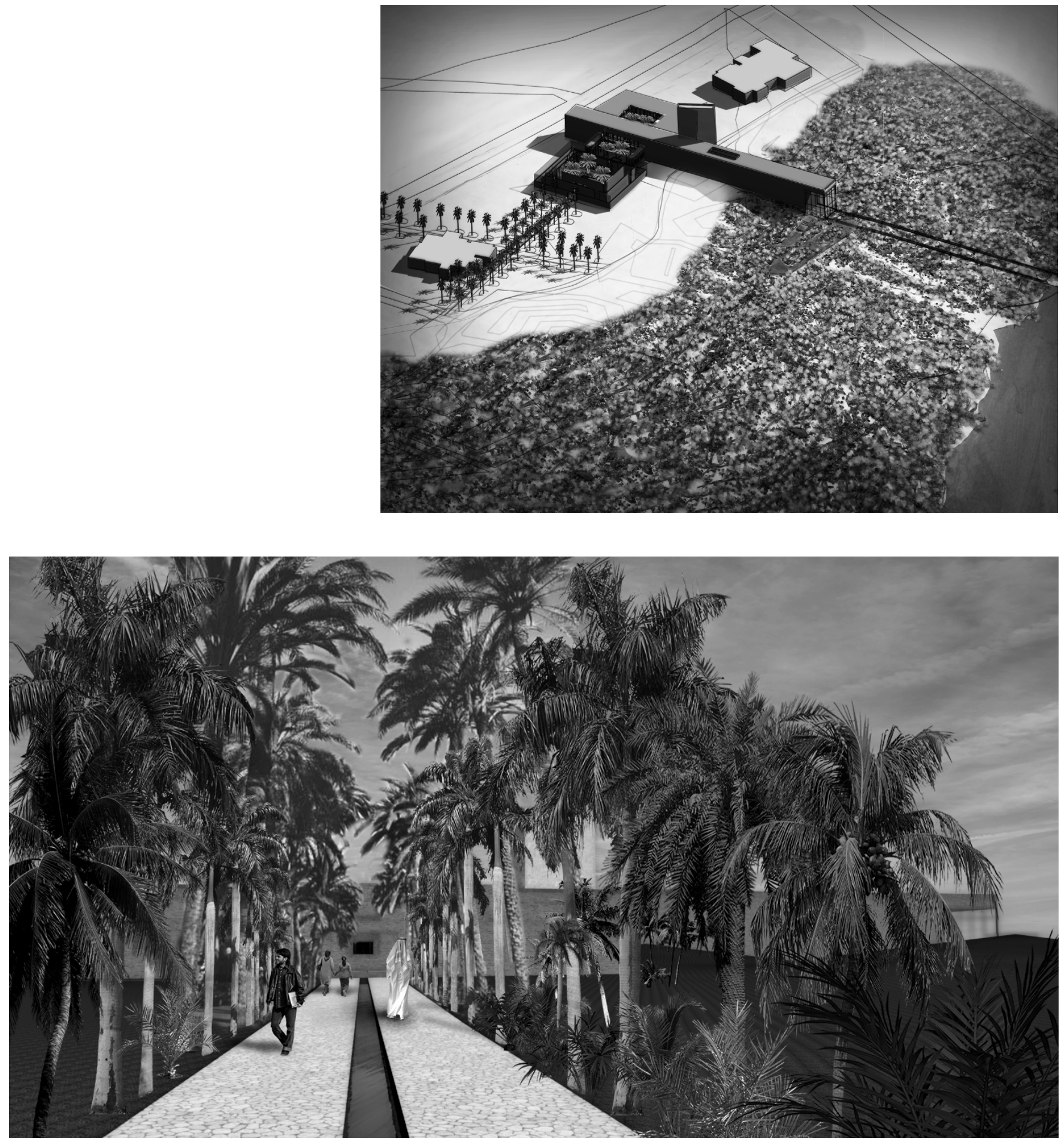

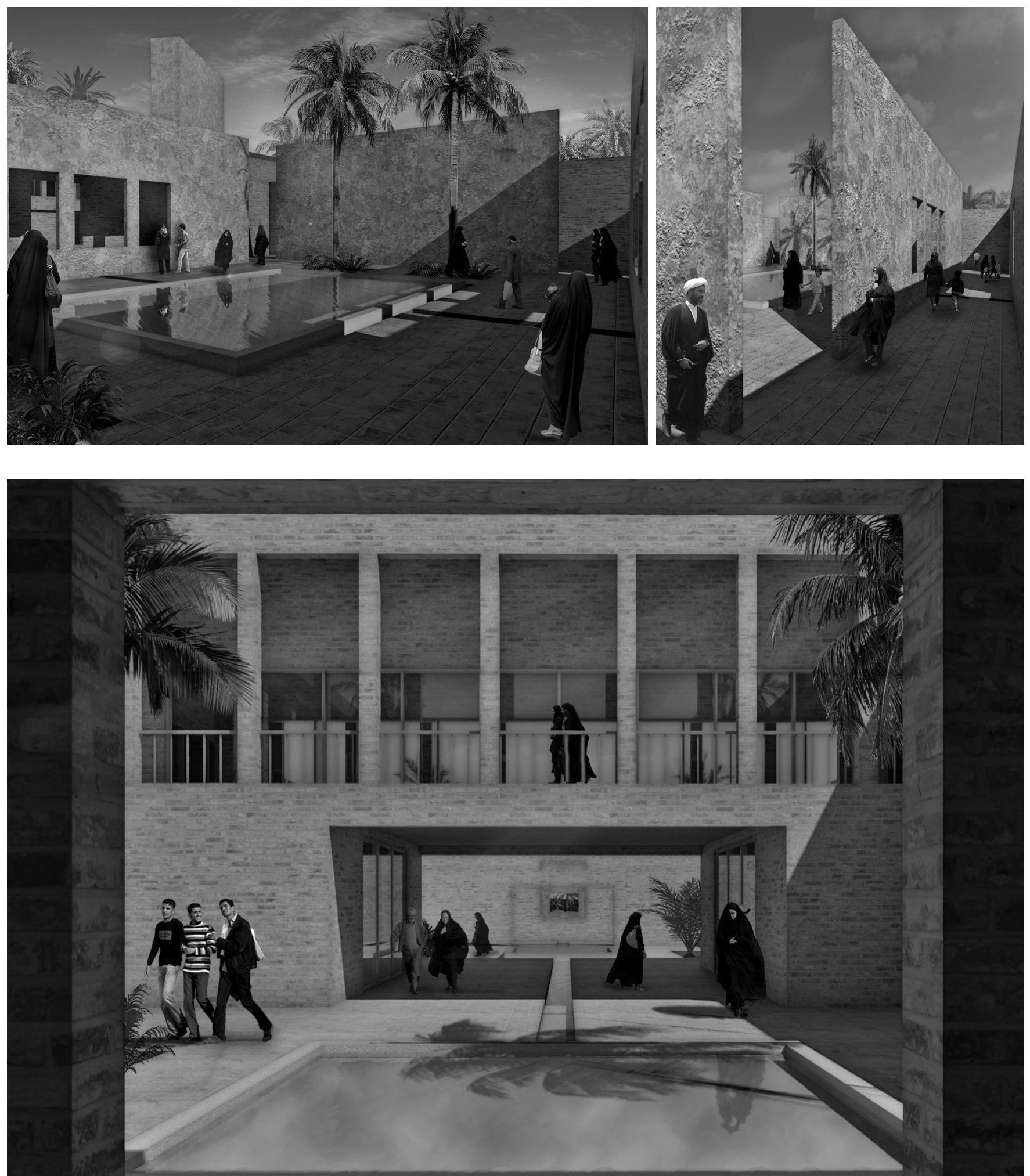


\section{Appendix C}

The following drawings and representations indicate the thesis project at the stage of Substantial Completion. (May 2016)
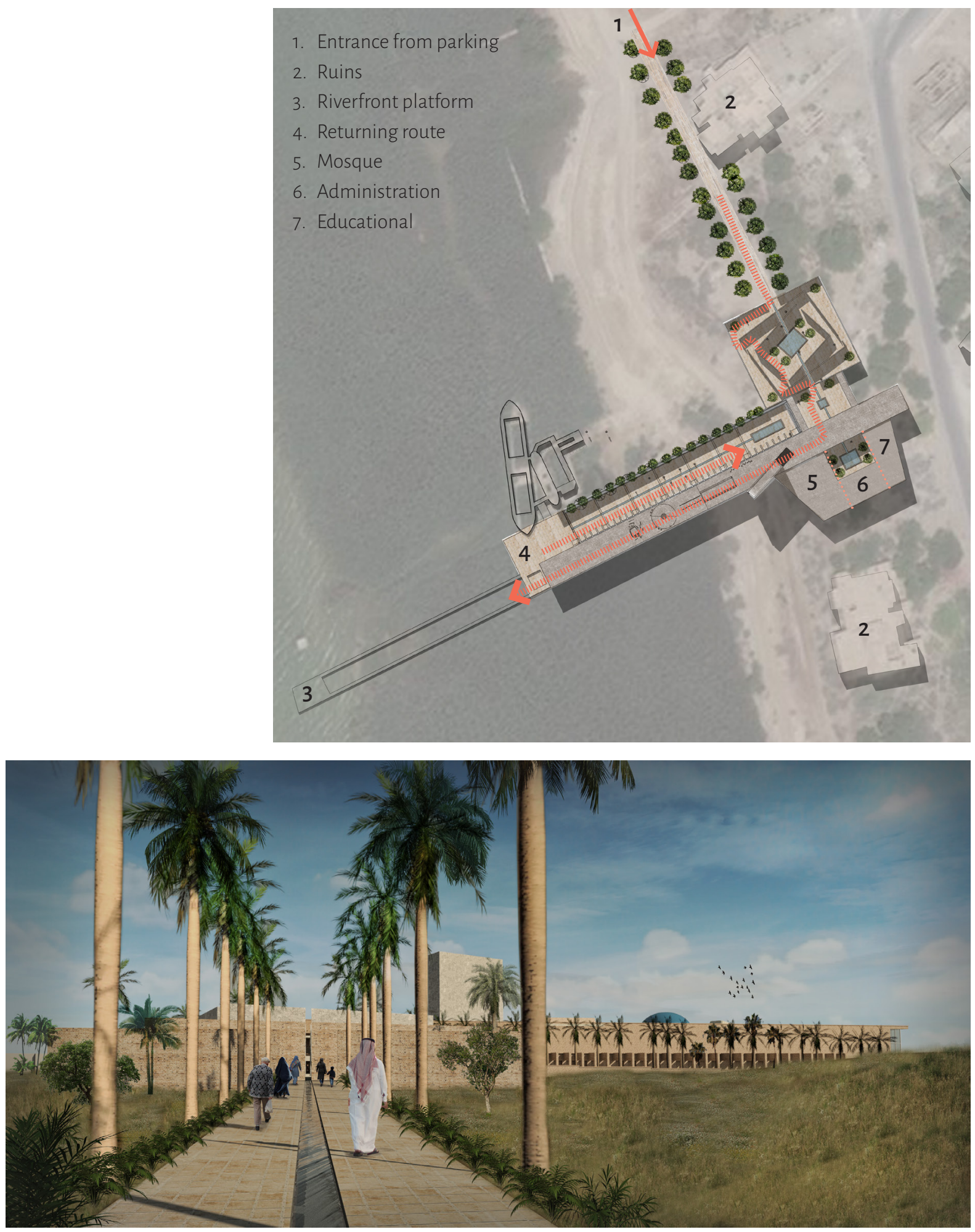

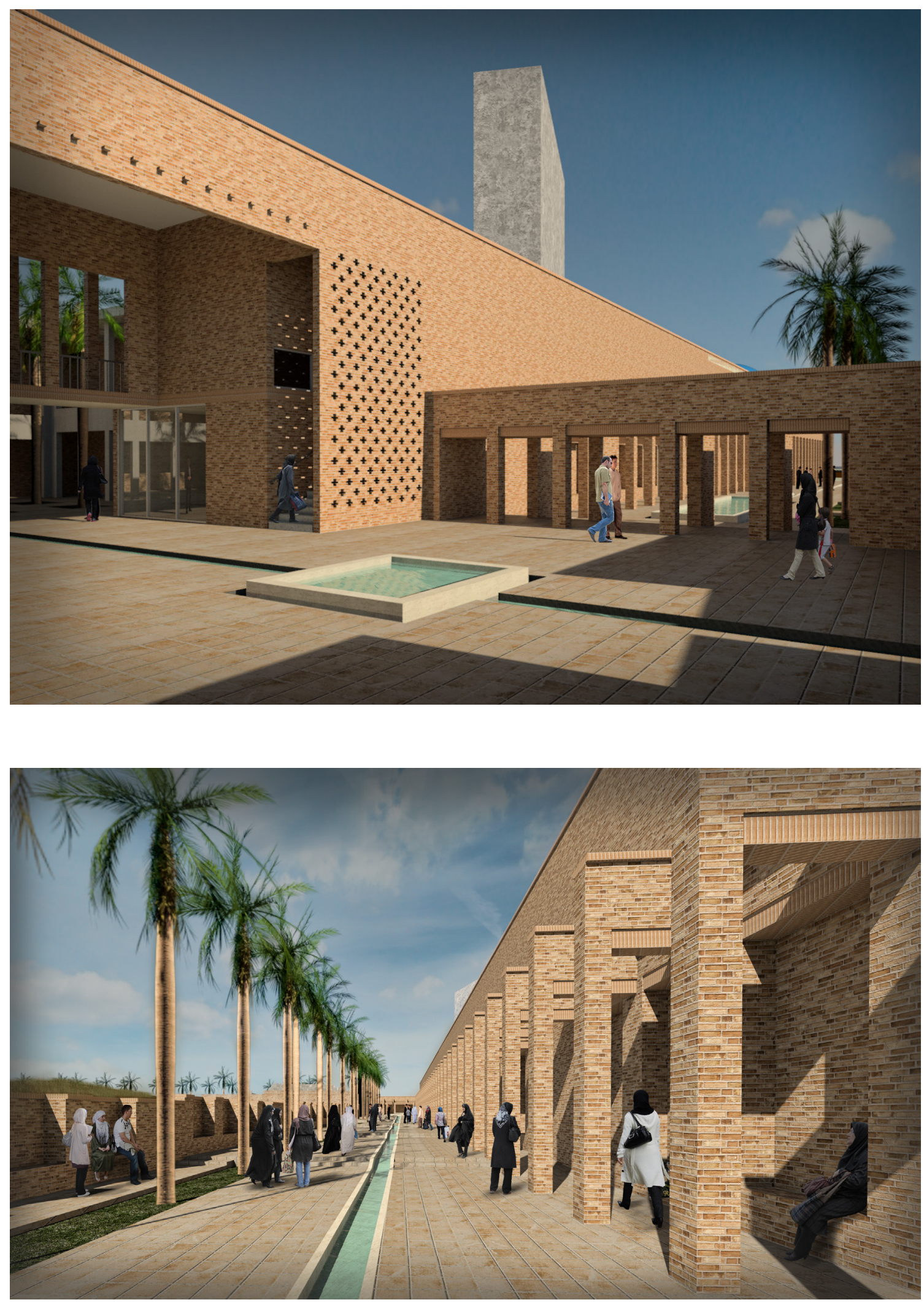


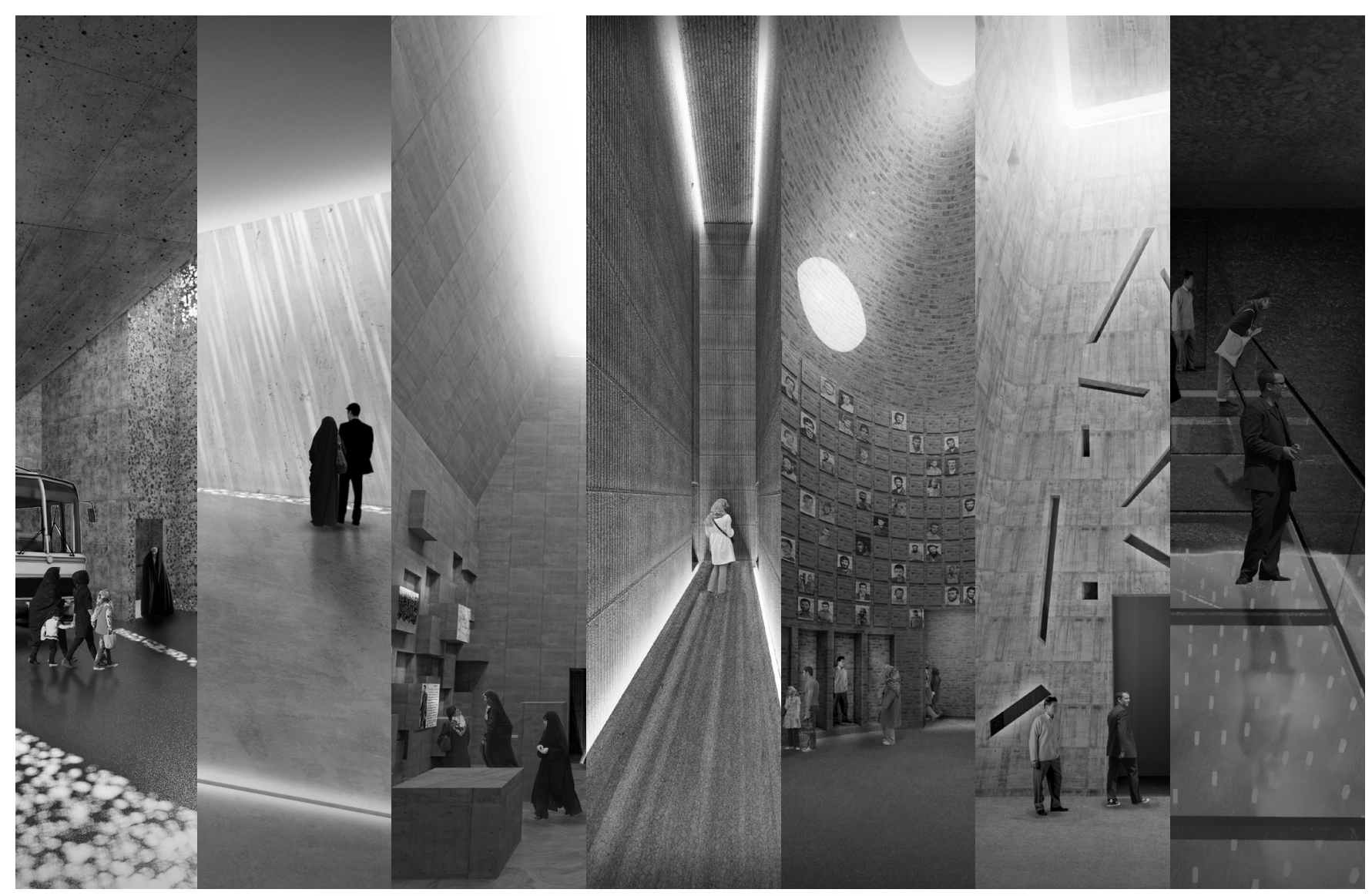

The Seven Stages
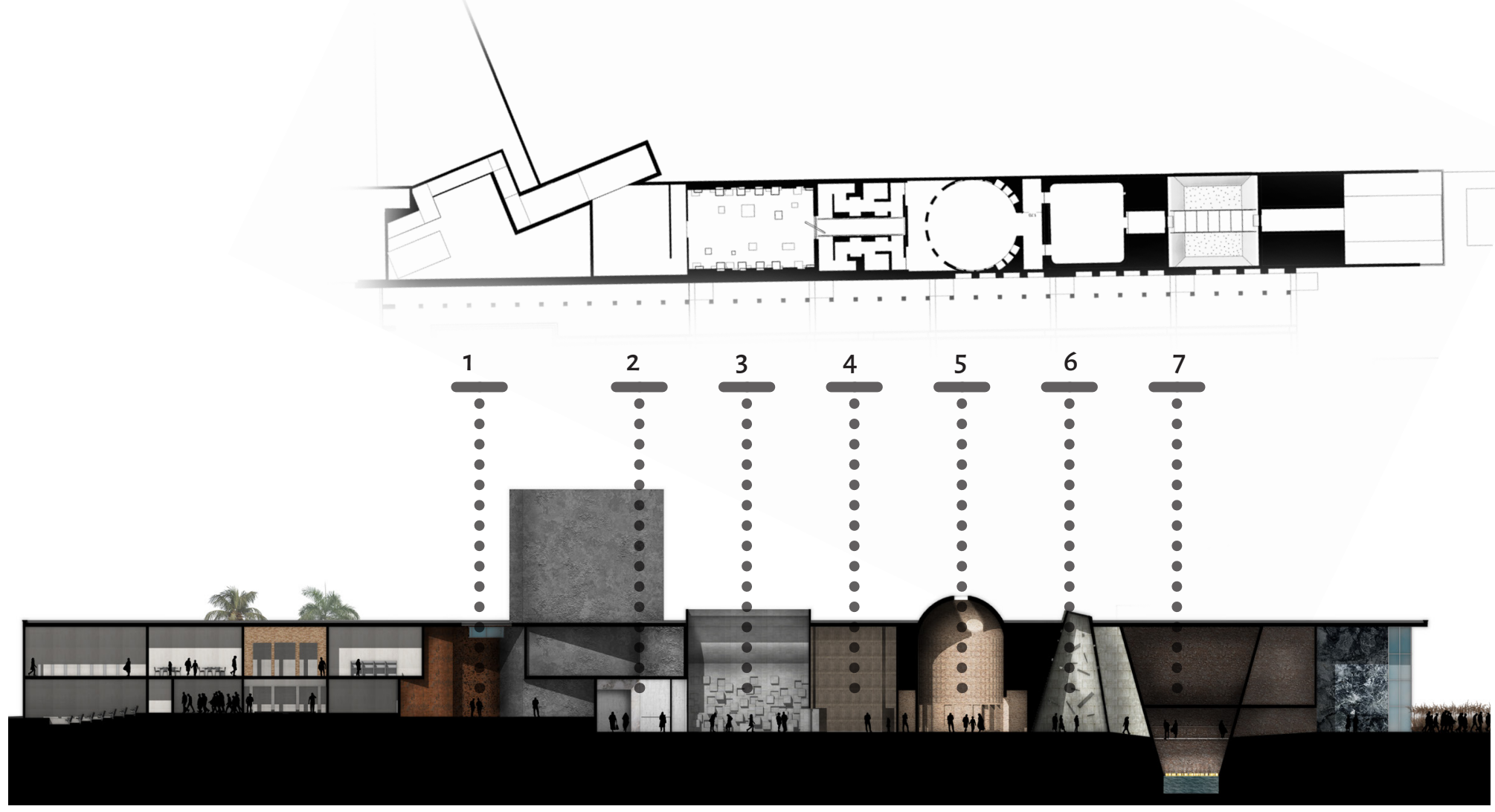



\section{Appendix D}

\section{Timeline of the history of Khorramshahr}

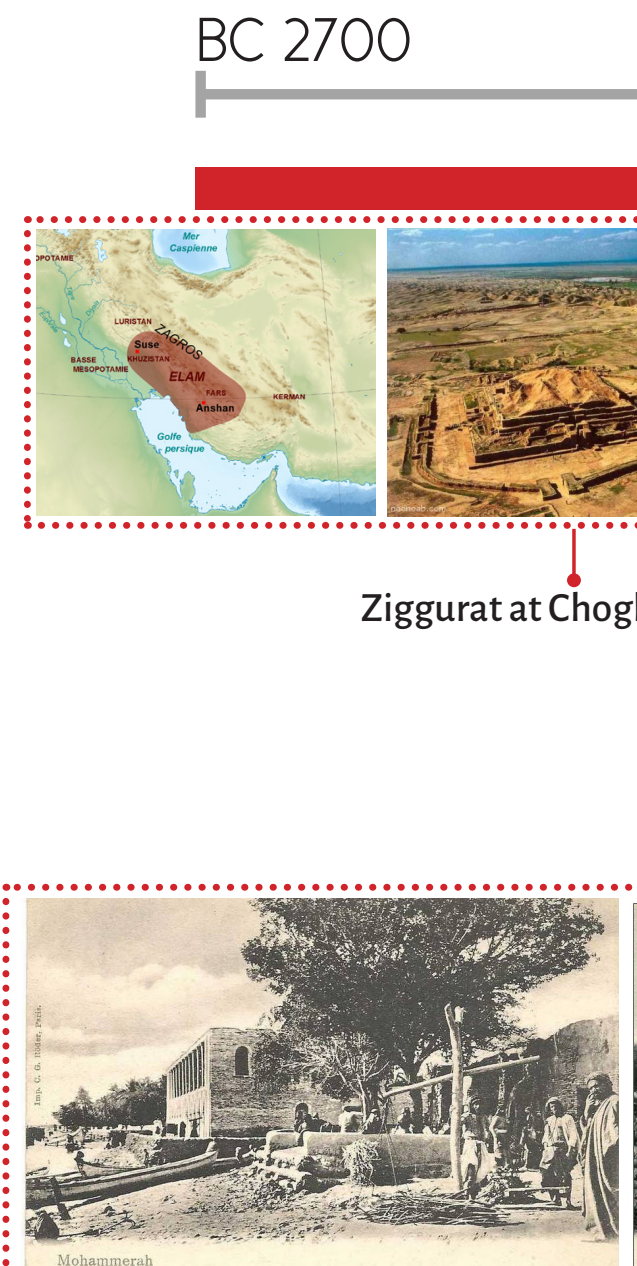

Elam Civilization $\quad$ BC 500

Barma

Shushtar historical

hydraulic system

Alexander attack to Persia
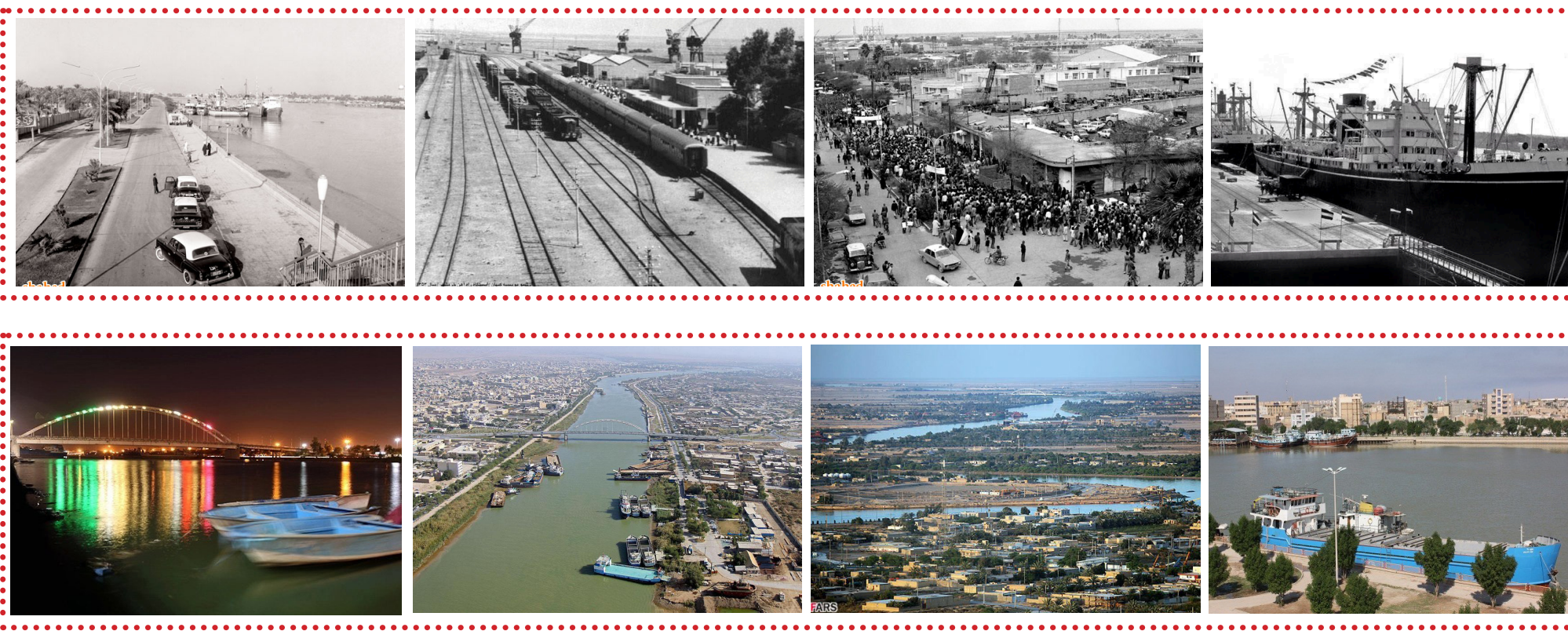

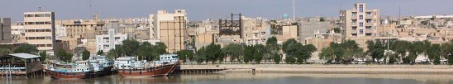




\section{Works Cited}

Antze, Paul and Michael Lamberk, eds. Tense Past: Cultural Essays in Trauma and Memory. Nueva York, Londres.: Routledge, 1996.

Ashworth, G. J., and B. J. Graham. Senses of Place: Senses of Time. Aldershot, England, Burlington, VT: Ashgate, 2005.

Attar, Farid u.-D., and Edward FitzCerald. Bird Parliament. London: Macmillan and Co., 1889.

Attar, Farid u.-D., and Mohammad R. Shafiei Kadkani. Mukhtār-Nāma. 2nd ed. Tehran: Sokhan, 1996.

_. Mantiq-uț-Tayr. 9th ed. Tehran: Sokhan, 2013.

Attār, Farīd a.-D., Afkham Darabandi, and Dick Davis. The Conference of the Birds. The Penguin classics. Harmondsworth: Penguin, 2011.

Attār, Farīd a.-D., and Peter Avery. The Speech of the Birds. Cambridge, U.K.: Islamic Texts Society, 1998.

Ayati, Ibrahim. A Probe Into the History of Ashura. Accra, Karachi: Islamic Seminary Publications, 1984.

Ayoub, Mahmoud M. Redemptive Suffering in Islam: A Study of the Devotional Aspects of Ashura in Twelver Shi'ism. Religion and society 10 . Berlin: De Cruyter, 1978.

Bastéa, Eleni. Memory and Architecture. Albuquerque: University of New Mexico Press, 2004.

Baxter-Tabriztchi, Gity. "Farid ud-Din Attar's The Conference of the Birds: A Study in Sufi Psychology and Spirituality.". PhD thesis, Argosy University, 2003.

Berger, Markus, and Liliane Wong. Interventions/Adaptive Reuse: Reconciling Meaning. Interventions and Adaptive Reuse (Int/AR) v. 04. Providence: Department of Interior Architecture, Rhode Island School of Design, 2013.

Bevan, Robert. The Destruction of Memory: Architecture at War. London: Reaktion, 2006.

Boyer, M. C. The City of Collective Memory: Its Historical Imagery and Architectural Entertainments. Cambridge, Mass.: MIT Press, 1994. 
Butler, Richard and Wantanee Suntikul, eds. Tourism and War. New York: Routledge, 2012.

Casey, Edward S. Remembering: A Phenomenological Study. 2nd ed. Bloomington, IN: Indiana University Press, 2009.

Coleman, Simon and John Eade, eds. Reframing Pilgrimage: Cultures in Motion. London, New York: Routledge, 2004.

Collins-Kreiner, N. “Researching Pilgrimage: Continuity and Transformations." Annals of Tourism Research 37, no. 2 (2010): 440-456.

Crinson, Mark, ed. Urban Memory: History and Amnesia in the Modern City. London, New York: Routledge, 2005.

da Silva Catela, L. "Staged memories: Conflicts and tensions in Argentine public memory sites." Memory Studies 8, no. 1 (2014): 9-21.

Dubisch, Jill. 'Heartland of America': Memory, motion and the (re) construction of history on a motorcycle pilgrimage." In Reframing Pilgrimage: Cultures in Motion. Edited by Simon Coleman and John Eade, 107-34. London, New York: Routledge, 2004.

Dunkley, Ria, Nigel Morgan, and Sheena Westwood. "Visiting the trenches: Exploring meanings and motivations in battlefield tourism." Tourism Management 32, no. 4 (2011): 860-868.

Durkheim, Émile. The Elementary Forms of the Religious Life. Free Press paperbacks. New York: Free Press, 1965.

Ezzati, A. "The Concept Of Martyrdom In Islam." Al-Serat12 (1986).

Fraser, Murray, and Nasser Colzari. Architecture and Clobalisation in the Persian CulfRegion. Burlington, VT: Ashgate Publishing Company, 2013.

Halbwachs, Maurice, and Lewis A. Coser. On Collective Memory. The Heritage of sociology. Chicago: University of Chicago Press, 1992.

Hayden, Dolores. The Power of Place: Urban Landscapes as Public History. Cambridge, Mass.: MIT Press, 1995.

Huyssen, Andreas. Present Pasts: Urban Palimpsests and the Politics of Memory. Cultural memory in the present. Stanford, Calif.: Stanford University Press, 2003. 
Hyder, Syed A. "Iqbal and Karbala: Re-Reading the Episteme of Martyrdom for a Poetics of Appropriation." Cultural Dynamics 13, no. 3 (2001): 339-362.

. Reliving Karbala: Martyrdom in South Asian memory. Oxford, New York: Oxford University Press, 2006.

Jalal, Ayesha. Partisans of Allah: Jihad in South Asia. Cambridge, London: Harvard University Press, 2008.

Johnson, Robert. The Iran-Iraq War. Houndmills, Basingstoke, Hampshire, New York: Palgrave Macmillan, 2011.

Kasravi, Ahmad. The 500-Year History of Khuzestan. Tehran: Khaju, 1983.

Khalafi, Yaser. Two Thousand years of Khorramshahr History. Tehran: Asar Afarin, 2015.

Khosronejad, Pedram. Unburied Memories: The Politics of Bodies of Sacred Defense Martyrs in Iran. London: Routledge, 2013.

Lowenthal, David. "Past Time, Present Place: Landscape and Memory." Ceographical Review 65, no. 1 (1975): 1.

Mahmoudi Farahani, Leila, Bahareh Motamed, and Elmira Jamei. "Persian Gardens: Meanings, Symbolism, and Design." Official Journal of the International Association for Landscape Ecology 46 (2016): 1-19.

Mann, Barbara E. “"An Apartment to Remember”: Palestinian Memory in the Israeli Landscape." History and Memory 27, no. 1 (2015): 83-115.

Masani, Rustom P. The Conference of the Birds: A Sufi Allegory: Being an Abridged Version of Farid-ud-Din Attar's Mantiq-ut-Tayr. New Delhi: Asian Educational Services, 2003.

Miles, Stephen T. “Battlefield tourism: meanings and interpretations.". PhD thesis, University of Glasgow, 2012.

Mitchell, Jolyon P. Promoting Peace, Inciting Violence: The Role of Religion and Media. London, New York: Routledge, 2012.

Nora, Pierre. "Between Memory and History: Les Lieux de Mémoire." Representations, no. 26 (1989): 7-24.

Nora, Pierre, and Lawrence D. Kritzman. Realms of memory: Rethinking the French past. European perspectives. New York: Columbia University Press, 1996. 
Ochsner, Jeffrey K. "A Space of Loss: The Vietnam Veterans Memorial." Journal of Architectural Education 50, no. 3 (1997): 156-171.

Osborne, Brian S. "Constructing landscapes of power: the George Etienne Cartier monument, Montreal." Journal of Historical Ceography 24, no. 4 (1998): 431-458.

Reader, lan. "Pilgrimage growth in the modern world: Meanings and implications." Religion 37, no. 3 (2007): 210-229.

Riegl, Alois. "The modern cult of monuments: Its character and its origin." (1982).

Russell, Amy. "Memory and Movement in the Roman Fora from Antiquity to Metro C." Journal of the Society of Architectural Historians 73, no. 4 (2014): 478-506.

Rustom, Mohammed. "The Metaphysics of the Heart in the Sufi Doctrine of Rumi." Studies in Religion 37, no. 1 (2008): 3-14.

Schääuble, Michaela. "How History Takes Place: Sacralized Landscapes in the Croatian-Bosnian Border Region." History and Memory 23, no. 1 (2011): $23-61$.

Schimmel, Annemarie. "Karbala and the Imam Husayn in Persian And IndoMuslim literature." Al-Serat 12 (1986).

Schmidt, William S. "Transformative Pilgrimage." Journal of Spirituality in Mental Health 11, 1-2 (2009): 66-77.

Seyed-Gohrab, Asghar. "Martyrdom as Piety: Mysticism and National Identity in Iran-Iraq War Poetry." Der Islam 87, no. 1 (2012): 248-273.

Shirvani, Hamid. "The Philosophy of Persian Garden Design: The Sufi Tradition." Landscape Journal 4, no. 1 (1985): 23-30.

Stubblefield, Thomas. “Do Disappearing Monuments Simply Disappear? The Counter-Monument in Revision." Future Anterior 8, no. 2 (2011): 1-11.

Sutton, David. "Tradition and Modernity Revisited: Existential Memory Work on a Greek Island." History \& Memory 20, no. 2 (2008): 84-105.

Tran, Ke L. "Architecture as Palimpsest: a Strategy of Intermediacy.". Master's dissertation, Ryerson University, 2011. 
Treib, Marc, ed. Spatial Recall: Memory in Architecture and Landscape. New York, London: Routledge, 2009.

Trigg, D. "The Place of Trauma: Memory, Hauntings, and the Temporality of Ruins." Memory Studies 2, no. 1 (2009): 87-101.

Wagner-Pacifici, Robin, and Barry Schwartz. "The Vietnam Veterans Memorial: Commemorating a Difficult Past." American Journal of Sociology 97, no. 2 (1991): 376-420.

Walkowitz, Daniel J., and Lisa M. Knauer. Memory and the Impact of Political Transformation in Public Space. Radical perspectives. Durham, N.C.: Duke University Press, 2004.

Wertsch, James V. Voices of Collective Remembering. Cambridge, U.K., New York: Cambridge University Press, 2002.

Wilber, Donald N. Persian Gardens and Garden Pavilions. 2d ed. Washington: Dumbarton Oaks, 1979.

Williams, Paul H. Memorial Museums: The Clobal Rush to Commemorate Atrocities. English ed. Oxford, New York: Berg, 2007.

Young, James E. “Daniel Libeskind's Jewish Museum in Berlin: The Uncanny Arts of Memorial Architecture." Jewish Social Studies 6, no. 2 (2000): 1-23. 

